TATIANA GUINOZA MATUDA

\title{
ANÁLISE TÉRMICA DA MASSA DE PÃO FRANCÊS DURANTE OS PROCESSOS DE CONGELAMENTO E DESCONGELAMENTO: OTIMIZAÇÃO DO USO DE ADITIVOS
}

Dissertação apresentada à Escola Politécnica da Universidade de São Paulo para obtenção do Título de Mestre em Engenharia.

São Paulo

2004 


\title{
ANÁLISE TÉRMICA DA MASSA DE PÃO FRANCÊS DURANTE OS PROCESSOS DE CONGELAMENTO E DESCONGELAMENTO: OTIMIZAÇÃO DO USO DE ADITIVOS
}

\author{
Dissertação apresentada à Escola Politécnica \\ da Universidade de São Paulo para obtenção \\ do Título de Mestre em Engenharia. \\ Área de Concentração: \\ Engenharia Química
}

Orientadora: Profa. Livre-Docente Carmen Cecília Tadini

\section{São Paulo}




\section{FICHA CATALOGRÁFICA}

Matuda, Tatiana Guinoza

Análise térmica da massa de pão francês durante os processos de congelamento e descongelamento: Otimização do uso de aditivos. São Paulo, 2004.

$142 \mathrm{p}$.

Dissertação (Mestrado) - Escola Politécnica da Universidade de São Paulo. Departamento de Engenharia Química.

1. Descongelamento 2. Congelamento 3. Massa de pão 4. Análise Térmica

I. Universidade de São Paulo. Escola Politécnica. Departamento de Engenharia Química II.t. 
À minha família 


\section{AGRADECIMENTOS}

Ao gracioso Deus.

À minha orientadora Prof ${ }^{\mathrm{a}}$. Dr ${ }^{\mathrm{a}}$. Carmen Cecília Tadini por tornar possível a execução deste trabalho.

Ao Dr. Ademar Benévolo Lugão do IPEN (Instituto de Pesquisas Energéticas e Nucleares) que disponibilizou o equipamento de DSC.

À Dr ${ }^{\mathrm{a}}$. Duclerc Fernades Parra pelo auxílio e disponibilidade nas análises de DSC e pelas sugestões no decorrer do trabalho.

À aluna de iniciação científica Clarissa Capelas Romeu e à técnica Denise Trigilio Tavares, pela participação e colaboração na parte experimental.

Ao Prof. Dr. R. Bruns pela atenção durante suas boas aulas.

À Danisco Cultor pela doação de emulsificantes.

Ao moinho Pacífico pela farinha de trigo.

À Capes e Fapesp pelo apoio financeiro.

Aos colegas Cynthia Ditchfield, Fabiana Hilsenrath, Ivan Nunes, Laura Carr, Lúcia Collet, Kátia Matsui, Nathalia Murasaki, Renato Fernandes, Rodrigo Martins, Tatiana Tribess, Vanessa Duarte, Gisele Miyashira, Sandra Orosco e Patrícia Hamano pela companhia, colaboração e pelos momentos juntos.

À Aurea e à Dê por muito me ouvir, ajudar e torcer.

Às famílias Yamamoto e Yanagihara pelo apoio e incentivo.

Aos meus pais, Yoshio e Vera, e às minhas irmãs, Carol e Nanda por tanto me suportarem.

Ao querido Jean pela paciência, companhia, incentivo e dedicação.

A todos que direta ou indiretamente colaboraram na execução deste trabalho. 


\section{SUMÁRIO}

\section{LISTA DE TABELAS}

LISTA DE FIGURAS

LISTA DE SIGLAS

1. INTRODUÇÃO............................................................................................ 1

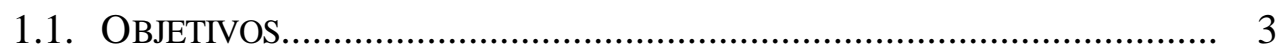

2. REVISÃO DA LITERATURA........................................................ 4

2.1. COMPOSIÇÃO DA MASSA DE PÃO..................................................... 4

2.1.1. Farinha de trigo.................................................................. 4

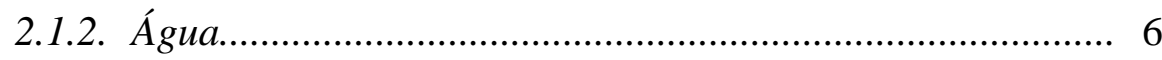

2.1.3. Fermento....................................................................... 7

2.1.4. Gordura ........................................................................... 8

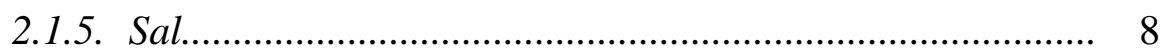

2.1.6. Açúcar.......................................................................... 8

2.1.7. Emulsificantes.............................................................. 9

2.1.8. Enzimas........................................................................ 11

2.1.9. Agentes Oxidantes........................................................... 12

2.2. Processamento do Pão de Massa Congelada......................................

2.2.1. Mistura ........................................................................... 14

2.2.2. Divisão e Modelagem..................................................... 16

2.2.3. Congelamento................................................................ 17

2.2.3.1. Influência do congelamento sobre a massa e a ação da

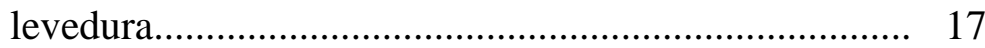

2.2.3.2. Congelamento e Transição Vítrea .............................. 19

2.2.3.3. Água não congelável (Wg') ....................................... 20

2.2.4. Embalagem................................................................... 22

2.2.5. Armazenamento................................................................. 22

2.2.6. Descongelamento....................................................... 24

2.2.7. Crescimento.................................................................... 24 
2.2.8. Assamento...................................................................... 24

2.2.8.1. Vaporização.......................................................... 25

2.2.8.2. Gelatinização........................................................ 26

2.2.8.3. Complexo amilose-lipídio......................................... 26

2.3. ENVELHECIMENTO DO PÃO......................................................... 28

2.4. QUALIDADE DA MASSA E DO PÃO................................................... 31

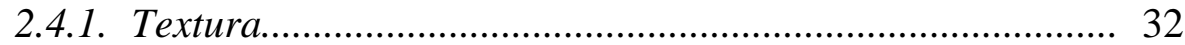

2.4.1.1. Textura da Massa....................................................... 32

2.4.1.2. Textura do Pão........................................................... 33

2.5. ANÁLISE TÉRMICA...................................................................... 36

2.5.1. Calorimetria Exploratória Diferencial (DSC)................... 36

2.5.2. Termogravimetria (TGA).............................................. 39

2.6. PlaneJAMENTO EXPERIMENTAL .................................................... 40

2.6.1. Projeto de Mistura............................................................. 40

3. MATERIAIS E MÉTODOS........................................................... 41

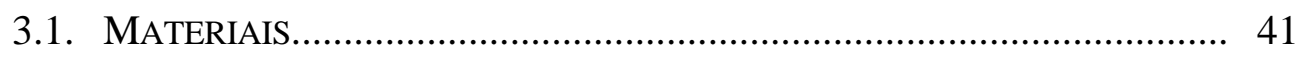

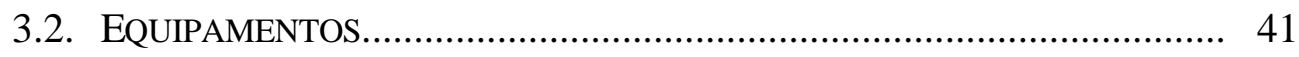

3.3. Procedimento EXPERIMENTAL E ANÁLISES.................................... 43

3.3.1. Primeira Etapa (Ensaios Preliminares)............................. 44

3.3.2. Segunda Etapa (Projeto de Mistura)................................. 51

3.3.3. Terceira Etapa (Ácido Ascórbico)..................................... 52

3.3.4. Quarta Etapa (Panificação)............................................ 53

3.4. TRATAMENTO DE DAdOS.............................................................. 57

4. RESULTADOS E DISCUSSÃO............................................................. 58

4.1. PRIMEIRA ETAPA................................................................... 58

4.1.1. Análise do Conteúdo de Água da Massa Fresca................ 59

4.1.2. Análise de Textura da Massa............................................... 63

4.1.3. Calorimetria Exploratória Diferencial (DSC)................... 69

4.1.3.1. Programa Ciclo Completo.......................................... 69

4.1.3.1.1. Entalpia de Congelamento e Descongelamento, Conteúdo de Água não Congelável e Concentração de sólidos em $\mathrm{Wg}$ '................................................. 69 
4.1.3.1.2. Primeiro e Segundo Aquecimentos e Ciclo de Retrogradação.................................................... 72

4.1.3.2. Programa Ciclo Parcial............................................... 77

4.1.3.2.1. Primeiro e Segundo Aquecimentos e Ciclo de Retrogradação..................................................... 77

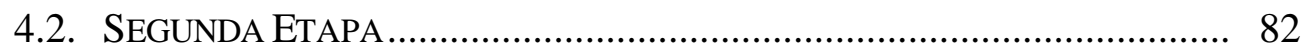

4.2.1. Parâmetros obtidos das curvas de congelamento................ 82

4.2.2. Conteúdo de Água............................................................ 83

4.2.3. Análise de Textura da Massa............................................... 84

4.2.4. Análise Térmica (Ciclo Completo)..................................... 93

4.2.4.1. Entalpia de Congelamento e Descongelamento, Conteúdo de Água não Congelável e Concentração de sólidos em Wg' ...................................................... 93

4.2.4.2. Primeiro e Segundo Aquecimentos e Ciclo de Retrogradação...................................................... 95

4.2.4.3. Ajuste dos resultados na análise térmica ao modelo cúbico especial............................................................ 95

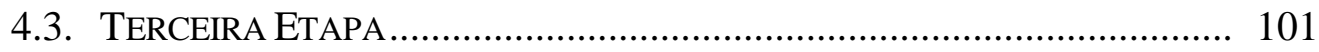

4.3.1. Parâmetros obtidos das curvas de congelamento................ 101

4.3.2. Conteúdo de Água........................................................... 101

4.3.3. Análise de Textura da Massa............................................. 102

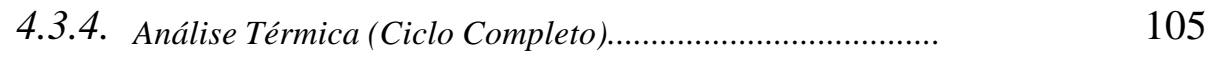

4.3.4.1. Entalpia de Congelamento e Descongelamento, Conteúdo de Água não Congelável e Concentração de sólidos em Wg' ......................................................... 105

4.3.4.2. Primeiro e Segundo Aquecimentos e Ciclo de Retrogradação.......................................................... 107

4.4. QUARTA ETAPA .......................................................................... 110

4.4.1. Parâmetros obtidos das curvas de congelamento................ 110

4.4.2. Conteúdo de Água das Massas Frescas.............................. 111

4.4.3. Textura da Massa Fresca.................................................... 111 
4.4.4. Medida de Produção de $\mathrm{CO}_{2}$, Permeabilidade da massa e Tolerância da massa durante a fermentação....................... 112

4.4.5. Pão Francês................................................................... 114

4.4.5.1. Conteúdo de água...................................................... 114

4.4.5.2. Massa e Volume específico........................................ 115

4.4.5.3. Perfil de Textura (TPA)........................................... 116

5. CONCLUSÕES......................................................................................... 118

6. SUGESTÕES PARA TRABALHOS FUTUROS....................................... 120

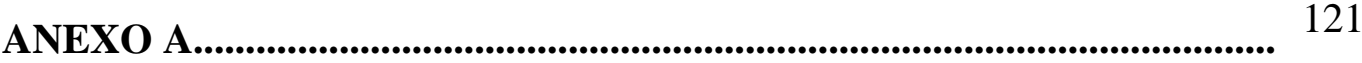

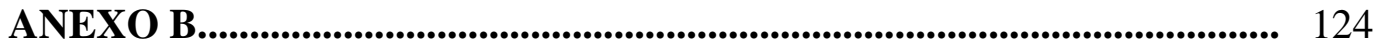

ANEXO C......................................................................................................... 129

REFERÊNCIAS BIBLIOGRÁFICAS......................................................... 135 


\section{LISTA DE TABELAS}

Tabela 2.1 Classificação dos principais emulsificantes utilizados em panificação.

Tabela 2.2 Definições de Parâmetros mecânicos de textura. Adaptado de Civille; Szczesniak, 1973 apud Szczesniak, 2002

Tabela 2.3 Interpretação da curva força-tempo (Figura 2.9) gerada pelo texturômetro.

Tabela 3.1 Misturas dos emulsificantes CSL (Estearoil-lactilato de cálcio), PS80 (Polisorbato 80) e GVH (gordura vegetal hidrogenada) relativas à primeira etapa do projeto.

Tabela 3.2 Programa Ciclo Completo do DSC que compreendeu um ciclo de congelamento-descongelamento e dois ciclos de aquecimento 48

Tabela 3.3 Programa Ciclo Parcial do DSC que compreendeu dois ciclos de aquecimento

Tabela 3.4 Programa Ciclo de Retrogradação do DSC que compreendeu um ciclo de aquecimento.

Tabela 3.5 Misturas dos emulsificantes CSL, PS80 e DATEM relativas à segunda etapa do projeto

Tabela 3.6 Programa Ciclo Completo do DSC para segunda etapa que compreendeu um ciclo de congelamento-descongelamento e dois de aquecimento.

Tabela 4.1 Transformação das variáveis originais em codificadas utilizadas nas análises de variância.

Tabela 4.2 Conteúdo de água das massas referentes à primeira etapa do projeto determinadas por estufa a $130{ }^{\circ} \mathrm{C}$, pela técnica de TGA e por balanço de massa

Tabela 4.3 Resultados da ANOVA aplicada aos valores de resistência à extensão $(\mathrm{N})$ da massa, ao longo do tempo de armazenamento congelado, obtidos no período de 17 de fevereiro a 16 de abril de 2003 
Tabela 4.4 Resultados da ANOVA aplicada aos valores de extensibilidade (mm) da massa, ao longo do tempo de armazenamento congelado, obtidos no período de 17 de fevereiro a 16 de abril de 2003

Tabela 4.5 Resultados da ANOVA aplicada aos valores de resistência à extensão $(\mathrm{N})$, ao longo do tempo de armazenamento congelado, obtidos no período entre 01 de julho e 28 de agosto de 2003

Tabela 4.6 da ANOVA aplicada aos valores de extensibilidade (mm), ao longo do tempo de armazenamento congelado, obtidos no período entre 01 de julho e 28 de agosto de 2003 .....

Tabela 4.7 Valores de resistência à extensão das massas frescas e congeladas até 56 dias de acordo com a mistura.

Tabela 4.8 Valores de extensibilidade das massas frescas e congeladas até 56 dias de acordo com a mistura

Tabela 4.9 Valores obtidos para os eventos de congelamento e descongelamento no DSC, programa Ciclo Completo. (Entalpia, $\mathrm{T}_{\text {on set }}, \mathrm{T}_{\text {pico }} \mathrm{e} \mathrm{T}_{\text {end set }}$ )

Tabela 4.10 Conteúdo de água não congelável (Wg') e a concentração de sólidos na água não congelável $\left(\mathrm{Cg}^{\prime}\right)$ nas massas congeladas de diferentes misturas

Tabela 4.11 Valores obtidos no primeiro e segundo aquecimentos no DSC, programa Ciclo Completo. (Entalpia, $\mathrm{T}_{\text {onset }}, \mathrm{T}_{\text {pico }} \mathrm{e} \mathrm{T}_{\text {endset }}$ )...

Tabela 4.12 Valores obtidos no programa ciclo retrogradação no DSC, programa ciclo completo. (Entalpia, $\mathrm{T}_{\text {onset }}, \mathrm{T}_{\text {pico }}$ e $\mathrm{T}_{\text {endset }}$ )........

Tabela 4.13 Resultados da ANOVA aplicada aos valores de entalpia do primeiro pico $(\mathrm{J} / \mathrm{g})$ do primeiro aquecimento, ciclo completo..... 76

Tabela 4.14 Resultados da ANOVA aplicada aos valores de entalpia do segundo pico ( $\mathrm{J} / \mathrm{g})$ do primeiro aquecimento, ciclo completo.... 76

Tabela 4.15 Valores obtidos no primeiro e segundo aquecimentos no DSC, programa Ciclo Parcial (Entalpia, $\mathrm{T}_{\text {onset }}, \mathrm{T}_{\text {pico }}$ e $\mathrm{T}_{\text {endset }}$ ). 
Tabela 4.16 Valores obtidos no programa ciclo retrogradação no DSC, programa ciclo parcial. (Entalpia, $\mathrm{T}_{\text {onset }}, \mathrm{T}_{\text {pico }}$ e $\mathrm{T}_{\text {endset }}$ )......... 81

Tabela 4.17 Resultados da ANOVA aplicada aos valores de entalpia do primeiro pico do ciclo de retrogradação, ciclo parcial................ 78

Tabela 4.18 Parâmetros obtidos das curvas de congelamento das massas de diferentes misturas

Tabela 4.19 Valores médios de conteúdo de água das massas referentes ao projeto de mistura (CSL, PS80 e DATEM)

Tabela 4.20 Modelos preditivos da resistência à extensão $(\mathrm{N})$ e da extensibilidade $(\mathrm{mm})$ das misturas relativas ao projeto de mistura de três componentes (CSL, PS80 e DATEM), com as variáveis codificadas, ao longo do tempo.

Tabela 4.21 Análise de variância da resistência à extensão em função do tempo de armazenamento congelado e da velocidade de resfriamento

Tabela 4.22 Formulações para os valores máximos de resistência à extensão para cada dia de armazenamento congelado obtidas através de otimização.

Tabela 4.23 Valores de resistência à extensão das massas frescas e congeladas até 22 dias de armazenamento congelado.....

Tabela 4.24 Valores de extensibilidade das massas frescas e congeladas até 22 dias de acordo com a mistura

Tabela 4.25 Valores obtidos para os eventos de congelamento e descongelamento no DSC, programa Ciclo Completo referente ao projeto de mistura (Entalpia, $\mathrm{T}_{\text {onset }}, \mathrm{T}_{\text {pico }}$ e $\mathrm{T}_{\text {endset }}$ ).

Tabela 4.26 Conteúdo de água não congelável (Wg') e a concentração de sólidos na água não congelável (Cg’) nas massas congeladas referentes ao projeto de mistura.

Tabela 4.27 Valores obtidos no primeiro e segundo aquecimentos no DSC, programa Ciclo Completo. (Entalpia, $\mathrm{T}_{\text {onset }}, \mathrm{T}_{\text {pico }} \mathrm{e} \mathrm{T}_{\text {endset }}$ ).......

Tabela 4.28 Valores obtidos no Programa Ciclo Retrogradação no DSC, programa Ciclo Completo. (Entalpia, $\mathrm{T}_{\text {onset }}, \mathrm{T}_{\text {pico }} \mathrm{e} \mathrm{T}_{\text {endset }}$ )..... 
Tabela 4.29 Equações preditivas obtidas para os eventos estudados na análise térmica

Tabela 4.30 Parâmetros obtidos nas curvas de congelamento das massas produzidas da mistura $(0,3 \%$ de PS80 e $0,2 \%$ de DATEM) acrescidas em 4 níveis de ácido ascórbico (0, 100, 200 e $300 \mathrm{ppm})$

Tabela 4.31 Valores médios do conteúdo de água das massas referentes à mistura $(0,3 \%$ de PS80 e $0,2 \%$ de DATEM) com adição de ácido ascórbico (0, 100, 200 e 300 ppm)

Tabela 4.32 Valores obtidos para os eventos de congelamento e descongelamento no DSC, programa Ciclo Completo para formulações com diferentes níveis de ácido ascórbico (0, 100, 200 e 300 ppm) (Entalpia, $\mathrm{T}_{\text {onset }}, \mathrm{T}_{\text {pico }}$ e $\left.\mathrm{T}_{\text {endset }}\right)$.......

Tabela 4.33 Conteúdo de água não congelável (Wg') e a concentração de sólidos na água não congelável (Cg') nas massas congeladas produzidas da mistura (0,3 \% de PS80 e 0,2 \% de DATEM) com diferentes níveis de ácido ascórbico (0, 100, 200 e $300 \mathrm{ppm})$

Tabela 4.34 Valores obtidos no primeiro e segundo aquecimentos no DSC, programa Ciclo Completo para formulações com diferentes níveis de ácido ascórbico (0, 100, 200 e 300 ppm) (Entalpia, $\mathrm{T}_{\text {onset }}, \mathrm{T}_{\text {pico }}$ e $\left.\mathrm{T}_{\text {endset }}\right)$

Tabela 4.35 Valores obtidos no Programa Ciclo Retrogradação no DSC, programa Ciclo Completo para formulações com diferentes níveis de ácido ascórbico (0, 100, 200 e 300 ppm) (Entalpia, $\mathrm{T}_{\text {onset }}, \mathrm{T}_{\text {pico }}$ e $\left.\mathrm{T}_{\text {endset }}\right)$.

Tabela 4.36 Entalpia do terceiro pico do ciclo de retrogradação da mistura (0,3\% de PS80 e 0,2 \% de DATEM) com diferentes níveis de ácido ascórbico (0, 100, 200 e 300 ppm)

Tabela 4.37 Parâmetros obtidos nas curvas de congelamento das massas da mistura $(0,3 \%$ de PS80 e $0,2 \%$ de DATEM) com adição de ácido ascórbico (0 ppm e 200 ppm). 
Tabela 4.38 Conteúdo de água das massas frescas da mistura $(0,3 \%$ de PS80 e 0,2 \% de DATEM) 0 e 200 ppm de ácido ascórbico utilizadas na etapa de panificação

Tabela 4.39 Resistência à extensão $(\mathrm{N})$ e extensibilidade $(\mathrm{mm})$ de massas frescas da mistura $(0,3 \%$ de PS80 e $0,2 \%$ de DATEM) sem e com fermento e diferentes níveis de ácido ascórbico $(0$ e $200 \mathrm{ppm})$.

Tabela 4.40 Parâmetros obtidos nas curvas geradas no reofermentômetro da mistura (0,3\% de PS80 e 0,2 \% de DATEM) com adição de 0 e 200 ppm de ácido ascórbico em função do tempo de armazenamento congelado.

Tabela 4.41 Análise de variância para Hm, altura máxima do desenvolvimento da massa, em função do conteúdo de ácido ascórbico

Tabela 4.42 Conteúdo de água dos pães produzidos de massas com diferentes níveis de ácido ascórbico (0 e 200 ppm)

Tabela A.1 Tempos de batimento e temperaturas da farinha e da água antes do batimento e da massa no final do batimento (Etapa I, com os componentes GVH, CSL e PS80).

Tabela A.2 Tempos de batimento e temperaturas da farinha e da água antes do batimento e da massa no final do batimento (Etapa II, Projeto de misturas com os componentes CSL, PS80 e DATEM)

Tabela A.3 Tempos de batimento e temperaturas da farinha e da água antes do batimento e da massa no final do batimento (Etapa III, com adição de ácido ascórbico em 4 níveis, 0, 100, 200 e 300 ppm).

Tabela A.4 Tempos de batimento e temperaturas da farinha e da água antes do batimento e da massa no final do batimento (Etapa IV) 


\section{LISTA DE FIGURAS}

Figura 2.1 Estrutura da amilose e da amilopectina presentes no amido da farinha de trigo....................................................................... 5

Figura 2.2 Estrutura do grânulo de amido presente na farinha de trigo............... 6

Figura 2.3 Mecanismo de ação das enzimas alfa e beta amilase nas cadeias de amilose e amilopectina presentes no amido da farinha de trigo.

Figura 2.4 Fluxograma simplificado do processo de fabricação de pão francês de massa congelada.

Figura 2.5 Rede de glúten em diferentes estágios de mistura. (a) início do processo de mistura, hidratação parcial; (b) massa parcialmente misturada; (c) massa no estágio de desenvolvimento máximo........... 16

Figura 2.6 Perfis de temperatura do pão francês durante o assamento............... 25

Figura 2.7 Forma I e II do complexo amilose-lipídio...................................... 27

Figura 2.8 Cinética de cristalização de polímeros parcialmente cristalinos (amido), onde $\mathrm{Tg}$ é a temperatura de transição vítrea e Tm é a temperatura de fusão.

Figura 2.9 Exemplo de curva força-tempo gerada pelo texturômetro em análise de dupla compressão (TPA)............................................... 34

Figura 2.10 Curva de DSC de amido de arroz, razão de aquecimento $10^{\circ} \mathrm{C} / \mathrm{min} . \quad 37$

Figura 2.11 Esquema de eventos que podem ser identificados através do DSC em misturas de amido e água.

Figura 3.1 Análise de textura da massa utilizando o analisador de textura TAXT2i da SMS com acessório A/KIE

Figura 3.2 Curva força-distância gerada por análise de textura da massa 46

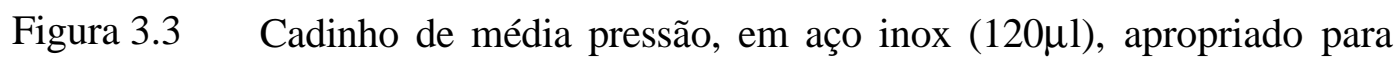
ensaios de materiais biológicos.

Figura 3.4 Exemplo de curva obtida no DSC para o programa Ciclo Completo. 48

Figura 3.5 Exemplo de curva obtida no DSC para o Programa Ciclo Parcial.... 49

Figura 3.6 Exemplo de curva obtida no DSC para o Programa Ciclo de Retrogradação....................................................................... 50

Figura $3.7 \quad$ Medidor de volume CHOPIN....................................................... 54 
Figura 3.8 Reofermentômetro F3 CHOPIN

Figura 3.9 Exemplo de curva do desenvolvimento da massa obtida no reofermentômetro CHOPIN

Figura 3.10 Exemplo de curva de geração de gás carbônico obtida no reofermentômetro CHOPIN

Figura 3.11 Análise de textura do pão utilizando o analisador de textura TAXT2i com acessório cilíndrico de $36 \mathrm{~mm}$.

Figura 4.1 Exemplo de curva obtida na análise de TGA, mistura 5.

Figura 4.2 Variação do conteúdo de água, em função dos níveis de GVH, CSL e PS80, presente nas massas frescas de diferentes misturas.....

Figura 4.3 Resistência à extensão (Força em N) e extensibilidade (Distância em $\mathrm{mm}$ ) em função do tempo de congelamento, referente às análises realizadas no período entre 17 de fevereiro e 16 de abril de 2003.

Figura 4.4 Resistência à extensão (Força em N) e extensibilidade (Distância em mm) em função do tempo de congelamento, referente às análises realizadas entre 01 de julho e 28 de agosto de 2003.

Figura 4.5 Pico de Fusão obtido através do DSC da mistura 2 no programa ciclo completo

Figura 4.6 Curvas obtidas através do DSC para o primeiro e segundo aquecimentos e ciclo de retrogradação para mistura 6. Dados referentes ao programa ciclo completo.

Figura 4.7 Curvas de contorno para projeto de mistura de três emulsificantes (CSL, PS80 e DATEM) para resistência à extensão (Força em N)..

Figura 4.8 sntorno para projeto de mistura de três emulsificantes (CSL, PS80 e DATEM) para Entalpia de congelamento (J/g)

Figura 4.9 Resistência à extensão (Força em N) e extensibilidade (Distância em mm) da mistura (0,3\% de PS80 e 0,2 \% de DATEM) contendo diferentes níveis de ácido ascórbico ao longo do tempo de armazenamento congelado. 
Figura 4.10 Resistência à extensão (Força em N) e extensibilidade (Distância em $\mathrm{mm}$ ) da mistura ( $0,3 \%$ de PS80 e $0,2 \%$ de DATEM) contendo diferentes níveis de ácido ascórbico ao longo do tempo de armazenamento congelado.

Figura 4.11 Volume específico em relação ao conteúdo de ácido ascórbico e ao tempo

Figura 4.12 Parâmetros de textura (Firmeza, elasticidade, coesividade e mastigabilidade) dos pães produzidos com a mistura $(0,3 \%$ de PS80 e 0,2\% de DATEM) em função do conteúdo de ácido ascórbico e do tempo de armazenamento congelado

Figura B.1 História de temperatura no centro geométrico da massa, ao longo do tempo de congelamento, referentes às misturas com os componentes CSL, PS80 e DATEM

Figura B.2 História de temperatura no centro geométrico da massa, ao longo do tempo de congelamento, referentes à mistura $(0,3 \%$ de PS80 e $0,2 \%$ de DATEM) com diferentes níveis de ácido ascórbico ( 0 , 100,200 e 300 ppm)

Figura B.3 História de temperatura no centro geométrico da massa, ao longo do tempo de congelamento, referentes à mistura $(0,3 \%$ de PS80 e 0,2 \% de DATEM) e adição de 0 e 200 ppm de ácido ascórbico.......

Figura C.1 Curvas de desenvolvimento das massas referentes à mistura $(0,3 \%$ de PS80 e 0,2 \% de DATEM) e adição de ácido ascórbico (0 e $200 \mathrm{ppm}$ ) ao longo do tempo de armazenamento congelado.

Figura C.2 Curvas de produção de $\mathrm{CO}_{2}$ das massas referentes à mistura $(0,3 \%$ de PS80 e 0,2\% de DATEM) e adição de ácido ascórbico ascórbico (0 e 200 ppm) ao longo do tempo de armazenamento congelado 


\section{LISTA DE SIGLAS}

AACC American Association of Cereal Chemists

ABIP

Associação Brasileira das Indústrias de Panificação

ANVISA Agência Nacional de Vigilância Sanitária

CSL Estearoil-2-lactilato de cálcio

DATA Ésteres de ácido diacetil tatártico de monoglicerídios

DATEM Ésteres de ácido diacetil tatártico de monoglicerídios

DMG Monoglicerídios destilados

DSC Calorimetria Exploratória Diferencial

FAO Food Agricultural Organization

GVH Gordura Vegetal Hidrogenada

ICC International Association for Cereal Science and Technology

OMS Organização Mundial da Saúde

ONU Organização das Nações Unidas

PS80 Polisorbato 80

SMS Stable Micro Systems

SSL Estearoil-2-lactil lactato de sódio

TGA Análise de Termogravimetria

TPA Texture Profile Analysis - Análise de Dupla Compressão 


\section{RESUMO}

O pão produzido de massa congelada tem sido aprimorado pelos avanços tecnológicos e diferentes formulações, porém ainda apresenta problemas como fermentação prolongada, baixo volume, textura e desempenho variados. O efeito do congelamento pode ser minimizado através do uso de aditivos e ingredientes adequados para a elaboração da massa. Entretanto o mecanismo de fortalecimento devido aos aditivos como, por exemplo, o emulsificante não é completamente conhecido. A análise térmica é uma ferramenta útil para pesquisa, desenvolvimento e controle de qualidade de alimentos, pois permite o estudo das alterações na sua estrutura durante um tratamento térmico. O objetivo do trabalho foi estudar a influência do uso de aditivos de panificação sobre o comportamento da massa de pão francês após ciclos de congelamento e descongelamento. O trabalho experimental foi dividido em quatro etapas: na primeira, diferentes formulações foram produzidas com os componentes estearoil-2-lactil lactato de cálcio (CSL), polisorbato 80 (PS80) e gordura vegetal hidrogenada $(\mathrm{GVH})$; na segunda etapa foi realizado um projeto de mistura com três componentes (CSL, PS80 e ésteres de ácido diacetil tartárico de mono e diglicerídio - DATEM); na terceira foi estudada a influência do ácido ascórbico sobre as características reológicas e os eventos determinados através de Calorimetria Exploratória Diferencial (DSC) afim de otimizar o uso destes aditivos em massas congeladas. A análise térmica mostrou-se adequada aos eventos de congelamento e descongelamento, porém não em relação aos eventos relativos aos aquecimentos. A resistência à extensão bem como a extensibilidade da massa foram influenciadas pelo tempo de armazenamento congelado. Na quarta etapa do projeto, foram produzidos pães franceses à partir de massas com a mistura $(0,3 \%$ de PS80 e $0,2 \%$ de DATEM sobre a farinha de trigo) e dois níveis de ácido ascórbico (0 e 200 ppm). Volume específico, perfil de textura, conteúdo de água e medida da produção de gás e tolerância da massa durante a fermentação foram determinados. Os pães produzidos com a adição de ácido ascórbico apresentaram maiores volumes específicos e menores valores para os parâmetros de textura dos pães (firmeza, elasticidade, coesividade e mastigabilidade). 


\begin{abstract}
Bread produced from frozen dough has been improved due to technological advances and formulation, however it still presents problems like long proofing, low specific volume, varied texture and performance. The effect of freezing can be minimized by use of additives and adequate ingredients. The mechanism of dough strengthening due to use of additives, such as emulsifiers, is not fully understood. Thermal analysis is a useful tool for food research, development and quality control, because it provides information on food structural changes during thermal treatment. The goal of this research is to study the influence of additives in bread making on French bread dough after a freeze-thaw cycles. The experimental part consists of four parts: in the first, different formulations were produced with the components calcium stearoyl-2-lactylate (CSL), polysorbate 80 (PS80) and vegetable shortening (VGH); in the second, a mixture design with three components (CSL, PS80 and diacetyl tartaric esters of mono and digliceride - DATEM) was made; in the third, influence of ascorbic acid was studied on rheological measurement and events determined by differential scanning calorimetry (DSC) to optimize the use of additives on frozen dough. Thermal analysis was adequate for the freeze-thaw events, however not for the heating events. Resistance to extension and dough extensibility were influenced by storage time. In the fourth part, French breads from frozen dough were produced with the mixture $(0,3 \%$ of PS80 and $0,2 \%$ of DATEM in flour basis) and two levels of ascorbic acid. Specific volume, texture profile, water content, gas production and mass tolerance during proofing were determined. Breads made with ascorbic acid addition presented a higher specific volume and lower values for texture profile (firmness, springiness, cohesiveness and chewiness).
\end{abstract}




\section{INTRODUÇÃO}

O pão está presente desde os primórdios da vida do homem pois vestígios mostram que já na pré-história, o ser humano se alimentava de um pão rudimentar.

No cristianismo, o pão simboliza o corpo de Cristo e é oferecido como sinal de boas vindas. Ele também está presente em outras culturas antigas como a egípcia e a romana e em fatos históricos como a política do "pão e circo".

Ao longo do tempo o pão foi aperfeiçoado, ganhou novas formas, formulações e processos. Os avanços tecnológicos permitiram a substituição ou a agregação de ingredientes como o ovo e a gordura, buscando uma melhor qualidade. A industrialização do fermento também contribuiu para este desenvolvimento (ARAÚJO, 1996).

Nos últimos anos, a produção de pães congelados acompanhou a tendência de alimentação prática e rápida. Enfim, o pão continua presente na vida do homem e na sua evolução, adaptando-se às suas culturas e necessidades.

Segundo a Associação Brasileira da Indústria de Panificação (2002), o segmento de Panificação e Confeitaria no Brasil representou um faturamento anual de aproximadamente U\$16 bilhões, empregando diretamente 580 mil pessoas e um consumo anual de $27 \mathrm{~kg}$ /capita, quantidade que representa metade da porção recomendada por organismos mundiais de alimentação como a OMS (Organização Mundial da Saúde-ONU), $60 \mathrm{~kg} / \mathrm{capita} / \mathrm{ano}$ e a FAO (Food Agricultural Organization), $50 \mathrm{~kg} /$ capita/ ano.

O pão francês é o tipo preferido em todas as classes sociais no Brasil e é responsável por $85 \%$ do total produzido (NUTRINEWS, 1999). Trata-se de um produto fermentado, preparado obrigatoriamente com farinha de trigo, sal (cloreto de sódio) e água, que se caracteriza por apresentar casca crocante de cor uniforme castanho-dourada e miolo de cor branco-creme, de textura e granulação fina não uniforme (AGÊNCIA NACIONAL DE VIGILÂNCIA SANITÁRIA, 2000).

Devido à praticidade, conveniência e redução de custos, estabelecimentos como lojas de conveniência e supermercados têm optado pela comercialização de massas congeladas, pães pré-assados congelados ou pães assados congelados. 
O pão assado congelado é comercializado pronto para consumo após o descongelamento ou ligeiro aquecimento.

O pão pré-assado congelado deve ser descongelado e ter o assamento finalizado no ponto de venda. Este tipo de pão tem apresentado vantagens em relação aos processos tradicionais devido aos seguintes fatores: tempo reduzido de preparo no ponto de venda (10 a 12 minutos), padronização do produto, redução de espaço, mão-de-obra não especializada e agilidade e flexibilidade para a produção. São indicados para lojas de conveniência, pontos quentes de supermercados e padarias com pequena área disponível (BONATTO, 1999). Klimaquip (2003) cita ainda outras vantagens como a criação de centrais de produção de pães semi-elaborados, produção em escala e conseqüente redução de custos, eliminação do trabalho noturno e maior oferta de produtos frescos dispostos o dia todo. $\mathrm{O}$ consumo de pães semiassados congelados na Europa é de $40 \%$ enquanto que no Brasil esta fatia é de apenas $1,6 \%$ do total (NUTRINEWS, 1999).

As vantagens do pão de massa congelada são praticamente as mesmas do pré-assado com exceção do tempo de preparo no ponto de venda (3 a 4 horas), pois inclui a etapa de fermentação. Mas o pão de massa congelada apresenta um menor custo com transporte e armazenamento, já que o volume da massa é menor que o do pão pré-assado (KLIMAQUIP, 2003).

O pão produzido de massa congelada tem sido aprimorado pelos avanços tecnológicos e diferentes formulações, porém ainda apresenta problemas como fermentação prolongada, baixo volume, textura e desempenho variados.

$\mathrm{O}$ efeito do congelamento pode ser minimizado através do uso de aditivos e ingredientes adequados para a elaboração da massa, porém o mecanismo de fortalecimento da massa devido a aditivação ainda não é completamente conhecido.

O objetivo desse trabalho foi contribuir para o estudo da fabricação do pão francês de massa congelada através da otimização do uso de aditivos conduzida por planejamento experimental. $\mathrm{O}$ estudo da interação aditivos-componentes da farinha de trigo por calorimetria exploratória diferencial e o comportamento reológico da massa após ciclos de congelamento e descongelamento foram conduzidos.

A otimização do uso de aditivos fundamentada nos dados desta pesquisa possibilitará a racionalização do seu uso e aplicação, evitando custos excessivos por parte das indústrias de panificação. 


\subsection{OBJETIVOS}

Neste trabalho, pretendeu-se contribuir com o segmento de Panificação e Confeitaria no Brasil, através de novas informações sobre o comportamento reológico e propriedades termofísicas da massa congelada após ciclo de congelamento e descongelamento, e otimizar o uso de aditivos (emulsificantes, gordura vegetal hidrogenada e ácido ascórbico) através das seguintes ferramentas:

- Projeto de mistura que permite combinar diferentes aditivos.

- Estudo da interação aditivos - componentes da farinha de trigo, através da Calorimetria Exploratória Diferencial (DSC).

- Estudo do comporta reológico da massa congelada, após período de armazenamento congelado. 


\section{REVISÃO DA LITERATURA}

\subsection{COMPOSIÇÃo da MASSA de PÃo}

O pão é composto basicamente de farinha de trigo, água, fermento biológico e sal (cloreto de sódio). Entretanto outros componentes são adicionados em pequena quantidade para melhorar as características da massa durante o processamento e do produto final. Estes componentes são gordura vegetal, açúcares, emulsificantes, agentes oxidantes e enzimas.

As massas congeladas para pães são produzidas através de métodos similares aos das massas convencionais.

\subsubsection{Farinha de trigo}

A composição da farinha de trigo se altera de acordo com a variedade do trigo e de seu grau de extração. Os lipídios são responsáveis por menos de $2 \%$ e as cinzas por menos de 0,5 \% de sua composição (PENFIELD; CAMPBELL, 1990).

As proteínas correspondem aproximadamente $12 \%$ da composição da farinha, dividindo-se em proteínas solúveis (albumina e globulina) responsáveis por um sexto do total e o restante referente às proteínas do glúten (gliadina e glutenina) que possuem as propriedades de panificação da farinha. A glutenina é responsável pela característica de extensibilidade e a gliadina pela coesão e elasticidade da massa (STAUFFER, 1998).

O principal carboidrato na farinha de trigo é o amido, responsável por aproximadamente $65 \%$ da sua composição. O amido apresenta-se em forma de grânulos sendo seu tamanho e formato característicos de sua origem botânica. A Figura 2.1 mostra os maiores componentes do amido: amilose (23\%) e amilopectina (73\%). A amilose é um polímero de cadeia linear com ligações glicosídicas $\alpha-1,4$ enquanto que a amilopectina é uma estrutura altamente ramificada formada por ligações glicosídicas $\alpha-1,4$ e $\alpha-1,6$ (STAUFFER, 1998). 


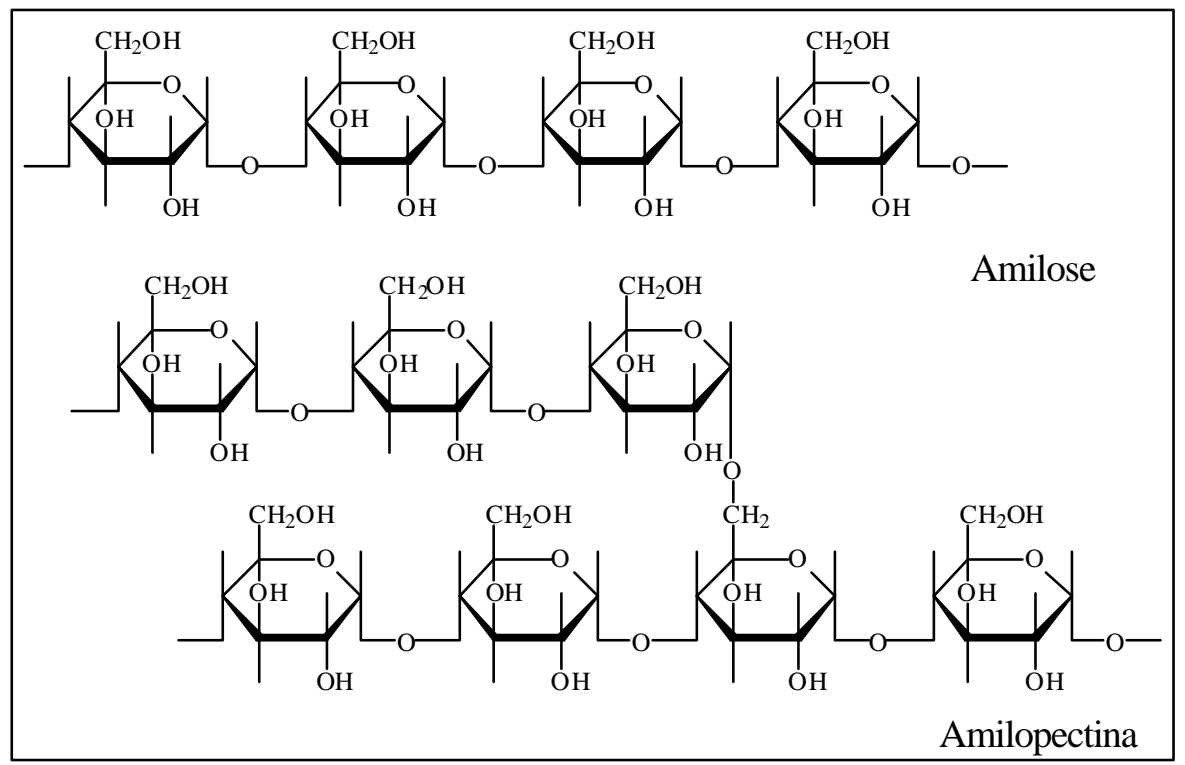

Figura 2.1: Estrutura da amilose e da amilopectina presentes no amido da farinha de trigo.

O grânulo de amido é parcialmente cristalino com grau de cristalinidade de 20-40\% (Figura 2.2). A camada menos densa é altamente amorfa e contém maior quantidade de água. A camada cristalina é formada por duplas hélices de amilopectina empacotadas em sentido paralelo, enquanto que os pontos de ramificação estão nas regiões amorfas. A localização exata das moléculas de amilose é desconhecida, entretanto acredita-se que estejam dispersas entre as moléculas de amilopectina e em maior quantidade na região amorfa. O grânulo de amido quando danificado, aumenta a capacidade de absorver água (JACOBS; DELCOUR, 1998).

Os demais polissacarídeos presentes na farinha são as pentosanas, responsáveis por 2 a $2,5 \%$ da farinha. 


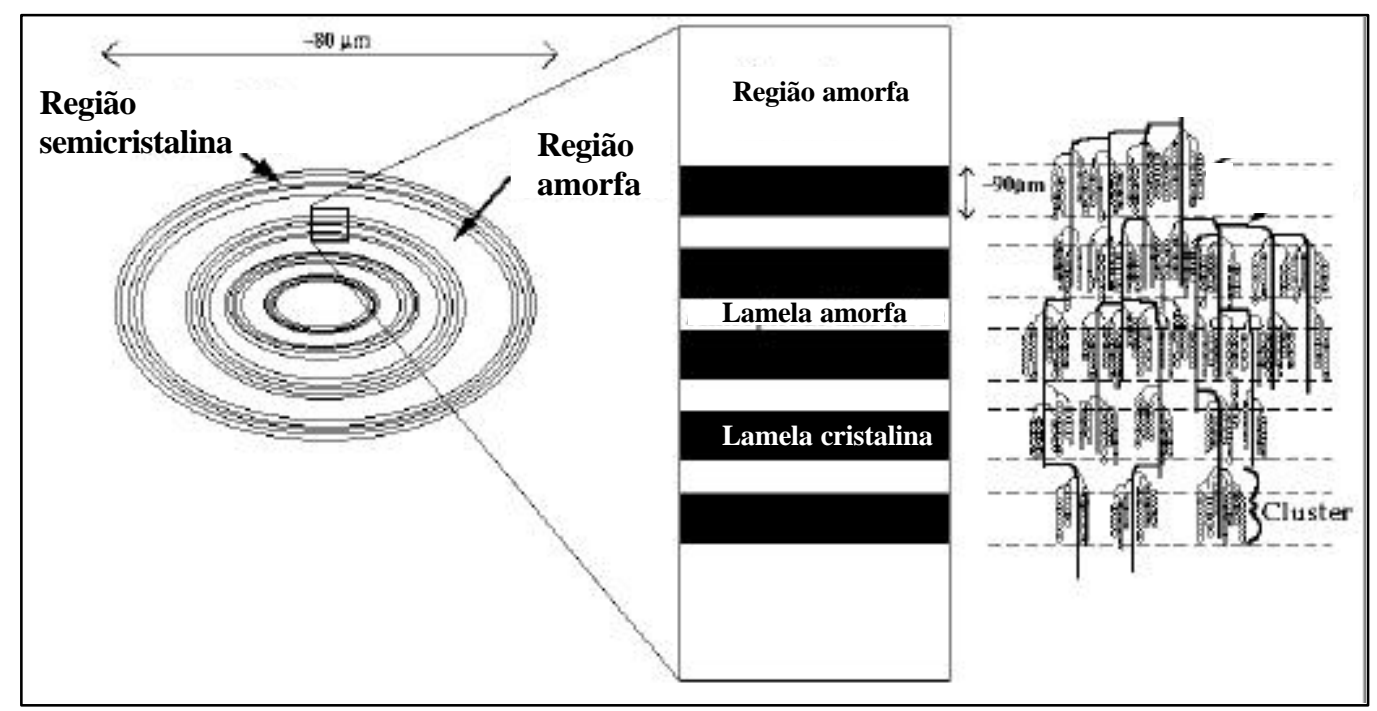

FONTE: DONALD (2004).

Figura 2.2: Estrutura do grânulo de amido presente na farinha de trigo.

A farinha de trigo é o principal ingrediente da massa de pão, sendo as quantidades dos demais ingredientes calculadas sobre a sua, que corresponde a uma base de $100 \%$. Os diferentes tipos de farinhas são utilizados de acordo com as características desejadas em uma massa. Nas congeladas, ela deve possuir alto conteúdo protéico e boa elasticidade a fim de minimizar o enfraquecimento da massa durante o congelamento devido a ações mecânicas dos cristais de gelo sobre a rede de glúten (LAAKSOMEN,2001); (LU; GRANT, 1999).

\subsection{2. Água}

A água é absorvida por proteínas, grânulos de amido íntegros e danificados e pentosanas presentes na farinha. Sua quantidade é determinada por absorção, através do farinograma, método 54-21 (AMERICAN ASSOCIATION OF CEREAL CHEMISTS, 1995); (STAUFFER, 1998).

A quantidade de água absorvida depende da qualidade da farinha de trigo. Uma farinha de boa qualidade garante boa absorção de água e retenção da umidade durante o processamento da massa. Melhores resultados de volume são obtidos quando o nível de água absorvido é o maior possível antes da massa se tornar 
pegajosa, porém o volume não depende apenas da absorção de água mas também do tempo de batimento (LAAKSONEN, 2001).

A água que não é absorvida pelos componentes da farinha, permanece como água livre e nas massas congeladas deve ser reduzida a fim de minimizar a formação de cristais de gelo obtendo melhor resultado no produto final. Segundo Inoue; Bushuk (1996) apud Laaksonen (2001) a absorção de água em massas congeladas deve ser decrescida de 3 a $5 \%$ comparadas a massa para pão fresco, no entanto, para Brack; Hanneforth (1995) um decréscimo de 1-2\% é suficiente. Salas-Mellado (2003) estudou o efeito da formulação na qualidade de massas congeladas para pães utilizando uma redução de $2 \%$.

\subsubsection{Fermento}

A levedura Saccharomyces cerevisiae é utilizada como fermento em panificação que metaboliza açúcares como glicose, frutose, sacarose e maltose, sob condições anaeróbias, produzindo gás carbônico $\left(\mathrm{CO}_{2}\right)$ necessário para o crescimento da massa e para a obtenção de compostos aromáticos característicos de produto de panificação fermentado. A reação de fermentação é dada por:

$$
\mathrm{C}_{6} \mathrm{H}_{12} \mathrm{O}_{6} \rightarrow 2 \mathrm{CO}_{2}+2 \mathrm{C}_{2} \mathrm{H}_{5} \mathrm{OH}
$$

A diminuição da viabilidade e da atividade do fermento devido ao armazenamento em baixas temperaturas, resulta na baixa produção de gás em massas congeladas, resultando na perda de qualidade do pão que pode ser minimizada com o aumento da quantidade de fermento ou pela seleção de cepas mais resistentes aos ciclos de congelamento e descongelamento (CASEY; FOY, 1995); (PENFIELD; CAMPBELL, 1990).

Existem três diferentes tipos de fermento disponíveis para massas congeladas: o fresco prensado, o seco instantâneo e o seco ativado. O fermento fresco prensado apresenta melhor estabilidade no tempo de fermentação quando comparado aos demais (LORENZ; KULP, 1995); (WOLT; D’APPOLONIA, 1984). Porém, alguns trabalhos sugerem que o fermento seco pode ser melhor que o 
prensado para massas congeladas (ZAEHRINGER; MAYFIELD; ODLAND, 1951; MERRITT, 1960 apud LORENZ; KULP, 1995).

\subsubsection{Gordura}

Segundo Penfield; Campbell (1990) a adição de $3 \%$ de gordura sobre o peso da farinha reduz a taxa de endurecimento dos pães. Em massas congeladas as gorduras saturadas fornecem melhores resultados (De STEFANIS; 1995).

No estudo de pão pré-assado congelado, a adição de $2 \%$ de gordura vegetal hidrogenada não influenciou os parâmetros físicos (massa, volume específico e conteúdo de água). No entanto, a adição de gordura vegetal hidrogenada influenciou a textura dos pães apresentando valores de firmeza e mastigabilidade menores (CARR; TADINI, 2003).

\subsubsection{Sal}

O sal interage na formação da rede de glúten e controla a fermentação devido ao efeito osmótico na célula da levedura, porém a sua função mais importante é a de fornecer sabor. A quantidade utilizada é aproximadamente de $2 \%$ sobre a farinha de trigo (PENFIELD; CAMPBELL, 1990); (WILLIAMS; PULLEN, 1998); (QUAGLIA, 1991).

\subsubsection{Açúcar}

A quantidade de açúcar varia de zero a $8 \%$ (PENFIELD; CAMPBELL, 1990). O açúcar é substrato para a fermentação e para as reações com aminoácidos (reação de Maillard) e de caramelização, responsáveis pela coloração e sabor característicos no final do assamento (QUAGLIA, 1991). 


\subsubsection{Emulsificantes}

Os emulsificantes são utilizados em panificação a fim de minimizar o envelhecimento dos pães, melhorar o manuseio e a força da massa, aumentar a tolerância ao tempo de descanso e de fermentação entre outras características não encontradas em um único emulsificante. Apresentam propriedades lipolítica e hidrolítica, reduzindo a tensão interfacial entre fases que normalmente não se misturam.

A propriedade do emulsificante de aumentar o volume do pão e prolongar o frescor da casca é comparável à adição de gordura na massa dos pães. Estudos da substituição da gordura pelo uso de emulsificante tem sido realizados devido à demanda por produtos de baixa caloria (STAMPFLI; NERSTEN, 1995).

Os emulsificantes são categorizados em duas classes (Tabela 2.1): os que formam complexos com o amido, favorecendo a maciez do miolo e prevenindo o envelhecimento, como por exemplo, os monoglicerídeos; e os que atuam na interação de proteínas, fortalecedores de massa que aumentam a habilidade do glúten de formar um filme que retém a produção de gás pela levedura, como por exemplo, o SSL (Estearoil-2-lactil lactato de sódio) e o CSL (Estearoil-2-lactil lactato de cálcio) desejados em massas congeladas.

Tabela 2.1: Classificação dos principais emulsificantes utilizados em panificação segundo Stampfli; Nersten (1995).

\begin{tabular}{lcc}
\hline \multicolumn{1}{c}{ Emulsificante } & $\begin{array}{c}\text { Maciez do } \\
\text { miolo }\end{array}$ & $\begin{array}{c}\text { Fortalecimento } \\
\text { da massa }\end{array}$ \\
\hline Lecitina & Boa & Nenhum \\
$\begin{array}{l}\text { DATEM - Ésteres de ácido diacetil tartárico de } \\
\text { monoglicerídios }\end{array}$ & Satisfatória & Excelente \\
SSL - Estearoil-2-lactil lactato de sódio & Muito boa & Excelente \\
CSL - Estearoil-2-lactil lactato de cálcio & Boa + & Excelente \\
DMG - Monoglicerídios destilados & Excelente & Nenhum \\
PS60 - Polisorbato 60 & Satisfatória & Muito Boa \\
\hline
\end{tabular}


Ésteres de ácido diacetil tartárico de mono e diglicerídios (DATEM), Esteroil-2-lactil lactato de sódio (SSL), Esteroil-2-lactil lactato de cálcio (CSL) e o Polisorbato são os mais utilizados para fortalecimento da massa, atuando na fermentação, manuseio, transporte e no crescimento no princípio do assamento, resultando maiores volumes do pão (TAMSTORF, 1983 apud STAMPFLI; NERSTEN, 1995).

O CSL é um sólido com alto ponto de fusão que pode ser adicionado na massa em forma de pó, sozinho ou com outros aditivos. Melhora a retenção de gás em massas e a vida de prateleira do produto, devido à capacidade de se ligar a amilose. Por ser miscível em gordura, é ideal para pães que contenham gordura, e apresenta melhores resultados quando o produto contém gordura e açúcar (WILIAMS; PULLEN, 1998). O Polisorbato 80 (PS80) atua na interação de proteínas, melhorando a retenção de gás, a textura e o volume (BRANDT, 1996).

O mecanismo de fortalecimento da massa devido ao emulsificante não é completamente conhecido e várias teorias foram revisadas por Krog (1981).

Brandt (1996) relata os fatores considerados na seleção de emulsificantes que no Brasil tem o uso regulamentado pela Agência Nacional de Vigilância Sanitária (ANVISA, 1999). 


\subsubsection{Enzimas}

A enzima alfa-amilase atua sobre as moléculas de amilose e amilopectina quebrando-as em cadeias menores denominadas dextrinas. A beta-amilase ataca somente as extremidades das cadeias de amilose e amilopectina formando moléculas de maltose (Figura 2.3).

A maioria das farinhas contém nível natural adequado de beta-amilase enquanto que o de alfa-amilase deve ser ajustado por adição, pois ocorre uma perda no processo de extração. Este ajuste assegura o nível adequado necessário de açúcar para o fermento durante a fermentação (WILLIAMS; PULLEN, 1998).

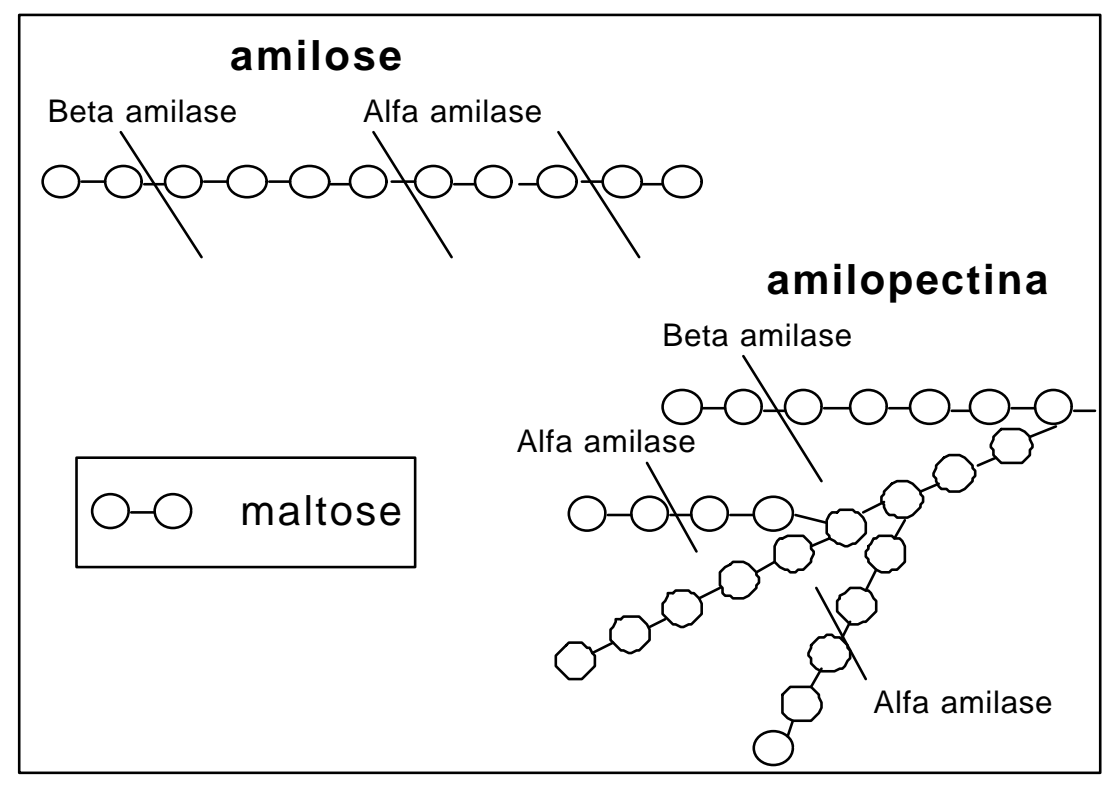

Figura 2.3: Mecanismo de ação das enzimas alfa e beta amilase nas cadeias de amilose e amilopectina presentes no amido da farinha de trigo.

León; Durán; Barber (2002) estudaram a influência de misturas de enzimas contendo alfa-amilase e lipase em formulações de pães ao longo do tempo e verificaram um efeito benéfico na manutenção das propriedades sensoriais, de firmeza e na formação do complexo amilose-lipídio mais termoestável. A retrogradação da amilopectina foi inibida pelo uso das enzimas. 


\subsubsection{Agentes Oxidantes}

As maiores contribuições de oxidantes em panificação estão na substituição do processo de maturação da farinha de trigo que ocorre normalmente de 1 a 2 meses após a sua produção; no branqueamento da farinha removendo a coloração amarelada; e no fortalecimento da matriz de glúten para resistir o estresse do batimento rápido (STAUFFER,1990).

A terceira contribuição, mencionada acima, é a de maior interesse no comportamento da massa durante o seu processamento, melhorando a reologia da massa e a qualidade final do produto. $\mathrm{O}$ ácido ascórbico é um agente oxidante que fortalece a rede de glúten através da criação de ligações dissulfídicas, responsável pelo aumento no tamanho do pão nos primeiros minutos de assamento (NAKAMURA; KURATA, 1997). As vantagens e desvantagens do uso do ácido ascórbico foram enumeradas por Williams; Pullen (1998).

Segundo Abd El-Hady; El-Samahy; Brümmer (1999), as perdas das propriedades reológicas e de panificação durante o armazenamento de massas não fermentadas congeladas podem ser minimizadas por adição de ácido ascórbico individualmente ou com bromato de potássio e SSL.

$\mathrm{O}$ bromato de potássio $\left(\mathrm{KBrO}_{3}\right)$, além do ácido ascórbico, está entre os agentes oxidantes mais conhecidos porém o seu uso é proibido no Brasil (ANVISA, 2001). 


\subsection{Processamento do Pão de Massa Congelada}

O processamento do pão de massa congelada é similar ao convencional até a etapa que antecede o congelamento como mostra a Figura 2.4.

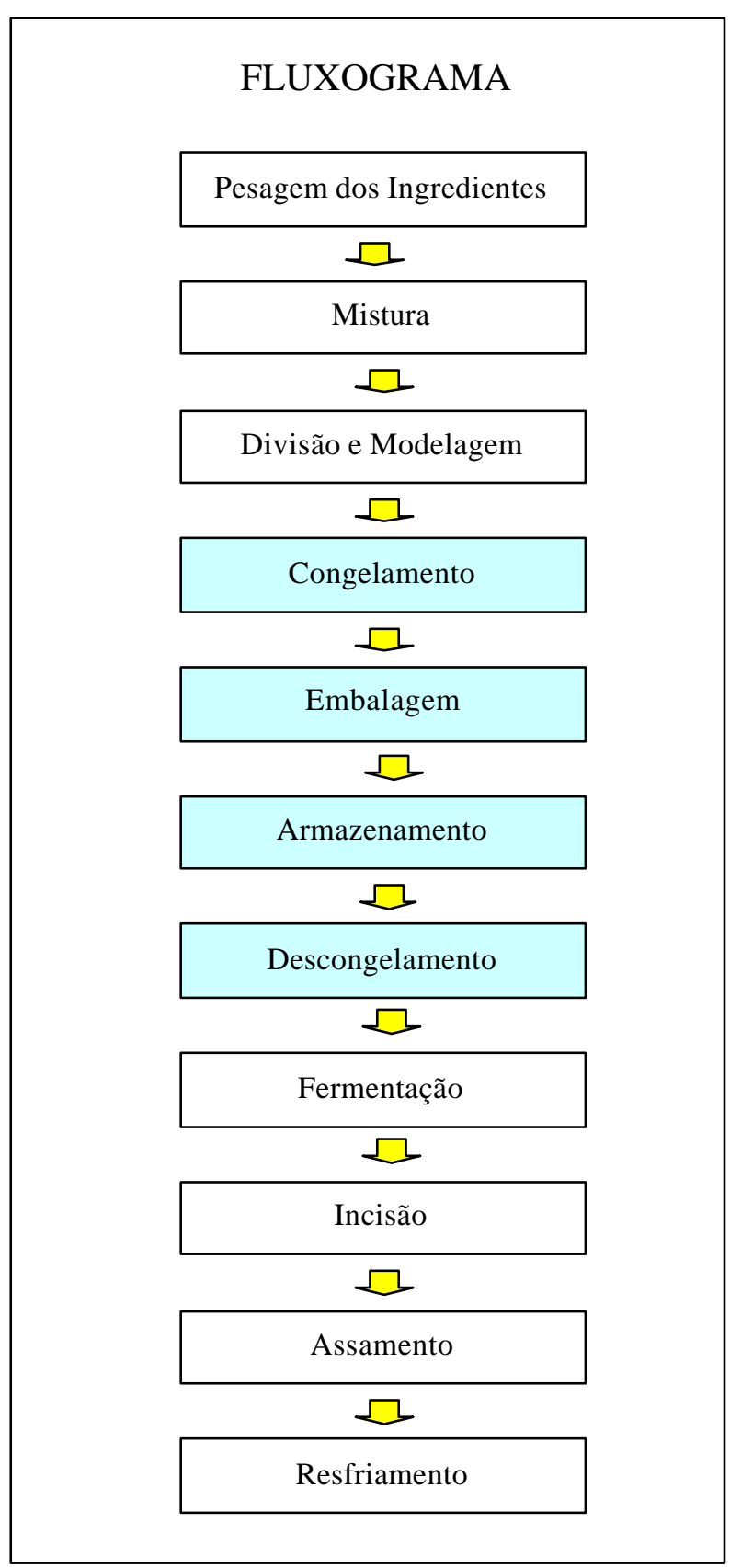

Figura 2.4: Fluxograma simplificado do processo de fabricação de pão francês de massa congelada. 


\subsubsection{Mistura}

A mistura consiste em homogeneizar os ingredientes, dispersar, solubilizar e hidratar uniformemente os componentes da massa. O trabalho mecânico contribui para o desenvolvimento da estrutura do glúten e incorpora bolhas de ar, assim uma mistura heterogênea e espessa de água e farinha é convertida em uma massa viscoelástica homogênea de aspecto seco (MARSH, 1998).

No glúten, além da interação de proteínas outros componentes da farinha como lipídios, sais, amidos e outros polissacarídios também participam de sua formação. Os grânulos de amido ficam envoltos pela fase protéica que é contínua (GIANNOU; KESSOGLOU; TZIA, 2003).

Existem diferentes métodos para se obter uma massa. No caso do processo direto são utilizadas duas velocidades de mistura. A primeira para homogeneização dos ingredientes e absorção da água e a segunda para o trabalho mecânico da massa.

Durante a mistura, a formação do glúten acontece em diferentes estágios: no primeiro, as moléculas de proteína são hidratadas e as suas fibrilas se aderem umas às outras formando uma rede desorganizada de fios espessos (Figura 2.5 a). A ação mecânica torna os fios mais finos e os orienta na direção em que foram submetidos à força, permitindo a interação entre eles (Figura 2.5 b). No último estágio aparece o pico de consistência (Figura 2.5 c), no qual as fibrilas de proteína têm seu diâmetro reduzido significativamente e interagem mais bidimensionalmente que em um único eixo. Neste estágio, a massa pode ser estendida em forma de filme contínuo (STAUFER, 1998).

A capacidade da massa de ser estendida em membrana fina é um importante parâmetro no processo, pois indica o batimento ótimo, mais conhecido como ponto de véu. Se a mistura continuar após o pico de resistência, a massa torna-se mole, menos resistente à ação mecânica e perde a habilidade de reter gás durante a fermentação. Uma boa massa é definida por sua habilidade de reter o gás e pela promoção de sua propriedade viscoelástica, assim o volume da massa pode expandir adequadamente durante a fermentação e nas etapas que antecedem o assamento (STAUFER, 1998). 
É importante que a mistura da massa para congelamento termine em temperaturas inferiores $\left(\sim 20^{\circ} \mathrm{C}\right)$ às da massa convencional $\left(27^{\circ} \mathrm{C}\right.$ a $\left.30^{\circ} \mathrm{C}\right)$, a fim de inibir a produção de gás pelas leveduras. Para isso, é necessário o uso de água gelada ou de masseira com jaqueta de resfriamento. A massa para congelamento apresenta maior rigidez devido à redução de água adicionada e menor temperatura no final da mistura (SALAS-MELLADO, 2003).

Para se atingir a temperatura final desejada na massa, a temperatura da água adicionada deve ser controlada e é determinada considerando os calores de fricção, gerado pelo motor da masseira, específico de cada ingrediente e de hidratação liberado quando uma substância sólida absorve água, envolvidos na etapa de mistura. Se a temperatura da farinha for elevada, deve ser utilizado gelo para ajustar a temperatura final da massa, o que envolverá calor de fusão. A temperatura da água a ser adicionada pode ser determinada pela Equação 2.1 (ASHRAE, 1994).

$$
\mathrm{T}_{\mathrm{a}}=2 \times \mathrm{T}_{\mathrm{m}}-\mathrm{T}_{\mathrm{F}}-\mathrm{Ff}
$$

em que:

$\mathrm{T}_{\mathrm{a}}, \mathrm{T}_{\mathrm{m}}$ temperatura da água e temperatura desejável para a massa $\left({ }^{\circ} \mathrm{C}\right)$

$\mathrm{T}_{\mathrm{F}} \quad$ temperatura da farinha $\left({ }^{\circ} \mathrm{C}\right)$

Ff elevação da temperatura devido ao fator de fricção $\left({ }^{\circ} \mathrm{C}\right)$

Rouillé; Le Bail; Courcoux (2000) estudaram a influencia da adição de ácido ascórbico e alfa-amilase com hemicelulase e do tempo de mistura sobre a pegajosidade da massa, o volume de gás produzido e o volume do pão e verificaram que o tempo de mistura foi o fator mais significativo sobre o volume do pão.

\footnotetext{
${ }^{(*)}$ Fonte: Fmaiis Indústria de Alimentos Ltda.
} 

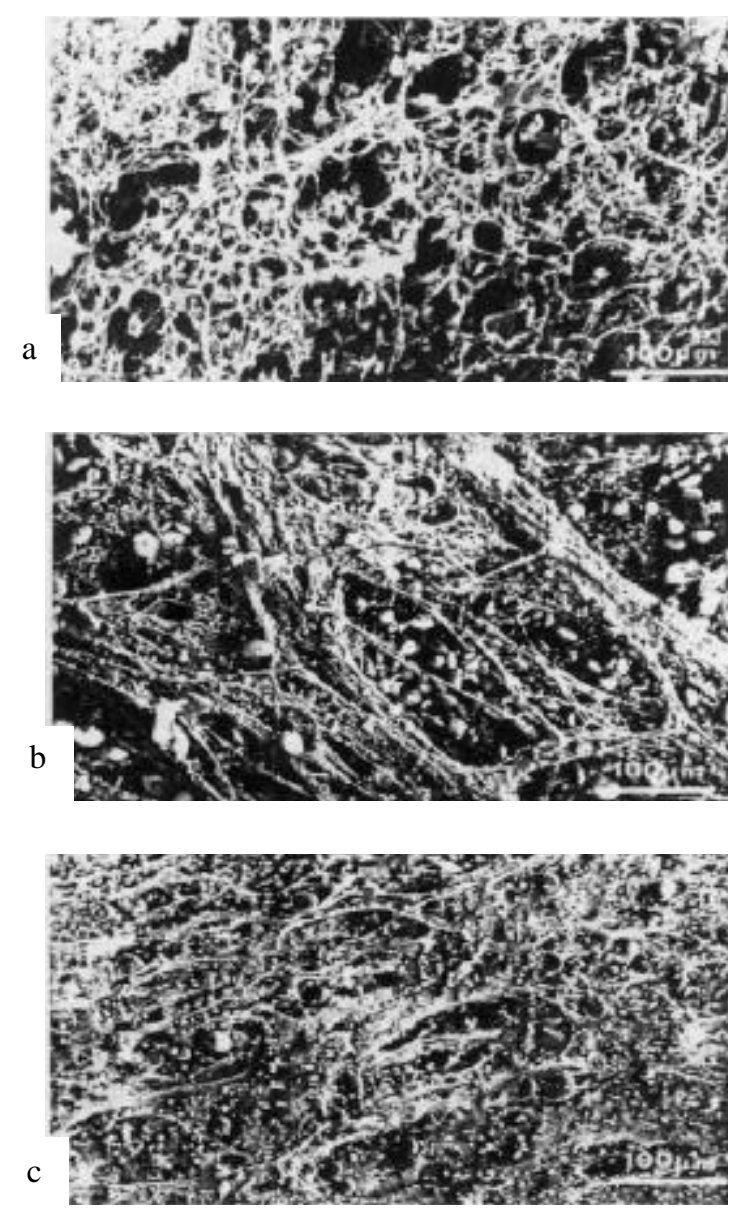

Figura 2.5: Rede de glúten em diferentes estágios de mistura: (a) início do processo de mistura, hidratação parcial; (b) massa parcialmente misturada; (c) massa no estágio de desenvolvimento máximo.

\subsubsection{Divisão e Modelagem}

Logo após o batimento, a massa é dividida em pedaços, com peso determinado, por divisora mecânica e depois moldada no formato desejado.

No processo de massas congeladas, a etapa de descanso é suprimida para que não ocorra fermentação antes do ciclo congelamento-descongelamento. 


\subsubsection{Congelamento}

O congelamento compreende a redução da temperatura e a mudança de estado da água presente na massa de pão, da fase líquida para a sólida e deve ser realizado imediatamente após a modelagem para evitar a fermentação.

A velocidade de resfriamento pode ser determinada pela razão da diferença de temperatura e a respectiva duração do congelamento (Equação 2.2) (HAVET; MANKAI; LE BAIL, 2000).

$$
v=\frac{T_{c}-T_{0}}{t_{c}-t_{0}}
$$

em que:

v velocidade de resfriamento $\left({ }^{\circ} \mathrm{C} / \mathrm{min}\right)$

$\mathrm{T}_{0} \quad$ temperatura no início do processo no centro geométrico $\left({ }^{\circ} \mathrm{C}\right)$

$\mathrm{T}_{\mathrm{c}} \quad$ temperatura inicial de congelamento no centro geométrico $\left({ }^{\circ} \mathrm{C}\right)$

$\mathrm{t}_{0} \quad$ tempo inicial do processo (min)

$t_{c} \quad$ tempo correspondente à $T_{c}(\min )$

\subsubsection{Influência do congelamento sobre a massa e a ação da levedura}

O congelamento provoca o enfraquecimento da estrutura da massa pelos danos causados na rede de glúten, reduzindo a sua capacidade de retenção de gás. Para explicar este fenômeno foram propostas duas teorias.

Segundo Kline; Sugihara (1968) apud Kenny et al. (1999) o enfraquecimento é causado por compostos redutores, provenientes das células de levedura, que rompem ligações dissulfídicas e Inoue; Bushuk (1991) sugerem que a estrutura do glúten de massa com fermento é mais vulnerável ao congelamento que em massas sem fermento. Porém Autio; Sinda (1992) verificaram que a presença de células de leveduras mortas na massa não afetaram as propriedades reológicas, indicando que mudanças estruturais na massa congelada e descongelada não estão associadas com a liberação de substâncias redutoras de células de leveduras. Para 
Berglund; Shelton; Freeman (1991) os danos na rede de glúten são devidos à ação mecânica dos cristais de gelo durante o congelamento.

As velocidades de congelamento e descongelamento afetam a viabilidade do fermento e ao contrário da maioria dos alimentos, o congelamento rápido não é recomendado para massas de pães devido à presença de levedura. Durante o congelamento lento, a água intracelular das células de levedura migra para fora, formando gelo no seu exterior que não é nocivo, pois a membrana da célula apresenta uma barreira efetiva a ele. Por outro lado, no congelamento rápido ocorre a formação de pequenos cristais de gelo no interior da célula que durante o descongelamento se recristalizam formando cristais grandes que podem ser letais (CASEY; FOY, 1995); (LORENZ; KULP, 1995).

A velocidade de congelamento ótima deve ser suficientemente lenta para prevenir a formação de cristais no interior da célula e ao mesmo tempo rápida, para minimizar o tempo de exposição da célula aos efeitos da concentração da solução provocada pela cristalização da água. Casey; Foy (1995) reportam estudos com velocidades de congelamento ótimas de $-7{ }^{\circ} \mathrm{C} / \mathrm{min}$ e $-4{ }^{\circ} \mathrm{C} / \mathrm{min}$. Para Giannou; Kessoglou; Tzia (2003), o congelamento de massas a velocidades inferiores a $-2{ }^{\circ} \mathrm{C} / \mathrm{min}$ é preferível para obter maior sobrevivência das leveduras e maior qualidade do produto final.

Segundo Stecchini et al. (2002), a viabilidade da levedura é principalmente afetada pelas temperaturas de congelamento e armazenamento. Em temperaturas inferiores à transição vítrea, que para a fase líquida da massa foi de $-58{ }^{\circ} \mathrm{C}$, obtevese maiores taxas de sobreviventes. Em temperaturas superiores, os fatores osmóticos, principalmente durante o congelamento, e os cinéticos no período de armazenamento parecem governar a sobrevivência da levedura.

Neyreneuf; Delpuech (1993) estudaram a influência de diferentes condições de congelamento criogênico, a $-40{ }^{\circ} \mathrm{C},-60{ }^{\circ} \mathrm{C},-80{ }^{\circ} \mathrm{C},-100{ }^{\circ} \mathrm{C}$ e $-120^{\circ} \mathrm{C}$ em massas fermentadas e verificaram que o congelamento criogênico a $-60{ }^{\circ} \mathrm{C}$ produziu os melhores resultados em relação a temperaturas inferiores em termos de volume do pão. O congelamento utilizado como referência foi o realizado em "freezer" convencional a $-40{ }^{\circ} \mathrm{C}$ que apresentou melhores resultados em relação ao volume, porém o tempo de congelamento foi superior. 
Havet; Mankai; Le Bail (2000) e Le Bail; Havet; Hayert (2000) estudaram a influência do congelamento sobre a massa de pão francês em relação à qualidade do pão produzido destas massas. No primeiro estudo, as massas foram congeladas a $-20{ }^{\circ} \mathrm{C}$ em congelador com ar forçado em três diferentes velocidades, 1,2 e $3 \mathrm{~m} / \mathrm{s}$, até atingir $-19{ }^{\circ} \mathrm{C}$ no centro. Os autores verificaram que ocorreu um declínio na qualidade do pão e perda da elasticidade da massa com o aumento da velocidade de congelamento. Segundo os autores, a origem do enfraquecimento da massa é devido à formação de cristais de gelo. No segundo estudo acima referenciado, massas produzidas de farinha fraca e forte foram congeladas em túnel de congelamento a $-30{ }^{\circ} \mathrm{C}$ e velocidade do ar de $4 \mathrm{~m} / \mathrm{s}$, até atingir duas condições, $-5{ }^{\circ} \mathrm{C}$ e $-15^{\circ} \mathrm{C}$ no centro da massa, que correspondem ao congelamento curto e longo respectivamente. O congelamento curto e a farinha forte apresentaram melhores resultados em relação ao volume específico dos pães.

\subsubsection{Congelamento e Transição vítrea}

Diferente de transições de fase como a cristalização e a fusão, a transição vítrea é de segunda ordem e não envolve calor latente, o alimento em estado amorfo passa do estado vítreo para estado borracha e vice-versa. A transição pode ser observada pela mudança da capacidade térmica, por propriedades mecânicas e dielétricas. Compreende uma faixa de temperatura e geralmente é determinada pela técnica de Calorimetria Exploratória Diferencial (DSC) que consiste em medir a diferença de energia entre uma substância amostra e o material de referência, quanto submetida a um programa de temperatura (MA; HARWALKAR; MAURICE, 1990); (LEVINE; SLADE, 1990).

Durante o congelamento, parte da água presente no alimento transforma-se em gelo e a porção não congelada tem sua concentração e viscosidade aumentadas com o decréscimo da temperatura. Quando não há mais a formação de gelo, a fase não congelável se torna mais viscosa, vítrea. A forma vítrea é caracterizada pela alta viscosidade (10 ${ }^{12}-10^{14}$ Pa.s) (LAAKSONEN, 2001).

Recomenda-se que os alimentos submetidos ao processo de congelamento sejam mantidos abaixo de sua transição vítrea, que varia de acordo com a sua composição. Quando a fase não congelável é mantida no estado vítreo, as reações e 
transformações são minimizadas devido à alta viscosidade. Segundo Levine; Slade apud Laaksonen; Ross (2000) a transição vítrea em massas congeladas ocorre entre $-30{ }^{\circ} \mathrm{C}$ e $-10{ }^{\circ} \mathrm{C}$ quando determinadas através de DSC. Porém para Laaksonen; Ross (2000), a transição vítrea de massas congeladas ocorre abaixo de $-30{ }^{\circ} \mathrm{C}$ o que sugere que temperatura usual de "freezer" doméstico $\left(-18^{\circ} \mathrm{C}\right)$ não é suficiente para manter o alimento no estado vítreo.

\subsubsection{3. Água não congelável ( $\mathrm{Wg}$ ')}

A água não congelável (Wg') na fase aquosa do alimento, altamente viscosa, é aquela que não se cristaliza em temperaturas abaixo da transição vítrea e que contém a máxima concentração de sólidos. Trata-se de uma medida da composição do material na temperatura de transição vítrea de máxima concentração de sólidos (Tg'), que também pode ser expressa em termos de concentração de sólidos na água não congelável (Cg').

Como a água pura é um plastificante e sua transição vítrea é aproximadamente $-135^{\circ} \mathrm{C}$, um maior conteúdo inicial de água no alimento faz com que sua transição diminua e se aproxime à da água pura. Quanto menor a temperatura de transição vítrea do alimento, menor é a temperatura de armazenamento necessária para manter a qualidade do alimento congelado, portanto os custos com o armazenamento serão maiores.

A água não congelável (Wg') e a concentração de sólidos na água não congelável (Cg') foram determinadas por Laaksomen; Roos (2001) através das Equações 2.3 e 2.4:

$$
\begin{gathered}
W g^{\prime}=\frac{w_{t o t}-\frac{\Delta H_{t o t}}{\Delta H_{m w}}}{C_{t o t}} \\
C g^{\prime}=\frac{C_{t o t}}{\left(w_{t o t}-\frac{\Delta H_{t o t}}{\Delta H_{m w}}\right)+C_{t o t}}
\end{gathered}
$$


Onde:

$\begin{array}{ll}\mathrm{Wg} & \text { Água não congelável }\left(\mathrm{g} \mathrm{H}_{2} \mathrm{O} / \mathrm{g} \text { sólidos) }\right. \\ \mathrm{W}_{\mathrm{tot}} & \text { Conteúdo inicial de água na amostra }(\mathrm{g}) \\ \Delta \mathrm{H}_{\mathrm{tot}} & \text { Calor total de fusão do gelo da amostra }(\mathrm{J}) \\ \Delta \mathrm{H}_{\mathrm{mw}} & \text { Calor latente de fusão do gelo - água pura (334 J/g) } \\ \mathrm{C}_{\text {tot }} & \text { Conteúdo inicial de sólidos na amostra (g) } \\ \mathrm{Cg}^{\prime} & \text { Concentração de sólidos em } \mathrm{Wg} \text { ' (\% de sólidos na água não } \\ \frac{\Delta H_{t o t}}{\Delta H_{m w}} & \text { congelável) } \\ \left(w_{t o t}-\frac{\Delta H_{t o t}}{\Delta H_{m w}}\right) & \text { Quantidade de gelo na amostra (g) }\end{array}$

O conteúdo de água congelada na massa pode ser calculado a partir da área da endoterma de fusão obtida no DSC. A diferença entre o conteúdo de água congelada (gelo), em massa, e o conteúdo total de água na solução inicial é o conteúdo, em massa, da água não congelável na Tg', por unidade de massa de sólidos (LEVINE; SLADE, 1990). Este cálculo não leva em consideração a dependência da temperatura no calor latente de fusão, na capacidade térmica e nas mudanças da concentração da água não congelável (LAAKSONEN, 2001).

Roman-Gutierrez; Guilbert; Cuq (2002) estudaram propriedades de congelamento e água não congelável em duas variedades de farinha de trigo (duro e mole) e de seus principais componentes (amido, amido danificado, glúten e pentosanas) utilizando DSC. O conteúdo de água não congelável da farinha forte variou de 29 a $31 \%$, da fraca de 30 a $32 \%$, do glúten de 38 a $47 \%$, do amido de 38 a $42 \%$, do amido danificado de 37 a $40 \%$ e das pentosanas de 40 a $51 \%$, base seca. A simples soma dos conteúdos de água não congelável de cada componente não deve ser usada para estimar o conteúdo de água não congelável da farinha. 


\subsubsection{Embalagem}

Possui a função de proteger, identificar e promover o produto. O material da embalagem deve possuir as seguintes características: evitar a perda de umidade do produto durante o armazenamento a baixas temperaturas, fator relacionado à queda na qualidade do produto final; barreira ao oxigênio; resistência física e mecânica e ser selável a quente (LORENZ; KULP, 1995).

\subsubsection{Armazenamento}

Todos os produtos possuem uma temperatura própria de armazenamento, porém comercialmente costuma-se armazenar a $-20{ }^{\circ} \mathrm{C}$, temperatura que para Cauvain (1998) está abaixo da transição vítrea de massas fermentadas. Mesmo a $-20{ }^{\circ} \mathrm{C}$, a massa congelada necessita de acondicionamento em sacos de polietileno ou de outro material que impeça a perda de água.

Existem vários estudos descritos na literatura sobre o armazenamento de massas congeladas para pães que relatam a perda de qualidade do produto final, como o volume, ao longo do tempo de armazenamento devido à perda de resistência à extensão da massa e o aumento do tempo de fermentação (WOLT; APPOLONIA, 1984); (INOUE; BUSHUK, 1991); (KENNY et al., 1999); (BHATTACHARYA; LANGSTAFF; BERZONSKY, 2003); (RIBOTTA; LEÓN; AÑÓN, 2001).

Bhattacharya; Langstaff; Berzonsky (2003) verificaram que a entalpia da água congelável foi de $76 \mathrm{~J} / g$ na massa fresca, $84 \mathrm{~J} / \mathrm{g}$ após 4 semanas e $86 \mathrm{~J} / \mathrm{g}$ após 12 semanas de armazenamento $\mathrm{a}-23{ }^{\circ} \mathrm{C}$. O maior aumento na entalpia ocorreu entre o armazenamento inicial e 4 semanas e este acontecimento foi atribuído à deterioração da rede de glúten.

Bot (2003) observou que o conteúdo de água não congelável no glúten diminuiu aproximadamente $1 \%$ nas três primeiras semanas de armazenamento congelado a $-15^{\circ} \mathrm{C}$, enquanto que a $-25^{\circ} \mathrm{C}$ essa mudança não foi observada. No armazenamento da massa $\mathrm{a}-15^{\circ} \mathrm{C}$ e $-25^{\circ} \mathrm{C}$, foram verificadas as mesmas alterações do glúten a $-15{ }^{\circ} \mathrm{C}$. As alterações ocorridas na massa em temperaturas inferiores são devido à menor temperatura de transição vítrea.

Varriano-Marston et al. (1980) e Wolt; d'Appolonia (1984) apud Rouillé; Le Bail; Courcoux (2000), observaram o aumento da resistência ao extensógrafo e 
diminuição da extensibilidade em massas submetidas a dois ciclos de congelamento e descongelamento, provavelmente devido à redistribuição da água causada pela mudança da capacidade de retenção de água de alguns constituintes da farinha de trigo. Efeito oposto foi observado por Inoue; Bushuk (1991). O uso de diferentes oxidantes pode explicar estes resultados (bromato de potássio por Wolf; d’Appolonia versus ácido ascórbico por Inoue; Bushuk).

Wolt; d'Appolonia (1984) e Ribotta; León; Añón (2001) estudaram massas congeladas aditivadas. No primeiro estudo, foi verificado que os emulsificantes SSL e ésteres de ácido diacetil tartárico de monoglicerídios (DATA ou DATEM) diminuíram o efeito do armazenamento nas propriedades reológicas e no segundo, massas com DATEM, glúten e goma guar produziram pães com maiores volumes que a massa sem aditivos, porém o tempo de fermentação não foi reduzido. Kenny et al. (1999) também estudaram medidas reológicas em massas frescas e congeladas contendo ácido ascórbico, SSL e DATEM. A resistência à extensão foi maior em massas com aditivos, tanto frescas quanto congeladas, e todas as massas apresentaram decréscimo na resistência ao longo do tempo de armazenamento e queda na qualidade do produto. Assim, os aditivos utilizados apresentaram efeitos positivos no crescimento, no volume e na firmeza.

Lu; Grant (1999) investigaram os efeitos do armazenamento no amido isolado de massas e em propriedades de panificação. A entalpia de gelatinização e a água congelável aumentaram com o tempo de armazenamento. Ribotta; León, Añón (2003) verificaram um aumento na entalpia de gelatinização após 150 dias de armazenamento congelado.

Zounis et al. (2002) e Berglund; Shelton; Freeman, (1991) estudaram as mudanças na estrutura de massas congeladas durante o armazenamento através de SEM do inglês, "Scanning Electron Microscopy". No primeiro estudo, a estrutura da massa tornou-se mais danificada com o tempo de armazenamento devido às mudanças na estrutura do cristal de gelo, alterações na rede de glúten e separação entre o glúten e o amido que aumentou com o tempo de armazenamento. No segundo estudo, verificou-se mudanças na distribuição da água durante o armazenamento e ciclos congelamento e descongelamento contribuindo para o prolongamento do tempo de fermentação e redução do volume. 


\subsubsection{Descongelamento}

A partir desta etapa, o processo é realizado no ponto de venda. O descongelamento é necessário para uma melhor performance da massa devido a reidratação do sistema, principalmente da matriz de glúten e do fermento. As condições de tempo-temperatura devem ser definidas de forma a não haver condensação na superfície e a proporcionar temperatura homogênea no assamento do pão, ou seja, evitar o assamento heterogêneo (superfície assada e miolo congelado) (GIANNOU; KESSOGLOU; TZIA, 2003).

\subsubsection{Crescimento}

O tempo de crescimento da massa é necessário para a atuação do fermento que é maior em massas congeladas que convencionais devido às baixas temperaturas em que a massa entra na etapa de crescimento e também à perda do poder de retenção e atividade da célula devido ao congelamento (BRÜMMER, 1995); (GIANNOU; KESSOGLOU; TZIA, 2003).

\subsubsection{Assamento}

O assamento de pães de massa congelada é realizado da mesma forma que no processo convencional, resultando mudanças físico-químicas e bioquímicas como expansão do volume, evaporação de água, formação de poros, desnaturação de proteínas, gelatinização do amido, formação da casca entre outros (GIANNOU; KESSOGLOU; TZIA, 2003).

Queiroz (2001) estudou as propriedades termofísicas do pão francês durante o assamento. As temperaturas no centro e na superfície do pão foram monitoradas durante o assamento em forno turbo com dispositivo de vaporização. A Figura 2.6 é um exemplo dos perfis de temperatura obtidos durante o assamento. 


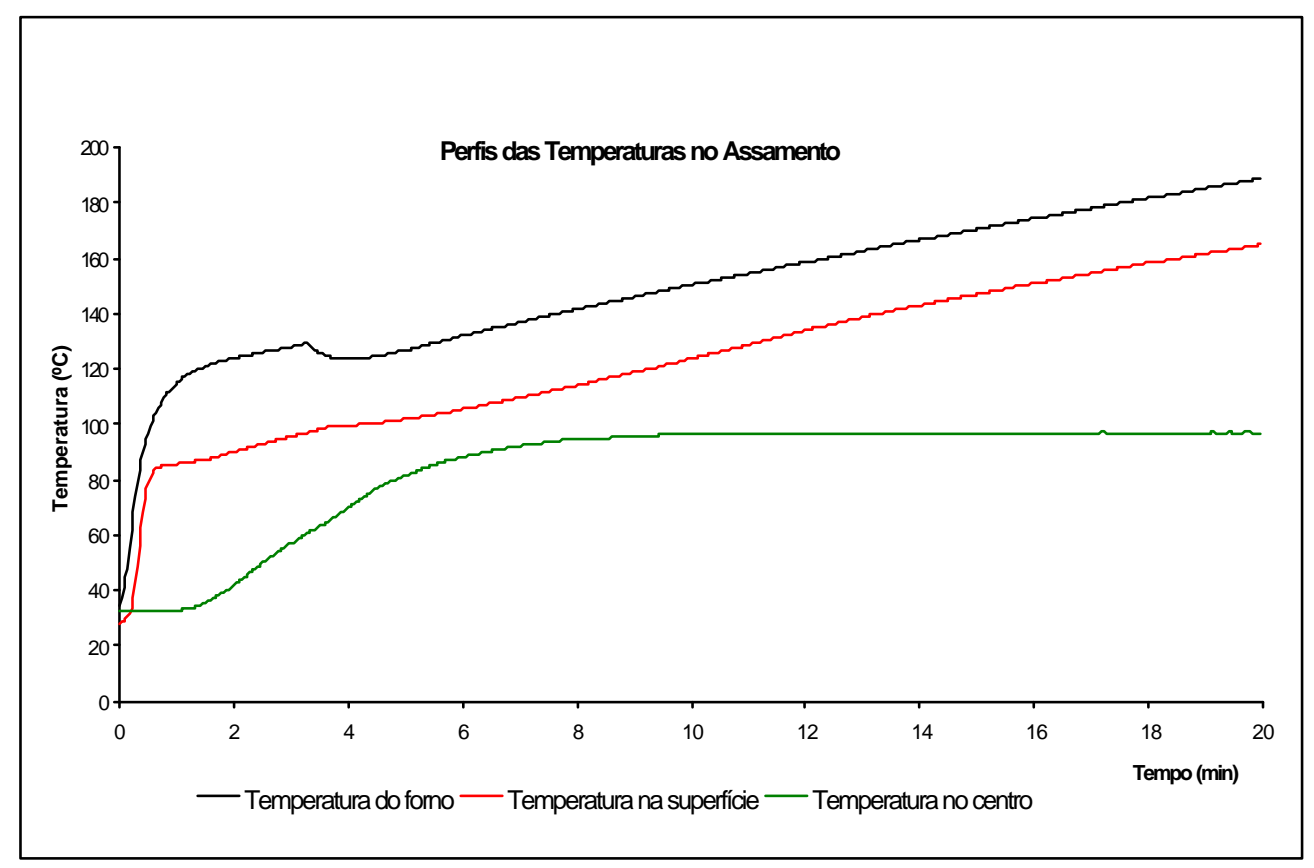

Figura 2.6: Perfis de temperatura do pão francês durante o assamento.

\subsubsection{Vaporização}

No início do assamento é realizada uma breve vaporização. O vapor se condensa sobre a superfície do pão e causa uma diferença de temperatura entre o forno $\left(220-250^{\circ} \mathrm{C}\right)$ e a massa $\left(25-30^{\circ} \mathrm{C}\right)$, formando uma película sutil. Este fenômeno torna a massa mais suave e cria uma barreira à saída de gás carbônico, permitindo maior desenvolvimento e crescimento, conferindo maior volume.

A película de água sobre a massa, formada pela condensação do vapor, se evapora lentamente. Assim, os processos químicos na superfície são lentos permitindo a obtenção de uma casca menos dura e mais crocante. $\mathrm{O}$ cozimento da casca torna-se regular e a abertura da pestana é retardada. As reações de Maillard e caramelização são influenciadas pela umidade do ambiente, assim a cor da casca é diferente. Em fornos saturados de vapor, a cor da casca é amarela dourada e com brilho que não é obtido na ausência de vapor (CALVEL, 1987); (QUAGLIA, 1991). 


\subsubsection{Gelatinização}

A gelatinização é uma combinação do evento de fusão da porção cristalina do grânulo de amido e da transição vítrea da porção amorfa do grânulo de amido. $\mathrm{O}$ grânulo de amido não é solúvel em água fria, porém quando aquecido em meio aquoso, absorve água e intumesce. Inicialmente o entumescimento é reversível, tornando-se irreversível a medida que aumenta a temperatura, alterando a estrutura do grânulo. Com o aumento da temperatura, pontes de hidrogênio são rompidas permitindo a incorporação de água pelo amido. Esta incorporação aumenta a separação entre as cadeias e a aleatoriedade e diminui o número e o tamanho das regiões cristalinas.

Quando a temperatura de fusão dos cristais de amido é excedida, o estado do sistema é próximo a um sólido. Este ponto é conhecido como ponto de gelatinização ou temperatura de gelatinização. Para pães, é a temperatura que a estrutura viscoelástica da massa torna-se uma esponja sólida e varia de 60 a $90{ }^{\circ} \mathrm{C}$. No produto final, os grânulos de amido variam de quase totalmente a totalmente gelatinizados (PATERAS, 1998).

Autio; Sinda (1992) mostraram que o congelamento e o descongelamento provocaram um atraso na gelatinização do amido, aumentando a sua temperatura. Segundo os autores, este fato é atribuído ao atraso na difusão de água ou ao aumento da cristalinidade no grânulo de amido.

\subsubsection{Complexo amilose-lipídio}

A formação do complexo amilose-lipídio ocorre com ácidos graxos ou fosfolipídios naturais durante a biossíntese do amido ou durante a gelatinização do amido em presença de lipídios naturais ou com adição de emulsificantes como monoglicerídeos, CSL, SSL (OPTA FOOD INGREDIENTS, 2003). 
Os complexos apresentam duas formas, I e II (Figura 2.7). A primeira é a associação das cadeias de amilose com a molécula de lipídio, promovendo conformação de hélice. A segunda forma é a organização das hélices em uma estrutura semicristalina (BILIADERIS; GALLOWAY apud OPTA FOOD INGREDIENTS, 2003).

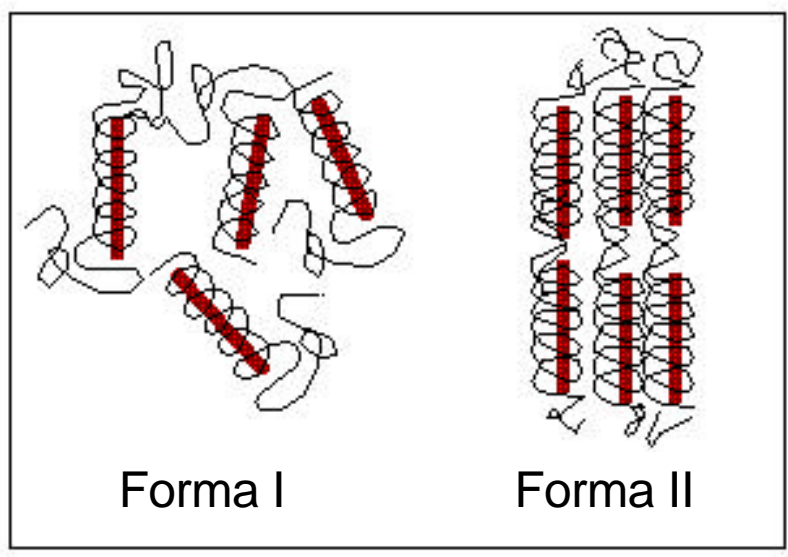

FONTE: OPTA FOOD INGREDIENTS (2003)

Figura2.7: Forma I e II do complexo de amilose-lipídio.

A presença de complexos amilose-lipídios é identificada por uma transição endotérmica entre $95^{\circ} \mathrm{C}$ e $130{ }^{\circ} \mathrm{C}$, temperaturas superiores a da gelatinização. A formação do complexo é termorreversível, o que pode ser evidenciado por uma transição exotérmica quando resfriado, porém esta transição mostra uma histerese térmica $\left(\Delta \mathrm{T}=15^{\circ} \mathrm{C}\right.$ a $25{ }^{\circ} \mathrm{C}$, com razões de resfriamento de $\left.-10^{\circ} \mathrm{C} \mathrm{a}-3{ }^{\circ} \mathrm{C} / \mathrm{min}\right)$. A entalpia das transições exotérmicas é geralmente menor (60-70\%) que das endotermas correspondentes para fusão dos complexos, variam de 2 a 6 cal/g $(8,37$ a 25,12 J) dependendo do agente complexante e das condições empregadas na sua formação. Valores de entalpia similares para a fusão e a formação do complexo em amido de milho durante ciclos repetidos de aquecimento-resfriamento numa mesma amostra também foram observados (BILIADERIS, 1990). 


\subsection{ENVELHECIMENTO DOPÃO}

O termo envelhecimento vem do inglês "staling" e refere-se ao decréscimo da aceitação do produto pão por parte dos consumidores devido às mudanças químicas e físicas que ocorrem na casca e no miolo durante o armazenamento, com exceção da deterioração microbiana. Inicia-se após o assamento e está associado principalmente à firmeza do miolo que durante o armazenamento se torna duro, seco e esfarelento e a casca borrachuda com aspecto mole (PATERAS, 1998).

A amilose presente no pão rapidamente se associa após o assamento, assim não interfere muito na firmeza do miolo que é atribuída à mudanças na orientação física da molécula ramificada de amilopectina no grânulo intumescido. No pão fresco, as cadeias ramificadas encontram-se planas e espalhadas na água disponível e se agregam gradualmente por ligações intermoleculares, aumentando a rigidez da estrutura interna do grânulo intumescido de amido causando endurecimento do miolo.

O processo de envelhecimento é causado pela transferência de umidade do miolo para a casca e a recristalização do amido durante o armazenamento e pode ser evitado através do uso de: enzima alfa-amilase, que hidrolisa parcialmente o amido em dextrinas menores; emulsificantes; açúcares e outros solutos que aumentam a temperatura de transição vítrea.

A recristalização da amilopectina, mecanismo predominante no envelhecimento, é denominada retrogradação. A amilopectina parte do estado completamente amorfo, no produto fresco, para o estado parcialmente cristalino com o passar do tempo. A taxa e a extensão da recristalização do amido são determinadas primeiramente pela mobilidade das ramificações cristalinas da amilopectina.

A retrogradação é formada por dois processos separados, a gelatinização da amilose solubilizada e a recristalização da amilopectina no grânulo gelatinizado. Pães envelhecidos mostram endoterma de fusão característica entre $50{ }^{\circ} \mathrm{C}$ a $60{ }^{\circ} \mathrm{C}$ que é ausente em produtos frescos. Esta transição aumenta progressivamente com o tempo. A recristalização do amido é afetada pela umidade, lipídios e outros ingredientes (BILIADERIS, 1990).

Segundo Smith (1999), a taxa máxima de recristalização do amido ocorre em temperatura mediana, entre a temperatura de transição vítrea $(\mathrm{Tg})$ e a de fusão 
(Tm), ou seja, no estado borrachudo. A taxa de nucleação dos cristais aumenta na direção da Tg e a taxa de crescimento na direção da Tm (Figura 2.8).

No entanto, para Pateras (1998) o congelamento previne o envelhecimento do pão através da cessão do processo de recristalização do amido. Porém em refrigeradores, o envelhecimento ocorre de forma mais rápida que em temperaturas ambientes. $\mathrm{O}$ fato de o envelhecimento ser mais rápido em refrigeradores é explicado pela teoria de recristalização de polímeros parcialmente cristalinos como o amido. A recristalização é composta de dois eventos, a nucleação e o crescimento do cristal. A nucleação é favorecida pela temperatura baixa e o crescimento pela mobilidade das cadeias do polímero (Figura 2.8).

Para evitar a retrogradação durante o armazenamento, o pão deve ser estocado em temperaturas abaixo da $\mathrm{Tg}$, pois se encontrará na forma vítrea, assim as reações e movimento de solutos como o açúcar e plastificante como a água são extremamente baixos. A faixa de temperatura de transição vítrea de pães encontra-se entre $-9{ }^{\circ} \mathrm{C}$ e $-7{ }^{\circ} \mathrm{C}$. Assim, pães armazenados a $21{ }^{\circ} \mathrm{C}$, ou seja, acima da transição vítrea, envelhecerão mais rápido (PATERAS, 1998). Este fato foi verificado por Ribotta; León; Añón (2003) que estudaram a retrogradação em pães frescos e em pães de massa congelada e observaram que foi maior quando armazenados a $4{ }^{\circ} \mathrm{C}$ do que a $20{ }^{\circ} \mathrm{C}$. Essa diferença foi maior nos pães produzidos de massa congelada.

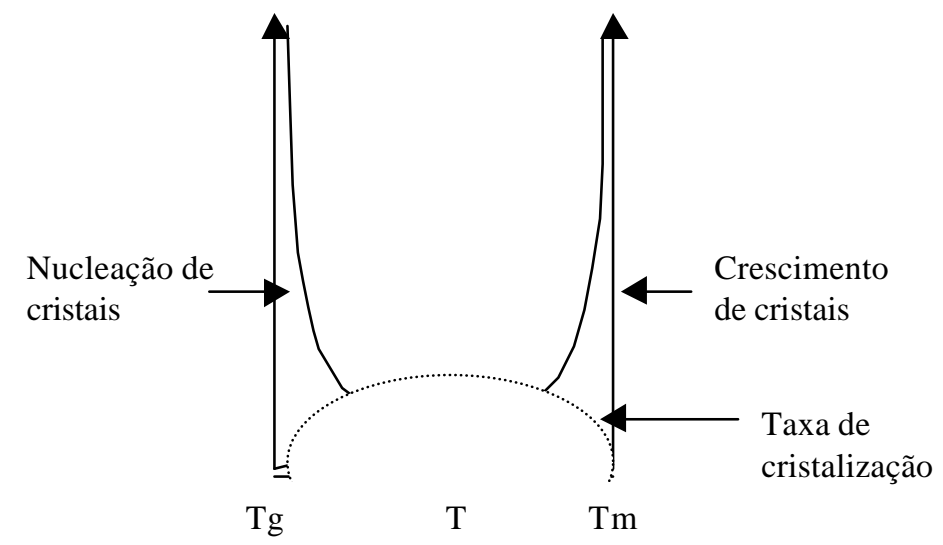

Figura 2.8: Cinética de cristalização de polímeros parcialmente cristalinos (amido), onde Tg é a temperatura de transição vítrea e Tm é a temperatura de fusão. 
A transição vítrea em carboidratos anidros aumenta com o peso molecular, varia de $5{ }^{\circ} \mathrm{C}$ para a frutose a um valor predito para o amido de $243{ }^{\circ} \mathrm{C}$. A presença de água diminui a $\mathrm{Tg}$ de alimentos, pois sua $\mathrm{Tg}$ é igual a $-135^{\circ} \mathrm{C}$ (BHANDARI; HOWES, 1999). Bhandari; Howes (1999) citam as relações matemáticas propostas por Couchmann; Karasz (1978) para determinar a transição vítrea de misturas de vários componentes, sendo que a Equação 2.5 foi proposta para misturas binárias e a Equação 2.6 na forma generalizada:

$$
\begin{aligned}
& T g_{m}=\frac{w_{1} \times T g_{1}+\left(\frac{\Delta C p_{2}}{\Delta C p_{1}}\right) \times w_{2} \times T g_{2}}{w_{1}+\left(\frac{\Delta C p_{2}}{\Delta C p_{1}}\right) \times w_{2}} \\
& T g_{m}=\frac{\sum_{i=1}^{n} w_{i} \times \Delta C p_{i} \times T g_{i}}{\sum_{i=1}^{n} w_{i} \times \Delta C p_{i}}
\end{aligned}
$$

Onde:

$\operatorname{Tg}_{\mathrm{m}} \quad$ Temperatura de transição vítrea da mistura

$\mathrm{W}_{\mathrm{i}} \quad$ Fração molar do componente i

$\Delta \mathrm{Cp}_{\mathrm{i}} \quad$ Mudança na capacidade térmica do componente $\mathrm{i}$ entre o estado vítreo e o de borracha

$\mathrm{Tg}_{\mathrm{i}} \quad$ Temperatura de transição vítrea do componente $\mathrm{i}$

Os métodos para estudo da retrogradação foram revisados por Karim; Norziah; Seow (2000) que citam vantagens e desvantagens de cada um. 


\subsection{QUALIDAde da MASSA E do PÃo}

As características externas freqüentemente avaliadas em pães são dimensão do produto, volume, aparência, cor e formação da casca. As internas são distribuição, tamanho e número de alvéolos no miolo, cor e textura (CAUVAIN; YOUNG, 1998). $\mathrm{Na}$ avaliação sensorial são verificados parâmetros de sabor e aroma.

O volume específico, ou razão entre massa e volume é um parâmetro de qualidade que indica se a fermentação do pão foi excessiva resultando num volume específico muito grande ou se ocorreu problemas na formação do glúten ou na fermentação resultando num baixo volume específico. Para o pão francês produzido na cidade de São Paulo, o valor do volume específico encontrado variou de 3,89 a $7,48 \mathrm{~cm}^{3} / \mathrm{g}$ (KOWASLKI; CARR; TADINI, 2002).

Um levantamento detalhado das características de segurança e qualidade em massas congeladas foi feito por Giannou; Kessoglou; Tzia (2003). Os autores concluíram que o fator mais importante na preservação adequada de produtos de panificação congelados é a temperatura de armazenamento, entretanto outros fatores como a qualidade original da matéria prima, processamento e material de embalagem também contribuem para a qualidade.

Baardseth et al. (2000) avaliaram a influência da qualidade da farinha, processos, mistura e tempo de crescimento na qualidade de pães franceses tipo baguete através de atributos sensoriais e análise de imagens. O processo tradicional apresentou melhores resultados em relação a porosidade, elasticidade, crocância da casca por determinações sensoriais, porosidade e volume por análise de imagem. $\mathrm{O}$ tempo de crescimento e a mistura também influenciaram a porosidade. Os parâmentros relacionados à qualidade da farinha foram porosidade, crocância da casca, brilho e volume. 


\subsubsection{Textura}

Assim como o sabor, a textura é um importante indicador de qualidade de um alimento. Segundo Szczesniak (2002), textura é a manifestação sensorial e funcional das propriedades estruturais, mecânicas e superficiais de alimentos detectados através dos sentidos de visão, audição, tato e sinestesia (relativo ao movimento).

A definição de textura engloba os seguintes conceitos:

- Propriedade sensorial perceptível e descrita somente pelo homem. Os analisadores de textura detectam e quantificam certos parâmetros físicos que posteriormente são interpretados em termos de percepção sensorial.

- Atributo de múltiplos parâmetros.

- É derivada da estrutura do alimento.

- É detectada por vários sentidos, sendo os mais importantes o tato e a pressão.

\subsubsection{Textura da massa}

As análises de textura geralmente utilizadas para avaliar a qualidade do glúten (resistência à extensão e a extensibilidade da massa a uma tensão constante) presente em massas ou farinhas de trigo são extensografia (ICC 114/1, 2003) e alveografia (ICC 121, 2003). A qualidade do glúten está relacionada ao volume dos pães, um parâmetro de qualidade, pois durante a fermentação a massa expande com a produção de $\mathrm{CO}_{2}$ que deve ser retido pela sua estrutura.

Kieffer et al. (1998) e Collar et al. (1999) utilizaram outra metodologia para avaliar a qualidade do glúten, o primeiro trabalho verificou a influência da adição de hidrocolóides e o segundo avaliou farinhas de 12 tipos de trigo. A elasticidade (resistência à extensão) e a extensibilidade foram medidas através de um analisador de textura TA-TX2i da Stable Micro Systems e acessório "Kieffer Dough and Gluten Extensibility Rig”. As vantagens deste método consistem em utilizar apenas um acessório para realização da análise, não sendo necessário um equipamento específico e permite várias repetições, pois demanda de pequena quantidade de amostra para cada determinação (SMS, 1995). 
Lu; Grant (1999) avaliaram os efeitos do armazenamento em temperaturas de congelamento na textura de massas congeladas e observaram que a resistência à extensão máxima após o descongelamento diminui com o tempo de armazenamento, entretanto trigos que apresentaram glúten forte apresentaram melhores resultados no produto final.

Outros trabalhos que analisaram a textura da massa devido à ação do congelamento-descongelamento, o armazenamento e a aditivação foram mencionados anteriormente (INOUE; BUSHUK, 1991); (AUTIO; SINDA, 1992); (ABD EL-HADY; EL-SAMAHY; BRÜMMER, 1999); (KENNY et al., 1999).

\subsubsection{Textura do Pão}

A análise de textura de alimentos sólidos e semi-sólidos é realizada pelo método de TPA (do inglês, "Texture Profile Analysis") aplicável tanto para medidas sensoriais como para instrumentais. O método instrumental compreende em comprimir o alimento pelo menos duas vezes e quantificar parâmetros mecânicos a partir de curvas força-deformação. Excelentes correlações entre análise de textura experimental e sensorial foram encontradas para o parâmetro dureza (SZCZESNIAK, 2002). A Tabela 2.2 mostra as definições de parâmetros mecânicos de textura em relação aos sensoriais.

A curva força-tempo (Figura 2.9) da análise de TPA gerada por analisador de textura, por exemplo o TA-TX2i da Stable Micro Systems, está interpretada na Tabela 2.3. 
Tabela 2.2: Definições de Parâmetros mecânicos de textura. Adaptado de Civille; Szczesniak, 1973 apud Szczesniak, 2002.

\begin{tabular}{|c|c|c|}
\hline & Físico & Sensorial \\
\hline Firmeza & $\begin{array}{l}\text { Força necessária para } \\
\text { atingir uma dada } \\
\text { deformação. }\end{array}$ & $\begin{array}{l}\text { Força requerida para comprimir } \\
\text { uma substância sólida entre os } \\
\text { dentes incisivos. }\end{array}$ \\
\hline Coesividade & $\begin{array}{l}\text { Extensão que o material } \\
\text { pode ser deformado antes } \\
\text { da ruptura. }\end{array}$ & $\begin{array}{l}\text { Grau de deformação da amostra } \\
\text { antes da ruptura com os molares. }\end{array}$ \\
\hline Elasticidade & $\begin{array}{l}\text { Taxa em que o material } \\
\text { deformado volta para a } \\
\text { condição inicial. }\end{array}$ & $\begin{array}{l}\text { Grau em que o produto retorna para } \\
\text { sua forma original quando } \\
\text { comprimido entre os dentes. }\end{array}$ \\
\hline Mastigabilidade & $\begin{array}{l}\text { Energia requerida para } \\
\text { desintegrar um alimento a } \\
\text { um estado pronto para ser } \\
\text { engolido. }\end{array}$ & $\begin{array}{l}\text { Número de mastigações } \\
\text { necessárias, com força constante, } \\
\text { para reduzir a amostra a uma } \\
\text { consistência adequada para ser } \\
\text { engolida. }\end{array}$ \\
\hline
\end{tabular}

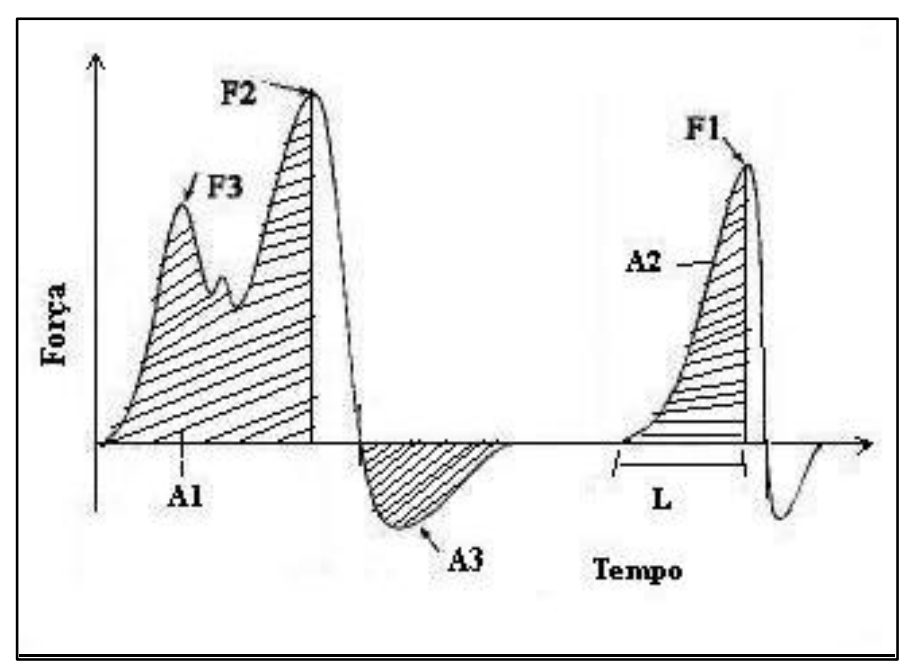

Figura 2.9: Exemplo de curva força-tempo gerada pelo texturômetro em análise de dupla compressão (TPA). 
Tabela 2.3: Interpretação da curva força-tempo (Figura 2.9) gerada pelo texturômetro.

\begin{tabular}{|c|c|c|}
\hline Parâmetros & Unidade & Definição \\
\hline Firmeza & $\mathbf{N}$ & Altura do pico do primeiro ciclo (F2). \\
\hline Coesividade & Adimensional & $\begin{array}{l}\text { Relação entre áreas do segundo ciclo (A2) e do } \\
\text { primeiro (A1), do contato inicial até o pico. }\end{array}$ \\
\hline Elasticidade & $\mathrm{m}$ & $\begin{array}{l}\text { Distância medida do contato inicial da amostra no } \\
\text { segundo ciclo até o pico F1 (L). }\end{array}$ \\
\hline Adesividade & $\mathbf{J}$ & $\begin{array}{l}\text { Área do pico negativo formado quando o êmbolo é } \\
\text { puxado da amostra (A3). }\end{array}$ \\
\hline Fraturabilidade & $\mathrm{N}$ & $\begin{array}{l}\text { Caracterizada pela forma dos multi-picos do } \\
\text { traçado do primeiro ciclo e é medida como o } \\
\text { primeiro máximo local da primeira compressão } \\
\text { (F3). }\end{array}$ \\
\hline Mastigabilidade & N.m & Firmeza x coesividade $\mathrm{x}$ elasticidade. \\
\hline Gomosidade & $\mathrm{N}$ & Firmeza x coesividade x 100. \\
\hline
\end{tabular}

Kowalski; Carr; Tadini (2002) realizaram análise de textura em pães franceses produzidos na cidade de São Paulo e os valores obtidos para os parâmetros de firmeza e mastigabilidade variaram de $2,76 \mathrm{~N}$ a $8,48 \mathrm{~N}$ e $3911.10^{-5} \mathrm{~J}$ (gf.mm) a $7519.10^{-5} \mathrm{~J}$ (gf.mm), respectivamente. 


\subsection{ANÁLISE TÉRMICA}

Análise térmica é definida pelo ICTA ("International Confederation for Thermal Analysis") como o grupo de técnicas que medem propriedades físicas de substâncias em função da temperatura através de um programa de controle de temperatura (HARWALKAR; MA, 1990).

A maioria dos alimentos sofre tratamento térmico durante seu processamento, tais como cocção, pasteurização, esterilização, refrigeração e congelamento que podem alterar as propriedades físico-químicas e funcionais e sua reologia, refletindo na qualidade e aceitabilidade desses alimentos. Portanto a análise térmica é uma ferramenta útil para pesquisa, desenvolvimento e controle de qualidade de alimentos (HARWALKAR; MA, 1990).

\subsubsection{Calorimetria Exploratória Diferencial (DSC)}

Calorimetria Exploratória Diferencial consiste em medir a diferença de energia fornecida a uma amostra e ao material de referência, quando submetida a um programa de temperatura. As medidas da variação de fluxo de calor nos instrumentos de DSC são conduzidas em pequenos cadinhos que podem ser herméticos, o que previne a perda de massa devido à evaporação de água em temperatura de ensaio igual ou superior a $100{ }^{\circ} \mathrm{C}$ (RAHMAN, 1995).

Yu; Christie (2001) estudaram a influência de diferentes tipos de cadinhos (alumínio, aço inoxidável com anel de borracha e aço inoxidável de alta pressão) no DSC em estudo de transição térmica de amidos. Os resultados obtidos para uma mesma amostra foram diferentes devido à massa e capacidade térmica dos cadinhos $\mathrm{e}$ à perda de massa devido à evaporação da água presente na amostra. Geralmente os cadinhos com maior massa e baixa condutividade térmica tiveram um maior atraso na resposta ao programa de temperatura.

O DSC determina transições relacionadas à desnaturação de proteínas, gelatinização de amido, fusão de cristais de gordura e transições vítreas em substâncias amorfas e produtos congelados (HARWALKAR; MA, 1990). As vantagens desta técnica em panificação são: possibilidade de análises para diferentes conteúdos de água; determinação direta da energia requerida para fusão e 
retrogradação de amido, sendo um método rápido que não necessita de preparação especial e requer pequena quantidade de amostra (NAKAZAWA et al., 1985 apud WHITE; ABBAS; JOHNSON, 1989). O conteúdo de água na amostra, bem como a razão de aquecimento modifica o perfil das curvas geradas pelo DSC. Geralmente o aquecimento lento decompõe um pico endotérmico em múltiplas fases.

Laaksomen; Roos (2000) estudaram o comportamento da massa de pão em temperaturas abaixo de zero através da análise térmica. No DSC, quantificaram a água não congelável presente na massa após ciclo de congelamento que apresentou valor de $0,35 \mathrm{~g} \mathrm{H}_{2} \mathrm{O} / \mathrm{g}$ soluto e temperatura "onset" de fusão igual a $-18{ }^{\circ} \mathrm{C}$. A transição vítrea que segundo Levine; Slade apud Laaksomen; Ross (2000) em massas congeladas ocorre entre $-30{ }^{\circ} \mathrm{C}$ e $-10{ }^{\circ} \mathrm{C}$, não foi verificada. Lu; Grant (1999) determinaram um aumento da Wg' da massa com o tempo de armazenamento congelado por DSC. Ribotta; León; Añón (2003) simularam no DSC o efeito do congelamento e do armazenamento de massas na gelatinização e retrogradação do amido. $\mathrm{O}$ congelamento e o armazenamento $\mathrm{a}-18{ }^{\circ} \mathrm{C}$ modificaram as propriedades do amido tendo importante influência na entalpia de gelatinização que variou de - 3,60 a -4,11 mJ/mg com 1 a 230 dias de armazenamento, enquanto que na massa fresca foi de $-3,75 \mathrm{~mJ} / \mathrm{mg}$.

A Figura 2.10 mostra um exemplo de curva de DSC em amido de arroz com $50 \%$ de umidade com várias transições. As de baixas temperaturas, $M_{1}$ e $M_{2}$, refletem um fenômeno de ordem-desordem dos cristais de amido (gelatinização) e as endotermas em altas temperaturas $\mathrm{M}_{3}$ e $\mathrm{M}_{4}$, reversíveis no reaquecimento imediato devem ser atribuídas à desorganização do complexo amilose-lipídio.

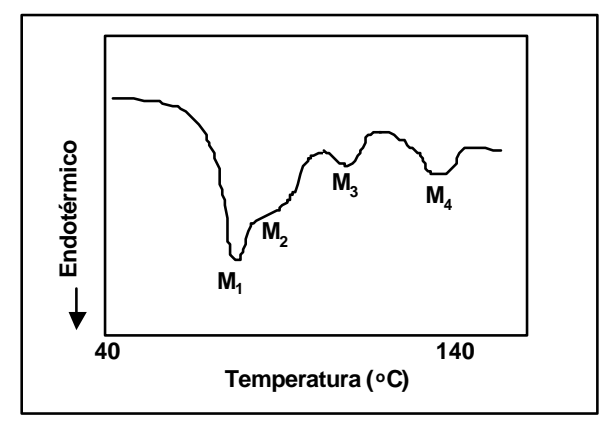

Figura 2.10: Curva de DSC de amido de arroz, razão de aquecimento $10^{\circ} \mathrm{C} / \mathrm{min}$ (BILIADERIS, 1990). 
Collar et al. (1999) estudaram o comportamento térmico da massa com adição de hidrocolóides através do DSC, simulando a temperatura no centro do pão durante o assamento. As amostras foram submetidas a dois ciclos de aquecimento. No primeiro foi calculada a entalpia de gelatinização e no segundo a entalpia de dissociação do complexo amilose-lipídio. Verificou-se que a entalpia de gelatinização foi maior para as massas contendo hidrocolóide que na amostra controle.

Fessas; Schiraldi (2000) estudaram a cinética de gelatinização do amido em massa de pão. Utilizaram cadinhos fechados e abertos contendo amostra para simular o assamento no centro do pão e próximo à superfície respectivamente. Elaboraram diagrama temperatura-tempo-transformação da gelatinização do amido, ferramenta para prever o progresso do assamento.

Vários estudos de retrogradação ou envelhecimento através de DSC estão presentes na literatura (AEE; HIE;NISHINARI, 1998); (FESSAS; SCHIRALDI, 1998); (DEFLOOR; DELCOUR, 1999); (CZUCHAJOWSKA; POMERANZ, 1989); (RIBOTTA; LEÓN; AÑÓN, 2003). White; Abbas; Johnson (1989), Takaya; Sano; Nishinari (2000) e Seetharaman et al. (2002) realizaram estudos similares utilizando repetidos aquecimentos. No primeiro aquecimento, foi verificada a entalpia de gelatinização, o cadinho contendo a mesma amostra foi guardado por determinado período e um novo ciclo de aquecimento foi realizado. A retrogradação foi determinada neste aquecimento.

Segundo Ma (1990), pouco se sabe sobre as características térmicas das proteínas do trigo, provavelmente devido ao fato de as gluteninas e gliadinas mostrarem pouca ou nenhuma resposta calorimétrica. Eliasson (1983) citado pelo mesmo autor conduziu estudos de DSC em misturas de glúten e amido. A presença do glúten diminuiu a entalpia e aumentou a temperatura de gelatinização, a água migra do glúten para o amido durante o aquecimento. Marchisano et al. (1996) realizaram DSC em farinha de trigo com diferentes conteúdos de água e tempo de mistura e sugerem que a interação água-amido na presença de uma rede de proteína é afetada pela disponibilidade de água pois há uma competição pela mesma entre a rede protéica e o amido. Apenas quando a quantidade de água é maior que 30-35\%, ocorre interação com o amido. 
Billiaderis (1990) relata estudos em que a cristalização do complexo amilose-lipídio ocorre durante a gelatinização. Os baixos valores de energia de gelatinização encontrados em amidos com alto conteúdo de lipídios refletem a ocorrência de dois processos térmicos concorrentes, endoterma de fusão do cristal de amido e a exoterma devido à formação do complexo amilose-lipídio. Sendo assim, a energia relativa ao complexo amilose-lipídio deve ser quantificada pela sua decomposição, pois se trata de um fenômeno termicamente reversível.

A Figura 2.11 mostra um esquema dos eventos que podem ser identificados em misturas de amido e água através do DSC no intervalo de $30^{\circ} \mathrm{C}$ a $140{ }^{\circ} \mathrm{C}$.

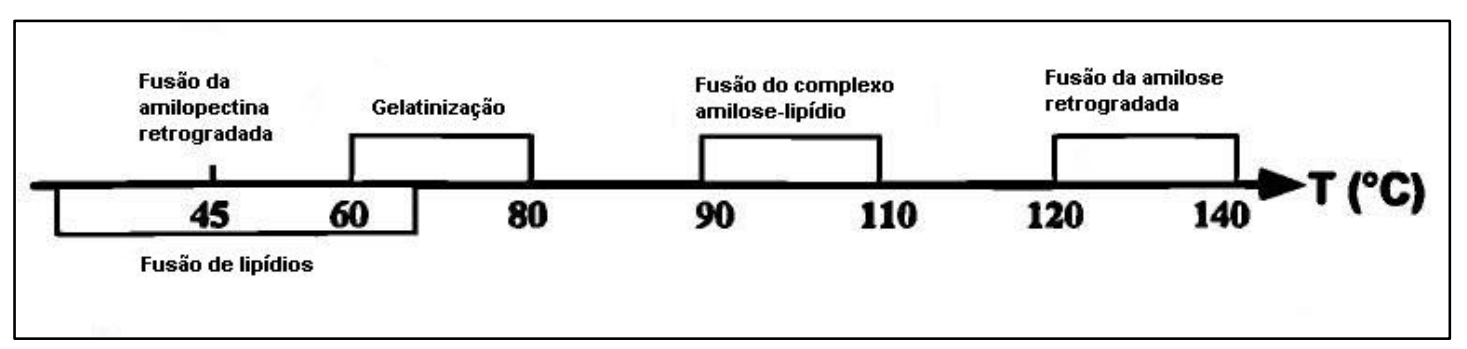

FONTE: LE BAIL (2001).

Figura 2.11: Esquema de eventos que podem ser identificados através do DSC em misturas de amido e água.

\subsubsection{Termogravimetria (TGA)}

A termogravimetria consiste em medir a variação de massa de um material quando submetido a um programa de controle de temperatura, sendo possível determinar o conteúdo de água, a decomposição de substâncias e o teor de cinzas de um alimento utilizando pequena quantidade de amostra.

Chevallier et al. (2000) utilizaram a TGA para determinar perda de massa entre 20 e $180^{\circ} \mathrm{C}$ em diferentes massas de biscoitos indicando o comportamento das massas durante o assamento. 


\subsection{PlaneJamento Experimental}

O planejamento experimental é uma ferramenta estatística que permite avaliar a influência de dois ou mais fatores em uma resposta. É utilizado a fim de minimizar o número de experimentos necessários para obtenção de uma resposta.

Em panificação, o planejamento experimental tem sido utilizado a fim de estudar variáveis de processo (aditivos, tempo de mistura) e de mistura (\% de cada componente na formulação ou de variedades de farinhas de trigo) (FARGESTAD et al., 1999); (NAS; BJERKE; FARGESTAD, 1999).

\subsubsection{Projeto de Mistura}

O projeto de mistura é um método de delineamento experimental que permite investigar propriedades de um sistema multicomponentes em função da sua composição. A característica principal do projeto de mistura é que a soma de todos os componentes deve ser igual a $100 \%$, o que significa que os componentes não podem ser manipulados independentemente (NETO; SCARMINIO; BRUNS, 2002).

Gorman; Hinman (1962), Kurotori (1966) e Cornell (1990) utilizaram projetos matriciais, que podem ser definidos como conjunto de pontos selecionados sobre o espaço da mistura no qual dados sobre a propriedade estudada são reunidos para ajustar uma equação resposta dentro do espaço estudado. Para um sistema de três componentes, o espaço é um triângulo equilátero onde cada um dos lados representa a quantidade de um componente variando de 0 a 1 , podendo-se também estudar subespaços da mistura, pois há uma relação linear entre estes e o espaço da mistura total.

O projeto de mistura é aplicável no estudo de propriedades intensivas e deve ser empregado em problemas que a composição das variáveis a serem estudadas representam uma pequena parcela da mistura total (GORMAN; HINMAN, 1962). Encontra grande aplicação em ciência de alimentos e nas indústrias quando se deseja desenvolver e ou otimizar formulações (BJERKE; NASS; ELLEKJ/AR, 2000). 


\section{MATERIAIS E MÉTODOS}

Neste capítulo estão apresentados os materiais, equipamentos, procedimentos experimentais e análises utilizados.

\subsection{MATERIAIS}

口 Ácido Ascórbico p.a.;

๑ Água Destilada;

a Cadinhos para DSC de Média Pressão com Anel de Viton, $120 \mu \mathrm{L}, \mathrm{ME}$ - 29990 Mettler;

a Ésteres de ácido diacetil tartárico de mono e diglicerídio (DATEM), Panodan ${ }^{\circledR}$ ALB 10PS DATEM, procedência Danisco

- Enzima Alfa-amilase, procedência Prozyn;

- Estearoil-lactilato de cálcio (CSL); procedência Purac Sínteses;

口 Farinha de Trigo (Primeiro Lote), 14,30 \% de conteúdo de água (AACC 45 - 15 A, 1995), 0,53\% de conteúdo mineral (ICC 104), 63,00 \% de absorção (AACC 54 - 21, 1995) e 10,8 \% de glúten seco (ICC 137), dados fornecidos pelo fabricante - Moinho Pacífico Ind. e Com. Ltda.;

a Farinha de Trigo (Segundo Lote), 13,60 \% de umidade (AACC 45 - 15 A, 1995), 0,55 \% de conteúdo mineral (ICC 104), 65,60 \% de absorção (AACC 54 - 21, 1995) e $8,1 \%$ de glúten seco (ICC 137), dados fornecidos pelo fabricante Moinho Pacífico Ind. e Com. Ltda.;

- Fermento Biológico Prensado, marca Fleischmann, adquirido no mercado;

- Gordura Vegetal Hidrogenada; marca Saúde, adquirida no mercado;

口 Polisorbato 80 DR, procedência KOLB NEDERLAND B.V.;

- Sacos Plásticos de Polietileno;

- Sal Refinado Extra Iodado Tradicional, marca Cisne, adquirido no mercado.

\subsection{EQUIPAMENTOS}

a Analisador de Textura Stable Micro Systems, modelo TA-TX2i com interface acoplada a um PC e programa Texture Expert versão 1.22, 230 V;

- Armário fechado móvel para 20 bandejas, Induspan;

- Balança analítica YMC, modelo JK-200, máximo 200 g, 0,0001 g, 220 V; 
\ Balança semi-analítica Mettler Toledo, modelo PB 8001-S, máximo 8100 g, $\mathrm{d}=0,1 \mathrm{~g}, 110 \mathrm{~V}$;

口 Câmara de fermentação Degânia com controle de temperatura de $20^{\circ} \mathrm{C}$ a $120^{\circ} \mathrm{C}$ e dispositivo umidificador, $220 \mathrm{~V}$;

- Câmara de simulação de características ambientais Veb Feutron Greiz, modelo $3522 / 51$, com controle de temperatura de $-75^{\circ} \mathrm{C}$ a $105^{\circ} \mathrm{C}$ e controle de umidade, $380 \mathrm{~V}$;

口 Divisora de massa rotativa Supremax, modelo DR, $220 \mathrm{~V}$;

- DSC (Differential Scanning Calorimetry) $822^{\mathrm{e}}$ Module, Mettler Toledo, apropriado para ensaios à temperatura sub ambiente;

- Estufa Nova Ética, série $410 \mathrm{D}, 220 \mathrm{~V}$, faixa de temperatura de trabalho: $20^{\circ} \mathrm{C}$ a $60^{\circ} \mathrm{C}$.

- Estufa FANEM, modelo Orion $515 \mathrm{C}, 110 \mathrm{~V}$, faixa de temperatura de trabalho: Temperatura ambiente $+5^{\circ} \mathrm{C}$ a $250{ }^{\circ} \mathrm{C}$;

口 Forno Degânia, modelo Turbo 4 , com controle de temperatura de $40{ }^{\circ} \mathrm{C}$ a $320^{\circ} \mathrm{C}$ e dispositivo de vaporização, $220 \mathrm{~V}$;

口 "Freezer" Plasma vertical, FANEM, modelo $349 \mathrm{FV},-30{ }^{\circ} \mathrm{C}, 220 \mathrm{~V}$;

口 “Freezer” Doméstico Metalfrio, modelo VFR 29E, 110 V;

口 "Freezer" Horizontal Metal Frio, 110 V;

- Massadeira espiral Supremax, modelo AL - 25 IM, com duas velocidades e capacidade de $25 \mathrm{~kg}$ de farinha, $220 \mathrm{~V}$;

- Medidor de volume para pães CHOPIN, modelo 206;

- Modeladora de coluna Supremax modelo MC - 50, 220 V;

口 Reofermentômetro CHOPIN; modelo F3, $230 \mathrm{~V}$;

- Seladora Haramura, modelo 40.08, 220 V;

\ Termômetro digital Instrutherm, modelo Type $\mathrm{K}$ e faixa de utilização $-70{ }^{\circ} \mathrm{C}$ a $+1200{ }^{\circ} \mathrm{C}$;

- TGA/SDTA (Thermogravimetric Analysis) $851^{\mathrm{e}}$ Module, Mettler Toledo;

a Utensílios comuns de laboratório. 


\subsection{Procedimento EXPerimental e AnÁLISES}

O planejamento experimental foi constituído de uma formulação base composta de farinha de trigo (100\%), sal (2\%), água (com a porcentagem definida pelo grau de absorção da farinha de trigo, método AACC 54 - 21, 1995) e a adição dos demais componentes conforme apresentado na Tabela 3.1. O fermento e a enzima alfa-amilase não foram utilizados para evitar interferência na análise térmica da massa, pois o objetivo do projeto foi verificar a interação dos emulsificantes com os outros componentes da farinha de trigo.

Todos os ingredientes, exceto a água e o sal, foram colocados na masseira em baixa velocidade e em seguida a água foi adicionada até obtenção de uma mistura homogênea. Após a mistura, o batimento foi conduzido em velocidade alta sendo o sal adicionado no início desta etapa. O final do batimento foi estabelecido através da obtenção do "ponto de véu" da massa. O tempo de mistura, de batimento e a temperatura da massa fresca foram monitorados (ver Anexo A). Foram retiradas amostras para análise de conteúdo de água, térmica e de textura da massa fresca. Para a análise de textura, ao longo do tempo de armazenamento congelado, foram separadas porções de massa com aproximadamente $60 \mathrm{~g}$, que foram moldadas, embaladas em filme de PVC individualmente, congeladas em "freezer" de plasma a $-30{ }^{\circ} \mathrm{C}$ ou em câmara climática a $-30^{\circ} \mathrm{C}$ e armazenadas em "freezer" doméstico a $-18^{\circ} \mathrm{C}$.

Toda a farinha de trigo utilizada nos experimentos (primeiro e segundo lotes) foi mantida em "freezer" plasma à $-30^{\circ} \mathrm{C}$, para manter as suas propriedades físico-químicas inalteradas.

Os emulsificantes CSL, DATEM e Polisorbato 80, o ácido ascórbico e a gordura vegetal hidrogenada, bem como suas quantidades, foram selecionados com base em trabalhos anteriores realizados no Laboratório de Engenharia de Alimentos EPUSP e na legislação em vigor no Brasil.

O procedimento experimental foi dividido em quatro etapas: 


\subsubsection{Primeira Etapa (Ensaios Preliminares)}

Estes ensaios seguiram o planejamento da Tabela 3.1 utilizando os seguintes emulsificantes: CSL e PS80 e a GVH. Os valores da tabela são em relação a uma base de $100 \%$ de farinha de trigo.

A quantidade de água utilizada nesta etapa foi de $57 \%$ em relação a farinha de trigo do primeiro lote.

Tabela 3.1: Misturas dos emulsificantes CSL (Estearoil-lactilato de cálcio), PS80 (Polisorbato 80) e GVH (gordura vegetal hidrogenada) relativas à primeira etapa do projeto.

\begin{tabular}{cccc}
\hline Mistura & GVH & CSL & PS 80 \\
\hline & $\%$ & $\%$ & $\%$ \\
\hline 0 & 0 & 0 & 0 \\
2 & 2 & 0 & 0 \\
3 & 0 & 0,5 & 0 \\
4 & 0 & 0 & 0,3 \\
5 & 1 & 0,25 & 0 \\
6 & 1 & 0 & 0,15 \\
7 & 0 & 0,25 & 0,15 \\
8 & 0,667 & 0,167 & 0,1 \\
\hline
\end{tabular}

As massas foram produzidas de acordo com o procedimento anteriormente descrito.

A princípio, pensou-se em realizar um projeto de mistura com os três componentes descritos acima. Porém verificou-se que o projeto de misturas não seria recomendado para este caso, uma vez que a soma dos componentes para todas as misturas não foi constante. Optou-se, então, por trabalhar com variáveis de processo e não variáveis de mistura. 
Para cada formulação foram realizadas as seguintes análises:

Determinação do conteúdo de água: Método com duas etapas de secagem devido ao alto teor de conteúdo de água presente na amostra da massa de pão: a primeira em temperatura ambiente e a segunda em estufa a $130{ }^{\circ} \mathrm{C}$, conforme descrito no método AACC $44-15$ A (AACC, 1995).

Análise de Textura da Massa: Análise da resistência à extensão (ou elasticidade) e extensibilidade da massa através do analisador de textura TA-XT2i com acessório A/KIE, conforme descrito no método DOU1/KIE (SMS, 1995).

As análises foram realizadas em amostras de massa fresca, retiradas após o batimento e em amostras de massa descongeladas ao longo do tempo de armazenamento em "freezer" doméstico $(2,7,14,21,28$ e 56 dias). Os testes foram realizados no modo "Measure Force in Tension" sob as seguintes condições:

- Velocidade do Pré-Teste: $2,0 \mathrm{~mm} / \mathrm{s}$;

- Velocidade do Teste: 3,3 mm/s;

- Velocidade do Pós-Teste: $10,0 \mathrm{~mm} / \mathrm{s}$;

- Distância: 75 mm (distância que o "probe" é deslocado);

- Gatilho: Auto - $5 \mathrm{~g}$ (ponto inicial da análise, quando o acessório encontra uma resistência igual ou superior a $5 \mathrm{~g}$ ).

A preparação da amostra para o teste consistiu em comprimir a massa durante 40 minutos em fôrma de teflon apropriada para separá-la em tiras. As tiras de massa foram submetidas ao teste conforme mostra a Figura 3.1. Na curva forçadistância gerada, a força máxima corresponde à resistência à extensão $(\mathrm{N})$ e a distância para quebrar a massa corresponde à extensibilidade da massa (mm), Figura 3.2. 


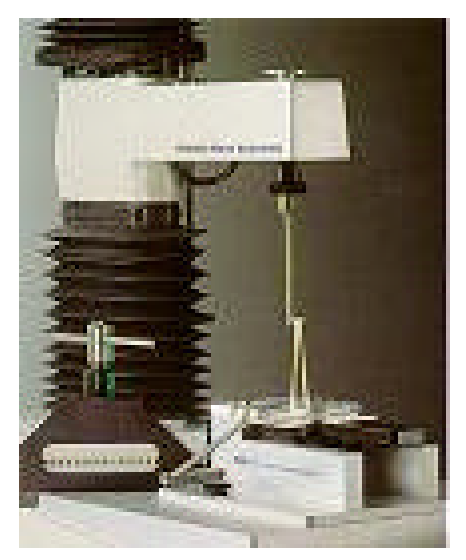

Figura 3.1: Análise de textura da massa utilizando o analisador de textura TA-XT2i da SMS com acessório A/KIE.

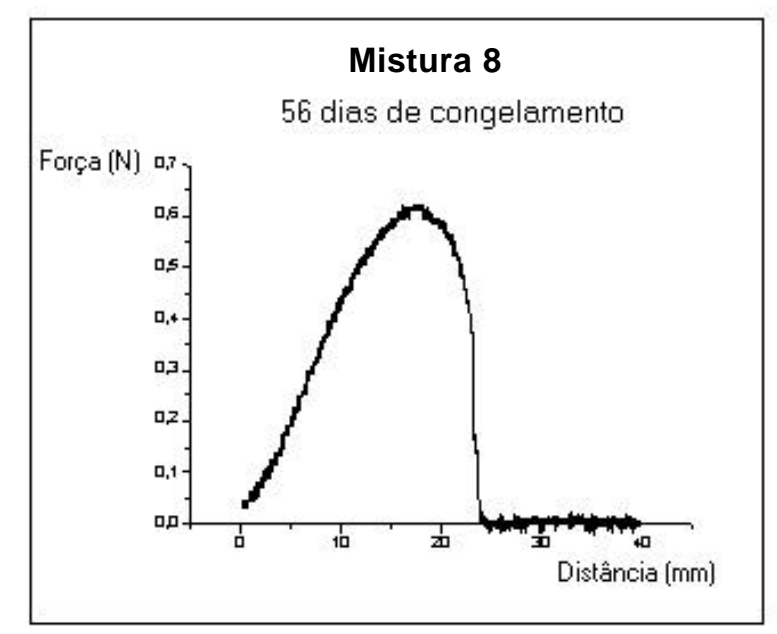

Figura 3.2: Curva força-distância gerada por análise de textura da massa.

Análise térmica: As análises foram realizadas no CQMA - IPEN (Centro de Química e Meio Ambiente do Instituto de Pesquisa Energéticas e Nucleares) com a cooperação dos Pesquisadores Dr. Ademar B. Lugão e Dra. Duclerc F. Parras, utilizando os equipamentos TGA/SDTA $851^{\mathrm{e}}$ Module e DSC $822^{\mathrm{e}}$ Module, Mettler Toledo. O DSC (do inglês 'Differential Scanning Calorimetry") apropriado para ensaios de Calorimetria Exploratória Diferencial à temperatura sub ambiente e cadinhos de média pressão selados, de aço inox $(120 \mu \mathrm{L})$, apropriados para materiais 
biológicos (Figura 3.3). O equipamento de DSC foi calibrado com In (m.p. $156.61^{\circ} \mathrm{C}$; $\Delta \mathrm{H}=28.54 \mathrm{~J} / \mathrm{g})$.

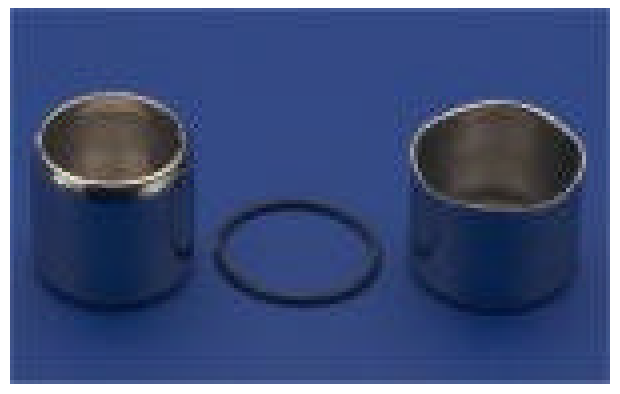

Figura 3.3: Cadinho de média pressão, em aço inox $(120 \mu \mathrm{L})$, apropriado para ensaios de materiais biológicos.

Através da análise de Termogravimetria, TGA (do inglês “Thermogravimetric Analysis"), pode-se determinar o comportamento de perda de massa da amostra quando submetida a um programa de aquecimento, permitindo determinar conteúdo de água, reações de decomposição e material residual. A razão de aquecimento empregada nas amostras foi de $10{ }^{\circ} \mathrm{C} / \mathrm{min}$ e o gás de arraste foi o oxigênio numa vazão de $50 \mathrm{~mL} / \mathrm{min}$.

No DSC as amostras foram submetidas a três diferentes programas de temperatura denominados: ciclo completo, ciclo parcial e ciclo de retrogradação, nos quais a temperatura variou entre -40 e $120^{\circ} \mathrm{C}$, conforme as Tabelas 3.2, 3.3 e 3.4, utilizando como referência um cadinho idêntico, porém vazio. Não foi utilizado gás de arraste para estas análises.

Foi realizado um ensaio para cada programa, utilizando um cadinho vazio. Os valores obtidos nestes ensaios foram relativos ao branco e o seu valor foi descontado de cada ensaio.

O ciclo completo compreendeu um ciclo de congelamento-descongelamento e dois ciclos de aquecimento. O ciclo de congelamento-descongelamento possibilita o cálculo de água não congelável (Wg') e de concentração de sólidos na água não congelável $\left(\mathrm{Cg}^{\prime}\right)$ através das Equações 2.3 e 2.4. O primeiro ciclo de aquecimento possibilita verificar a energia relacionada a eventos de gelatinização, fusão de gorduras, relativos ao glúten e a de dissociação do complexo amilose-lipídio, 
enquanto que no segunda verifica-se a quantidade reversível do complexo amiloselipídio após resfriamento.

As Figuras 3.4, 3.5 e 3.6 são exemplos de curvas de DSC obtidas através do programa STARe Software para os programas Ciclo Completo, Ciclo Parcial e Ciclo de Retrogradação, respectivamente.

Tabela 3.2: Programa Ciclo Completo do DSC que compreendeu um ciclo de congelamento-descongelamento e dois ciclos de aquecimento.

\begin{tabular}{ccc}
\hline $\begin{array}{c}\text { Razão de } \\
\text { aquecimento } \\
\left({ }^{\mathbf{C}} \mathbf{C} / \mathbf{m i n}\right)\end{array}$ & $\begin{array}{c}\text { Intervalo de } \\
\text { temperatura } \\
\left({ }^{\mathbf{C}} \mathbf{C}\right)\end{array}$ & $\begin{array}{c}\text { Isoterma } \\
(\mathbf{m i n})\end{array}$ \\
\hline-3 & 20 a -40 & 3 \\
3 & -40 a 20 & 3 \\
10 & 20 a 130 & 3 \\
-10 & 130 a 20 & 3 \\
10 & 20 a 130 &
\end{tabular}

Tempo total de ciclo: 85 minutos.

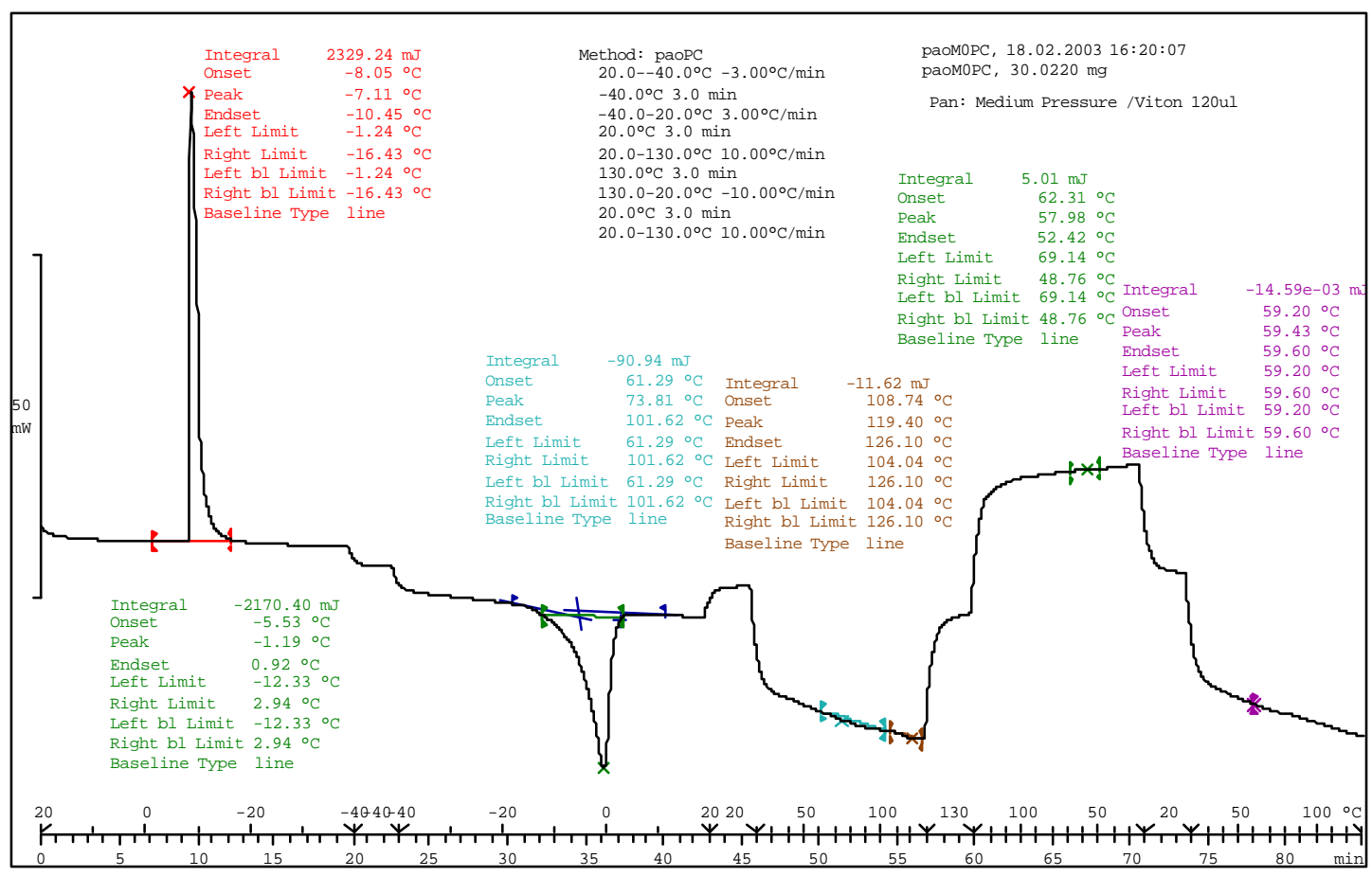

Figura 3.4: Exemplo de curva obtida no DSC para o programa Ciclo Completo. 
O ciclo parcial consiste de dois ciclos de aquecimento com a mesma finalidade dos ciclos de aquecimentos do ciclo completo, ou seja, verificar a energia relacionada a eventos de gelatinização, fusão de gorduras, relativa ao glúten, à dissociação e reversibilidade do complexo amilose-lipídio, porém em massas não congeladas.

Tabela 3.3: Programa Ciclo Parcial do DSC que compreendeu dois ciclos de aquecimento.

\begin{tabular}{ccc}
\hline $\begin{array}{c}\text { Razão de } \\
\text { aquecimento } \\
\left({ }^{\mathbf{0}} \mathbf{C} / \mathbf{m i n}\right)\end{array}$ & $\begin{array}{c}\text { Intervalo de } \\
\text { temperatura } \\
\left({ }^{\mathbf{0}} \mathbf{C}\right)\end{array}$ & $\begin{array}{c}\text { Isoterma } \\
(\mathbf{m i n})\end{array}$ \\
\hline 10 & 20 a 130 & 3 \\
-10 & 130 a 20 & 3 \\
10 & 20 a 130 & \\
\hline
\end{tabular}

Tempo total de ciclo: 39 minutos.

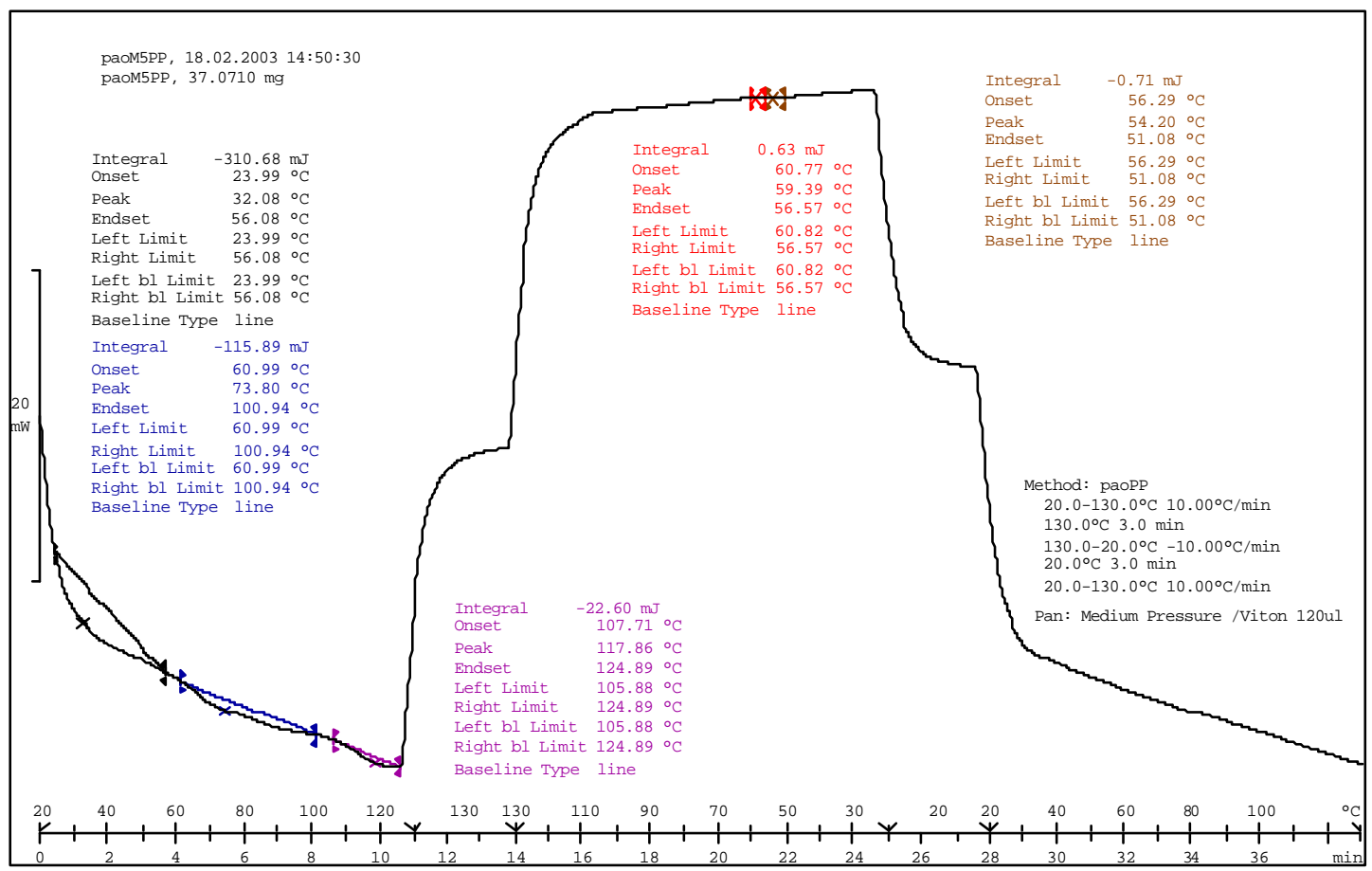

Figura 3.5: Exemplo de curva obtida no DSC para o Programa Ciclo Parcial. 
$\mathrm{O}$ ciclo de retrogradação possui apenas um ciclo de aquecimento com a mesma razão de aquecimento dos outros ciclos. Os cadinhos utilizados nos ciclos completo e parcial foram mantidos à temperatura ambiente por uma semana e então novamente analisados. Através deste ciclo é possível verificar se houve retrogradação do amido presente na massa ao longo de uma semana. Esta informação é útil para o estudo do envelhecimento de pães.

Tabela 3.4: Programa Ciclo de Retrogradação do DSC que compreendeu um ciclo de aquecimento.

\begin{tabular}{ccc}
\hline $\begin{array}{c}\text { Razão de } \\
\text { aquecimento } \\
\left({ }^{\mathbf{0}} \mathbf{C} / \mathbf{m i n}\right)\end{array}$ & $\begin{array}{c}\text { Intervalo de } \\
\text { temperatura } \\
\left({ }^{\mathbf{0}} \mathbf{C}\right)\end{array}$ & $\begin{array}{c}\text { Isoterma } \\
(\mathbf{m i n})\end{array}$ \\
\hline 10 & 20 a 150 & \\
\hline
\end{tabular}

Tempo total do ciclo: 13 minutos.

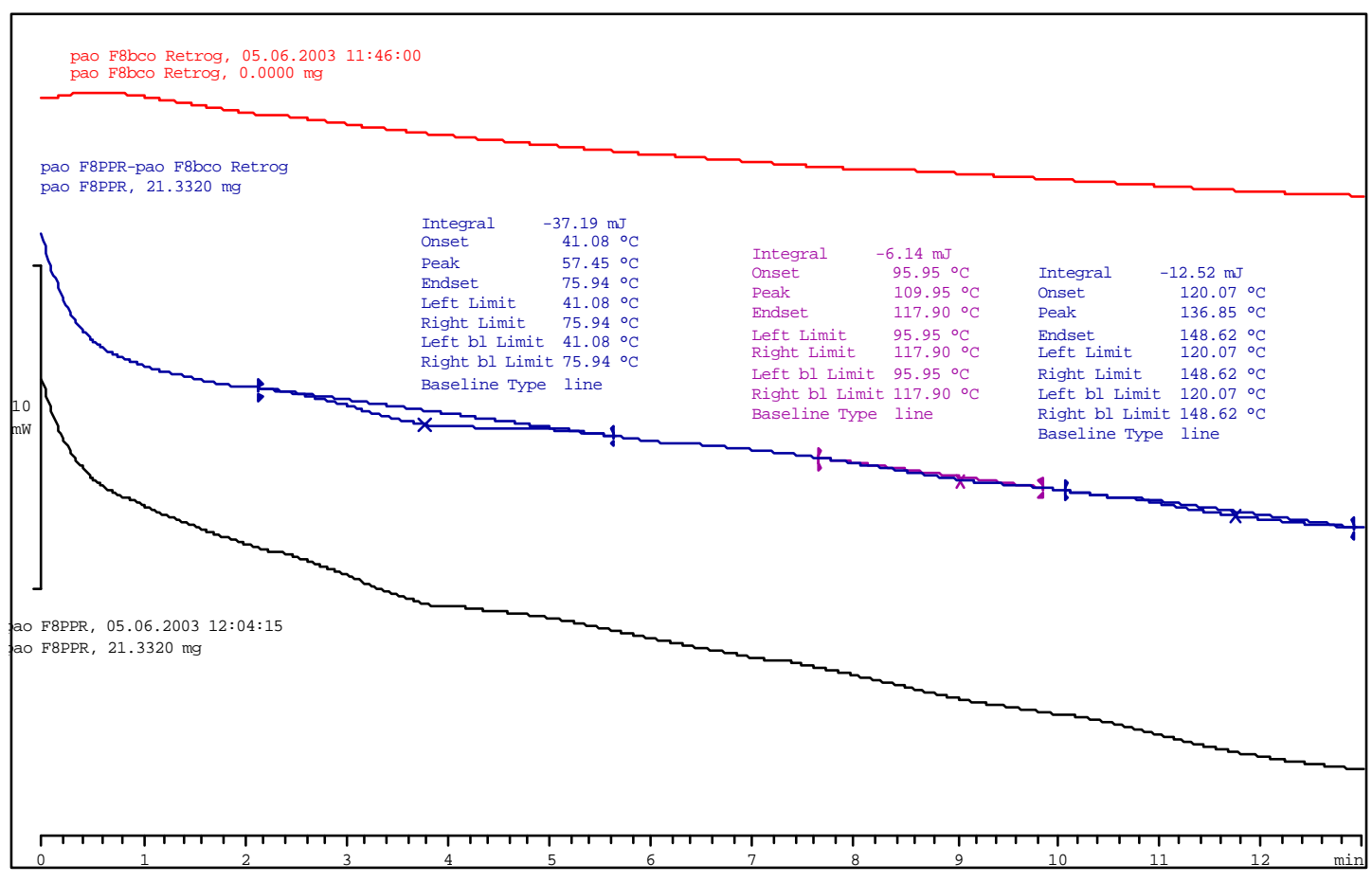

Figura 3.6: Exemplo de curva obtida no DSC para o Programa Ciclo de Retrogradação. 
Os valores descritos nas tabelas acima foram determinados baseando-se na literatura e em estudos preliminares de forma a verificar as melhores condições para aquisição dos dados.

\subsubsection{Segunda Etapa (Projeto de Mistura)}

$\mathrm{Na}$ segunda etapa do projeto, foi realizado um projeto de mistura de três componentes com os emulsificantes CSL, PS80 e DATEM descrito na Tabela 3.5, sendo os valores desta tabela em relação a uma base de $100 \%$ de farinha de trigo. A quantidade de GVH (1\%) foi determinada baseada nos resultados da primeira etapa.

A quantidade de água utilizada foi de $60 \%$ em relação a $100 \%$ de farinha de trigo do segundo lote. E a temperatura da água adicionada passou a ser controlada (Equação 2.1).

Tabela 3.5: Misturas dos emulsificantes CSL, PS80 e DATEM relativas à segunda etapa do projeto.

\begin{tabular}{ccccccc}
\hline Mistura & \multicolumn{2}{c}{ CSL } & \multicolumn{2}{c}{ PS80 } & \multicolumn{2}{c}{ DATEM } \\
\hline & $\mathrm{x}_{1}$ & $\mathrm{C}_{1}(\%)$ & $\mathrm{x}_{2}$ & $\mathrm{C}_{2}(\%)$ & $\mathrm{x}_{3}$ & $\mathrm{C}_{3}(\%)$ \\
\hline 0 & 0 & 0 & 0 & 0 & 0 & 0 \\
1 & 1 & 0,5 & 0 & 0 & 0 & 0 \\
2 & 0 & 0 & 1 & 0,5 & 0 & 0 \\
3 & 0 & 0 & 0 & 0 & 1 & 0,5 \\
4 & 0,5 & 0,25 & 0,5 & 0,25 & 0 & 0 \\
5 & 0,5 & 0,25 & 0 & 0 & 0,5 & 0,25 \\
6 & 0 & 0 & 0,5 & 0,25 & 0,5 & 0,25 \\
7 & 0,333 & 0,167 & 0,333 & 0,167 & 0,333 & 0,167 \\
$7 \mathrm{~b}$ & 0,333 & 0,167 & 0,333 & 0,167 & 0,333 & 0,167 \\
$7 \mathrm{c}$ & 0,333 & 0,167 & 0,333 & 0,167 & 0,333 & 0,167 \\
\hline
\end{tabular}


Foram realizados os mesmos testes da primeira etapa, porém o tempo de armazenamento congelado para as análises de textura foi de $0,1,7,14,18$ e 22 dias. A análise de textura sofreu uma alteração a partir desta etapa que foi a temperatura controlada através de estufa $\left(30^{\circ} \mathrm{C}\right)$ do período de descanso de 40 minutos de permanência da massa na forma de Teflon.

Foram obtidas curvas de temperatura durante o congelamento das massas através de termopares inseridos no centro geométrico da massa de pão. A aquisição foi realizada através de interface National Instruments acoplada em PC e programa LabView 5.1. A partir dessas curvas foi possível determinar a velocidade de resfriamento (Equação 2.2).

$\mathrm{Na}$ análise térmica foram realizados apenas os ciclos completo, com algumas modificações conforme programa apresentado na Tabela 3.6 com gás de arraste Nitrogênio para algumas análises (vazão de $50 \mathrm{~mL} / \mathrm{min}$ ), e o de retrogradação, no intervalo de 25 a $150^{\circ} \mathrm{C}$ e uma razão de aquecimento de $10^{\circ} \mathrm{C} / \mathrm{min}$ com gás de arraste Nitrogênio numa vazão de $50 \mathrm{~mL} / \mathrm{min}$.

Tabela 3.6: Programa Ciclo Completo do DSC para segunda etapa que compreendeu um ciclo de congelamento-descongelamento e dois de aquecimento.

\begin{tabular}{ccc}
\hline $\begin{array}{c}\text { Razão de aquecimento } \\
\left({ }^{\mathbf{0}} \mathbf{C} / \text { minuto }\right)\end{array}$ & $\begin{array}{c}\text { Intervalo de } \\
\text { temperatura }\end{array}$ & $\begin{array}{c}\text { Isoterma } \\
\text { (minutos) }\end{array}$ \\
\hline-3 & 25 a -40 & 5 \\
3 & -40 a 25 & 5 \\
10 & 25 a 100 & 5 \\
-5 & 100 a 25 & 5 \\
10 & 25 a 130 & \\
\hline
\end{tabular}

\subsubsection{Terceira Etapa (Ácido Ascórbico)}

Baseado nos resultados da segunda etapa foi selecionada uma formulação (0 \% de CSL, 0,3\% de PS80 e 0,2\% de DATEM) para dar prosseguimento ao estudo da influência do ácido ascórbico, adicionado em 4 níveis (0, 100, 200 e 300 ppm em relação a farinha de trigo do segundo lote). 
Foram realizadas as mesmas análises de textura da segunda etapa porém com o tempo de armazenamento congelado de $0,1,4,7,10$ e 13 dias.

$\mathrm{Na}$ análise térmica foram realizadas duas medidas de cada formulação de acordo com os programas descritos na segunda etapa, porém com utilização do gás de arraste Nitrogênio a uma vazão de $50 \mathrm{~mL} / \mathrm{min}$ para em todas as determinações.

\subsubsection{Quarta Etapa (Panificação)}

A partir da formulação que apresentou-se mais estável na etapa anterior (200 ppm) e a padrão (0 ppm de ácido ascórbico) utilizando farinha de trigo do segundo lote, $59 \%$ de água e $3 \%$ de fermento fresco em relação a farinha de trigo, foram produzidos pães franceses de massa congelada e as análises descritas a seguir foram realizadas após aproximadamente uma hora e meia do término do assamento, tempo em que o pão ainda é considerado fresco.

As análises foram conduzidas em pães produzidos de massas frescas e congeladas, armazenadas em "freezer" ao longo de 1, 4, 7, 11, e 13 dias. As massas foram descongeladas por uma hora a $30^{\circ} \mathrm{C}$, fermentadas durante uma hora e assadas por aproximadamente 10 minutos com temperatura do forno ajustada para $250{ }^{\circ} \mathrm{C}$.

Os resultados foram comparados com os obtidos em trabalhos anteriores realizados no laboratório de Engenharia de Alimentos da Escola Politécnica da USP (KOWALSKI; CARR; TADINI, 2002); (CARR; TADINI, 2003).

\section{Análises nas massas:}

A análise de textura da massa só foi possível na massa fresca pois nas massas congeladas houve uma fermentação excessiva durante o período de descanso de 40 minutos na forma de Teflon. Foi realizada análise de umidade da massa fresca conforme método citado anteriormente.

\section{Análises nos pães:}

Massa: Medida direta com o valor médio de seis pães.

Volume: Determinação como o valor médio de seis pães em triplicata, por deslocamento de sementes de painço, utilizando o Medidor de Volume CHOPIN (Figura 3.7), previamente calibrado. 


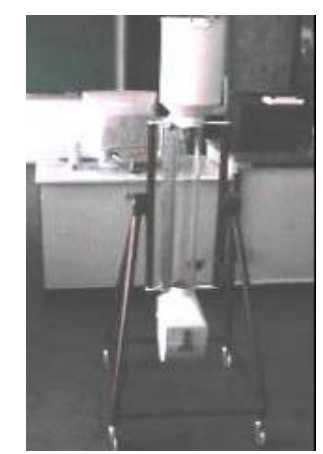

Figura 3.7: Medidor de volume CHOPIN.

Volume Específico: Obtido pela razão entre volume e massa.

Determinação do conteúdo de água: Método com duas etapas de secagem (em temperatura ambiente e estufa) devido ao alto teor de água presente na amostra de pão, conforme o método 44 - 15 A (AACC, 1995).

Medidas de Produção de gás, Permeabilidade da massa e tolerância durante a fermentação: Conduzidas no Reofermentômetro CHOPIN (Figura 3.8) e obtidas através das curvas de desenvolvimento da massa e de geração de gás carbônico.

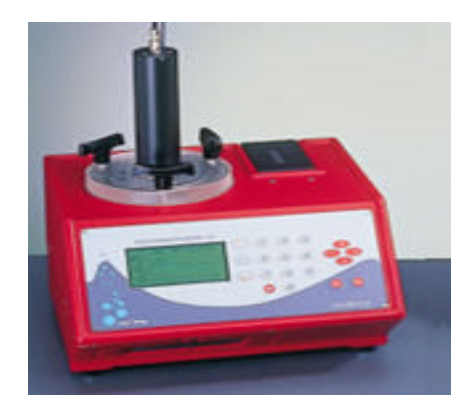

Figura 3.8: Reofermentômetro F3 CHOPIN.

Antes de realizar estas medidas no reofermentômetro, as massas foram descongeladas em ambiente de temperatura controlada $\left(30^{\circ} \mathrm{C}\right)$ por uma hora. Amostras de $200 \mathrm{~g}$ de massa descongelada foram colocadas no cesto do equipamento, com temperatura controlada $\left(32^{\circ} \mathrm{C}\right)$ por três horas.

A Figura 3.9 é um exemplo de curva de desenvolvimento da massa obtida a partir de dados fornecidos em intervalo de tempo regular por um sensor óptico e a Figura 3.10 é um exemplo de curva de geração de $\mathrm{CO}_{2}$ obtida através da conversão 
de ciclos de medida de pressão realizada por um circuito pneumático, através da qual é possível determinar a quantidade de gás total produzido e a retida pela massa.

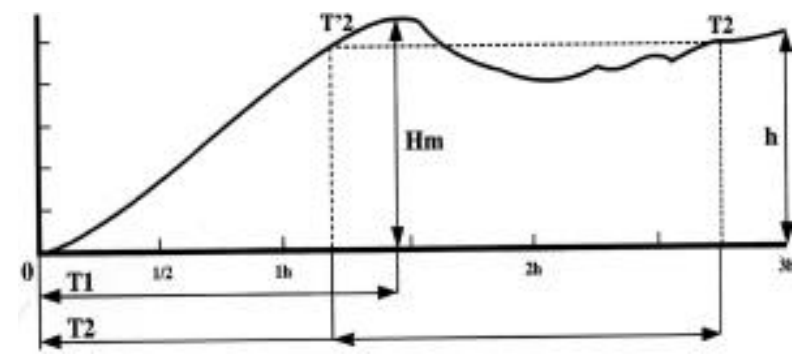

Figura 3.9: Exemplo de curva do desenvolvimento da massa obtida no reofermentômetro CHOPIN.

Onde:

T1: Tempo relativo ao crescimento máximo da massa, $\mathrm{Hm}$, em horas;

Hm: Altura máxima do desenvolvimento da massa sob compressão, expresso em $\mathrm{mm}$

T2 e T'2: Tempo de estabilidade relativa no ponto máximo, a altura de $12 \%$ da altura máxima sem ser menor que $6 \mathrm{~mm}$, em horas;

$\Delta \mathrm{T} 2=\mathrm{T} 2-\mathrm{T}$ '2: Tolerância da massa, em horas;

h: Altura do desenvolvimento da massa no final do teste, em mm;

$(\mathrm{Hm}-\mathrm{h}) / \mathrm{Hm}$ : Coeficiente de enfraquecimento da massa, adimensional ou em \%.

Os resultados de $\mathrm{T} 1 \mathrm{e}(\mathrm{Hm}-\mathrm{h}) / \mathrm{Hm}$ indicam o melhor tempo para a massa ser trabalhada, Hm está associado ao volume do pão, T2 é um indicador de tolerância da massa durante a fermentação e T1 está associado à atividade do fermento.

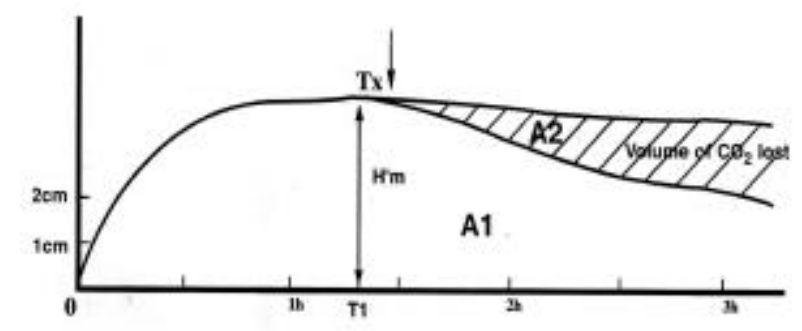

Figura 3.10: Exemplo de curva de geração de gás carbônico obtida no reofermentômetro CHOPIN. 
Onde:

H'm: Altura máxima da curva de geração de $\mathrm{CO}_{2}$, em mm;

T'1: Tempo necessário para alcançar H'm, em horas;

Tx: Tempo necessário para o aparecimento de porosidade na massa (início da liberação de $\mathrm{CO}_{2}$ ), em horas;

Área (A1+A2): Volume total de gás liberado, em mL;

Área A1: Volume de $\mathrm{CO}_{2}$ mantido na massa ao final do teste;

Área A2: Volume de $\mathrm{CO}_{2}$ liberado pela massa durante a fermentação.

O coeficiente de retenção ( $\mathrm{R} \%$ ) é obtido através da razão entre volume retido e o total.

Perfil de Textura: Obtido no analisador de textura TA-XT2i SMS utilizando o “probe" P36 cilíndrico, 36 mm de diâmetro (Figura 3.11), método AACC 74-09 (AACC, 1995) com adaptações feitas por Carr; Tadini (2003). As medidas dos parâmetros de textura foram realizadas após uma hora do assamento final.

Os parâmetros medidos foram firmeza, coesividade e elasticidade. Estes parâmetros foram escolhidos devido à sua relação com parâmetros sensoriais.

Os testes foram conduzidos no modo TPA ("Texture Profile Analysis") em dez amostras preparadas com a retirada das extremidades dos pães, sob as seguintes condições (CARR; TADINI, 2003):

- Velocidade do Pré-Teste: $2,0 \mathrm{~mm} / \mathrm{s}$;

- Velocidade do Teste: $5,0 \mathrm{~mm} / \mathrm{s}$;

- Velocidade do Pós-Teste: 5,0 mm/s;

- Distância: 20 mm;

- Gatilho: Auto - 20 g (ponto inicial da análise, quando o "probe" encontra uma resistência igual ou superior a $20 \mathrm{~g}$ );

- Tempo entre as duas compressões: $5 \mathrm{~s}$. 
O método utilizado consiste na dupla compressão da amostra, gerando gráfico força-tempo e força-distância, dos quais obtém-se valores necessários para o cálculo dos parâmetros de textura.

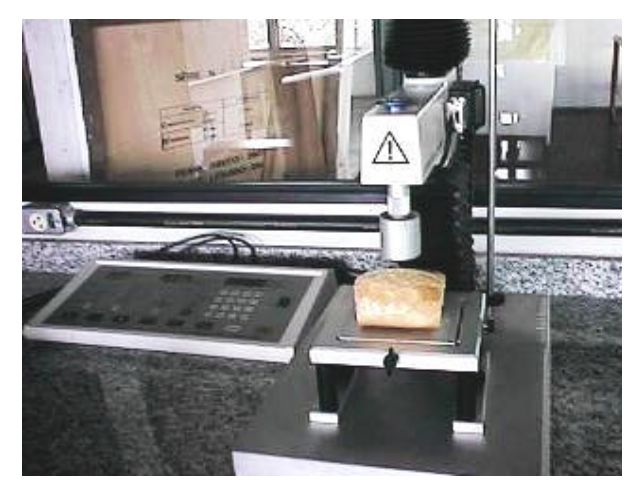

Figura 3.11: Análise de textura do pão utilizando o analisador de textura TA-XT2i com acessório cilíndrico de $36 \mathrm{~mm}$.

Os parâmetros de textura foram calculados através da curva (ver Figura 2.9) da seguinte forma (BRENNAN, 1988):

- Firmeza: pico de força medido durante o primeiro ciclo de compressão $(\mathrm{N})$;

- Coesividade: relação entre as áreas da segunda e primeira compressões do ponto inicial até o pico (adimensional);

- Elasticidade: distância do ponto inicial da segunda compressão até o pico (m);

- Mastigabilidade: produto da firmeza, coesividade e elasticidade (J).

\subsection{Tratamento de Dados}

O tratamento dos dados obtidos da Análise Térmica foi realizado utilizandose os programas STARe Software, Mettler Toledo e ORIGIN 6.0, OriginLab.

Análises de variância (ANOVA) e regressões lineares e não lineares foram conduzidas utilizando o programa STATGRAPHICS PLUS 4.0 for Windows. 


\section{RESULTADOS E DISCUSSÃO}

\subsection{PRimeira ETAPa}

As análises térmicas foram feitas sem repetições devido ao alto custo dos cadinhos para análise de DSC. Foram realizados ensaios em duplicata para análise de textura e as massas foram congeladas em "freezer" plasma.

Para análise estatística dos dados, as variáveis originais foram transformadas em codificadas como indicado nas Equações 4.1, 4.2, 4.3. A Tabela 4.1 mostra as variáveis originais e as respectivas variáveis codificadas utilizadas nas análises de variância. O ponto central, 7, não foi considerado para análise de variância (ANOVA).

$$
\begin{aligned}
& x_{1}=\frac{G V H-\frac{(2+0)}{2}}{\frac{(2+0)}{2}}=\frac{G V H-1}{1} \\
& x_{2}=\frac{C S L-\frac{(0,5+0)}{2}}{\frac{(0,5+0)}{2}}=\frac{C S L-0,25}{0,25} \\
& x_{3}=\frac{P S 80-\frac{(0,3+0)}{2}}{\frac{(0,3+0)}{2}}=\frac{P S 80-0,15}{0,15}
\end{aligned}
$$


Tabela 4.1: Transformação das variáveis originais em codificadas utilizadas nas análises de variância.

\begin{tabular}{ccccccc}
\hline Mistura & \multicolumn{3}{c}{ Variáveis originais* } & \multicolumn{3}{c}{ Variáveis codificadas } \\
& GVH & CSL & PS80 & $\mathrm{x}_{1}$ & $\mathrm{x}_{2}$ & $\mathrm{x}_{3}$ \\
\hline 0 & 0 & 0 & 0 & -1 & -1 & -1 \\
1 & 2 & 0 & 0 & 1 & -1 & -1 \\
2 & 0 & 0,5 & 0 & -1 & 1 & -1 \\
3 & 0 & 0 & 0,3 & -1 & -1 & 1 \\
4 & 1 & 0,25 & 0 & 0 & 0 & -1 \\
5 & 1 & 0 & 0,15 & 0 & -1 & 0 \\
6 & 0 & 0,25 & 0,15 & -1 & 0 & 0 \\
7 & 0,667 & 0,167 & 0,1 & $-0,333$ & $-0,333$ & $-0,333$ \\
8 & 2 & 0,5 & 0,3 & 1 & 1 & 1 \\
\hline
\end{tabular}

*valores em porcentagem sobre uma base de $100 \%$ de farinha.

\subsubsection{Análise de Conteúdo de Água da Massa Fresca}

A análise de conteúdo de água por estufa a $130{ }^{\circ} \mathrm{C}$ foi realizada em duplicata e na análise estatística as medidas foram consideradas réplicas. A análise de termogravimetria foi realizada sem réplicas.

Foi aplicada ANOVA "one-way" para os resultados de conteúdo de água obtidos pelo método estufa a $130{ }^{\circ} \mathrm{C}$, executada no intervalo de confiança de $95 \%$ e confirmada pelo teste de Tukey HSD (Tabela 4.2). A ANOVA indicou que as massas frescas das diferentes misturas apresentaram diferença significativa entre si quanto ao conteúdo de água. As misturas 1 e 8, com maior quantidade de GVH apresentaram menores valores de conteúdo de água como era esperado, e as misturas com $0 \%$ de $\mathrm{GVH}(0,2,3$ e 6$)$ apresentaram maior conteúdo de água. 
Tabela 4.2: Conteúdo de água das massas referentes à primeira etapa do projeto determinadas por estufa a $130{ }^{\circ} \mathrm{C}$, pela técnica de TGA e por balanço de massa.

\begin{tabular}{|c|c|c|c|c|}
\hline \multirow{3}{*}{ Mistura } & \multicolumn{4}{|c|}{ Conteúdo de água $(\%)$} \\
\hline & \multicolumn{2}{|c|}{ Estufa $130^{\circ} \mathrm{C}$} & \multirow[t]{2}{*}{ TGA $^{1}$} & \multirow{2}{*}{$\begin{array}{c}\text { Balanço de } \\
\text { massa }^{3}\end{array}$} \\
\hline & Valor médio & $\mathrm{DP}^{2}$ & & \\
\hline 0 & $43,93^{\mathrm{d}}$ & 0,08 & 43,24 & 44,84 \\
\hline 1 & $43,02^{\mathrm{a}}$ & 0,22 & 42,87 & 44,29 \\
\hline 2 & $43,51^{\mathrm{bcd}}$ & 0,24 & 43,00 & 44,70 \\
\hline 3 & $43,63^{\mathrm{cd}}$ & 0,10 & 42,99 & 44,76 \\
\hline 4 & $43,27^{\mathrm{abc}}$ & 0,27 & 42,00 & 44,49 \\
\hline 5 & $43,47^{\mathrm{abcd}}$ & 0,12 & 42,73 & 44,52 \\
\hline 6 & $43,18^{a b}$ & 0,42 & 43,70 & 44,73 \\
\hline 7 & $43,49^{\mathrm{bcd}}$ & 0,22 & 43,93 & 44,58 \\
\hline 8 & $43,08^{\mathrm{a}}$ & 0,16 & 42,81 & 44,07 \\
\hline
\end{tabular}

*Médias com letras iguais, não diferem estatisticamente entre si ao nível de $95 \%$ de confiança.

${ }^{1}$ TGA - Análise de termogravimetria

${ }^{2} \mathrm{DP}$ - Desvio Padrão

${ }^{3}$ Balanço de massa - considerando conteúdo de água da farinha $14,30 \%$ e adição de $57 \%$ de água, o conteúdo de água nos demais componentes foi desconsiderado.

A Figura 4.1 ilustra uma curva típica obtida na análise de termogravimetria (TGA) indicando o ponto final da determinação do conteúdo de água da massa. Durante a análise de TGA notou-se que a perda de massa começava no momento em que as amostras eram colocadas no equipamento, antes da aquisição de dados ser iniciada. Essa perda de massa inicial foi adicionada ao valor do conteúdo de água obtido pela curva. 


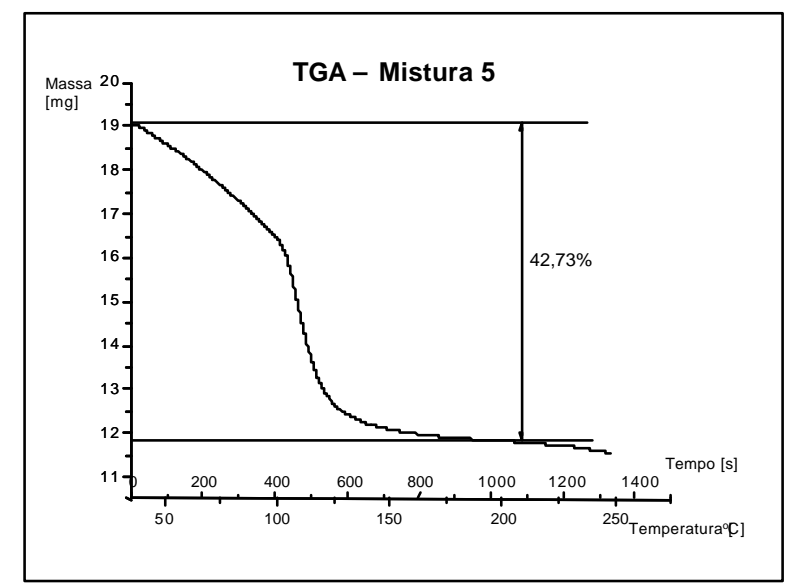

Figura 4.1: Exemplo de curva obtida na análise de TGA, mistura 5.

Análise de variância múltipla indicou que a GVH e o CSL influenciaram significativamente no conteúdo de água das massas, no intervalo de confiança de 95\%, confirmado pelo teste de Tukey HSD (Figura 4.2). Observa-se que a GVH, quando utilizada em maior quantidade, influenciou o conteúdo de água negativamente. 


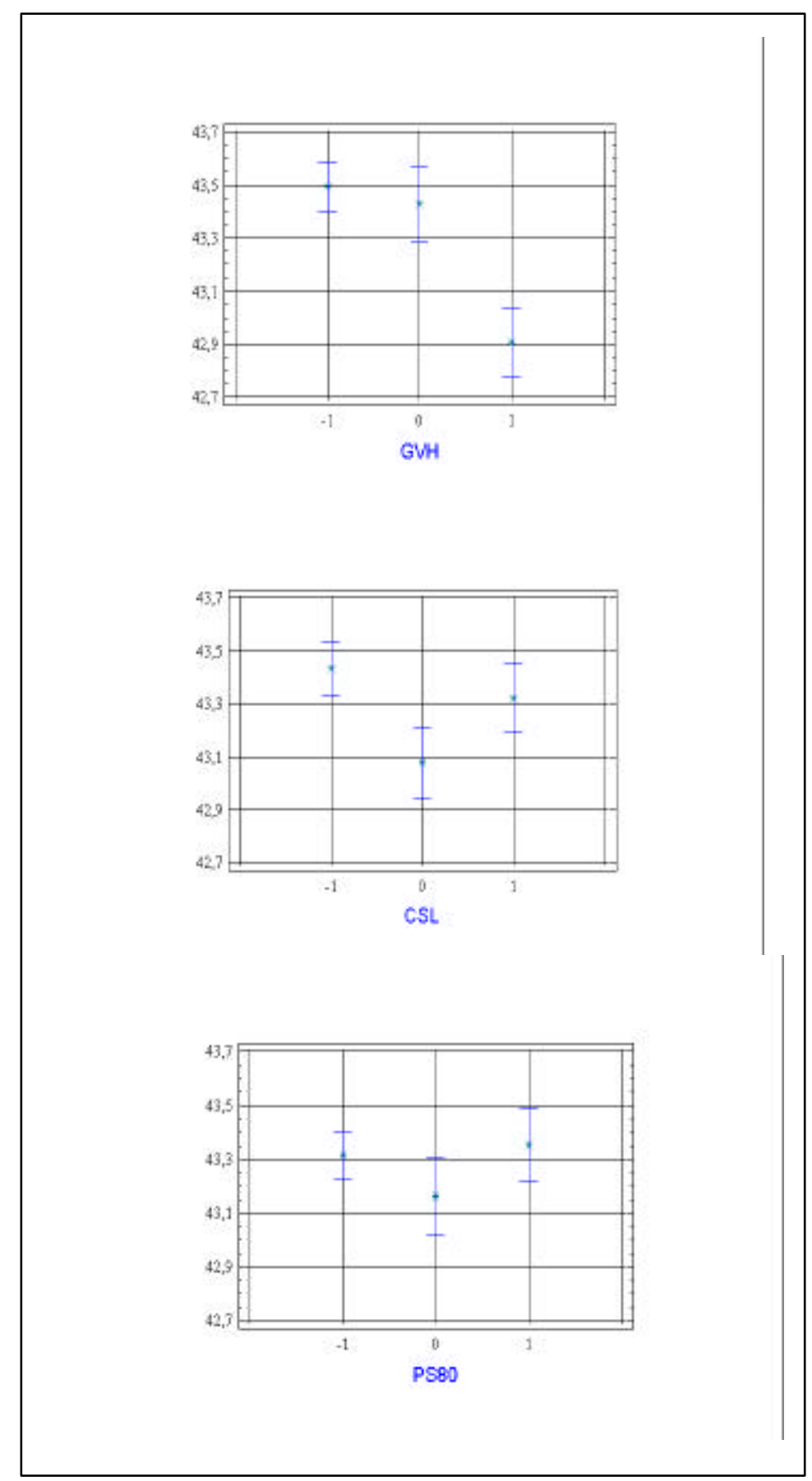

Figura 4.2: Variação do conteúdo de água, em função dos níveis de GVH, CSL e PS80, presente nas massas frescas de diferentes misturas. 


\subsubsection{Análise de Textura da Massa}

Análise de variância foi executada no intervalo de confiança de $95 \%$ e confirmada pelo teste de Tukey HSD para verificar a influência de GVH, CSL e PS80 sobre a textura da massa. As Tabelas 4.3 e 4.4 são referentes às determinações realizadas no período de 17 de fevereiro e 16 de abril de 2003 e as Tabelas 4.5 e 4.6, ao período de 01 de julho a 28 de agosto de 2003. A análise estatística foi realizada nestes períodos separadamente pois observou-se variação entre as duplicatas tanto para resistência à extensão quanto para extensibilidade. Foram realizadas no mínimo sete medidas para cada determinação de análise de textura.

A análise estatística indicou que o componente CSL e o tempo de armazenamento congelado influenciaram significativamente a resistência à extensão das massas, no intervalo de confiança de 95\%, confirmado pelo teste de Tukey HSD, nas análises realizadas nos períodos de 17 de fevereiro a 16 de abril e 01 de julho a 28 de agosto de 2003. No entanto, foi verificado a influência do componente PS80, sobre a resistência à extensão da massa somente no período entre 17 de fevereiro a 16 de abril de 2003 (Tabelas 4.3 e 4.5).

Já em relação à extensibilidade, os componentes GVH e PS80 e o tempo de armazenamento congelado influenciaram significativamente, no intervalo de confiança de $95 \%$, confirmado pelo teste Tukey HSD, nas análises realizadas nos períodos de 17 de fevereiro a 16 de abril e 01 de julho a 28 de agosto de 2003 . No entanto, o CSL influenciou significativamente a extensibilidade apenas no período de 01 de julho a 28 de agosto de (Tabelas 4.4 e 4.6).

As Figuras 4.3 e 4.4 mostram o comportamento da resistência à extensão e extensibilidade, ao longo do tempo de armazenamento congelado. Nota-se que a resistência à extensão apresentou comportamento semelhante em ambos períodos de análise, até 7 dias e de 28 a 56 dias de armazenamento. No entanto a extensibilidade apresentou um comportamento distinto ao longo do armazenamento congelado. 
Tabela 4.3: Resultados da ANOVA aplicada aos valores de resistência à extensão (N) da massa, ao longo do tempo de armazenamento congelado, obtidos no período de 17 de fevereiro a 16 de abril de 2003.

\begin{tabular}{|c|c|c|c|c|}
\hline \multirow[t]{2}{*}{ Fator } & \multicolumn{3}{|c|}{ Nível } & \multirow[t]{2}{*}{$\mathbf{D M S}^{1}$} \\
\hline & -1 & 0 & 1 & \\
\hline GVH & $0,552^{\mathrm{a}}$ & $0,552^{\mathrm{a}}$ & $0,544^{\mathrm{a}}$ & 0,029 \\
\hline CSL & $0,503^{\mathrm{a}}$ & $0,538^{\mathrm{b}}$ & $0,610^{\mathrm{c}}$ & 0,026 \\
\hline PS80 & $0,509^{a}$ & $0,535^{\mathrm{a}}$ & $0,607^{\mathrm{b}}$ & 0,026 \\
\hline
\end{tabular}

*Médias com letras iguais na mesma linha, não diferem estatisticamente entre si ao nível de $95 \%$ de confiança.

${ }^{1}$ Diferença mínima significativa.

Tabela 4.4: Resultados da ANOVA aplicada aos valores de extensibilidade (mm) da massa, ao longo do tempo de armazenamento congelado, obtidos no período de 17 de fevereiro a 16 de abril de 2003.

\begin{tabular}{lcccc}
\hline Fator & \multicolumn{3}{c}{ Nível } & DMS $^{\mathbf{1}}$ \\
& $\mathbf{- 1}$ & $\mathbf{0}$ & $\mathbf{1}$ & \\
\hline GVH & $17,493^{\mathrm{a}}$ & $18,514^{\mathrm{b}}$ & $18,081^{\mathrm{ab}}$ & 0,888 \\
CSL & $17,663^{\mathrm{a}}$ & $18,362^{\mathrm{a}}$ & $18,063^{\mathrm{a}}$ & 0,872 \\
PS80 & $18,890^{\mathrm{b}}$ & $17,763^{\mathrm{a}}$ & $17,436^{\mathrm{a}}$ & 0,889
\end{tabular}

*Médias com letras iguais na mesma linha, não diferem estatisticamente entre si ao nível de $95 \%$ de confiança.

${ }^{1}$ Diferença mínima significativa.

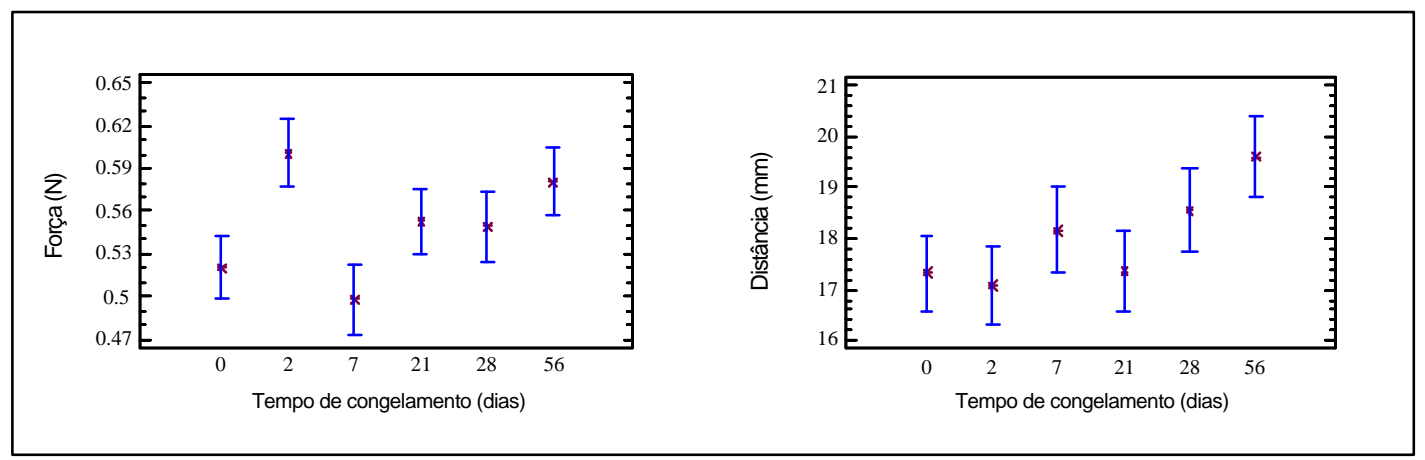

Figura 4.3: Resistência à extensão (Força em N) e extensibilidade (Distância em $\mathrm{mm}$ ) em função do tempo de congelamento, referente às análises realizadas no período entre 17 de fevereiro e 16 de abril de 2003. 
Tabela 4.5: Resultados da ANOVA aplicada aos valores de resistência à extensão $(\mathrm{N})$, ao longo do tempo de armazenamento congelado, obtidos no período entre 01 de julho e 28 de agosto de 2003.

\begin{tabular}{lcccc}
\hline Fator & \multicolumn{3}{c}{ Nível } & DMS $^{\mathbf{1}}$ \\
& $\mathbf{- 1}$ & $\mathbf{0}$ & $\mathbf{1}$ & \\
\hline GVH & $0,721^{\mathrm{a}}$ & $0,703^{\mathrm{a}}$ & $0,708^{\mathrm{a}}$ & 0,027 \\
CSL & $0,745^{\mathrm{b}}$ & $0,691^{\mathrm{a}}$ & $0,696^{\mathrm{a}}$ & 0,027 \\
PS80 & $0,716^{\mathrm{a}}$ & $0,721^{\mathrm{a}}$ & $0,695^{\mathrm{a}}$ & 0,027
\end{tabular}

*Médias com letras iguais na mesma linha, não diferem estatisticamente entre si ao nível de $95 \%$ de confiança.

${ }^{1}$ Diferença mínima significativa.

Tabela 4.6: Resultados da ANOVA aplicada aos valores de extensibilidade (mm), ao longo do tempo de armazenamento congelado, obtidos no período entre 01 de julho e 28 de agosto de 2003.

\begin{tabular}{lcccc}
\hline Fator & \multicolumn{5}{c}{ Nível } & DMS $^{\mathbf{1}}$ \\
& $\mathbf{- 1}$ & $\mathbf{0}$ & $\mathbf{1}$ & \\
\hline GVH & $17,257^{\mathrm{b}}$ & $16,201^{\mathrm{a}}$ & $15,876^{\mathrm{a}}$ & 0,659 \\
CSL & $16,044^{\mathrm{a}}$ & $17,263^{\mathrm{b}}$ & $16,026^{\mathrm{a}}$ & 0,657 \\
PS80 & $16,618^{\mathrm{b}}$ & $15,720^{\mathrm{a}}$ & $16,996^{\mathrm{b}}$ & 0,654
\end{tabular}

*Médias com letras iguais na mesma linha, não diferem estatisticamente entre si ao nível de $95 \%$ de confiança.

${ }^{1}$ Diferença mínima significativa
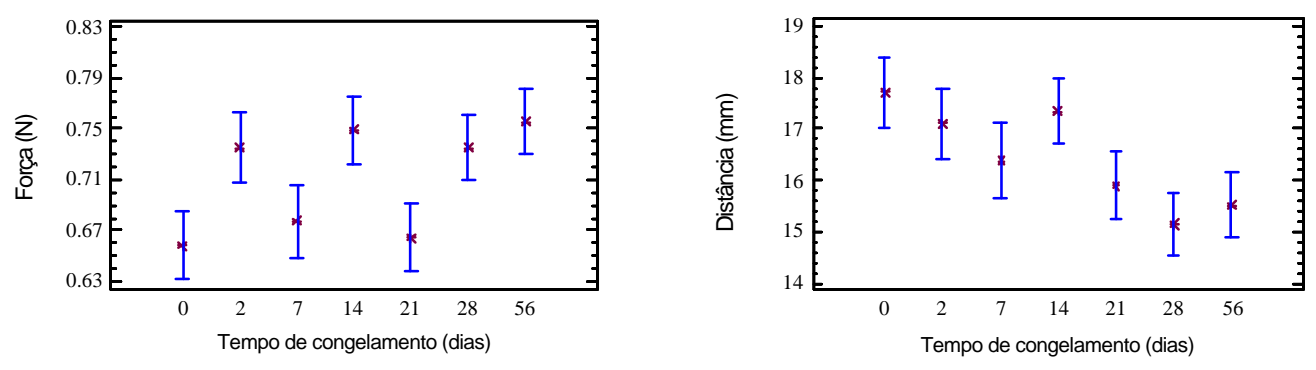

Figura 4.4: Resistência à extensão (Força em N) e extensibilidade (Distância em $\mathrm{mm}$ ) em função do tempo de congelamento, referente às análises realizadas entre 01 de julho e 28 de agosto de 2003. 
O componente GVH não influenciou significativamente a resistência à extensão, parâmetro diretamente relacionado à rigidez da massa. Mesmo não influenciando este parâmetro, a GVH não deve ser eliminado da composição da massa, pois reduz a taxa de endurecimento (PENFIELD; CAMPBELL 1990) e melhora os parâmetros de textura dos pães (CARR; TADINI, 2003).

As diferenças encontradas nos valores entre os períodos de análise ocorreram provavelmente devido à diferença da temperatura ambiente nos dias das análises, uma vez que os primeiros ensaios foram realizados no período de $17 \mathrm{de}$ fevereiro a 16 de abril e as duplicatas no período de 01 de julho a 28 de agosto de 2003. Mediante esses resultados, sugeriu-se nas próximas etapas do projeto deixar a massa durante o descongelamento e as tiras de massa no acessório do texturômetro em ambiente de temperatura controlada $\left(30^{\circ} \mathrm{C}\right)$ durante os 40 minutos de repouso como descrito no método.

Foi aplicada ANOVA "one way" para verificar a influência do tempo, nos resultados de resistência à extensão e extensibilidade das misturas, executada no intervalo de confiança de $95 \%$ e confirmada pelo teste de Tukey HSD (Tabelas 4.7 e 4.8). Observou-se variação entre as duplicatas tanto para resistência à extensão quanto para extensibilidade. 
Tabela 4.7: Valores de resistência à extensão das massas frescas e congeladas até 56 dias de acordo com a mistura.



*Médias com letras iguais na mesma linha, não diferem estatisticamente entre si ao nível de $95 \%$ de confiança.

Valores em cor preta são referentes às análises realizadas entre 17 de fevereiro a 16 de abril de 2003.

Valores em cor azul são referentes às análises realizadas entre 01 de julho a 28 de agosto de 2003. 
Tabela 4.8: Valores de extensibilidade das massas frescas e congeladas até 56 dias de acordo com a mistura.

\begin{tabular}{|c|c|c|c|c|c|c|c|c|}
\hline & \multicolumn{6}{|l}{ Extensibilidade da massa ao longo do tempo de armazenamento congelado } \\
(mm)
\end{tabular}

*Médias com letras iguais na mesma linha, não diferem estatisticamente entre si ao nível de $95 \%$ de confiança.

Valores em cor preta são referentes às análises realizadas entre 17 de fevereiro a 16 de abril de 2003.

Valores em cor azul são referentes às análises realizadas entre 01 de julho a 28 de agosto de 2003 


\subsubsection{Calorimetria Exploratória Diferencial (DSC)}

\subsubsection{Programa Ciclo Completo}

O programa ciclo completo foi apresentado na Tabela 3.2 e o programa ciclo de retrogradação na Tabela 3.4.

\subsection{Entalpia de congelamento e descongelamento, conteúdo de} água não congelável ( $\mathrm{g} \mathrm{H}_{2} \mathrm{O}$ / g de sólidos) e concentração de sólidos em Wg' (\%)

A Tabela 4.9 mostra os valores de entalpia obtidos para os eventos de congelamento (cristalização) e de descongelamento (fusão), os valores de temperatura de "onset" (o início do evento), de "endset" (o final do evento), e de pico.

O conteúdo de água não congelável (Wg’) e da concentração de sólidos em Wg' (Cg') calculados a partir das Equações 2.3 e 2.4, estão apresentados na Tabela 4.10. A Figura 4.5 ilustra um exemplo de curva obtida através do DSC, relativa ao evento de fusão para determinação da entalpia de descongelamento.

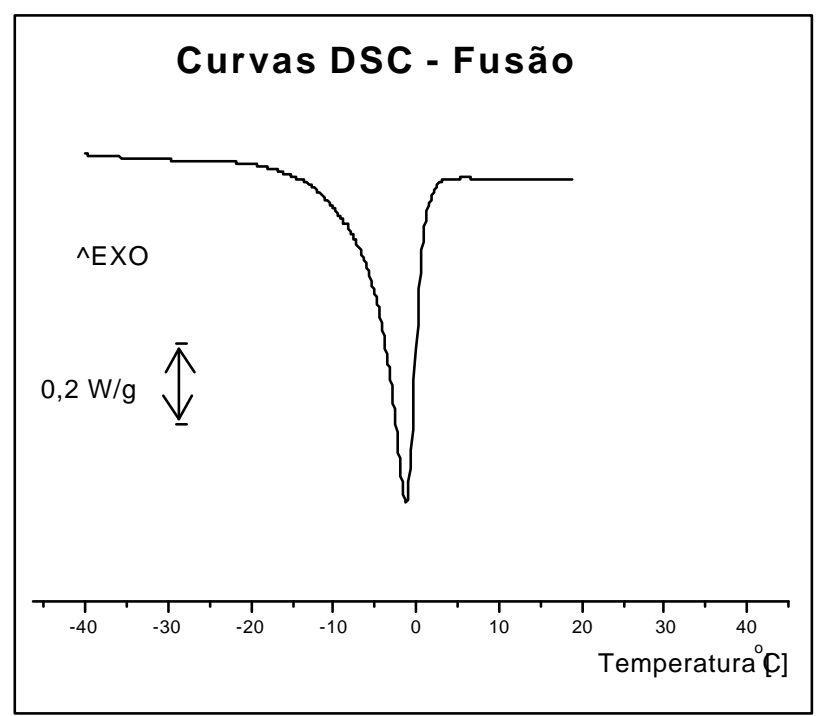

Figura 4.5: Pico de Fusão obtido através do DSC da mistura 2 no programa ciclo completo. 
Tabela 4.9: Valores obtidos para os eventos de congelamento e descongelamento no DSC, programa Ciclo Completo. (Entalpia, $\mathrm{T}_{\text {onset }}, \mathrm{T}_{\text {pico }}$ e $\mathrm{T}_{\text {endset }}$ ).

\begin{tabular}{|l|c|c|c|c|c|c|c|c|c|c|c|}
\hline \multicolumn{10}{|c|}{ CICLO COMPLETO } \\
\hline \multicolumn{10}{|c|}{ Congelamento } \\
\hline Mistura & $\mathbf{0}$ & $\mathbf{1}$ & $\mathbf{2}$ & $\mathbf{3}$ & $\mathbf{4}$ & $\mathbf{5}$ & $\mathbf{6}$ & $\mathbf{7}$ & $\mathbf{7 a}$ & $\mathbf{8}$ & $\mathbf{8 a}$ \\
\hline $\begin{array}{l}\text { Massa } \\
{[\mathrm{mg}]}\end{array}$ & 30,022 & 25,036 & 27,892 & 28,686 & 22,385 & 22,072 & 28,090 & 20,390 & 19,447 & 19,126 & 13,507 \\
\hline $\begin{array}{l}\text { Entalpia } \\
{[\mathrm{J} / \mathrm{g}]}\end{array}$ & 81,15 & 83,64 & 82,53 & 83,91 & 83,61 & 82,83 & 78,32 & 78,42 & 75,97 & 76,82 & 75,17 \\
\hline $\mathrm{T}_{\text {onset }}\left[{ }^{\circ} \mathrm{C}\right]$ & $-8,09$ & $-8,49$ & $-8,69$ & $-8,71$ & $-8,21$ & $-8,19$ & $-8,90$ & $-7,58$ & $-8,48$ & $-7,30$ & $-8,45$ \\
\hline $\mathrm{T}_{\text {pico }}\left[{ }^{\circ} \mathrm{C}\right]$ & $-7,15$ & $-7,21$ & $-7,46$ & $-7,45$ & $-7,07$ & $-7,16$ & $-7,72$ & $-6,83$ & $-7,19$ & $-6,07$ & $-7,15$ \\
\hline $\left.\mathrm{T}_{\text {endset }}{ }^{\circ} \mathrm{C}\right]$ & $-10,50$ & $-10,13$ & $-10,54$ & $-10,50$ & $-9,54$ & $-9,78$ & $-10,73$ & $-9,26$ & $-9,30$ & $-8,44$ & $-8,93$ \\
\hline & & & & Descongelamento & & & \\
\hline Mistura $^{-3}$ & $\mathbf{0}$ & $\mathbf{1}$ & $\mathbf{2}$ & $\mathbf{3}$ & $\mathbf{4}$ & $\mathbf{5}$ & $\mathbf{6}$ & $\mathbf{7}$ & $\mathbf{7 a}$ & $\mathbf{8}$ & $\mathbf{8 a}$ \\
\hline $\begin{array}{l}\text { Entalpia } \\
{[\mathrm{J} / \mathrm{g}]}\end{array}$ & $-85,62$ & $-87,09$ & $-89,61$ & $-90,08$ & $-88,24$ & $-88,87$ & $-84,72$ & $-85,27$ & $-81,37$ & $-78,41$ & $-74,64$ \\
\hline $\mathrm{T}_{\text {onset }}\left[{ }^{\circ} \mathrm{C}\right]$ & $-5,72$ & $-5,54$ & $-5,47$ & $-5,53$ & $-5,23$ & $-5,37$ & $-5,40$ & $-5,21$ & $-5,35$ & $-4,24$ & $-5,32$ \\
\hline $\mathrm{T}_{\text {pico }}\left[{ }^{\circ} \mathrm{C}\right]$ & $-1,21$ & $-1,41$ & $-1,17$ & $-1,07$ & $-1,36$ & $-1,32$ & $-1,09$ & $-1,39$ & $-1,76$ & $-0,75$ & $-2,20$ \\
\hline $\left.\mathrm{T}_{\text {endset }}{ }^{\circ} \mathrm{C}\right]$ & 0,97 & 0,50 & 0,85 & 0,99 & 0,26 & 0,31 & 0,85 & 0,28 & $-0,45$ & 1,02 & $-1,08$ \\
\hline
\end{tabular}


Tabela 4.10: Conteúdo de água não congelável (Wg’) e a concentração de sólidos na água não congelável (Cg') nas massas congeladas de diferentes misturas.

\begin{tabular}{ccc}
\hline Mistura & $\begin{array}{c}\mathbf{W g} \\
\mathbf{( g ~ H} \mathbf{O} \mathbf{O} \text { sólidos })\end{array}$ & $\begin{array}{c}\text { Cg' } \\
\text { (\% de sólidos na Wg') }\end{array}$ \\
\hline 0 & 0,326 & 75,40 \\
1 & 0,297 & 77,08 \\
2 & 0,295 & 77,20 \\
3 & 0,296 & 77,19 \\
4 & 0,297 & 77,10 \\
5 & 0,298 & 77,02 \\
6 & 0,314 & 76,13 \\
7 & 0,318 & 75,88 \\
7 a & 0,339 & 74,71 \\
8 & 0,344 & 74,38 \\
8 a & 0,364 & 73,30 \\
\hline
\end{tabular}

Os valores obtidos para Wg' estão próximos aos de água não congelável para farinha de trigo (29 a 32\%), com diferentes conteúdos de água, relatados por Roman-Gutierrez; Guilbert; Cuq (2002).

Análise de variância foi aplicada em todas as misturas, para verificar a influência dos componentes GVH, CSL e PS80 sobre a entalpia dos eventos de congelamento, descongelamento e sobre os valores obtidos de Wg' e Cg'. A ANOVA indicou que os fatores GVH, CSL e PS80 não influenciaram significativamente sobre nenhum dos parâmetros citados. 


\subsection{Primeiro e segundo aquecimentos e ciclo de retrogradação}

A Figura 4.6 é um exemplo de curvas obtidas no primeiro e segundo ciclos de aquecimento e no ciclo de retrogradação.

Os valores dos picos obtidos através do DSC no primeiro e segundo aquecimentos do programa ciclo completo estão apresentados na Tabela 4.11 e do ciclo retrogradação na Tabela 4.12.

Na Tabela 4.11 os valores de entalpia do primeiro pico, $\mathrm{T}_{\text {onset, }} \mathrm{T}_{\text {pico, }} \mathrm{T}_{\text {endset }}$ e os respectivos valores referentes ao segundo pico das misturas 7 a, 8 e 8 a foram discrepantes em relação aos demais.

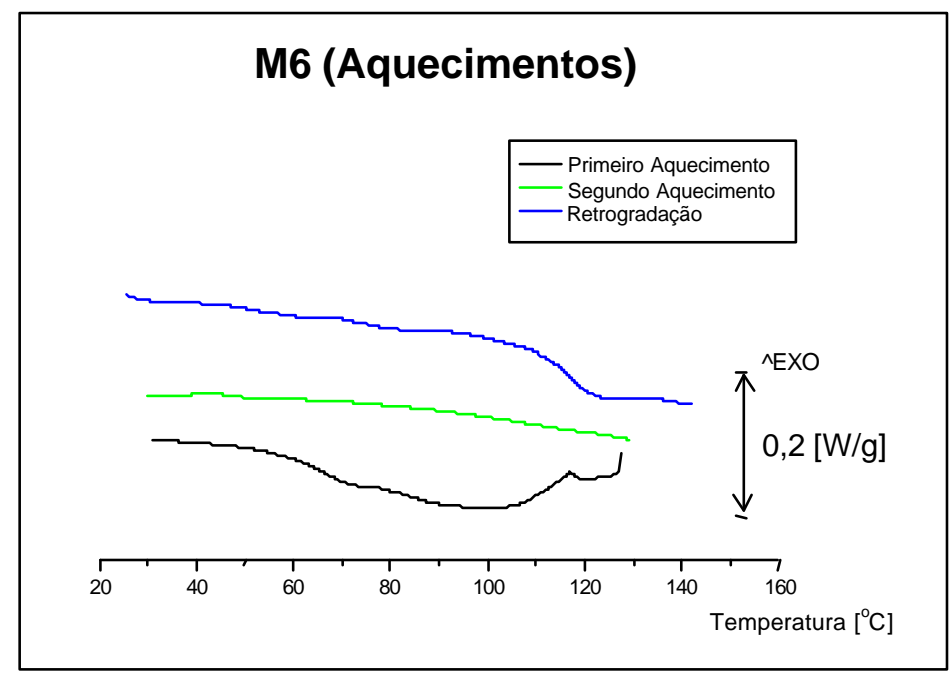

Figura 4.6: Curvas obtidas através do DSC para o primeiro e segundo aquecimentos e ciclo de retrogradação para mistura 6. Dados referentes ao programa ciclo completo. 
Tabela 4.11: Valores obtidos no primeiro e segundo aquecimentos no DSC, programa Ciclo Completo. (Entalpia, $\mathrm{T}_{\text {onset }}, \mathrm{T}_{\text {pico }}$ e $\mathrm{T}_{\text {endset }}$ ).

\begin{tabular}{|l|c|c|c|c|c|c|c|c|c|c|c|}
\hline \multicolumn{10}{|c|}{ PRIMEIRO AQUECIMENTO } \\
\hline \multicolumn{10}{|c|}{ Primeiro Pico } \\
\hline Mistura & $\mathbf{0}$ & $\mathbf{1}$ & $\mathbf{2}$ & $\mathbf{3}$ & $\mathbf{4}$ & $\mathbf{5}$ & $\mathbf{6}$ & $\mathbf{7}$ & $\mathbf{7 a}$ & $\mathbf{8}$ & $\mathbf{8 a}$ \\
\hline $\begin{array}{l}\text { Entalpia } \\
{[\mathrm{J} / \mathrm{g}]}\end{array}$ & $-16,99$ & $-18,79$ & $-14,88$ & $-17,61$ & $-18,81$ & $-21,90$ & $-14,75$ & $-20,03$ & $-4,20$ & $-2,29$ & $-2,69$ \\
\hline $\mathrm{T}_{\text {onset }}\left[{ }^{\circ} \mathrm{C}\right]$ & 56,30 & 55,94 & 59,35 & 55,60 & 57,11 & 55,01 & 58,05 & 57,71 & 39,33 & 35,54 & 46,79 \\
\hline $\mathrm{T}_{\text {pico }}\left[{ }^{\circ} \mathrm{C}\right]$ & 93,12 & 94,52 & 93,23 & 92,79 & 94,92 & 95,42 & 94,49 & 98,24 & 70,57 & 71,13 & 69,81 \\
\hline $\mathrm{T}_{\text {endset }}\left[{ }^{\circ} \mathrm{C}\right]$ & 117,15 & 117,20 & 117,03 & 117,18 & 117,12 & 117,34 & 117,12 & 117,29 & 101,83 & 102,75 & 101,08 \\
\hline & & & & \multicolumn{1}{|c|}{ Segundo Pico } & & & & & \\
\hline $\mathbf{M i s t u r a}$ & $\mathbf{0}$ & $\mathbf{1}$ & $\mathbf{2}$ & $\mathbf{3}$ & $\mathbf{4}$ & $\mathbf{5}$ & $\mathbf{6}$ & $\mathbf{7}$ & $\mathbf{7 a}$ & $\mathbf{8}$ & $\mathbf{8 a}$ \\
\hline $\begin{array}{l}\text { Entalpia } \\
{[\mathrm{J} / \mathrm{g}]}\end{array}$ & $-0,25$ & $-0,17$ & $-0,24$ & $-0,20$ & $-0,28$ & $-0,22$ & $-0,26$ & $-0,25$ & $-0,75$ & $-0,80$ & $-0,78$ \\
\hline $\mathrm{T}_{\text {onset }}\left[{ }^{\circ} \mathrm{C}\right]$ & 117,75 & 118,22 & 117,90 & 117,56 & 117,63 & 117,95 & 117,67 & 117,94 & 106,67 & 107,41 & 107,07 \\
\hline $\mathrm{T}_{\text {pico }}\left[{ }^{\circ} \mathrm{C}\right]$ & 121,11 & 121,03 & 120,85 & 120,78 & 121,05 & 120,94 & 120,81 & 121,07 & 117,25 & 118,98 & 117,32 \\
\hline $\mathrm{T}_{\text {endset }}\left[{ }^{\circ} \mathrm{C}\right]$ & 127,30 & 126,95 & 126,88 & 127,15 & 125,28 & 127,30 & 127,25 & 124,99 & 126,86 & 126,56 & 126,40 \\
\hline
\end{tabular}


Continuação da Tabela 4.11.

\begin{tabular}{|c|c|c|c|c|c|c|c|c|c|c|c|}
\hline \multicolumn{12}{|c|}{ SEGUNDO AQUECIMENTO } \\
\hline \multicolumn{12}{|c|}{ Primeiro Pico } \\
\hline Mistura & $\mathbf{0}$ & $\mathbf{1}$ & 2 & 3 & 4 & 5 & 6 & 7 & $7 \mathbf{a}$ & 8 & $8 \mathbf{8 a}$ \\
\hline $\begin{array}{l}\text { Massa } \\
{[\mathrm{mg}]}\end{array}$ & 30,022 & 25,036 & 27,892 & 28,686 & 22,385 & 22,072 & 28,090 & 20,390 & 19,447 & 19,126 & \\
\hline $\begin{array}{l}\text { Entalpia } \\
{[\mathrm{J} / \mathrm{g}]}\end{array}$ & $-0,19$ & $-0,25$ & 0,03 & $-0,49$ & $-0,16$ & $-0,73$ & $-0,05$ & 0,59 & $-0,15$ & $-0,09$ & \\
\hline $\mathrm{T}_{\text {on set }}\left[{ }^{\circ} \mathrm{C}\right]$ & 49,75 & 46,21 & 41,88 & 44,71 & 43,34 & 44,15 & 45,66 & 43,93 & 39,62 & 36,56 & \\
\hline $\mathrm{T}_{\text {pico }}\left[{ }^{\circ} \mathrm{C}\right]$ & 59,47 & 55,38 & 53,28 & 54,65 & 53,32 & 55,93 & 53,84 & 73,89 & 51,66 & 42,22 & \\
\hline $\mathrm{T}_{\text {end set }}\left[{ }^{\circ} \mathrm{C}\right]$ & 90,39 & 101,85 & 85,48 & 98,54 & 95,43 & 119,04 & 60,09 & 96,88 & 65,93 & 67,43 & \\
\hline \multicolumn{12}{|c|}{ Segundo Pico } \\
\hline Mistura & $\mathbf{0}$ & 1 & 2 & 3 & 4 & 5 & 6 & 7 & $7 \mathbf{a}$ & 8 & $\mathbf{8 a}$ \\
\hline $\begin{array}{l}\text { Entalpia } \\
{[\mathrm{J} / \mathrm{g}]}\end{array}$ & $-0,01$ & 0,05 & $-0,17$ & $-0,13$ & $-0,16$ & $-0,19$ & $-0,05$ & $-0,07$ & $-0,28$ & $-0,36$ & $-1,05$ \\
\hline $\mathrm{T}_{\text {on set }}\left[{ }^{\circ} \mathrm{C}\right]$ & 100,14 & 84,19 & 92,83 & 96,22 & 91,13 & 92,57 & 100,65 & 98,04 & 93,56 & 97,67 & 92,94 \\
\hline $\mathrm{T}_{\text {pico }}\left[{ }^{\circ} \mathrm{C}\right]$ & 107,68 & 95,45 & 115,91 & 113,66 & 114,28 & 112,99 & 116,68 & 112,79 & 109,80 & 114,34 & 110,53 \\
\hline $\mathrm{T}_{\text {end set }}\left[{ }^{\circ} \mathrm{C}\right]$ & 122,35 & 122,36 & 127,40 & 128,06 & 127,55 & 127,68 & 124,52 & 128,27 & 127,27 & 129,40 & 126,87 \\
\hline
\end{tabular}

Espaços vazios: Eventos não encontrados 
Tabela 4.12: Valores obtidos no programa ciclo retrogradação no DSC, programa ciclo completo. (Entalpia, $\mathrm{T}_{\text {onset }}, \mathrm{T}_{\text {pico }}$ e $\mathrm{T}_{\text {endset }}$ ).

\begin{tabular}{|c|c|c|c|c|c|c|c|c|c|c|c|}
\hline \multicolumn{12}{|c|}{ RETROGRADAÇÃO } \\
\hline \multicolumn{12}{|c|}{ Primeiro Pico } \\
\hline Mistura & $\mathbf{0}$ & $\mathbf{1}$ & 2 & 3 & 4 & 5 & 6 & 7 & $7 \mathbf{a}$ & 8 & $\mathbf{8 a}$ \\
\hline \begin{tabular}{|l} 
Entalpia \\
{$[\mathrm{J} / \mathrm{g}]$}
\end{tabular} & $-0,94$ & $-2,12$ & $-0,40$ & $-2,19$ & 0,60 & $-1,61$ & $-0,15$ & $-0,54$ & $-1,71$ & $-0,72$ & $-1,01$ \\
\hline $\mathrm{T}_{\text {on set }}\left[{ }^{\circ} \mathrm{C}\right]$ & 46,13 & 46,15 & 50,67 & 49,04 & 71,58 & 50,50 & 56,27 & 45,36 & 45,94 & 34,15 & 41,09 \\
\hline $\mathrm{T}_{\text {pico }}\left[{ }^{\circ} \mathrm{C}\right]$ & 62,52 & 63,24 & 64,37 & 63,50 & 75,55 & 62,77 & 64,41 & 63,81 & 57,36 & 56,67 & 56,98 \\
\hline $\mathrm{T}_{\text {end set }}\left[{ }^{\circ} \mathrm{C}\right]$ & 83,65 & 98,94 & 97,55 & 96,32 & 78,20 & 93,67 & 70,12 & 75,17 & 71,18 & 77,11 & 75,54 \\
\hline \multicolumn{12}{|c|}{ Segundo Pico } \\
\hline Mistura & $\mathbf{0}$ & 1 & 2 & 3 & 4 & 5 & 6 & 7 & $7 \mathbf{a}$ & 8 & $8 \mathbf{8 a}$ \\
\hline \begin{tabular}{|l} 
Entalpia \\
{$[\mathrm{J} / \mathrm{g}]$}
\end{tabular} & $-1,57$ & & $-0,08$ & & $-0,05$ & $-0,12$ & $-0,24$ & $-0,29$ & & $-0,16$ & $-0,12$ \\
\hline $\mathrm{T}_{\text {on set }}\left[{ }^{\circ} \mathrm{C}\right]$ & 103,29 & & 114,96 & & 114,54 & 100,98 & 77,61 & 75,17 & & 78,86 & 78,55 \\
\hline $\mathrm{T}_{\text {pico }}\left[{ }^{\circ} \mathrm{C}\right]$ & 113,97 & & 115,25 & & 115,26 & 106,76 & 84,86 & 83,94 & & 82,12 & 92,25 \\
\hline $\mathrm{T}_{\text {end set }}\left[{ }^{\circ} \mathrm{C}\right]$ & 147,97 & & 117,62 & & \begin{tabular}{|l|}
119,89 \\
\end{tabular} & 116,34 & 91,84 & 97,27 & & 94,62 & 100,02 \\
\hline \multicolumn{12}{|c|}{ Terceiro Pico } \\
\hline Mistura & $\mathbf{0}$ & 1 & 2 & 3 & 4 & 5 & 6 & 7 & $7 a$ & 8 & $8 \mathbf{a}$ \\
\hline $\begin{array}{l}\text { Entalpia } \\
{[\mathrm{J} / \mathrm{g}]}\end{array}$ & & $-0,57$ & $-0,27$ & $-0,36$ & & $-0,78$ & $-1,19$ & $-0,05$ & $-0,17$ & $-0,23$ & $-0,12$ \\
\hline $\mathrm{T}_{\text {on set }}\left[{ }^{\circ} \mathrm{C}\right]$ & & 118,36 & 126,45 & 113,74 & & 120,36 & 118,93 & 114,56 & 136,17 & 97,38 & 134,35 \\
\hline $\mathrm{T}_{\text {pico }}\left[{ }^{\circ} \mathrm{C}\right]$ & & 133,44 & $\begin{array}{l}134,69 \\
\end{array}$ & 131,84 & & 135,14 & 126,87 & 115,37 & 140,65 & 111,35 & 142,65 \\
\hline $\mathrm{T}_{\text {end set }}\left[{ }^{\circ} \mathrm{C}\right]$ & & 140,65 & 148,31 & 145,65 & & 148,52 & 134,64 & 121,77 & 149,36 & 117,86 & 149,61 \\
\hline
\end{tabular}


Através da análise de variância, foi verificado que a GVH, o CSL e o PS80 influenciaram significativamente, no intervalo de confiança de $95 \%$, confirmada pelo teste de Tukey HSD, as entalpias referentes ao primeiro e segundo picos, do primeiro ciclo de aquecimento do programa ciclo completo (Tabela 4.13 e 4.14). O primeiro pico, provavelmente, indica o evento de gelatinização e fusão de lipídios, que pode ser observado pelas $\mathrm{T}_{\text {onset }}$ e $\mathrm{T}_{\text {pico }}$ e o segundo seria referente à fusão do complexo amilose-lipídio (LE BAIL, 2001).

Tabela 4.13: Resultados da ANOVA aplicada aos valores de entalpia do primeiro pico $(\mathrm{J} / \mathrm{g})$ do primeiro aquecimento, ciclo completo.

\begin{tabular}{|c|c|c|c|c|}
\hline \multirow[t]{2}{*}{ Fator } & \multicolumn{3}{|c|}{ Nível } & \multirow[t]{2}{*}{ DMS } \\
\hline & -1 & $\mathbf{0}$ & 1 & \\
\hline GVH & $-15,745^{a}$ & $-16,526^{a}$ & $-10,141^{b}$ & 4,308 \\
\hline CSL & $-19,431^{\mathrm{a}}$ & $-13,062^{b}$ & $-9,919^{b}$ & 4,308 \\
\hline PS80 & $-17,492^{\mathrm{a}}$ & $-14,213^{\mathrm{ab}}$ & $-10,707^{b}$ & 4,308 \\
\hline
\end{tabular}

Tabela 4.14: Resultados da ANOVA aplicada aos valores de entalpia do segundo pico (J/g) do primeiro aquecimento, ciclo completo.

\begin{tabular}{|c|c|c|c|c|}
\hline \multirow[t]{2}{*}{ Fator } & \multicolumn{3}{|c|}{ Nível } & \multirow[t]{2}{*}{$\mathbf{D M S}^{1}$} \\
\hline & -1 & 0 & 1 & \\
\hline GVH & $-0,234^{b}$ & $-0,402^{\mathrm{ab}}$ & $-0,491^{a}$ & 0,212 \\
\hline CSL & $-0,197^{b}$ & $-0,402^{a b}$ & $-0,527^{\mathrm{a}}$ & 0,212 \\
\hline PS80 & $-0,230^{\mathrm{b}}$ & $-0,374^{\mathrm{ab}}$ & $-0,523^{a}$ & 0,212 \\
\hline
\end{tabular}


No segundo aquecimento do ciclo completo foram observados dois picos, o primeiro, provavelmente, indica os eventos de gelatinização do amido não gelatinizado remanescente do primeiro aquecimento e de fusão de lipídios e o segundo, provavelmente, a fusão do complexo amilose-lipídio que pode ser observado pelas $\mathrm{T}_{\text {onset }}$ e $\mathrm{T}_{\text {pico }}$.

As curvas do ciclo de retrogradação apresentaram três picos que provavelmente indicam os eventos de fusão da amilopectina retrogradada e de lipídios, do complexo amilose-lipídio e da amilose retrogradada respectivamente (LE BAIL, 2001).

Não foi verificada influência significativa dos componentes (GVH, CSL e PS80) referente à fusão do complexo amilose-lipídio, nem ao evento de retrogradação.

\subsubsection{Programa Ciclo Parcial}

O programa ciclo parcial está descrito na Tabela 3.3 e o programa ciclo de retrogradação na Tabela 3.4 .

\subsection{Primeiro e segundo aquecimentos e ciclo de retrogradação}

Os valores dos picos obtidos através do DSC no primeiro e segundo aquecimentos do programa ciclo parcial estão apresentados na Tabela 4.15 e no ciclo retrogradação na Tabela 4.16 .

No primeiro aquecimento foram verificados dois picos que estão relacionados provavelmente aos eventos de gelatinização e fusão de lipídios e de fusão do complexo amilose-lipídio. No segundo aquecimento não foi verificado pico na faixa de temperatura de gelatinização nas diferentes massas, como esperado, pois a gelatinização, não deve aparecer num aquecimento seguido a um outro. $\mathrm{O}$ pico encontrado no segundo aquecimento é provavelmente referente a fusão do complexo amilose-lipídio.

No ciclo de retrogradação foram verificados três picos que provavelmente indicam os eventos de fusão da amilopectina retrogradada e de lipídios, do complexo amilose-lipídio e da amilose retrogradada respectivamente (LE BAIL, 2001). 
Foi aplicada análise de variância nos resultados e verificou-se que o primeiro e o segundo picos do primeiro ciclo de aquecimento e o pico do segundo aquecimento não foram influenciados significativamente por GVH, CSL e PS80. Porém, diferente do ciclo completo, na retrogradação os fatores GVH e CSL influenciaram significativamente no intervalo de confiança de $95 \%$, confirmado pelo teste de Tukey HSD (Tabela 4.17).

Tabela 4.17: Resultados da ANOVA aplicada aos valores de entalpia do primeiro pico do ciclo de retrogradação, ciclo parcial.

\begin{tabular}{lcccc}
\hline Fator & \multicolumn{3}{c}{ Nível } & DMS $^{\mathbf{1}}$ \\
& $\mathbf{- 1}$ & $\mathbf{0}$ & $\mathbf{1}$ & \\
\hline GVH & $-1,587^{\mathrm{ab}}$ & $-2,405^{\mathrm{a}}$ & $-1,180^{\mathrm{b}}$ & 0,823 \\
CSL & $-2,170^{\mathrm{a}}$ & $-1,028^{\mathrm{b}}$ & $-1,974^{\mathrm{ab}}$ & 0,823
\end{tabular}

*Médias com letras iguais na mesma linha, não diferem estatisticamente entre si ao nível de $95 \%$ de confiança.

${ }^{1}$ Diferença mínima significativa.

Comparando os resultados obtidos nos ciclos completos e parciais para o primeiro e o segundo aquecimento, verificou-se que de forma geral os valores para o primeiro pico do primeiro aquecimento foram maiores nos ciclos completos que nos parciais. Quanto a $\mathrm{T}_{\text {onset }}$ do pico relacionado à gelatinização do amido, em geral, não foram observados maiores valores no programa completo em relação ao parcial como mencionado por Autio; Sinda (1992). Esse fato pode estar relacionado à presença de outros componentes na massa além do amido e da água, pois como mostrado por Marchiano et al. (1996), o glúten também apresenta picos no DSC numa faixa de temperatura similar ao da gelatinização. 
Tabela 4.15: Valores obtidos no primeiro e segundo aquecimentos no DSC, programa Ciclo Parcial. (Entalpia, $\mathrm{T}_{\text {onset }}, \mathrm{T}_{\text {pico }}$ e $\mathrm{T}_{\text {endset }}$ ).

\begin{tabular}{|c|c|c|c|c|c|c|c|c|c|}
\hline \multicolumn{10}{|c|}{ PRIMEIRO AQUECIMENTO } \\
\hline \multicolumn{10}{|c|}{ Primeiro Pico } \\
\hline Mistura & $\mathbf{0}$ & 1 & 2 & 3 & 4 & 5 & 6 & 7 & 8 \\
\hline \begin{tabular}{|l|} 
Massa \\
{$[\mathrm{mg}]$}
\end{tabular} & 27,196 & 21,190 & 34,861 & 24,922 & 39,054 & 37,071 & 27,821 & 27,705 & 21,332 \\
\hline $\begin{array}{l}\text { Entalpia } \\
{[\mathrm{J} / \mathrm{g}]}\end{array}$ & $-2,73$ & $-3,04$ & $-3,05$ & $-3,21$ & $-3,62$ & $-3,20$ & $-3,03$ & $-2,80$ & $-3,22$ \\
\hline $\mathrm{T}_{\text {onset }}\left[{ }^{\circ} \mathrm{C}\right]$ & 62,80 & 61,20 & 50,30 & 60,31 & 46,89 & 59,64 & 48,86 & 49,23 & 58,88 \\
\hline $\mathrm{T}_{\text {pico }}\left[{ }^{\circ} \mathrm{C}\right]$ & 75,93 & 73,23 & 72,89 & 71,80 & 71,79 & 73,33 & 71,52 & 69,50 & 70,41 \\
\hline $\mathrm{T}_{\text {endset }}\left[{ }^{\circ} \mathrm{C}\right]$ & 102,07 & 100,55 & 99,75 & 100,38 & 102,06 & 101,12 & 102,33 & 100,59 & 96,78 \\
\hline \multicolumn{10}{|c|}{ Segundo Pico } \\
\hline Mistura & $\mathbf{0}$ & 1 & 2 & 3 & 4 & 5 & 6 & 7 & 8 \\
\hline $\begin{array}{l}\text { Entalpia } \\
{[\mathrm{J} / \mathrm{g}]}\end{array}$ & $-0,26$ & $-0,37$ & $-0,92$ & $-0,49$ & $-0,54$ & $-0,58$ & $-1,28$ & $-0,73$ & $-1,82$ \\
\hline $\mathrm{T}_{\text {onset }}\left[{ }^{\circ} \mathrm{C}\right]$ & 110,61 & 109,93 & 110,02 & 109,11 & 108,81 & 109,14 & 107,77 & 107,81 & 101,06 \\
\hline $\mathrm{T}_{\text {pico }}\left[{ }^{\circ} \mathrm{C}\right]$ & 117,51 & 117,64 & 118,69 & 117,18 & 119,21 & 117,36 & 117,33 & 116,8 & 117,25 \\
\hline $\mathrm{T}_{\text {endset }}\left[{ }^{\circ} \mathrm{C}\right]$ & 124,56 & 125,29 & 125,48 & 125,65 & 124,99 & 125,49 & 125,87 & 125,33 & 125,55 \\
\hline
\end{tabular}


Continuação da Tabela 4.15.

\begin{tabular}{|l|c|c|c|c|c|c|c|c|c|}
\hline \multicolumn{10}{|c|}{ SEGUNDO AQUECIMENTO } \\
\hline Mistura & $\mathbf{0}$ & $\mathbf{1}$ & $\mathbf{2}$ & $\mathbf{3}$ & $\mathbf{4}$ & $\mathbf{5}$ & $\mathbf{6}$ & $\mathbf{7}$ & $\mathbf{8}$ \\
\hline $\begin{array}{l}\text { Entalpia } \\
\mathrm{J} / \mathrm{g}]\end{array}$ & & $-0,17$ & $-0,25$ & $-0,13$ & $-0,03$ & $-0,01$ & $-0,07$ & $-0,07$ & $-0,35$ \\
\hline $\mathrm{T}_{\text {onset }}\left[{ }^{\circ} \mathrm{C}\right]$ & & 50,60 & 101,21 & 95,14 & 103,88 & 115,10 & 107,84 & 104,22 & 95,51 \\
\hline $\mathrm{T}_{\text {pico }}\left[{ }^{\circ} \mathrm{C}\right]$ & & 111,01 & 116,90 & 113,05 & 114,11 & 120,21 & 112,69 & 114,51 & 114,29 \\
\hline $\mathrm{T}_{\text {endset }}\left[{ }^{\circ} \mathrm{C}\right]$ & & 129,64 & 126,75 & 129,51 & 119,56 & 125,60 & 126,37 & 122,42 & 126,65 \\
\hline
\end{tabular}

Espaços vazios: Eventos não encontrados 
Tabela 4.16: Valores obtidos no programa ciclo retrogradação no DSC, programa ciclo parcial. (Entalpia, $\mathrm{T}_{\text {onset }}, \mathrm{T}_{\text {pico }}$ e $\mathrm{T}_{\text {endset }}$ ).

\begin{tabular}{|c|c|c|c|c|c|c|c|c|c|}
\hline \multicolumn{10}{|c|}{ RETROGRADAÇÃO } \\
\hline \multicolumn{10}{|c|}{ Primeiro Pico } \\
\hline Mistura & $\mathbf{0}$ & $\mathbf{1}$ & 2 & 3 & 4 & 5 & 6 & 7 & 8 \\
\hline $\begin{array}{l}\text { Entalpia } \\
{[\mathrm{J} / \mathrm{g}]}\end{array}$ & $-2,22$ & $-1,86$ & $-2,07$ & $-2,38$ & $-1,93$ & $-2,30$ & $-0,34$ & $-0,70$ & $-1,74$ \\
\hline $\mathrm{T}_{\text {onset }}\left[{ }^{\circ} \mathrm{C}\right]$ & 47,15 & 50,95 & 46,25 & 48,03 & 52,10 & 48,78 & 49,03 & 52,79 & 41,08 \\
\hline$\overline{\mathrm{T}_{\text {pico }}\left[{ }^{\mathrm{O}} \mathrm{C}\right]}$ & 62,89 & 63,31 & 65,05 & 62,88 & 66,20 & 63,23 & 62,24 & 63,73 & 57,45 \\
\hline $\mathrm{T}_{\text {endset }}\left[{ }^{\circ} \mathrm{C}\right]$ & 97,90 & 97,30 & 96,97 & 100,39 & 103,97 & 96,87 & 74,40 & 76,43 & 75,94 \\
\hline \multicolumn{10}{|c|}{ Segundo Pico } \\
\hline Mistura & $\mathbf{0}$ & 1 & 2 & 3 & 4 & 5 & 6 & 7 & 8 \\
\hline $\begin{array}{l}\text { Entalpia } \\
{[\mathrm{J} / \mathrm{g}]}\end{array}$ & & & $-0,17$ & & $-0,26$ & $-0,13$ & $-0,15$ & $-0,11$ & $-0,29$ \\
\hline$\overline{\mathrm{T}_{\text {onset }}\left[{ }^{\circ} \mathrm{C}\right]}$ & & & 114,03 & & 120,46 & 104,31 & 76,31 & 82,98 & 95,95 \\
\hline$\overline{\mathrm{T}_{\text {pico }}\left[{ }^{\circ} \mathrm{C}\right]}$ & & & 115,03 & & 123,78 & 112,99 & 83,02 & 88,01 & 109,95 \\
\hline $\mathrm{T}_{\text {endset }}\left[{ }^{\circ} \mathrm{C}\right]$ & & & 118,09 & & 126,50 & 119,50 & 95,94 & 98,40 & 117,90 \\
\hline \multicolumn{10}{|c|}{ Terceiro Pico } \\
\hline Mistura & $\mathbf{0}$ & 1 & 2 & 3 & 4 & 5 & 6 & 7 & 8 \\
\hline $\begin{array}{l}\text { Entalpia } \\
{[\mathrm{J} / \mathrm{g}]}\end{array}$ & $-0,52$ & $-1,46$ & $-0,26$ & $-0,78$ & $-0,08$ & $-0,33$ & $-0,05$ & $-0,04$ & $-0,59$ \\
\hline $\mathrm{T}_{\text {onset }}\left[{ }^{\circ} \mathrm{C}\right]$ & 121,51 & 110,21 & 129,73 & 112,41 & 135,92 & 126,02 & 118,90 & 114,88 & 120,07 \\
\hline $\mathrm{T}_{\text {pico }}\left[{ }^{\circ} \mathrm{C}\right]$ & 134,10 & 123,91 & 141,43 & 132,89 & 143,21 & 134,20 & 120,40 & 115,28 & 136,85 \\
\hline $\mathrm{T}_{\text {endset }}\left[{ }^{\circ} \mathrm{C}\right]$ & 149,20 & 147,43 & 148,45 & 148,18 & 148,80 & 147,72 & 122,60 & 117,92 & 148,62 \\
\hline
\end{tabular}

Espaços vazios: Eventos não encontrados 


\subsection{SEGUNDA ETAPA}

Nesta etapa foi realizado um projeto de mistura modelo cúbico especial com os emulsificantes DATEM, PS80 e CSL. Análise de regressão foi aplicada para ajustar os dados ao modelo cúbico especial utilizando o programa STARGRAPHICS Plus 4.0 for Windows, não sendo considerados os resultados relativos à mistura 0 (sem adição de emulsificantes).

\subsubsection{Parâmetros obtidos das curvas de congelamento}

O processo de congelamento foi conduzido em "freezer" plasma ou na câmara climática, sempre a $-30^{\circ} \mathrm{C}$ e as temperaturas foram registradas (ver Tabela 4.18). As curvas de congelamento estão apresentadas no Anexo B.

Tabela 4.18: Parâmetros obtidos das curvas de congelamento das massas de diferentes misturas.

\begin{tabular}{cccccccc}
\hline Mistura & & $\begin{array}{c}\text { To } \\
\left({ }^{\mathbf{0}} \mathbf{C}\right)\end{array}$ & $\begin{array}{c}\mathbf{T c} \\
\left({ }^{\mathbf{0}} \mathbf{C}\right)\end{array}$ & $\begin{array}{c}\mathbf{t} \\
(\mathbf{m i n})\end{array}$ & $\begin{array}{c}\mathbf{T f} \\
\left({ }^{\mathbf{0}} \mathbf{C}\right)\end{array}$ & $\begin{array}{c}\mathbf{t}_{\mathbf{c}} \\
(\mathbf{m i n})\end{array}$ & $\begin{array}{c}\mathbf{v} \\
\left({ }^{\mathbf{0}} \mathbf{C} / \mathbf{m i n}\right)\end{array}$ \\
\hline 0 & Câmara & 22,0 & $-3,2$ & 60,0 & $-22,5$ & 25,2 & $-1,35$ \\
1 & Plasma & 23,6 & $-3,6$ & 175,3 & $-27,3$ & 53,4 & $-0,83$ \\
\hline 2 & Câmara & 23,2 & $-3,8$ & 85,7 & $-23,2$ & 40,2 & $-1,25$ \\
3 & Plasma & 24,6 & $-3,1$ & 177,0 & $-22,9$ & 64,2 & $-0,82$ \\
4 & Câmara & 24,9 & $-2,4$ & 79,3 & $-18,2$ & 34,8 & $-1,34$ \\
5 & Câmara & 24,6 & $-3,3$ & 70,5 & $-21,9$ & 28,2 & $-1,41$ \\
6 & Câmara & 23,5 & $-3,2$ & 67,3 & $-18,1$ & 29,6 & $-1,37$ \\
7 a & Plasma & 25,0 & $-3,9$ & 175,3 & $-30,0$ & 52,8 & $-0,84$ \\
7 b & Câmara & 24,2 & $-3,3$ & 73,1 & $-23,8$ & 30,9 & $-1,55$ \\
7 c & Câmara & 24,6 & $-3,9$ & 82,8 & $-18,1$ & 37,2 & $-1,25$ \\
\hline
\end{tabular}

To temperatura no início do processo no centro geométrico

Tc temperatura inicial de congelamento no centro geométrico

t tempo total decorrido no processo de congelamento até fim da aquisição

Tf temperatura no final do processo no centro geométrico

$t_{c}$ tempo decorrido na zona crítica, na mudança de fase

$\mathrm{v}$ velocidade de resfriamento entre To e Tc 
O congelamento em "freezer" de plasma apresentou velocidade de resfriamento inferior (média de $-0,84^{\circ} \mathrm{C} / \mathrm{min}$ ) em relação ao realizado em câmara climática (média de $-1,36^{\circ} \mathrm{C} / \mathrm{min}$ ).

A diferença da velocidade de resfriamento encontrada nos dois processos de congelamento utilizados pode provocar alterações nos parâmetros de textura das massas pois com o aumento da velocidade observa-se a perda da resistência à extensão. Porém os valores de velocidade de resfriamento apresentados na Tabela 4.18 estão de acordo com o indicado $\left(<2{ }^{\circ} \mathrm{C} / \mathrm{min}\right)$ por Giannou; Kessoglou; Tzia (2003) para se obter maior sobrevivência de leveduras e maior qualidade do produto final.

\subsubsection{Conteúdo de água}

Os valores médios de conteúdo de água obtidos estão apresentados na Tabela 4.19. Análise de regressão foi aplicada aos resultados para o modelo cúbico especial do projeto de mistura com três componentes (CSL, PS80 e DATEM). O modelo encontrado não foi significativo ao nível de $95 \%$ de confiança. 
Tabela 4.19: Valores médios de conteúdo de água das massas referentes ao projeto de mistura (CSL, PS80 e DATEM).

\begin{tabular}{ccc}
\hline & \multicolumn{2}{c}{ Conteúdo de água (\%) } \\
\hline Mistura & \multicolumn{2}{c}{ Estufa $\mathbf{1 3 0}^{\mathbf{0}} \mathbf{C}$} \\
& Média & $\mathrm{DP}^{1}$ \\
\hline 0 & 44,33 & 0,05 \\
1 & 44,31 & 0,02 \\
2 & 44,19 & 0,05 \\
3 & 44,10 & 0,09 \\
4 & 44,27 & 0,03 \\
5 & 44,09 & 0,02 \\
6 & 44,20 & 0,10 \\
7 a & 44,15 & 0,11 \\
7 b & 44,35 & 0,05 \\
7 c & 44,18 & 0,11 \\
\hline
\end{tabular}

\subsubsection{Textura}

As equações obtidas através da regressão, para os resultados de resistência à extensão e extensibilidade em função do tempo, ajustada para o modelo cúbico especial do projeto de mistura estão apresentados na Tabela 4.20. Nesta etapa, foram realizadas dez medidas de cada determinação da análise de textura. 
Tabela 4.20: Modelos preditivos da resistência à extensão $(\mathrm{N})$ e da extensibilidade $(\mathrm{mm})$ das misturas relativas ao projeto de mistura de três componentes (CSL, PS80 e DATEM), com as variáveis codificadas, ao longo do tempo

\begin{tabular}{|c|c|c|c|}
\hline $\begin{array}{l}\text { Tempo } \\
\text { (dias) }\end{array}$ & Resistência à extensão (N) & $\mathbf{p}$ & $\mathbf{R}^{2}{ }_{\text {aj }}$ \\
\hline 0 & $\begin{array}{l}\mathrm{F}(0)=(0,339 * \mathrm{CSL}+0,382 * \mathrm{PS} 80+0,292 * \mathrm{DATEM}-0,358 * \mathrm{CSL} * \mathrm{PS} 80 \\
+0,473 * \mathrm{PS} 80 * \mathrm{DATEM}-1,535 * \mathrm{CSL} * \mathrm{PS} 80 * \mathrm{DATEM}) \pm 0,023\end{array}$ & 0,0000 & 76,08 \\
\hline 1 & $\begin{array}{l}\mathrm{F}(1)=(0,302 * \text { CSL }+0,412 * \text { PS80+0,323*DATEM-0,155*CSL*PS80 } \\
+0,134 * \text { PS80*DATEM-0,386*CSL*PS80*DATEM }) \pm 0,017\end{array}$ & 0,0067 & 84,09 \\
\hline 7 & $\begin{array}{l}\mathrm{F}(7)=(0,257 * \mathrm{CSL}+0,379 * \text { PS80+0,309*DATEM-0,587*CSL*PS80 } \\
+0,498 * \mathrm{CSL} * \mathrm{DATEM}-1,954 * \text { CSL*PS80*DATEM }) \pm 0,036\end{array}$ & 0,0000 & 68,57 \\
\hline 14 & $\begin{array}{l}\mathrm{F}(14)=(0,351 * \mathrm{CSL}+0,405 * \mathrm{PS} 80+0,311 * \mathrm{DATEM}+0,120 * \mathrm{CSL} * \mathrm{PS} 80- \\
0,237 * \mathrm{CSL} * \mathrm{DATEM}+0,198 * \mathrm{PS} 80 * \text { DATEM- } \\
2,167 * \mathrm{CSL} * \mathrm{PS} 80 * \mathrm{DATEM}) \pm 0,024\end{array}$ & 0,0000 & 84,58 \\
\hline 18 & $\begin{array}{l}\mathrm{F}(18)=(0,267 * \mathrm{CSL}+0,331 * \mathrm{PS} 80+0,387 * \mathrm{DATEM}+0,132 * \mathrm{CSL} * \mathrm{PS} 80 \\
+0,180 * \mathrm{CSL} * \mathrm{DATEM}-0,956 * \text { CSL } * \text { PS80* DATEM }) \pm 0,023\end{array}$ & 0,0000 & 63,02 \\
\hline \multirow[t]{2}{*}{22} & $\begin{array}{l}\mathrm{F}(22)=(0,299 * \mathrm{CSL}+0,436 * \mathrm{PS} 80+0,306 * \mathrm{DATEM}+ \\
0,065 * \mathrm{CSL} * \mathrm{DATEM}-0,591 * \mathrm{CSL} * \mathrm{PS} 80 * \mathrm{DATEM}) \pm 0,014\end{array}$ & 0,0000 & 89,78 \\
\hline & Extensibilidade (mm) & & \\
\hline 0 & $\begin{array}{l}\mathrm{D}(0)=(23,738 * \mathrm{CSL}+23,385 * \mathrm{PS} 80+23,635 * \mathrm{DATEM} \\
+23,683 * \mathrm{CSL} * \mathrm{PS} 80+132,960 * \mathrm{CSL} * \mathrm{PS} 80 * \mathrm{DATEM}) \pm 7,289\end{array}$ & 0,0471 & 12,66 \\
\hline 1 & $\begin{array}{l}\mathrm{D}(1)=(30,907 * \mathrm{CSL}+27,749 * \mathrm{PS} 80+28,355 * \mathrm{DATEM}+21,270 * \mathrm{CSL} * \mathrm{PS} 80 \\
+22,158 * \mathrm{CSL} * \mathrm{DATEM}-121,274 * \mathrm{CSL} * \mathrm{PS} 80 * \mathrm{DATEM}) \pm 3,6171\end{array}$ & 0,0021 & 34,25 \\
\hline 7 & $\begin{array}{l}\mathrm{D}(7)=(38,501 * \mathrm{CSL}+32,595 * \mathrm{PS} 80+25,150 * \mathrm{DATEM}-37,968 * \mathrm{CSL} * \mathrm{PS} 80- \\
10,097 * \mathrm{CSL} * \mathrm{DATEM}+48,561 * \mathrm{CSL} * \mathrm{PS} 80 * \mathrm{DATEM}) \pm 3,361\end{array}$ & 0,1509 & 55,98 \\
\hline 14 & $\begin{array}{l}\mathrm{D}(14)=(29,458 * \mathrm{CSL}+27,024 * \text { PS80+36,152*DATEM- } \\
18,825 * \mathrm{CSL} * \mathrm{PS} 80-19,261 * \mathrm{CSL} * \mathrm{DATEM} \\
+175,883 * \mathrm{CSL} * \mathrm{PS} 80 * \mathrm{DATEM}) \pm 4,350\end{array}$ & 0,0006 & 44,52 \\
\hline 18 & $\begin{array}{l}\mathrm{D}(18)=(41,755 * \mathrm{CSL}+28,415 * \mathrm{PS} 80+19,778 * \mathrm{DATEM}- \\
32,275 * \mathrm{CSL} * \mathrm{PS} 80-43,492 * \mathrm{CSL} * \mathrm{DATEM}-19,432 * \mathrm{PS} 80 * \mathrm{DATEM} \\
+300,885 * \mathrm{CSL} * \mathrm{PS} 80 * \mathrm{DATEM}) \pm 4,871\end{array}$ & 0,0000 & 63,50 \\
\hline 22 & $\begin{array}{l}\mathrm{D}(22)=26,849 * \mathrm{CSL}+25,491 * \mathrm{PS} 80+26,888 * \mathrm{DATEM}+13,752 * \mathrm{CSL} * \mathrm{PS} 80 \\
-8,305 * \mathrm{PS} 80 * \mathrm{DATEM}+34,005 * \mathrm{CSL} * \mathrm{PS} 80 * \mathrm{DATEM}) \pm 3,072\end{array}$ & 0,1842 & 20,39 \\
\hline
\end{tabular}


Todos os modelos para resistência à extensão foram significativos a $95 \%$ de intervalo de confiança o que pode ser observado pelo valor de $\mathrm{p}<0,05$ e pelo coeficiente de determinação $\left(\mathrm{R}^{2} \geq 63 \%\right.$ ajustado para o grau de liberdade) (Tabela 4.20). Porém em relação à extensibilidade os modelos não foram significativos a $95 \%$ de intervalo de confiança e o $\mathrm{R}_{\text {aj }}^{2}$ dos modelos ajustados variou de 12,75 a 63,5 \%. A Figura 4.7 mostra as curvas de contorno da resistência à extensão ao longo do tempo de armazenamento congelado.

Para dar prosseguimento ao trabalho foi necessário verificar a influência da velocidade de resfriamento (em "freezer" de plasma ou em câmara climática) através de análise de variância (ANOVA) e teste de Tukey com intervalo de confiança de $95 \%$ ao longo do tempo de armazenamento congelado (Tabela 4.21). Em relação à velocidade de resfriamento foram encontradas diferenças significativas para resistência à extensão nos tempos 1, 7 e 22 dias de armazenamento congelado.

Foi realizada análise de variância para os valores de resistência à extensão da massa congelada em relação à velocidade de resfriamento ao longo do tempo de armazenamento congelado. Verificou-se que a resistência foi influenciada pela velocidade após 1,7 e 22 dias de armazenamento congelado. Os valores de resistência à extensão foram sempre maiores para massas congeladas em uma velocidade maior indicando, provavelmente, uma maior rigidez da massa. A diferença encontrada pode ser devido a uma mudança estrutural na massa pela migração de água (Tabela 4.21). 
Tabela 4.21: Análise de variância da resistência à extensão em função do tempo de armazenamento congelado e da velocidade de resfriamento.

\begin{tabular}{|c|c|c|}
\hline $\begin{array}{l}\text { Tempo } \\
\text { (dias) }\end{array}$ & $\begin{array}{c}\text { Velocidade de } \\
\text { resfriamento }\left({ }^{\circ} \mathrm{C} / \mathrm{min}\right)\end{array}$ & $\begin{array}{l}\text { Resistência à } \\
\text { extensão }(\mathbf{N})\end{array}$ \\
\hline \multirow[t]{3}{*}{0} & $-0,83$ & $0,309^{\mathrm{a}}$ \\
\hline & $-1,36$ & $0,330^{\mathrm{a}}$ \\
\hline & $\mathrm{DMS}^{1}$ & 0,034 \\
\hline \multirow[t]{3}{*}{1} & $-0,83$ & $0,320^{\mathrm{a}}$ \\
\hline & $-1,36$ & $0,356^{\mathrm{b}}$ \\
\hline & DMS & 0,019 \\
\hline \multirow[t]{3}{*}{7} & $-0,83$ & $0,283^{\mathrm{a}}$ \\
\hline & $-1,36$ & $0,397^{\mathrm{b}}$ \\
\hline & DMS & 0,020 \\
\hline \multirow[t]{3}{*}{14} & $-0,83$ & $0,324^{\mathrm{a}}$ \\
\hline & $-1,36$ & $0,346^{\mathrm{a}}$ \\
\hline & DMS & 0,028 \\
\hline \multirow[t]{3}{*}{18} & $-0,83$ & $0,317^{\mathrm{a}}$ \\
\hline & $-1,36$ & $0,336^{\mathrm{a}}$ \\
\hline & DMS & 0,019 \\
\hline \multirow[t]{3}{*}{22} & $-0,83$ & $0,312^{\mathrm{a}}$ \\
\hline & $-1,36$ & $0,367^{\mathrm{b}}$ \\
\hline & DMS & 0,018 \\
\hline
\end{tabular}

Com base nas equações preditivas para resistência à extensão da massa congelada, foi realizada uma otimização para cada dia de armazenamento congelado (Tabela 4.22 e Figura 4.7), com o objetivo de encontrar a formulação que durante o período de armazenamento congelado até 14 dias apresentasse o máximo valor desse parâmetro.

De acordo com a legislação brasileira, é permitido o uso de emulsificante no máximo de 0,3 \% de PS80, 0,5 \% de DATEM e de CSL em relação a porcentagem de farinha (ANVISA, 1999). Mediante esta restrição e com base nos resultados de 
textura, a mistura de $0,3 \%$ de PS80 e $0,2 \%$ de DATEM foi a indicada para a realização da etapa seguinte deste trabalho.

Foi aplicada ANOVA “one way" para verificar a influência do tempo, nos resultados de resistência à extensão e extensibilidade das misturas, executada no intervalo de confiança de 95\% e confirmada pelo teste de Tukey HSD (Tabelas 4.23 e 4.24).

Tabela 4.22: Formulações para os valores máximos de resistência à extensão para cada dia de armazenamento congelado obtidas através de otimização.

\begin{tabular}{|c|c|c|c|c|c|c|c|}
\hline \multirow[t]{2}{*}{$\begin{array}{c}\text { Tempo } \\
\text { (dia) }\end{array}$} & \multicolumn{3}{|c|}{ Variáveis codificadas } & \multicolumn{3}{|c|}{ Variáveis originais* } & \multirow[t]{2}{*}{$\begin{array}{c}\text { Resistência à } \\
\text { extensão } \\
\text { máxima (N) }\end{array}$} \\
\hline & $\mathbf{x}_{1}$ & $\mathbf{x}_{2}$ & $\mathbf{x}_{3}$ & CLS & PS80 & DATEM & \\
\hline 0 & 0,00 & 0,60 & 0,40 & 0,00 & 0,30 & 0,20 & 0,459 \\
\hline 1 & 0,00 & 0,83 & 0,17 & 0,00 & 0,42 & 0,08 & 0,416 \\
\hline 7 & 0,40 & 0,60 & 0,00 & 0,20 & 0,30 & 0,00 & 0,471 \\
\hline 14 & 0,00 & 0,74 & 0,26 & 0,00 & 0,37 & 0,13 & 0,419 \\
\hline 18 & 0,17 & 0,00 & 0,83 & 0,09 & 0,00 & 0,41 & 0,392 \\
\hline 22 & 0,00 & 1,00 & 0,00 & 0,00 & 0,50 & 0,00 & 0,436 \\
\hline
\end{tabular}

* valores em relação a $100 \%$ de farinha de trigo 

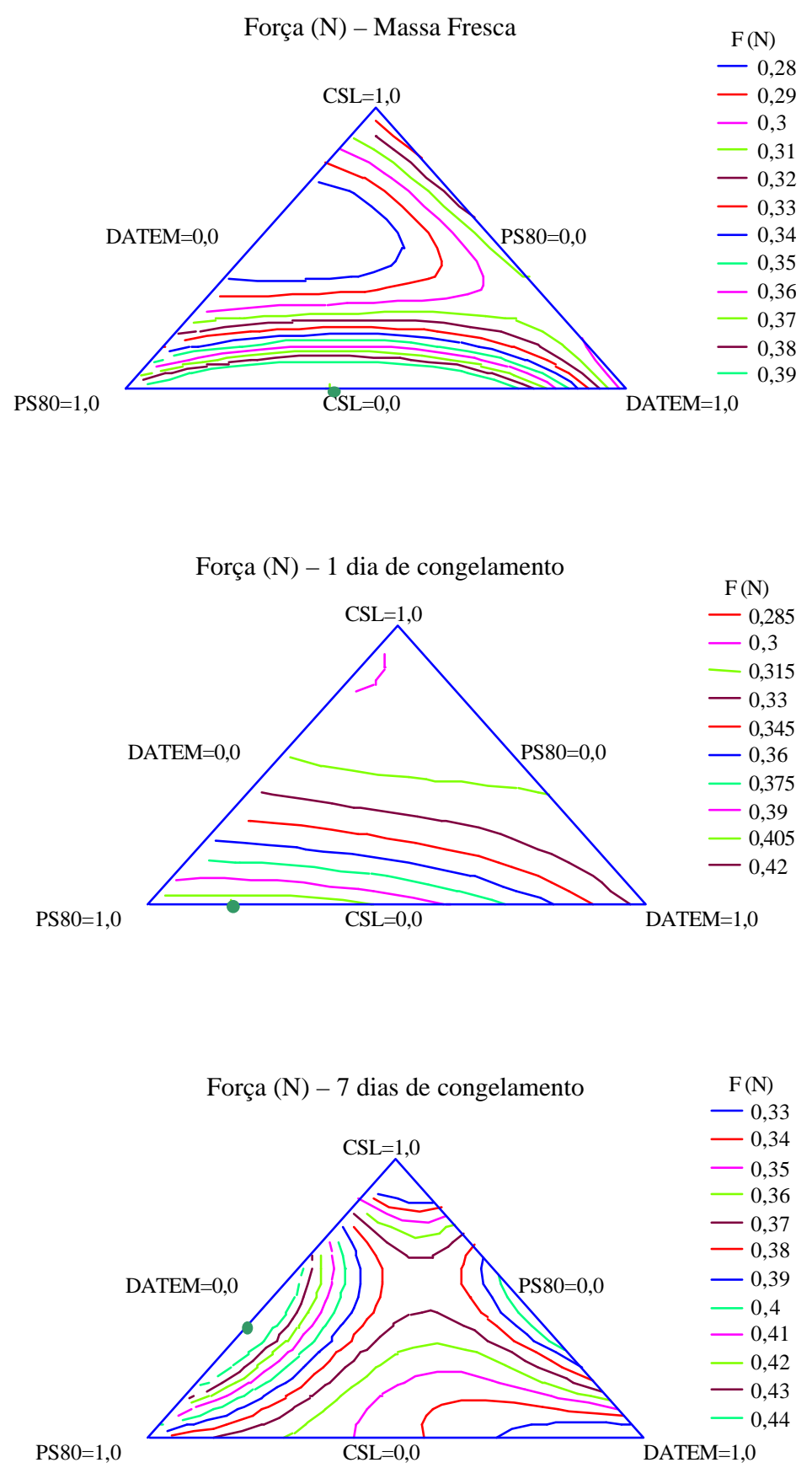

Figura 4.7: Curvas de contorno para projeto de mistura de três emulsificantes (CSL, PS80 e DATEM) para resistência à extensão (Força em N). 

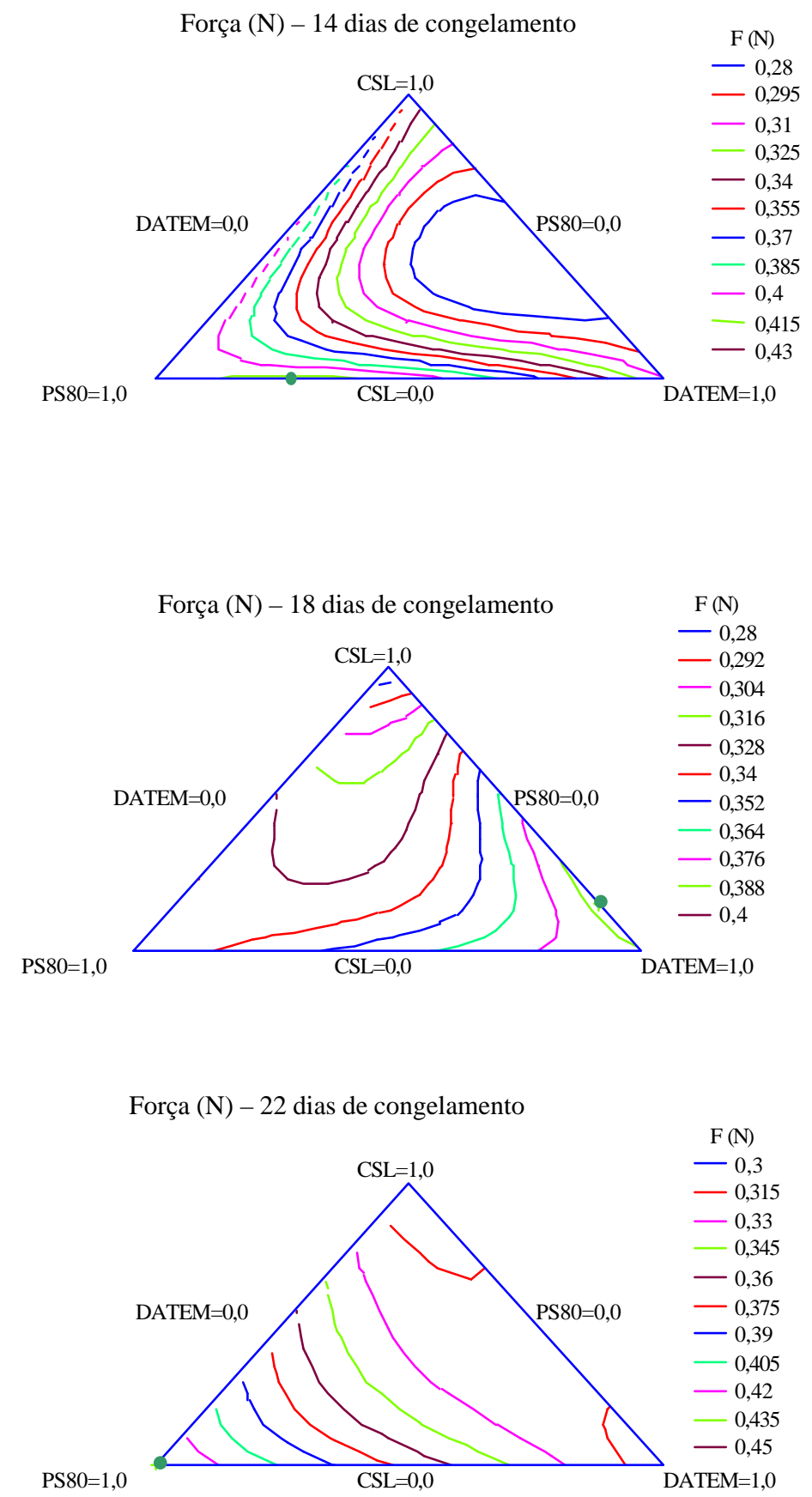

Figura 4.7 (continuação): Curvas de contorno para projeto de mistura de três emulsificantes (CSL, PS80 e DATEM) para resistência à extensão (Força em N). 
Tabela 4.23: Valores de resistência à extensão das massas frescas e congeladas até 22 dias de armazenamento congelado.

\begin{tabular}{|c|c|c|c|c|c|c|c|}
\hline \multicolumn{6}{|c|}{ Resistência à extensão da massa ao longo do tempo de armazenamento } \\
\hline Mistura & $\mathbf{0}$ dias & $\mathbf{1}$ dia & $\mathbf{7}$ dias & $\mathbf{1 4}$ dias & $\mathbf{1 8}$ dias & $\mathbf{2 2}$ dias & DMS \\
\hline 0 & $0,379^{\mathrm{b}}$ & $0,403^{\mathrm{c}}$ & $0,388^{\mathrm{bc}}$ & $0,471^{\mathrm{d}}$ & $0,340^{\mathrm{a}}$ & $0,378^{\mathrm{b}}$ & 0,020 \\
\hline 1 & $0,334^{\mathrm{cd}}$ & $0,306^{\mathrm{bc}}$ & $0,250^{\mathrm{a}}$ & $0,351^{\mathrm{d}}$ & $0,263^{\mathrm{a}}$ & $0,300^{\mathrm{b}}$ & 0,025 \\
\hline 2 & $0,370^{\mathrm{b}}$ & $0,405^{\mathrm{c}}$ & $0,372^{\mathrm{b}}$ & $0,408^{\mathrm{c}}$ & $0,327^{\mathrm{a}}$ & $0,436^{\mathrm{d}}$ & 0,017 \\
\hline 3 & $0,284^{\mathrm{a}}$ & $0,337^{\mathrm{c}}$ & $0,296^{\mathrm{ab}}$ & $0,302^{\mathrm{ab}}$ & $0,382^{\mathrm{d}}$ & $0,317^{\mathrm{bc}}$ & 0,023 \\
\hline 4 & $0,273^{\mathrm{a}}$ & $0,320^{\mathrm{b}}$ & $0,478^{\mathrm{e}}$ & $0,411^{\mathrm{d}}$ & $0,345 \mathrm{~b}^{\mathrm{c}}$ & $0,369^{\mathrm{c}}$ & 0,027 \\
\hline 5 & $0,338^{\mathrm{b}}$ & $0,323^{\mathrm{b}}$ & $0,395^{\mathrm{d}}$ & $0,276^{\mathrm{a}}$ & $0,368^{\mathrm{c}}$ & $0,325^{\mathrm{b}}$ & 0,018 \\
\hline 6 & $0,455^{\mathrm{d}}$ & $0,405^{\mathrm{c}}$ & $0,347^{\mathrm{a}}$ & $0,401^{\mathrm{c}}$ & $0,361^{\mathrm{a}}$ & $0,377^{\mathrm{bc}}$ & 0,027 \\
\hline $7 \mathrm{a}$ & $0,307^{\mathrm{ab}}$ & $0,329^{\mathrm{bc}}$ & $0,294^{\mathrm{a}}$ & $0,303^{\mathrm{a}}$ & $0,332^{\mathrm{c}}$ & $0,331^{\mathrm{c}}$ & 0,022 \\
\hline $7 \mathrm{~b}$ & $0,220^{\mathrm{a}}$ & $0,338^{\mathrm{c}}$ & $0,373^{\mathrm{d}}$ & $0,297^{\mathrm{b}}$ & $0,320^{\mathrm{c}}$ & $0,323^{\mathrm{c}}$ & 0,018 \\
\hline $7 \mathrm{c}$ & $0,325^{\mathrm{bc}}$ & $0,338^{\mathrm{cd}}$ & $0,395^{\mathrm{e}}$ & $0,264^{\mathrm{a}}$ & $0,312^{\mathrm{b}}$ & $0,353^{\mathrm{d}}$ & 0,020 \\
\hline
\end{tabular}

*Médias com letras minúsculas iguais na mesma linha não diferem estatisticamente entre si ao nível de $95 \%$ de confiança 
Tabela 4.24: Valores de extensibilidade das massas frescas e congeladas até 22 dias de acordo com a mistura.

\begin{tabular}{|c|c|c|c|c|c|c|c|}
\hline & \multicolumn{7}{|c|}{ Extensibilidade ao longo do tempo de armazenamento congelado (N) } \\
\hline Mistura & O dias & 1 dia & 7 dias & 14 dias & 18 dias & 22 dias & DMS \\
\hline 0 & $24,422^{b}$ & $25,302^{b}$ & $29,419^{\mathrm{c}}$ & $21,074^{\mathrm{a}}$ & $24,904^{b}$ & $26,672^{\mathrm{bc}}$ & 2,895 \\
\hline 1 & $24,034^{\mathrm{a}}$ & $32,001^{\mathrm{c}}$ & $37,856^{\mathrm{d}}$ & $30,278^{\mathrm{bc}}$ & $41,991^{\mathrm{d}}$ & $27,028^{\mathrm{ab}}$ & 4,030 \\
\hline 2 & $23,719^{\mathrm{a}}$ & $27,108^{b}$ & $31,663^{\mathrm{c}}$ & $26,270^{\mathrm{ab}}$ & $29,255^{b c}$ & $26,201^{\mathrm{ab}}$ & 3,051 \\
\hline 3 & $24,272^{\mathrm{ab}}$ & $29,398^{c}$ & $20,349^{\mathrm{a}}$ & $37,792^{\mathrm{d}}$ & $19,996^{\mathrm{a}}$ & $26,991^{b c}$ & 3,763 \\
\hline 4 & $33,682^{\mathrm{cd}}$ & $34,640^{d}$ & $25,384^{\mathrm{ab}}$ & $22,212^{\mathrm{a}}$ & $24,971^{\mathrm{ab}}$ & $29,482^{\mathrm{bc}}$ & 4,843 \\
\hline 5 & $22,727^{\mathrm{ab}}$ & $36,116^{\mathrm{d}}$ & $28,848^{\mathrm{c}}$ & $28,173^{\mathrm{c}}$ & $20,290^{\mathrm{a}}$ & $25,363^{b c}$ & 3,257 \\
\hline 6 & $22,247^{\mathrm{ab}}$ & $26,376^{\mathrm{cd}}$ & $30,126^{\mathrm{de}}$ & $31,530^{\mathrm{e}}$ & $19,635^{\mathrm{a}}$ & $24,203^{b c}$ & 3,646 \\
\hline $7 a$ & $25,148^{\mathrm{ab}}$ & $23,964^{\mathrm{a}}$ & $28,840^{\mathrm{bc}}$ & $36,532^{d}$ & $37,792^{\mathrm{d}}$ & $31,905^{\mathrm{c}}$ & 4,657 \\
\hline $7 \mathrm{~b}$ & $47,196^{\mathrm{c}}$ & $32,799^{b}$ & $28,568^{\mathrm{a}}$ & $26,501^{\mathrm{a}}$ & $27,516^{\mathrm{a}}$ & $28,702^{\mathrm{a}}$ & 3,172 \\
\hline $7 \mathrm{c}$ & $25,175^{\mathrm{a}}$ & $32,800^{\mathrm{c}}$ & $27,919^{\mathrm{ab}}$ & $29,429^{b c}$ & $26,631^{\mathrm{ab}}$ & $26,439^{\mathrm{ab}}$ & 3,239 \\
\hline
\end{tabular}

*Médias com letras minúsculas iguais na mesma linha não diferem estatisticamente entre si ao nível de $95 \%$ de confiança 


\subsubsection{Análise térmica (Ciclo Completo)}

O programa ciclo completo para a segunda etapa está apresentado na Tabela 3.6 e o programa ciclo de retrogradação na no item 3.3.2.

\subsubsection{Entalpia de congelamento e descongelamento, conteúdo de água} não congelável ( $\mathrm{g} \mathrm{H}_{2} \mathrm{O} / \mathrm{g}$ de sólidos) e concentração de sólidos em Wg' (\%)

A Tabela 4.25 apresenta os valores de entalpia obtidos para os eventos de congelamento (cristalização) e de descongelamento (fusão), os valores de temperatura de "onset" (o início do evento) e de pico obtidos nas curvas da análise térmica, programa ciclo completo para as misturas 0 a $7 \mathrm{c}$.

A velocidade de resfriamento $\left(-3^{\circ} \mathrm{C} / \mathrm{min}\right)$ aplicada na análise térmica foi superior às obtidas nas curvas de congelamento da massa (item 4.2.1).

O conteúdo de água não congelável (Wg') e a concentração de sólidos em Wg' (Cg') calculados a partir das Equações 2.3 e 2.4, estão apresentados na Tabela 4.26.

Tabela 4.26: Conteúdo de água não congelável (Wg') e a concentração de sólidos na água não congelável ( $\mathrm{Cg}^{\prime}$ ) nas massas congeladas referentes ao projeto de mistura.

\begin{tabular}{cccccc}
\hline Mistura & CSL & PS80 & DATEM & $\begin{array}{c}\text { Wg' } \\
\left(\mathbf{g} \mathbf{H}_{2} \mathbf{O} / \mathbf{g} \text { sólidos }\right)\end{array}$ & $\begin{array}{c}\text { Cg' } \\
\text { (\% de sólidos na Wg') }\end{array}$ \\
\hline 0 & 0 & 0 & 0 & 0,332 & 75,06 \\
1 & 0,5 & 0 & 0 & 0,323 & 75,58 \\
2 & 0 & 0,5 & 0 & 0,320 & 75,78 \\
3 & 0 & 0 & 0,5 & 0,335 & 74,89 \\
4 & 0,25 & 0,25 & 0 & 0,326 & 75,42 \\
5 & 0,25 & 0 & 0,25 & 0,310 & 76,35 \\
6 & 0 & 0,25 & 0,25 & 0,310 & 76,35 \\
7 a & 0,167 & 0,167 & 0,167 & 0,338 & 74,74 \\
7 b & 0,167 & 0,167 & 0,167 & 0,332 & 75,07 \\
7 c & 0,167 & 0,167 & 0,167 & 0,318 & 75,87 \\
\hline
\end{tabular}


Tabela 4.25: Valores obtidos para os eventos de congelamento e descongelamento no DSC, programa Ciclo Completo referente ao projeto de mistura (Entalpia, $\mathrm{T}_{\text {onset }}, \mathrm{T}_{\text {pico }}$ e $\mathrm{T}_{\text {endset }}$ ).

\begin{tabular}{|c|c|c|c|c|c|c|c|c|c|c|}
\hline \multicolumn{11}{|c|}{ CICLO COMPLETO } \\
\hline \multicolumn{11}{|c|}{ Congelamento } \\
\hline Mistura & $\mathbf{0}$ & 1 & 2 & 3 & 4 & 5 & 6 & $7 \mathbf{a}$ & $7 \mathrm{~b}$ & $7 \mathrm{c}$ \\
\hline $\begin{array}{l}\text { Massa } \\
{[\mathrm{mg}]}\end{array}$ & 97,957 & 90,441 & 86,801 & 80,577 & 80,435 & 86,124 & 89,342 & 91,350 & 81,766 & 91,693 \\
\hline $\begin{array}{l}\text { Entalpia } \\
{[\mathrm{J} / \mathrm{g}]}\end{array}$ & 82,05 & 82,24 & 82,66 & 82,58 & 80,78 & 82,74 & 82,49 & 80,04 & 79,98 & 80,10 \\
\hline $\mathrm{T}_{\text {onset }}\left[{ }^{\circ} \mathrm{C}\right]$ & $-8,83$ & $-8,76$ & $-8,86$ & $-8,85$ & $-8,34$ & $-8,18$ & $-8,45$ & $-8,19$ & $-8,29$ & $-8,64$ \\
\hline $\mathrm{T}_{\text {pico }}\left[{ }^{\circ} \mathrm{C}\right]$ & $-7,11$ & $-7,28$ & $-7,29$ & $-7,35$ & $-7,19$ & $-6,48$ & $-6,97$ & $-7,19$ & $-7,00$ & $-7,41$ \\
\hline $\mathrm{T}_{\text {endset }}\left[{ }^{\circ} \mathrm{C}\right]$ & $-13,66$ & $-15,21$ & $-14,68$ & $-14,56$ & $-15,00$ & $-14,11$ & $-15,02$ & $-15,38$ & $-14,97$ & $-15,51$ \\
\hline \multicolumn{11}{|c|}{ Descongelamento } \\
\hline Mistura & $\mathbf{0}$ & 1 & 2 & 3 & 4 & 5 & 6 & $7 \mathbf{a}$ & $7 \mathrm{~b}$ & $7 \mathrm{c}$ \\
\hline $\begin{array}{l}\text { Entalpia } \\
{[\mathrm{J} / \mathrm{g}]}\end{array}$ & $-86,27$ & $-87,89$ & $-88,01$ & $-84,70$ & $|-87,20|$ & $-89,40$ & $-89,90$ & $-84,41$ & $-86,40$ & $-88,27$ \\
\hline $\mathrm{T}_{\text {onset }}\left[{ }^{\circ} \mathrm{C}\right]$ & $-6,80$ & $-6,89$ & $-6,73$ & $-6,80$ & $-6,46$ & $-6,69$ & $-6,83$ & $-6,69$ & $-6,40$ & $-6,17$ \\
\hline $\mathrm{T}_{\text {pico }}\left[{ }^{\circ} \mathrm{C}\right]$ & 0,52 & 0,39 & 0,21 & $-0,051$ & 0,74 & 0,22 & 0,25 & 0,80 & 0,79 & 0,89 \\
\hline $\mathrm{T}_{\text {endset }}\left[{ }^{\circ} \mathrm{C}\right]$ & 6,42 & 5,67 & 5,30 & 4,95 & 5,98 & 5,24 & 5,89 & 6,08 & 6,14 & 6,20 \\
\hline
\end{tabular}




\subsubsection{Primeiro e segundo aquecimentos e ciclo de retrogradação}

Os valores dos picos obtidos através do DSC no primeiro e segundo aquecimentos do programa ciclo completo estão apresentados na Tabela 4.27 e do ciclo retrogradação na Tabela 4.28.

No primeiro aquecimento foi observado apenas um pico para a maioria das misturas, com exceção da 7 a. Este pico, provavelmente, está relacionado à fusão de lipídios e ao evento de gelatinização. No segundo aquecimento, foi observado um pico que pode corresponder à fusão do complexo amilose-lipídio como pode ser observado pelas $\mathrm{T}_{\text {onset }}$ e $\mathrm{T}_{\text {pico }}$ (LE BAIL, 2001).

No ciclo de retrogradação, foram observados dois picos. O primeiro, provavelmente, está relacionado à fusão da amilopectina retrogradada e à fusão de lipídios e o segundo à fusão do complexo amilose-lipídio e à fusão da amilose retrogradada.

\subsubsection{Ajuste dos resultados na análise térmica ao modelo cúbico} especial.

Análise de regressão foi aplicada aos resultados obtidos dos eventos de congelamento e descongelamento, primeiro e segundo aquecimentos e ciclo de retrogradação.

A Tabela 4.29 apresenta as equações obtidas da análise de regressão após eliminação dos coeficientes não significativos. 
Tabela 4.27: Valores obtidos no primeiro e segundo aquecimentos no DSC, programa Ciclo Completo. (Entalpia, $\mathrm{T}_{\text {onset }}, \mathrm{T}_{\text {pico }}$ e $\mathrm{T}_{\text {endset }}$ ).

\begin{tabular}{|c|c|c|c|c|c|c|c|c|c|c|}
\hline \multicolumn{11}{|c|}{ PRIMEIRO AQUECIMENTO } \\
\hline \multicolumn{11}{|c|}{ Primeiro Pico } \\
\hline Mistura & $\mathbf{0}$ & 1 & 2 & 3 & 4 & 5 & 6 & $7 \mathbf{a}$ & $7 \mathbf{b}$ & $7 \mathrm{c}$ \\
\hline $\begin{array}{l}\text { Entalpia } \\
{[\mathrm{J} / \mathrm{g}]}\end{array}$ & $-1,81$ & $-2,13$ & $-1,93$ & $-1,81$ & $-1,77$ & $-2,14$ & $-1,63$ & $-1,69$ & $-0,44$ & $-1,57$ \\
\hline $\mathrm{T}_{\text {onset }}\left[{ }^{\circ} \mathrm{C}\right]$ & 61,39 & 61,39 & 61,04 & 62,69 & 62,06 & 61,99 & 62,72 & 62,12 & 60,10 & 63,76 \\
\hline $\mathrm{T}_{\text {pico }}\left[{ }^{\circ} \mathrm{C}\right]$ & 77,63 & 74,14 & 74,97 & 75,12 & 74,27 & 73,78 & 76,25 & 74,68 & 74,28 & $\overline{74,43}$ \\
\hline $\mathrm{T}_{\text {endset }}\left[{ }^{\circ} \mathrm{C}\right]$ & 95,54 & 95,55 & 95,73 & 95,79 & 95,72 & 95,54 & 95,72 & 95,84 & 86,50 & 94,27 \\
\hline \multicolumn{11}{|c|}{ Segundo Pico } \\
\hline Mistura & $\mathbf{0}$ & 1 & 2 & 3 & 4 & 5 & 6 & $7 \mathbf{a}$ & $7 \mathrm{~b}$ & $7 \mathrm{c}$ \\
\hline $\begin{array}{l}\text { Entalpia } \\
{[\mathrm{J} / \mathrm{g}]}\end{array}$ & & & & & & & & & $-0,22$ & \\
\hline $\mathrm{T}_{\text {onset }}\left[{ }^{\circ} \mathrm{C}\right]$ & & & & & & & & & 86,56 & \\
\hline $\mathrm{T}_{\text {pico }}\left[{ }^{\circ} \mathrm{C}\right]$ & & & & & & & & & 89,49 & \\
\hline $\mathrm{T}_{\text {endset }}\left[{ }^{\circ} \mathrm{C}\right]$ & & & & & & & & & 95,66 & \\
\hline
\end{tabular}

Espaços vazios: Eventos não encontrados 
Continuação da Tabela 4.27.

\begin{tabular}{|c|c|c|c|c|c|c|c|c|c|c|}
\hline \multicolumn{11}{|c|}{ SEGUNDO AQUECIMENTO } \\
\hline \multicolumn{11}{|c|}{ Primeiro Pico } \\
\hline Mistura & $\mathbf{0}$ & 1 & 2 & 3 & 4 & 5 & 6 & $7 \mathbf{a}$ & $7 \mathrm{~b}$ & $7 \mathrm{c}$ \\
\hline $\begin{array}{l}\text { Massa } \\
{[\mathrm{mg}]}\end{array}$ & 97,957 & 90,441 & 86,801 & 80,577 & 80,435 & 86,124 & 89,342 & 91,350 & 81,766 & 91,693 \\
\hline \begin{tabular}{|l|} 
Entalpia \\
{$[\mathrm{J} / \mathrm{g}]$} \\
\end{tabular} & $-0,59$ & $-0,83$ & $-0,78$ & $-0,75$ & $-0,71$ & $-0,99$ & $-0,69$ & $-0,58$ & $-0,79$ & $-0,63$ \\
\hline $\mathrm{T}_{\text {onset }}\left[{ }^{\circ} \mathrm{C}\right]$ & 104,51 & 107,00 & 104,36 & 104,50 & 106,77 & 104,79 & 104,37 & 107,05 & 105,58 & 106,79 \\
\hline $\mathrm{T}_{\text {pico }}\left[{ }^{\circ} \mathrm{C}\right]$ & 116,98 & 118,45 & 116,97 & 117,50 & 118,50 & 117,81 & 117,43 & 116,67 & 117,81 & 118,46 \\
\hline $\mathrm{T}_{\text {endset }}\left[{ }^{\circ} \mathrm{C}\right]$ & 125,73 & 125,92 & 125,85 & 126,16 & 125,81 & 125,52 & 126,01 & 125,99 & 126,09 & 125,87 \\
\hline
\end{tabular}


Tabela 4.28: Valores obtidos no Programa Ciclo Retrogradação no DSC, programa ciclo completo. (Entalpia, $\mathrm{T}_{\text {onset }}, \mathrm{T}_{\text {pico }} \mathrm{e} \mathrm{T}_{\text {endset }}$ ).

\begin{tabular}{|c|c|c|c|c|c|c|c|c|c|c|}
\hline \multicolumn{11}{|c|}{ RETROGRADAÇÃO } \\
\hline \multicolumn{11}{|c|}{ Primeiro Pico } \\
\hline Mistura & $\mathbf{0}$ & 1 & 2 & 3 & 4 & 5 & 6 & $7 \mathbf{a}$ & $7 \mathrm{~b}$ & $7 \mathrm{c}$ \\
\hline \begin{tabular}{|l} 
Entalpia \\
{$[\mathrm{J} / \mathrm{g}]$}
\end{tabular} & $-1,27$ & $-0,69$ & $-1,38$ & $-1,26$ & $-0,90$ & $-0,56$ & $-1,27$ & $-1,60$ & $-1,16$ & $-1,34$ \\
\hline $\mathrm{T}_{\text {onset }}\left[{ }^{\circ} \mathrm{C}\right]$ & 52,80 & 55,14 & 51,17 & 52,09 & 51,57 & 41,36 & 51,86 & 50,41 & 51,15 & 51,28 \\
\hline $\mathrm{T}_{\text {pico }}\left[{ }^{\mathrm{O}} \mathrm{C}\right]$ & 64,52 & 63,92 & 63,50 & 61,74 & 62,91 & 43,78 & 64,25 & 62,70 & 61,10 & 61,83 \\
\hline $\mathrm{T}_{\text {endset }}\left[{ }^{\circ} \mathrm{C}\right]$ & 82,08 & \begin{tabular}{|l|}
76,87 \\
\end{tabular} & 80,35 & 75,10 & 78,13 & 50,09 & 78,64 & 78,58 & 74,29 & 76,97 \\
\hline \multicolumn{11}{|c|}{ Segundo Pico } \\
\hline Mistura & $\mathbf{0}$ & 1 & 2 & 3 & 4 & 5 & 6 & $7 \mathbf{a}$ & $7 \mathrm{~b}$ & $7 \mathrm{c}$ \\
\hline \begin{tabular}{|l} 
Entalpia \\
{$[\mathrm{J} / \mathrm{g}]$}
\end{tabular} & $-0,40$ & $-0,84$ & $-0,86$ & $-0,80$ & $-1,02$ & $-0,74$ & $-0,56$ & $-0,94$ & $-1,15$ & $-1,02$ \\
\hline $\mathrm{T}_{\text {onset }}\left[{ }^{\circ} \mathrm{C}\right]$ & 107,13 & 105,2 & 102,75 & 103,80 & 100,27 & 52,99 & 102,20 & 103,72 & 101,31 & 103,69 \\
\hline $\mathrm{T}_{\text {pico }}\left[{ }^{\circ} \mathrm{C}\right]$ & 118,76 & 116,32 & 118,26 & 119,30 & 115,81 & 63,60 & 117,66 & 117,06 & 116,30 & 117,47 \\
\hline $\mathrm{T}_{\text {endset }}\left[{ }^{\circ} \mathrm{C}\right]$ & 127,48 & 124,79 & 129,84 & 127,60 & 126,17 & 81,47 & 125,90 & 127,18 & 126,65 & 127,89 \\
\hline \multicolumn{11}{|c|}{ Terceiro Pico } \\
\hline Mistura & $\mathbf{0}$ & 1 & 2 & 3 & 4 & 5 & 6 & $7 \mathbf{a}$ & $7 \mathrm{~b}$ & $7 \mathrm{c}$ \\
\hline \begin{tabular}{|l} 
Entalpia \\
{$[\mathrm{J} / \mathrm{g}]$} \\
\end{tabular} & & & & & & $-1,73$ & & & & \\
\hline $\mathrm{T}_{\text {onset }}\left[{ }^{\circ} \mathrm{C}\right]$ & & & & & & 111,15 & & & & \\
\hline $\mathrm{T}_{\text {pico }}\left[{ }^{\circ} \mathrm{C}\right]$ & & & & & & 122,81 & & & & \\
\hline $\mathrm{T}_{\text {endset }}\left[{ }^{\circ} \mathrm{C}\right]$ & & & & & & 133,96 & & & & \\
\hline
\end{tabular}

Espaços vazios: Eventos não encontrados 
Tabela 4.29: Equações preditivas obtidas para os eventos estudados na análise térmica.

\begin{tabular}{|c|c|c|c|}
\hline Evento & Equações preditivas & $\mathbf{p}$ & $\mathbf{R}_{\text {aj }}^{2}$ \\
\hline Congelamento & $\begin{array}{l}\Delta \mathrm{H}_{\text {Cong }}=82,24 * \mathrm{CSL}+82,62 * \mathrm{PS} 80+82,54 * \text { DATEM- } \\
6,59 * \mathrm{CSL} * \mathrm{PS} 80+1,38 * \mathrm{CSL} * \text { DATEM- } \\
49,87 * \mathrm{CSL} * \mathrm{PS} 80 * \mathrm{DATEM}\end{array}$ & 0,0009 & 99,60 \\
\hline Descongelamento & $\begin{array}{l}\Delta \mathrm{H}_{\text {Descong }}=-87,64 * \mathrm{CSL}-87,76 * \text { PS80-84,70*DATEM- } \\
12,93 * \mathrm{CSL} * \text { DATEM-14,67*PS80*DATEM } \\
+91,92 * \mathrm{CSL} * \text { PS } 80 * \text { DATEM }\end{array}$ & 0,2411 & 27,49 \\
\hline Wg' & $\begin{array}{l}\Delta \mathrm{H}_{\mathrm{Wg}}=0,32 * \mathrm{CSL}+0,32 * \mathrm{PS} 80+0,34 * \mathrm{DATEM}- \\
0,08 * \mathrm{CSL} * \mathrm{DATEM}-0,07 * \mathrm{PS} 80 * \mathrm{DATEM} \\
+0,53 * \mathrm{CSL} * \mathrm{PS} 80 * \mathrm{DATEM}\end{array}$ & 0,2194 & 29,34 \\
\hline $\mathrm{Cg}^{\prime}$ & $\begin{array}{l}\Delta \mathrm{H}_{\mathrm{Cg}}=75,49 * \mathrm{CSL}+75,69 * \mathrm{PS} 80+74,89 * \mathrm{DATEM}+ \\
4,61 * \mathrm{CSL} * \mathrm{DATEM}+4,23 * \mathrm{PS} 80 * \mathrm{DATEM}- \\
30,10 * \mathrm{CAL} * \mathrm{PS} 80 * \mathrm{DATEM}\end{array}$ & 0,2170 & 30,15 \\
\hline $\begin{array}{l}1^{\circ} \text { pico do primeiro } \\
\text { aquecimento }\end{array}$ & $\begin{array}{l}\Delta \mathrm{H}=-2,13 * \mathrm{CSL}-1,93 * \mathrm{PS} 80-1,81 * \text { DATEM } \\
+1,03 * \mathrm{CSL} * \mathrm{PS} 80-0,68 * \mathrm{CSL} * \mathrm{DATEM} \\
+0,98 * \mathrm{PS} 80 * \mathrm{DATEM}+4,84 * \mathrm{CSL} * \mathrm{PS} 80 * \mathrm{DATEM}\end{array}$ & 0,3049 & 83,54 \\
\hline $\begin{array}{l}1^{\circ} \text { pico do segundo } \\
\text { aquecimento }\end{array}$ & $\begin{array}{l}\Delta \mathrm{H}=-0,83 * \mathrm{CSL}-0,78 * \mathrm{PS} 80-0,75 * \mathrm{DATEM} \\
+0,35 * \mathrm{CSL} * \mathrm{PS} 80-0,79 * \mathrm{CSL} * \mathrm{DATEM} \\
+0,30 * \mathrm{PS} 80 * \mathrm{DATEM}+2,37 * \mathrm{CSL} * \mathrm{PS} 80 * \text { DATEM }\end{array}$ & 0,6038 & 0,00 \\
\hline $\begin{array}{l}1^{\circ} \text { pico do ciclo de } \\
\text { retrogradação }\end{array}$ & $\begin{array}{l}\Delta \mathrm{H}=-0,65 * \text { CSL-1,33*PS80-1,25*DATEM } \\
+0,84 * \text { CSL*DATEM-10,26*CSL*PS80*DATEM }\end{array}$ & 0,1765 & 71,21 \\
\hline $\begin{array}{l}2^{\circ} \text { pico do ciclo de } \\
\text { retrogradação }\end{array}$ & $\begin{array}{l}\Delta \mathrm{H}=-0,89 * \mathrm{CSL}-0,91 * \mathrm{PS} 80-0,81 * \text { DATEM- } \\
3,30 * \mathrm{CSL} * \mathrm{DATEM}+1,42 * \mathrm{PS} 80 * \text { DATEM }\end{array}$ & 0,2771 & 87,52 \\
\hline
\end{tabular}

As equações obtidas apresentadas na Tabela 4.29, com exceção a de entalpia de congelamento, não foram significativos no intervalo de $95 \%$ de confiança. Portanto para dar prosseguimento à Etapa III levou-se consideração apenas a análise de textura. A Figura 4.8 mostra as curvas de contorno para projeto de mistura de três emulsificantes (CSL, PS80 e DATEM) para entalpia de congelamento. 


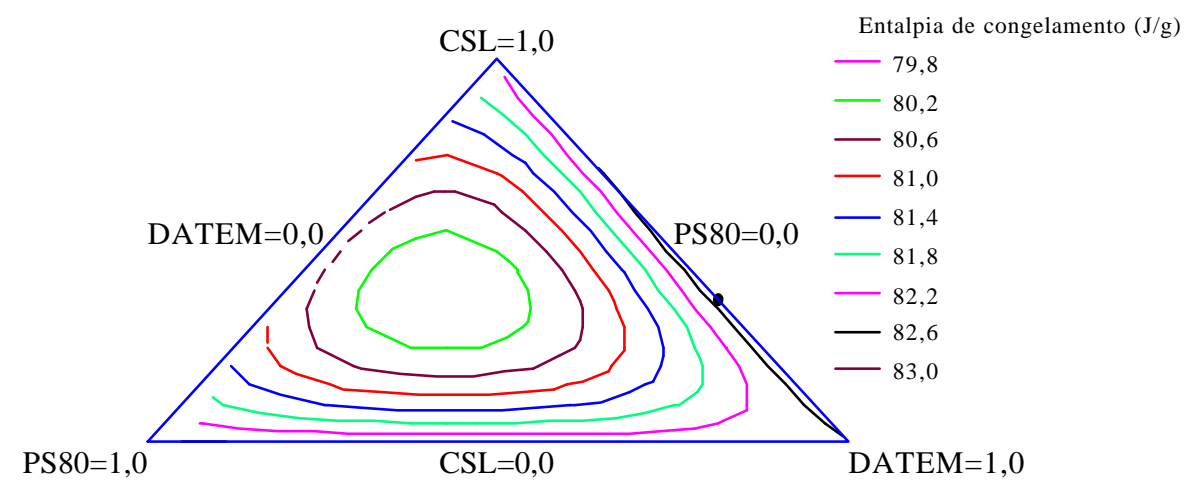

Figura 4.8: Curvas de contorno para projeto de mistura de três emulsificantes (CSL, PS80 e DATEM) para Entalpia de congelamento (J/g). 


\subsection{TERCEIRA ETAPA}

\subsubsection{Parâmetros obtidos na curvas de congelamento}

Massas produzidas da mistura ( $0,3 \%$ de PS80 e 0,2 \% de DATEM) e com adição de ácido ascórbico em quatro níveis (0, 100, 200 e 300 ppm) foram congeladas na câmara climática a $-30^{\circ} \mathrm{C}$. Os parâmetros obtidos das curvas de congelamento estão apresentados na Tabela 4.30 e as curvas de congelamento estão apresentadas no Anexo B.

Tabela 4.30: Parâmetros obtidos nas curvas de congelamento das massas produzidas da mistura (0,3\% de PS80 e 0,2 \% de DATEM) acrescidas em 4 níveis de ácido ascórbico (0, 100, 200 e 300 ppm).

\begin{tabular}{ccccccc}
\hline $\begin{array}{c}\text { Ácido } \\
\text { ascórbico } \\
(\mathbf{p p m})\end{array}$ & $\begin{array}{c}\mathbf{T o} \\
\left({ }^{\mathbf{0}} \mathbf{C}\right)\end{array}$ & $\begin{array}{c}\mathbf{T c} \\
\left({ }^{\mathbf{0}} \mathbf{C}\right)\end{array}$ & $\begin{array}{c}\mathbf{t} \\
(\mathbf{m i n})\end{array}$ & $\begin{array}{c}\mathbf{T f} \\
\left({ }^{\mathbf{0}} \mathbf{C}\right)\end{array}$ & $\begin{array}{c}\mathbf{t}_{\mathbf{c}} \\
(\mathbf{m i n})\end{array}$ & $\begin{array}{c}\mathbf{v} \\
\left({ }^{\mathbf{0}} \mathbf{C} / \mathbf{m i n}\right)\end{array}$ \\
\hline 0 & & & & & & \\
100 & 27,4 & $-4,0$ & 54,8 & $-21,3$ & 21,6 & $-1,67$ \\
200 & 26,6 & $-4,4$ & 65,4 & $-21,9$ & 25,2 & $-1,57$ \\
300 & 26,3 & $-3,8$ & 61,3 & $-21,3$ & 21,0 & $-1,61$ \\
& 26,9 & $-3,8$ & 68,0 & $-20,0$ & 26,3 & $-1,50$ \\
\hline
\end{tabular}

To temperatura no início do processo no centro geométrico

Tc temperatura inicial de congelamento no centro geométrico

$\mathrm{t}$ tempo total decorrido no processo de congelamento até fim da aquisição

Tf temperatura no final do processo no centro geométrico

$\mathrm{t}_{\mathrm{c}}$ tempo decorrido na zona crítica, na mudança de fase

$\mathrm{v}$ velocidade de resfriamento entre To e Tc

\subsubsection{Conteúdo de água}

Os valores obtidos para o conteúdo de água da mistura $(0,3 \%$ de PS80 e 0,2 \% de DATEM) com diferentes níveis de ácido ascórbico estão apresentadas na Tabela 4.31. Análise de variância mostrou que o ácido ascórbico não influenciou o conteúdo de água no intervalo de confiança de 95\%, como esperado, pois a 
quantidade utilizada de ácido ascórbico é muito menor que as dos outros componentes da massa.

Tabela 4.31: Valores médios do conteúdo de água das massas referentes à mistura (0,3 \% de PS80 e 0,2 \% de DATEM) com adição de ácido ascórbico $(0,100,200$ e $300 \mathrm{ppm})$

\begin{tabular}{ccc}
\hline & \multicolumn{2}{c}{ Conteúdo de água (\%) } \\
\hline Ácido ascórbico $(\mathbf{p p m})$ & \multicolumn{2}{c}{ Estufa $\mathbf{1 3 0}^{\mathbf{0}} \mathbf{C}$} \\
& Média & $\mathrm{DP}^{1}$ \\
\hline 0 & 44,27 & 0,04 \\
100 & 44,18 & 0,13 \\
200 & 44,17 & 0,06 \\
300 & 44,19 & 0,05 \\
\hline${ }^{1} \mathrm{DP}-$ Desvio Padrão & &
\end{tabular}

\subsubsection{Textura}

As Figuras 4.9 e 4.10 mostram o comportamento das massas da mistura (0,3 \% de PS80 e 0,2 \% de DATEM) com diferentes níveis de adição de ácido ascórbico em relação aos parâmetros de textura (resistência à extensão e extensibilidade) em função do tempo de armazenamento congelado.

A resistência à extensão aumentou enquanto que a extensibilidade diminuiu com o aumento da quantidade adicionada de ácido ascórbico, como esperado, pois o ácido ascórbico sendo um agente oxidante fortalece a rede de glúten através de criação de pontes dissulfídicas (NAKAMURA; KURATA, 1997). Entretanto, observa-se que o armazenamento congelado causou um declínio na resistência à extensão e um aumento na extensibilidade. Este efeito pode ser melhor visualizado na Figura 4.10. Análise de variância (ANOVA) e teste de Tukey HSD com intervalo de confiança de $95 \%$, foram aplicados nos resultados e não foi verificada uma tendência para a resistência à extensão e extensibilidade, entretanto observou-se que 
a resistência à extensão diminuiu com o tempo de armazenamento congelado e que a massa fresca possui comportamento diferenciado dos demais dias de análise.

Na Figura 4.9 também pode ser observado que a adição de ácido ascórbico à mistura $(0,3 \%$ de PS80 e 0,2 \% de DATEM) causa um aumento da resistência à extensão até o nível de adição de 200 ppm. Efeito oposto ocorre com a extensibilidade da massa, ou seja, até o nível de adição de 200 ppm ocorre uma diminuição desse parâmetro. A massa com a mistura (0,3 \% de PS80, 0,2 \% de DATEM) selecionada na Etapa II desse trabalho com adição de 200 ppm de ácido ascórbico foi selecionada então para prosseguir na Etapa IV, produzindo pães de massa congelada.

As perdas das propriedades reológicas da massa congelada durante o armazenamento congelado, pelo período de três semanas, foram minimizadas pela adição de ácido ascórbico (10 e $20 \mu \mathrm{g} / \mathrm{g}$ ) (ABD EL-HADY; EL-SAMAHY; BRÜMMER, 1999).
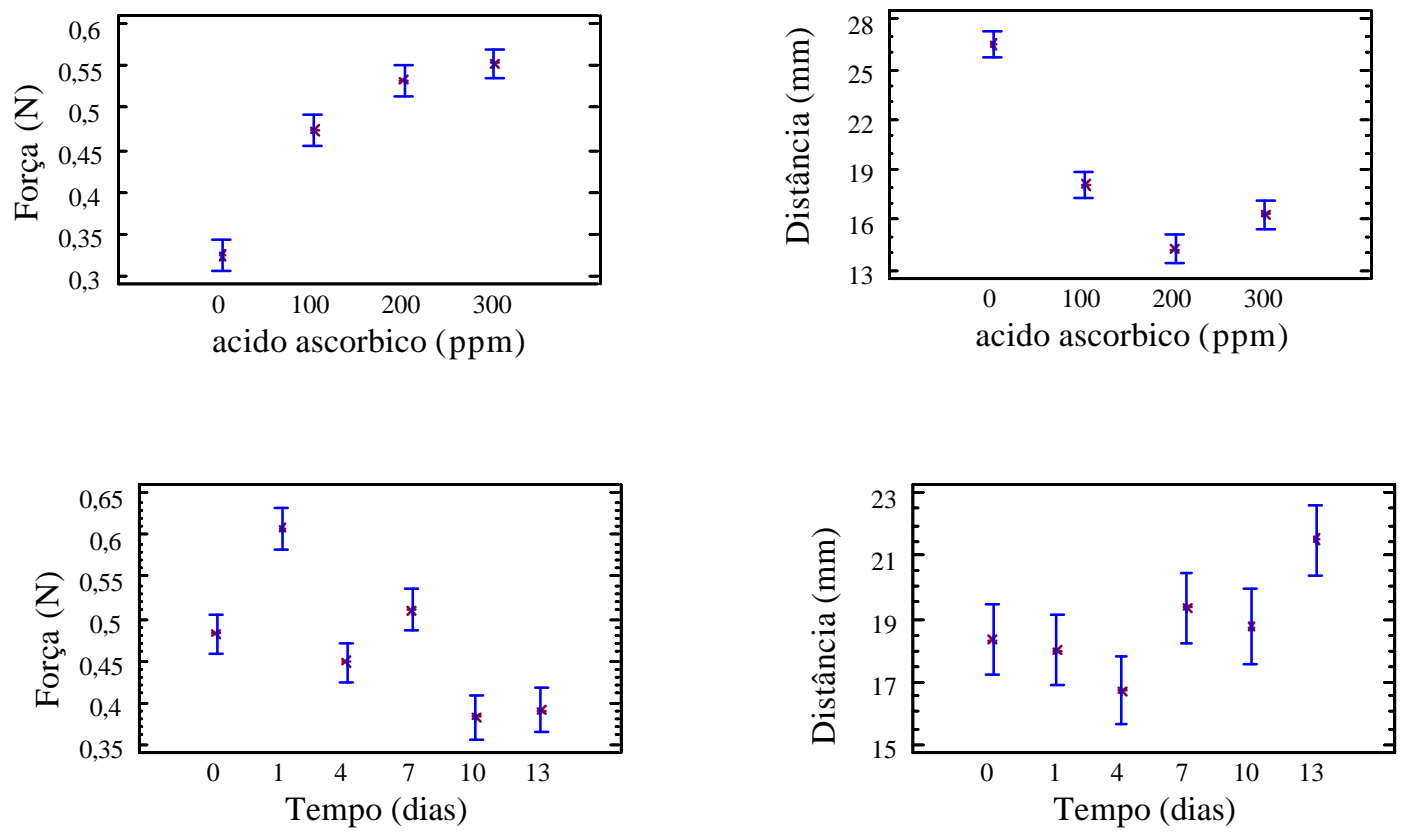

Figura 4.9: Resistência à extensão (Força em N) e extensibilidade (Distância em mm) da mistura $(0,3 \%$ de PS80 e $0,2 \%$ de DATEM) contendo diferentes níveis de ácido ascórbico ao longo do tempo de armazenamento congelado. 

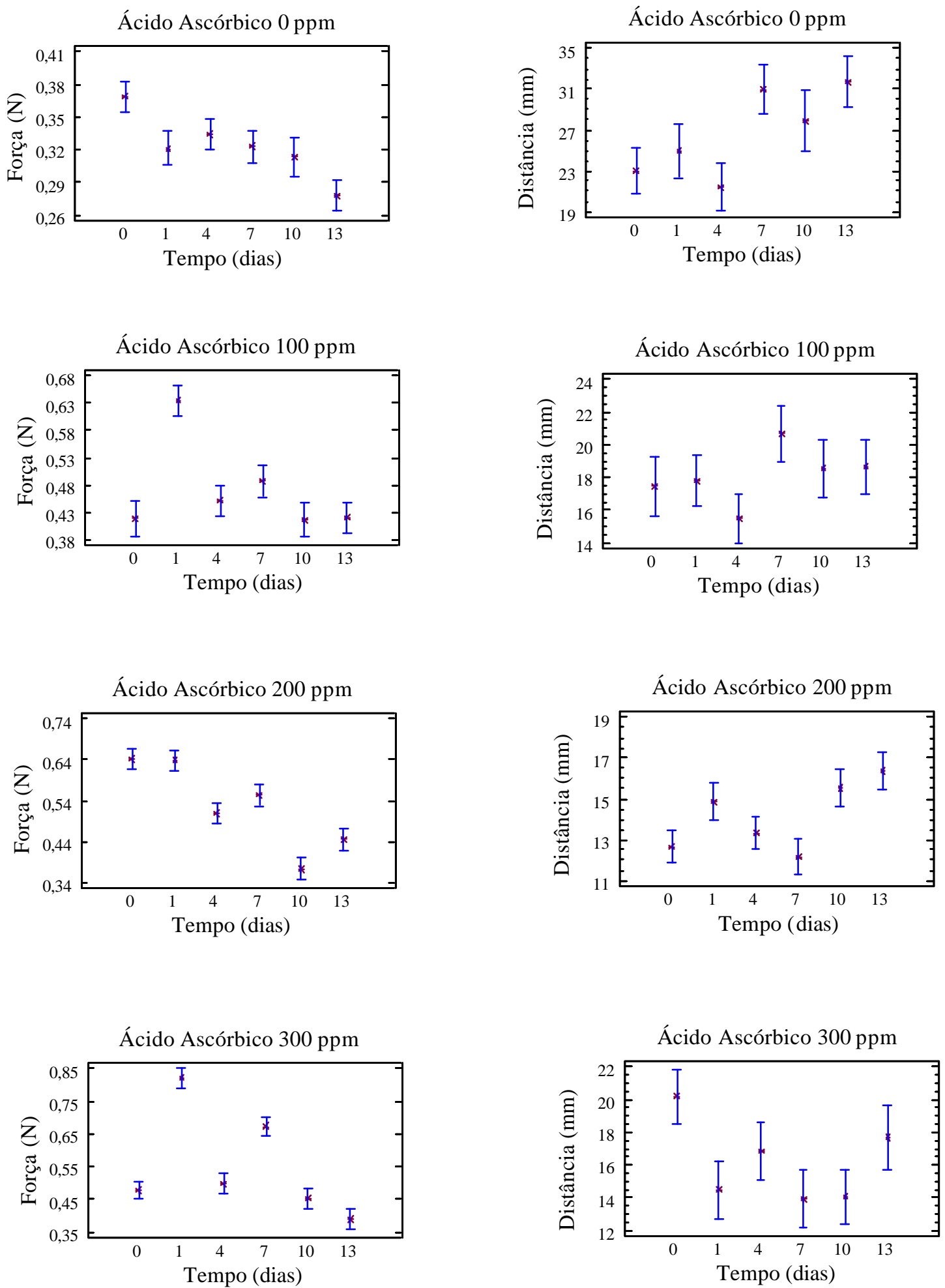

Figura 4.10: Resistência à extensão (Força em N) e extensibilidade (Distância em mm) da mistura $(0,3 \%$ de PS80 e $0,2 \%$ de DATEM) contendo diferentes níveis de ácido ascórbico ao longo do tempo de armazenamento congelado. 


\subsubsection{Análise térmica (Ciclo Completo)}

O programa ciclo completo está descrito na Tabela 3.6. Nesta etapa, as análises no DSC foram realizadas em duplicata.

\subsubsection{Entalpia de congelamento e descongelamento, conteúdo de água} não congelável ( $\mathrm{g} \mathrm{H}_{2} \mathrm{O}$ / g de sólidos) e concentração de sólidos em Wg' (\%)

A Tabela 4.32 mostra os valores de entalpia obtidos para os eventos de congelamento (cristalização) e de descongelamento (fusão), os valores de temperatura "onset", "endset" e de pico.

O conteúdo de água não congelável (Wg’) e da concentração de sólidos em Wg'(Cg') calculados a partir das Equações 2.3 e 2.4 estão apresentados na Tabela 4.33. Análise de variância mostrou que o ácido ascórbico não influenciou significativamente o conteúdo de $\mathrm{Wg}$, nem o de Cg' no intervalo de confiança de $95 \%$.

Tabela 4.33: Conteúdo de água não congelável (Wg’) e a concentração de sólidos na água não congelável ( $\left.\mathrm{Cg}^{\prime}\right)$ nas massas congeladas produzidas da mistura (0,3\% de PS80 e 0,2 \% de DATEM) com diferentes níveis de ácido ascórbico (0, 100, 200 e 300 ppm).

\begin{tabular}{ccc}
\hline Ácido ascórbico (ppm) & $\begin{array}{c}\text { Wg' } \\
(\mathbf{g ~ H} \mathbf{~} \mathbf{O} / \mathbf{g} \text { sólidos })\end{array}$ & $\begin{array}{c}\text { Cg' } \\
(\% \text { de sólidos na } \mathbf{~ W g})\end{array}$ \\
\hline 0 & $0,315^{\mathrm{a}}$ & $76,08^{\mathrm{a}}$ \\
100 & $0,323^{\mathrm{a}}$ & $75,58^{\mathrm{a}}$ \\
200 & $0,321^{\mathrm{a}}$ & $75,72^{\mathrm{a}}$ \\
300 & $0,330^{\mathrm{a}}$ & $75,17^{\mathrm{a}}$ \\
$\mathrm{DMS}^{1}$ & 0,024 & 1,38 \\
\hline
\end{tabular}

*Médias com letras iguais na mesma coluna, não diferem estatisticamente entre si ao nível de $95 \%$ de confiança.

${ }^{1}$ Diferença mínima significativa 
Tabela 4.32: Valores obtidos para os eventos de congelamento e descongelamento no DSC, programa Ciclo Completo para formulações com diferentes níveis de ácido ascórbico (0, 100, 200 e 300 ppm) (Entalpia, $\mathrm{T}_{\text {onset }}, \mathrm{T}_{\text {pico }}$ e $\left.\mathrm{T}_{\text {endset }}\right)$.

\begin{tabular}{|c|c|c|c|c|c|c|c|c|}
\hline \multicolumn{9}{|c|}{ CICLO COMPLETO } \\
\hline \multicolumn{9}{|c|}{ Congelamento } \\
\hline \begin{tabular}{|l|} 
Ácido \\
ascórbico \\
\end{tabular} & $\mathbf{0}$ & $\mathbf{0}$ & 100 & 100 & 200 & 200 & 300 & 300 \\
\hline $\begin{array}{l}\text { Massa } \\
{[\mathrm{mg}]}\end{array}$ & 95,778 & 87,795 & 85,699 & 89,144 & 96,859 & 86,586 & 86,33 & 92,456 \\
\hline \begin{tabular}{|l} 
Entalpia \\
{$[\mathrm{J} / \mathrm{g}]$}
\end{tabular} & 80,82 & 84,52 & 81,60 & 83,41 & 81,26 & 82,49 & 79,99 & 81,19 \\
\hline $\mathrm{T}_{\text {onset }}\left[{ }^{\circ} \mathrm{C}\right]$ & $-8,410$ & $-8,80$ & $-8,05$ & $-8,96$ & $-8,71$ & $-7,76$ & $-8,50$ & $-8,68$ \\
\hline $\mathrm{T}_{\text {pico }}\left[{ }^{\circ} \mathrm{C}\right]$ & $-7,18$ & $-7,10$ & $-6,73$ & $-7,53$ & $-7,34$ & $-6,70$ & $-7,05$ & $-7,02$ \\
\hline $\mathrm{T}_{\text {endset }}\left[{ }^{\circ} \mathrm{C}\right]$ & $-15,53$ & $-14,60$ & $-14,74$ & $-15,24$ & $-15,62$ & $-14,63$ & $-13,65$ & $-12,12$ \\
\hline \multicolumn{9}{|c|}{ Descongelamento } \\
\hline \begin{tabular}{|l|} 
Ácido \\
ascórbico
\end{tabular} & $\mathbf{0}$ & $\mathbf{0}$ & 100 & 100 & 200 & 200 & 300 & 300 \\
\hline \begin{tabular}{|l} 
Entalpia \\
{$[\mathrm{J} / \mathrm{g}]$}
\end{tabular} & $-88,85$ & $-89,79$ & $-87,46$ & $-87,20$ & $-88,02$ & $-86,87$ & $-84,68$ & $-87,45$ \\
\hline $\mathrm{T}_{\text {onset }}\left[{ }^{\circ} \mathrm{C}\right]$ & $-7,22$ & $-6,72$ & $-6,83$ & $-7,04$ & $-7,14$ & $-7,09$ & $-6,85$ & $-7,30$ \\
\hline $\mathrm{T}_{\text {pico }}\left[{ }^{\circ} \mathrm{C}\right]$ & 0,42 & 0,33 & 0,35 & 0,21 & 0,75 & $-0,11$ & 0,14 & $-0,03$ \\
\hline $\mathrm{T}_{\text {endset }}\left[{ }^{\circ} \mathrm{C}\right]$ & 5,92 & 5,23 & 5,73 & 5,44 & 5,96 & 5,17 & 5,57 & 5,80 \\
\hline
\end{tabular}




\subsubsection{Primeiro e segundo aquecimentos e ciclo de retrogradação}

Os valores dos picos obtidos nos aquecimentos e no ciclo de retrogradação obtidos nesta etapa do projeto estão apresentados nas Tabelas 4.34 e 4.35. Apenas o terceiro pico do ciclo de retrogradação apresentou diferença significativa em relação ao conteúdo de ácido ascórbico (Tabela 4.36).

O primeiro aquecimento apresentou apenas um pico, provavelmente, relacionado aos eventos de fusão de lipídios e de gelatinização. No segundo aquecimento, o único pico encontrado pode ser relativo à fusão do complexo amilose lipídio como pode ser observado através dos valores de $\mathrm{T}_{\text {onset }} \mathrm{e} \mathrm{T}_{\text {pico }}$ (Tabela 4.34). No ciclo de retrogradação, foram encontrados três picos que provavelmente estão associados a fusão da amilopectina retrograda e fusão de lipídios, fusão do complexo amilose-lipídio e da amilose retrogradada respectivamente (LE BAIL, 2001).

Tabela 4.36: Entalpia do terceiro pico do ciclo de retrogradação da mistura (0,3 \% de PS80 e 0,2 \% de DATEM) com diferentes níveis de ácido ascórbico (0, 100, 200 e 300 ppm).

\begin{tabular}{llllll}
\hline \multicolumn{5}{c}{ Ácido ascórbico $(\mathbf{p p m})$} \\
& $\mathbf{0}$ & $\mathbf{1 0 0}$ & $\mathbf{2 0 0}$ & $\mathbf{3 0 0}$ & $\mathbf{D M S}^{\mathbf{1}}$ \\
\hline Entalpia [J/g] & $-0,48^{\mathrm{a}}$ & $-0,90^{\mathrm{b}}$ & $-0,89^{\mathrm{b}}$ & $-0,88^{\mathrm{b}}$ & 0,35 \\
\hline *Médias com letras iguais na mesma linha, não diferem estatisticamente entre si ao nível de \\
$\begin{array}{l}\text { 95\% de confiança. } \\
{ }^{1} \text { Diferença mínima significativa }\end{array}$
\end{tabular}


Tabela 4.34: Valores obtidos no primeiro e segundo aquecimentos no DSC, programa ciclo completo para formulações com diferentes níveis de ácido ascórbico $\left(0,100,200\right.$ e 300 ppm) (Entalpia, $\mathrm{T}_{\text {onset }}, \mathrm{T}_{\text {pico }} \mathrm{e}$ $\mathrm{T}_{\text {endset}}$ ).

\begin{tabular}{|c|c|c|c|c|c|c|c|c|}
\hline \multicolumn{9}{|c|}{ PRIMEIRO AQUECIMENTO } \\
\hline \multicolumn{9}{|c|}{ Primeiro Pico } \\
\hline \begin{tabular}{|l|} 
Ácido \\
ascórbico
\end{tabular} & $\mathbf{0}$ & $\mathbf{0}$ & 100 & 100 & 200 & 200 & 300 & 300 \\
\hline $\begin{array}{l}\text { Entalpia } \\
{[\mathrm{J} / \mathrm{g}]}\end{array}$ & $-1,98$ & $-1,98$ & $-2,03$ & $-2,08$ & $-1,91$ & $-2,31$ & $-2,15$ & $-2,12$ \\
\hline $\mathrm{T}_{\text {onset }}\left[{ }^{\circ} \mathrm{C}\right]$ & 61,43 & 61,43 & 65,79 & 61,82 & 61,17 & 62,08 & 61,20 & 61,97 \\
\hline $\mathrm{T}_{\text {pico }}\left[{ }^{\circ} \mathrm{C}\right]$ & 75,35 & 75,35 & 74,54 & 74,44 & 74,87 & 74,00 & 74,93 & 74,25 \\
\hline $\mathrm{T}_{\text {endset }}\left[{ }^{\circ} \mathrm{C}\right]$ & 95,58 & 95,58 & 95,38 & 95,48 & 95,58 & 95,78 & 95,67 & 95,70 \\
\hline \multicolumn{9}{|c|}{ SEGUNDO AQUECIMENTO } \\
\hline \multicolumn{9}{|c|}{ Primeiro Pico } \\
\hline \begin{tabular}{|l} 
Ácido \\
ascórbico
\end{tabular} & $\mathbf{0}$ & $\mathbf{0}$ & 100 & 100 & 200 & 200 & 300 & 300 \\
\hline $\begin{array}{l}\text { Entalpia } \\
{[\mathrm{J} / \mathrm{g}]}\end{array}$ & $-0,73$ & $-0,73$ & $-0,69$ & $-0,72$ & $-0,64$ & $-1,01$ & $-0,96$ & $-0,67$ \\
\hline $\mathrm{T}_{\text {onset }}\left[{ }^{\circ} \mathrm{C}\right]$ & 104,55 & 104,55 & 105,40 & 104,98 & 105,42 & 104,38 & 106,81 & 106,52 \\
\hline $\mathrm{T}_{\text {pico }}\left[{ }^{\circ} \mathrm{C}\right]$ & 117,33 & 117,33 & 117,22 & 117,42 & 117,69 & 117,33 & 118,76 & 117,40 \\
\hline $\mathrm{T}_{\text {endset }}\left[{ }^{\circ} \mathrm{C}\right]$ & 125,81 & 125,81 & 126,04 & 126,04 & 126,04 & 126,28 & 126,44 & 125,89 \\
\hline
\end{tabular}


Tabela 4.35: Valores obtidos no Programa Ciclo Retrogradação no DSC, programa Ciclo Completo para formulações com diferentes níveis de ácido ascórbico (0, 100, 200 e 300 ppm) (Entalpia, $\mathrm{T}_{\text {onset }}, \mathrm{T}_{\text {pico }}$ e $\left.\mathrm{T}_{\text {endset }}\right)$.

\begin{tabular}{|c|c|c|c|c|c|c|c|c|}
\hline \multicolumn{9}{|c|}{ RETROGRADAÇÃOO } \\
\hline \multicolumn{9}{|c|}{ Primeiro Pico } \\
\hline \begin{tabular}{|l} 
Ácido \\
ascórbico
\end{tabular} & $\mathbf{0}$ & $\mathbf{0}$ & 100 & 100 & 200 & 200 & 300 & 300 \\
\hline \begin{tabular}{|l|} 
Entalpia \\
{$[\mathrm{J} / \mathrm{g}]$}
\end{tabular} & $-0,20$ & $-0,36$ & $-0,23$ & $-0,46$ & $-0,34$ & $-0,36$ & $-0,35$ & $-0,48$ \\
\hline $\mathrm{T}_{\text {onset }}\left[{ }^{\circ} \mathrm{C}\right]$ & 58,69 & 52,88 & 56,32 & 55,93 & 56,23 & 49,10 & 55,44 & 53,95 \\
\hline $\mathrm{T}_{\text {pico }}\left[{ }^{\circ} \mathrm{C}\right]$ & 64,81 & 62,93 & 63,81 & 65,22 & 64,49 & 61,96 & 63,65 & 63,52 \\
\hline $\mathrm{T}_{\text {endset }}\left[{ }^{\circ} \mathrm{C}\right]$ & 73,66 & 72,53 & 72,11 & 75,97 & 74,35 & 69,05 & 72,60 & 73,96 \\
\hline \multicolumn{9}{|c|}{ Segundo Pico } \\
\hline \begin{tabular}{|l} 
Ácido \\
ascórbico
\end{tabular} & $\mathbf{0}$ & $\mathbf{0}$ & 100 & 100 & 200 & 200 & 300 & 300 \\
\hline $\begin{array}{l}\text { Entalpia } \\
{[\mathrm{J} / \mathrm{g}]}\end{array}$ & $-0,08$ & $-0,14$ & $-0,17$ & $-0,05$ & $-0,10$ & $-0,08$ & $-0,13$ & $-0,15$ \\
\hline $\mathrm{T}_{\text {onset }}\left[{ }^{\circ} \mathrm{C}\right]$ & 75,80 & 74,51 & 74,80 & 79,02 & 77,51 & 77,44 & 75,97 & 77,46 \\
\hline $\mathrm{T}_{\text {pico }}\left[{ }^{\circ} \mathrm{C}\right]$ & 85,63 & 85,74 & 85,47 & 85,89 & 85,81 & 85,11 & 85,15 & 85,33 \\
\hline $\mathrm{T}_{\text {endset }}\left[{ }^{\circ} \mathrm{C}\right]$ & 92,53 & 97,28 & 94,15 & 124,07 & 93,63 & 91,92 & 92,96 & 94,12 \\
\hline \multicolumn{9}{|c|}{ Terceiro Pico } \\
\hline \begin{tabular}{|l|} 
Ácido \\
ascórbico
\end{tabular} & $\mathbf{0}$ & $\mathbf{0}$ & 100 & 100 & 200 & 200 & 300 & 300 \\
\hline \begin{tabular}{|l|} 
Entalpia \\
{$[\mathrm{J} / \mathrm{g}]$}
\end{tabular} & $-0,56$ & $-0,40$ & $-0,95$ & $-0,84$ & $-0,89$ & $-0,90$ & $-0,95$ & $-0,81$ \\
\hline $\mathrm{T}_{\text {onset }}\left[{ }^{\circ} \mathrm{C}\right]$ & 105,72 & 110,65 & 101,28 & 103,25 & 102,11 & 101,55 & 100,95 & 102,37 \\
\hline $\mathrm{T}_{\text {pico }}\left[{ }^{\circ} \mathrm{C}\right]$ & 118,17 & 117,81 & 117,05 & 116,95 & 117,86 & 116,51 & 117,05 & 117,22 \\
\hline $\mathrm{T}_{\text {endset }}\left[{ }^{\circ} \mathrm{C}\right]$ & 127,92 & 126,72 & 127,84 & 127,62 & 128,34 & 127,08 & 127,90 & 127,70 \\
\hline
\end{tabular}




\subsection{QUARTA ETAPA}

Foram produzidos pães franceses a partir de massas congeladas da mistura (0,3\% de PS80 e 0,2 \% de DATEM) com 0 ppm e 200 ppm da Etapa III. A quantidade de $200 \mathrm{ppm}$ de ácido ascórbico foi selecionada por ter apresentado melhor desempenho em relação à textura uma vez que os parâmetros verificados na análise térmica não apresentaram diferença significativa a $95 \%$ de intervalo de confiança através do teste de Tukey HSD.

\subsubsection{Parâmetros obtidos nas curvas de congelamento}

O congelamento foi realizados em câmara climática $\left(-30^{\circ} \mathrm{C}\right)$. Foram obtidas curvas de congelamento das quais foi possível calcular a velocidade de resfriamento das massas (Tabela 4.37). As curvas de congelamento estão apresentadas no Anexo B.

Tabela 4.37: Parâmetros obtidos nas curvas de congelamento das massas da mistura (0,3\% de PS80 e 0,2 \% de DATEM) com adição de ácido ascórbico (0 ppm e 200 ppm).

\begin{tabular}{ccccccc}
\hline $\begin{array}{c}\text { Ácido ascórbico } \\
(\mathbf{p p m})\end{array}$ & $\begin{array}{c}\mathbf{T o} \\
\left({ }^{\mathbf{0}} \mathbf{C}\right)\end{array}$ & $\begin{array}{c}\mathbf{T c} \\
\left({ }^{\mathbf{0}} \mathbf{C}\right)\end{array}$ & $\begin{array}{c}\mathbf{t} \\
(\mathbf{m i n})\end{array}$ & $\begin{array}{c}\mathbf{T f} \\
\left({ }^{\mathbf{0}} \mathbf{C}\right)\end{array}$ & $\begin{array}{c}\mathbf{t}_{\mathbf{c}} \\
(\mathbf{m i n})\end{array}$ & $\begin{array}{c}\mathbf{v} \\
\left({ }^{\mathbf{0}} \mathbf{C} / \mathbf{m i n}\right)\end{array}$ \\
\hline 0 & 22,5 & $-3,1$ & 56,6 & $-16,3$ & 17,1 & $-1,50$ \\
200 & 23,8 & $-4,4$ & 74,4 & $-17,5$ & 18,0 & $-1,56$ \\
\hline
\end{tabular}

To temperatura no início do processo no centro geométrico

Tc temperatura inicial de congelamento no centro geométrico

t tempo total decorrido no processo de congelamento até fim da aquisição

Tf temperatura no final do processo no centro geométrico

$t_{c}$ tempo decorrido na zona crítica, na mudança de fase

$\mathrm{v}$ velocidade de resfriamento entre To e Tc 


\subsubsection{Conteúdo de água das massas frescas}

O conteúdo de água das massas frescas produzidas à partir da mistura (0,3 \% de PS80 e 0,2 \% de DATEM) com 0 ppm e 200 ppm de ácido ascórbico não apresentou diferença significativa no intervalo de confiança de $95 \%$ no teste de Tukey HSD (Tabela 4.38).

Tabela 4.38: Conteúdo de água das massas frescas da mistura $(0,3 \%$ de PS80 e 0,2 \% de DATEM) 0 e 200 ppm de ácido ascórbico utilizadas na etapa de panificação.

\begin{tabular}{ccc}
\hline & \multicolumn{2}{c}{ Conteúdo de água $(\%)$} \\
\hline $\begin{array}{c}\text { Ácido ascórbico } \\
(\mathbf{p p m})\end{array}$ & \multicolumn{2}{c}{ Estufa $\mathbf{1 3 0}^{\mathbf{0}} \mathbf{C}$} \\
& Média & $\mathrm{DP}^{1}$ \\
\hline 0 & 47,17 & 0,42 \\
200 & 47,71 & 0,43 \\
\hline${ }^{1} \mathrm{DP}-$ Desvio Padrão & &
\end{tabular}

A farinha utilizada para a Etapa IV foi a do lote 2, ou seja, a mesma utilizada nas Etapas II e III. O conteúdo de água nas massas da Etapa IV foi em torno de $47 \%$ enquanto que nas demais foi de $44 \%$. Apesar da diminuição da quantidade de água acrescentada em $1 \%$ na Etapa IV, foi utilizado o fermento fresco (3\%) que é o provável responsável pelo maior conteúdo de água nas massas.

\subsubsection{Textura da massa fresca}

Foram determinados os parâmetros de resistência à extensão e extensibilidade da massa fresca. Não foi possível realizar a análise de textura nas massas congeladas devido ao processo de fermentação durante o período de descongelamento da amostra $\left(60\right.$ minutos a $\left.30^{\circ} \mathrm{C}\right)$. 
Análise de variância mostrou que o ácido ascórbico influenciou significativamente, no intervalo de $95 \%$ de confiança, a resistência à extensão e a extensibilidade da massa fresca (Tabela 4.39).

Os valores obtidos para resistência à extensão foram menores do que em massas com mesma formulação porém sem adição de fermento e para os de extensibilidade, a massa sem adição de ácido ascórbico $(0$ ppm $)$ apresentou maior valor do que em massas sem adição do fermento, entretanto em massas com ácido ascórbico (200 ppm) este efeito foi oposto (Figura 4.10). A resistência à extensão de massas com fermento é menor devido à fermentação durante o tempo de descanso da massa em forma de Teflon por 40 minutos a $30^{\circ} \mathrm{C}$. A presença de ar no interior das tiras de massa para esta análise acarreta em menor resistência à extensão.

Tabela 4.39: Resistência à extensão $(\mathrm{N})$ e extensibilidade $(\mathrm{mm})$ de massas frescas da mistura $(0,3 \%$ de PS80 e $0,2 \%$ de DATEM) sem e com fermento e diferentes níveis de ácido ascórbico (0 e 200 ppm)

\begin{tabular}{lcccc}
\hline $\begin{array}{c}\text { Ácido ascórbico } \\
\text { (ppm) }\end{array}$ & \multicolumn{2}{c}{$\mathbf{0}$} & \multicolumn{2}{c}{$\mathbf{2 0 0}$} \\
\hline & $\begin{array}{c}\text { Sem } \\
\text { fermento }\end{array}$ & $\begin{array}{c}\text { Com } \\
\text { fermento }\end{array}$ & $\begin{array}{c}\text { Sem } \\
\text { fermento }\end{array}$ & $\begin{array}{c}\text { Com } \\
\text { fermento }\end{array}$ \\
\hline $\begin{array}{l}\text { Resistência à } \\
\text { extensão (N) }\end{array}$ & 0,369 & 0,226 & 0,642 & 0,266 \\
$\begin{array}{l}\text { Extensibilidade } \\
(\mathrm{mm})\end{array}$ & 22,980 & 24,652 & 12,645 & 10,639 \\
\hline
\end{tabular}

4.4.4. Medida de produção de $\mathrm{CO}_{2}$, permeabilidade da massa e tolerância da massa durante a fermentação

Os parâmetros obtidos das curvas de desenvolvimento da massa e de geração de $\mathrm{CO}_{2}$ estão apresentados na Tabela 4.40. As curvas estão apresentadas no Anexo C. 
Tabela 4.40: Parâmetros obtidos nas curvas geradas no reofermentômetro da mistura (0,3\% de PS80 e 0,2 \% de DATEM) com adição de 0 e 200 ppm de ácido ascórbico em função do tempo de armazenamento congelado.

\begin{tabular}{|c|c|c|c|c|c|c|c|c|}
\hline \multicolumn{9}{|c|}{ 0ppm } \\
\hline $\begin{array}{l}\text { Tempo } \\
\text { (dias) }\end{array}$ & $\begin{array}{c}\mathrm{T} 1 \\
\text { (h:mm:ss) }\end{array}$ & $\begin{array}{l}\mathrm{Hm} \\
(\mathrm{mm})\end{array}$ & $\begin{array}{c}(\mathrm{Hm}-\mathrm{h}) / \mathrm{Hm} \\
(\%)\end{array}$ & $\begin{array}{l}\mathrm{H}^{\prime} \mathrm{m} \\
(\mathrm{mm})\end{array}$ & $\begin{array}{c}\text { T'1 } \\
\text { (h:mm:ss) }\end{array}$ & $\begin{array}{c}\text { Tx } \\
\text { (h:mm:ss) }\end{array}$ & $\begin{array}{l}\mathrm{A} 1+\mathrm{A} 2 \\
(\mathrm{~mL})\end{array}$ & $\begin{array}{c}\mathrm{R} \\
(\%)\end{array}$ \\
\hline 0 & 2:39:00 & 56,5 & 2,5 & 59,4 & $1: 52: 30$ & $1: 27: 00$ & 1314 & 94,3 \\
\hline 1 & $2: 46: 30$ & 58,2 & 1,9 & 56,7 & 1:54:00 & $1: 43: 30$ & 1320 & 94,1 \\
\hline 4 & 2:31:30 & 56,8 & 3,7 & 55,7 & 2:12:00 & $1: 58: 30$ & 1256 & 93,7 \\
\hline 7 & 3:00:00 & 61,8 & 0,0 & 55,4 & 2:12:00 & 2:09:00 & 1254 & 96,5 \\
\hline 11 & 3:00:00 & 58,0 & 0,0 & 55,4 & 2:07:30 & 2:15:00 & 1247 & 96,9 \\
\hline 13 & 2:49:30 & 53,3 & 2,1 & 53,6 & $2: 10: 30$ & 1:55:30 & 1206 & 96,4 \\
\hline \multicolumn{9}{|c|}{ 200ppm } \\
\hline $\begin{array}{l}\text { Tempo } \\
\text { (dias) }\end{array}$ & $\begin{array}{c}\mathrm{T} 1 \\
\text { (h:mm:ss) }\end{array}$ & $\begin{array}{l}\mathrm{Hm} \\
(\mathrm{mm})\end{array}$ & $\begin{array}{c}(\mathrm{Hm}-\mathrm{h}) / \mathrm{Hm} \\
(\%)\end{array}$ & $\begin{array}{l}\mathrm{H}^{\prime} \mathrm{m} \\
(\mathrm{mm})\end{array}$ & $\begin{array}{c}\text { T'1 } \\
\text { (h:mm:ss) }\end{array}$ & $\begin{array}{c}\text { Tx } \\
\text { (h:mm:ss) }\end{array}$ & $\begin{array}{l}\mathrm{A} 1+\mathrm{A} 2 \\
(\mathrm{~mL})\end{array}$ & $\begin{array}{c}\mathrm{R} \\
(\%)\end{array}$ \\
\hline 0 & 3:00:00 & 69,1 & 0,0 & 61,9 & $2: 04: 30$ & 2:12:00 & 1306 & 93,9 \\
\hline 1 & 3:00:00 & 73,1 & 0,0 & 58,9 & 2:00:00 & 1:48:00 & 1311 & 94,5 \\
\hline 4 & 3:00:00 & 68,4 & 0,0 & 58,5 & 2:19:30 & 1:54:00 & 1289 & 96,6 \\
\hline 7 & 3:00:00 & 68,9 & 0,0 & 56,3 & 2:07:30 & 2:03:00 & 1240 & 95,6 \\
\hline 11 & $2: 22: 30$ & 71,7 & 2,2 & 57,5 & 2:15:00 & 2:06:00 & 1271 & 94,7 \\
\hline 13 & 2:57:00 & 66,9 & 3,6 & 55,8 & 2:18:00 & 2:12:00 & 1193 & 96,1 \\
\hline
\end{tabular}

T1 tempo relativo ao crescimento máximo da massa

Hm altura máxima do desenvolvimento da massa sob compressão

$(\mathrm{Hm}-\mathrm{h}) / \mathrm{Hm}$ coeficiente de enfraquecimento da massa

$\mathrm{H}$ 'm altura máxima da curva de geração de $\mathrm{CO}_{2}$

T'1 tempo necessário para alcançar H'm

Tx tempo necessário para o aparecimento da porosidade na massa (início da liberação de $\mathrm{CO}_{2}$ )

$\mathrm{A} 1+\mathrm{A} 2$ volume total de $\mathrm{CO}_{2}$ produzido

$\mathrm{R}$ coeficiente de retenção, razão entre volume retido e total de $\mathrm{CO}_{2}$

Pode-se observar na Tabela 4.40 que os valores obtidos de Hm e H'm para a massa com 200 ppm de ácido ascórbico foram maiores do que para a massa com 0 ppm, o que comprova a influência do ácido ascórbico nas características reológicas da massa, fortalecendo a rede de glúten (NAKAMURA; KURATA, 1997).

A quantidade de $\mathrm{CO}_{2}$ produzido $(\mathrm{A} 1+\mathrm{A} 2)$ diminuiu com o tempo de armazenamento tanto para a massa com 200 ppm quanto para a massa com 0 ppm de ácido ascórbico indicando que a levedura perde capacidade fermentativa durante o tempo de armazenamento congelado. 
Análise de variância aplicada nos parâmetros da Tabela 4.40 indicou que nem o ácido ascórbico nem o tempo de armazenamento congelado influenciaram significativamente, no intervalo de $95 \%$ de confiança, os parâmetros R, coeficiente de retenção e o coeficiente de enfraquecimento da massa. No entanto o parâmetro Hm, foi influenciado pela adição de ácido ascórbico. A adição do ácido ascórbico aumentou o valor de $\mathrm{Hm}$, ou seja, altura máxima do desenvolvimento da massa pelos mesmos motivos discutidos na análise de textura, porém o tempo de armazenamento congelado não influenciou este parâmetro (Tabela 4.41).

Tabela 4.41: Análise de variância para Hm, altura máxima do desenvolvimento da massa, em função do conteúdo de ácido ascórbico.

\begin{tabular}{|c|c|c|c|}
\hline Ácido ascórbico (ppm) & $\mathbf{0}$ & 200 & DMS \\
\hline $\mathrm{Hm}(\mathrm{mm})$ & $57,43^{\mathrm{a}}$ & $69,68^{b}$ & 2,89 \\
\hline
\end{tabular}

\subsubsection{Pão Francês}

As massas foram descongeladas em ambiente de temperatura controlada $\left(30^{\circ} \mathrm{C}\right)$ por uma hora, fermentadas por uma hora $\left(\sim 32^{\circ} \mathrm{C}\right)$, assadas por 7 a $10 \mathrm{~min} \mathrm{e}$ resfriadas a temperatura ambiente $\left(24,7\right.$ a $\left.28,0^{\circ} \mathrm{C}\right)$ por aproximadamente uma hora e vinte minutos. Os pães produzidos dessas massas apresentaram as seguintes características:

\subsubsection{Conteúdo de água}

O conteúdo de água não variou significativamente no intervalo de confiança de $95 \%$ do teste de Tukey HSD em relação ao tempo de armazenamento congelado (0, 1, 4, 7, 11 e 13 dias). No entanto, o ácido ascórbico influenciou o conteúdo de água dos pães (Tabela 4.42). O valor médio obtido foi de $33,20 \%$ que é maior quando comparado ao conteúdo de água de pães franceses comercializados na cidade de São Paulo que variou de 27,8 \% a 31,6 \% (KOWASLKI; CARR; TADINI, 2002). 
Tabela 4.42: Conteúdo de água dos pães produzidos de massas com diferentes níveis de ácido ascórbico (0 e 200 ppm).

\begin{tabular}{|c|c|c|c|}
\hline Ácido ascórbico (ppm) & $\mathbf{0}$ & 200 & DMS \\
\hline Conteúdo de água (\%) & $33,98^{b}$ & $32,47^{\mathrm{a}}$ & 0,62 \\
\hline
\end{tabular}

\subsubsection{Massa e volume específico}

O valor médio obtido para a massa de dois pães foi de 103,11 g. Através do teste de Tukey HSD com intervalo de confiança de $95 \%$, verificou-se que massa de dois pães não variou significativamente com o tempo de armazenamento congelado nem com a adição de ácido ascórbico.

Entretanto o tempo de armazenamento congelado e a adição de ácido ascórbico influenciaram significativamente o volume específico conforme ilustra a Figura 4.11. Os pães produzidos a partir da massa contendo $200 \mathrm{ppm}$ de ácido ascórbico apresentaram maiores valores conforme encontrado na literatura (NAKAMURA; KURATA, 1997); (ABD EL-HADY; EL-SAMAHY; BRÜMMER, 1990).

Em relação ao tempo de armazenamento congelado observa-se que os maiores valores para o volume específico estão nos primeiros dias de armazenamento congelado. O valor referente a um dia de congelamento foi maior do que para o pão de massa fresca o que pode indicar que as formulações estudadas são melhores para as massas que sofrem congelamento ou que a massa congelada teve o início da fermentação ainda no período de descongelamento o que implica em um maior tempo de fermentação. Este efeito não foi observado no estudo de pães pré-assados congelados, no qual o volume específico dos pães diminuiu com o tempo de armazenamento congelado ( 0 a 28 dias) variando de 5,52 a 3,45 $\mathrm{cm}^{3} / \mathrm{g}$ (CARR; TADINI, 2003). 

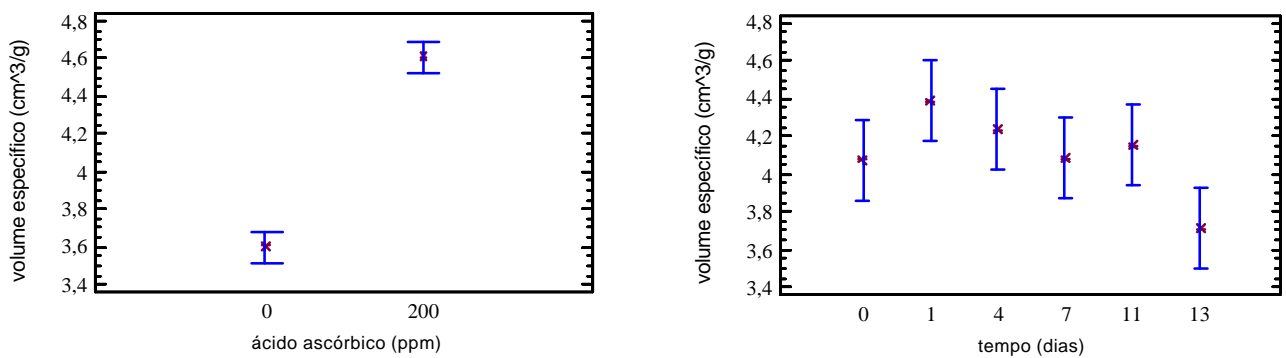

Figura 4.11: Volume específico em relação ao conteúdo de ácido ascórbico e ao tempo.

O valor médio encontrado de massa de dois pães, 103,11 g, está no intervalo de valores obtidos para pães franceses produzidos na cidade de São Paulo (93 a 142 g) conforme o estudo de Kowaslki; Carr; Tadini (2002) porém em relação ao volume específico apenas os pães produzidos com a adição de 200 ppm de ácido ascórbico ficaram dentro da faixa obtida neste estudo $\left(3,89\right.$ a 7,48 $\left.\mathrm{cm}^{3} / \mathrm{g}\right)$.

\subsubsection{Perfil de textura (TPA)}

O teste de Tukey HSD com intervalo de confiança de $95 \%$ foi aplicado aos parâmetros de firmeza, elasticidade, mastigabilidade e coesividade medidos nos pães. Todos estes parâmetros foram influenciados significativamente tanto pelo tempo de armazenamento congelado como pelo conteúdo de ácido ascórbico presente na massa como ilustra a Figura 4.12. O tempo de 11 dias de armazenamento congelado apresentou-se diferente da tendência dos demais pontos.

Os resultados de firmeza, coesividade e mastigabilidade obtidos para as massas com 0 e 200 ppm de ácido ascórbico estão compreendidos no intervalo obtido para os pães produzidos na cidade de São Paulo que para a firmeza foi de 3,8 a 7,4 N, para a coesividade de 0,57 a 0,74 e para a mastigabilidade de 0,051 a $0,075 \mathrm{~J}$. Porém em relação à elasticidade, os valores obtidos neste trabalho foram superiores aos relatados por Kowaslki; Carr; Tadini (2002).

Os valores dos parâmetros de firmeza, elasticidade, coesividade e mastigabilidade deste estudos estão dentro dos intervalos obtidos no estudo de pães 
franceses pré-assados congelados ao longo do tempo de armazenamento ( 0 a 28 dias) que para firmeza foi de 5,48 a 7,26 N, para a elasticidade de 0,0183 a $0,0190 \mathrm{~m}$, para a coesividade de 0,65 a 0,72 e para a mastigabilidade de 0,0673 a 0,0919 (CARR; TADINI, 2003).
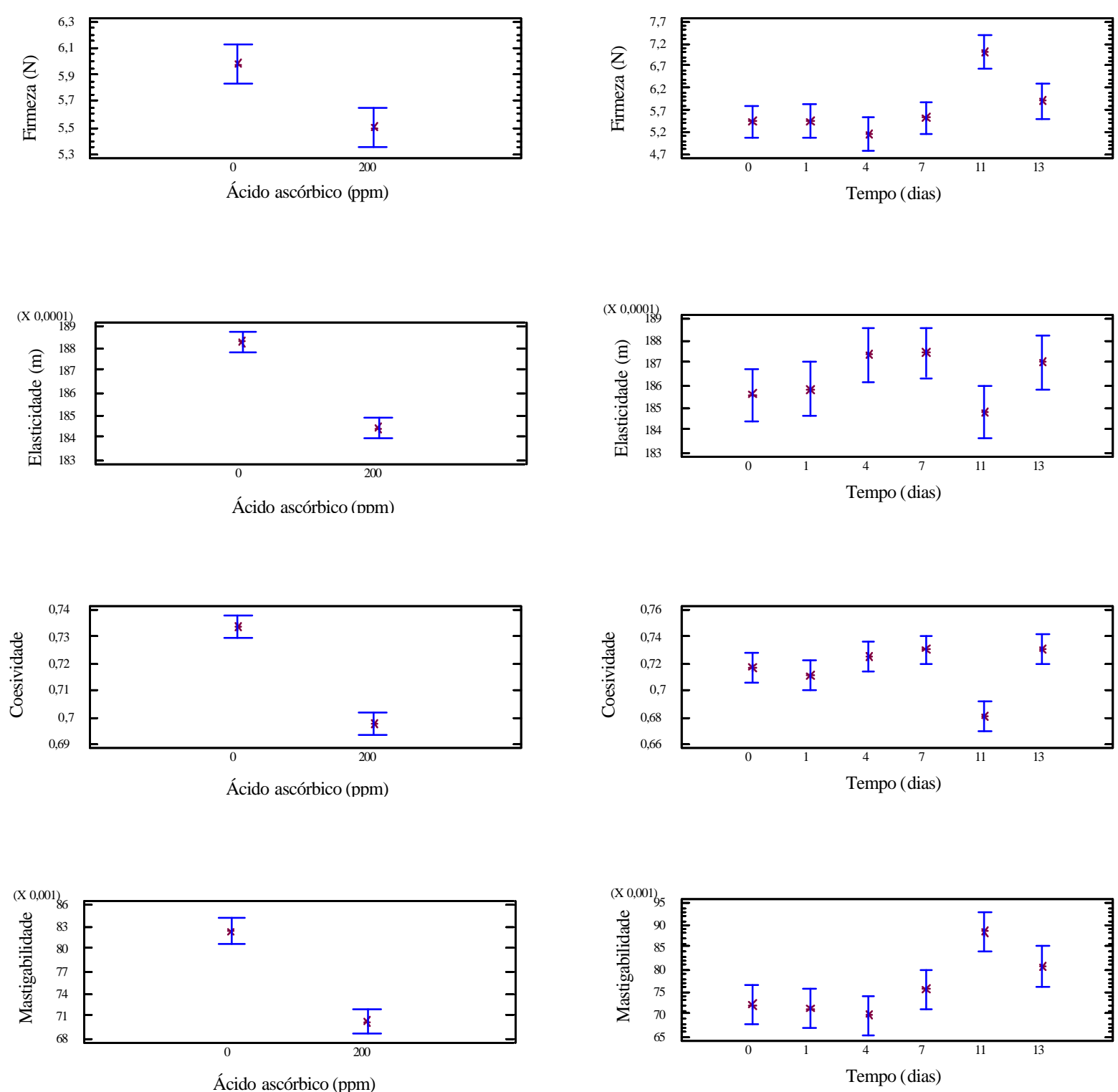

Figura 4.12: Parâmetros de textura (Firmeza, elasticidade, coesividade e mastigabilidade) dos pães produzidos com a mistura (0,3 \% de PS80 e 0,2 \% de DATEM) em função do conteúdo de ácido ascórbico e do tempo de armazenamento congelado. 


\section{CONCLUSÕES}

Na Etapa I do projeto foi estudada a influência dos emulsificantes estearoillactilato de cálcio (CSL) e polisorbato 80 (PS80) e da gordura vegetal hidrogenada $(\mathrm{GVH})$ sobre o conteúdo de água da massa de pão, parâmetros de textura e sobre os eventos de congelamento, descongelamento, gelatinização, complexo amilose-lipídio e retrogradação.

O conteúdo de água e a extensibilidade da massa fresca de pão francês foram influenciados significativamente pela gordura vegetal hidrogenada (GVH), porém a resistência à extensão não foi influenciada por este ingrediente. No entanto, a GVH não deve ser eliminada da composição da massa, pois reduz o envelhecimento e melhora a textura dos pães.

O tempo de armazenamento congelado influenciou significativamente os parâmetros de textura da massa.

Os picos que provavelmente estão relacionados ao evento de gelatinização foram maiores no programa ciclo completo, que compreende ciclo de congelamentodescongelamento e duplo aquecimento daqueles obtidos no ciclo parcial, que constituiu apenas de dois aquecimentos na análise térmica.

Com a intenção de realizar um projeto de mistura (Etapa II), foi necessário escolher um novo emulsificante para que a soma destes fosse constante. Como a GVH não poderia ser eliminada da composição da massa congelada devido aos benefícios por ela proporcionados, sua quantidade foi fixada em $1 \%$ sobre a farinha de trigo e foi selecionado o éster de ácido diacetil tartárico de mono e diglicerídio (DATEM) como novo emulsificante.

Na Etapa II do trabalho, foi realizado um projeto de mistura com três componentes (CSL, PS80 e DATEM) para verificar a influência destes emulsificantes sobre os mesmos parâmetros avaliados na Etapa I.

A resistência à extensão da massa, ao longo do tempo de armazenamento congelado, foi influenciada principalmente pelos componentes PS80 e DATEM. No entanto, as equações preditivas obtidas para extensibilidade não foram significativas no intervalo de confiança de $95 \%$. 
A velocidade de resfriamento influenciou a resistência à extensão da massa após 1, 7 e 22 dias de armazenamento congelado. Os valores de resistência à extensão foram sempre maiores para massas congeladas em uma velocidade maior. A diferença encontrada pode ser devido à mudança estrutural na massa pela migração de água.

As condições empregadas para as análises térmicas podem não ter sido adequadas aos eventos que ocorreram durante os aquecimentos devido à composição do material estudado, ou ao projeto de mistura, pois as equações encontradas não foram estatisticamente significativas, com exceção da entalpia de congelamento.

A escolha da mistura $(0,3 \%$ de PS80 e $0,2 \%$ de DATEM em relação à farinha de trigo) para dar continuidade ao trabalho (Etapa III) foi baseada nos modelos obtidos para resistência à extensão da massa e na legislação brasileira que restringe o uso do PS80 a $0,3 \%$.

Na Etapa III foi estudada a influência do ácido ascórbico em quatro níveis de adição $(0,100,200$ e 300 ppm) na mistura escolhida na etapa anterior sobre os mesmos parâmetros avaliados na Etapa I.

A resistência à extensão da massa aumentou enquanto a extensibilidade diminuiu com o aumento da quantidade de ácido ascórbico até adição de 200 ppm em relação à farinha de trigo. A resistência à extensão diminuiu e a extensibilidade aumentou ao longo do tempo de armazenamento congelado.

$\mathrm{Na}$ análise térmica, foi verificada apenas a influência do ácido ascórbico apenas no terceiro pico do ciclo de retrogradação que provavelmente está relacionado à fusão da amilose retrogradada.

A Etapa IV compreendeu a parte de panificação. Foram produzidos pães de massas congeladas à partir da mistura $(0,3 \%$ de PS80 e 0,2\% de DATEM) com adição de ácido ascórbico (0 e 200 ppm em relação à farinha de trigo).

O conteúdo de água da massa fresca foi maior que na Etapa III devido a adição de fermento prensado. No entanto, a resistência à extensão foi menor em massas com fermento, o que pode estar associado à fermentação durante o tempo de descanso da massa em forma de Teflon por 40 minutos a $30 \mathrm{C}$. As massas produzidas 
com adição de 200 ppm de ácido ascórbico apresentaram maiores valores para altura máxima do desenvolvimento na análise do reofermentômetro.

Os pães produzidos com a mistura (0,3 \% de PS80 e 0,2 \% de DATEM) com adição de 200 ppm de ácido ascórbico apresentaram maior volume específico, e menores valores dos parâmetros de textura (firmeza, elasticidade, coesividade e mastigabilidade) em comparação aos produzidos com a mesma mistura, porém sem adição de ácido ascórbico.

\section{SUGESTÕES PARA TRABALHOS FUTUROS}

A análise térmica poderá ser utilizada no estudo dos eventos de congelamento e descongelamento de massas de pão, com a variação da fração seca ou do conteúdo de água e da velocidades de aquecimento, verificando a influência sobre o comportamento da água não congelável.

Estes estudos poderão ser útil na investigação das propriedades termofísicas (condutividade térmica, difusividade térmica, calor específico e densidade aparentes) e também na determinação da temperatura de transição vítrea com vistas a minimizar o efeito do tempo e da temperatura de armazenamento congelado sobre a migração de água na amostra e consequentemente sua estrutura.

Um estudo em escala piloto permitirá a modelagem, otimização e projeto de equipamentos utilizados no processo de fabricação de pão de massa congelada. $\mathrm{O}$ tempo de congelamento poderá ser determinado através de modelos preditivos em massas com diferentes composições (conteúdo de água) e em diferentes velocidades de congelamento. 


\section{ANEXO A}

Tabela A.1: Tempos de batimento e temperaturas da farinha e da água antes do batimento e da massa no final do batimento (Etapa I, com os componentes GVH, CSL e PS80)

\begin{tabular}{cccccccc}
\hline Mistura & $\begin{array}{c}\mathbf{T}_{\text {ambiente }} \\
\left(\mathbf{T}_{\text {farinha }}\right.\end{array}$ & $\begin{array}{c}\mathbf{T}_{\text {água }} \\
\left({ }^{\mathbf{}} \mathbf{C}\right) *\end{array}$ & $\begin{array}{c}\mathbf{1}^{\mathbf{a}} \text { velocidade } \\
\left({ }^{\mathbf{C}} \mathbf{C}\right)\end{array}$ & $\begin{array}{c}\mathbf{2}^{\mathbf{a}} \text { velocidade } \\
(\mathbf{m m}: \mathbf{s s})\end{array}$ & $\begin{array}{c}\mathbf{T}_{\text {final }} \\
(\mathbf{m m}: \mathbf{s s})\end{array}$ & $\left({ }^{\mathbf{}} \mathbf{C}\right)$ & \\
\hline 0 & 26,8 & $-8,6$ & 10,6 & $07: 22$ & $14: 22$ & 29,7 & $17 / \mathrm{Fev}$ \\
1 & 26,8 & $-2,4$ & 9,8 & $09: 25$ & $13: 00$ & 28,9 & $17 / \mathrm{Fev}$ \\
2 & 24,6 & $-19,4$ & 9,4 & $07: 22$ & $11: 45$ & 26,5 & $19 / \mathrm{Fev}$ \\
3 & 26,8 & $-13,7$ & 10,2 & $07: 25$ & $11: 30$ & 26,5 & $17 / \mathrm{Fev}$ \\
4 & 24,6 & $-7,6$ & 9,3 & $06: 13$ & $11: 54$ & 27,3 & $19 / \mathrm{Fev}$ \\
5 & 26,8 & $-9,1$ & 9,7 & $06: 00$ & $11: 00$ & 25,9 & $17 / \mathrm{Fev}$ \\
6 & 24,6 & $-10,8$ & 8,6 & $06: 25$ & $11: 03$ & 26,8 & $19 / \mathrm{Fev}$ \\
7 & 24,6 & $-15,2$ & 10,1 & $05: 34$ & $11: 28$ & 27,0 & $19 / \mathrm{Fev}$ \\
8 & 18,7 & $-7,3$ & 7,9 & $10: 23$ & $10: 38$ & 19,8 & $28 / \mathrm{Mai}$ \\
0 & 18,2 & $-9,5$ & 3,8 & $11: 00$ & $09: 30$ & 20,9 & $03 / \mathrm{Jul}$ \\
1 & 19,5 & $-5,4$ & 8,6 & $11: 00$ & $11: 00$ & 23,0 & $01 / \mathrm{Jul}$ \\
2 & 19,5 & $-6,6$ & 9,2 & $11: 48$ & $10: 00$ & 22,5 & $01 / \mathrm{Jul}$ \\
3 & 18,2 & $-7,8$ & 7,1 & $10: 00$ & $11: 00$ & 21,0 & $03 / \mathrm{Jul}$ \\
4 & 19,5 & $-9,1$ & 8,8 & $11: 30$ & $09: 23$ & 22,3 & $01 / \mathrm{Jul}$ \\
5 & 19,5 & $-7,3$ & 8,3 & $11: 00$ & $11: 05$ & 23,0 & $01 / \mathrm{Jul}$ \\
6 & 19,5 & $-0,8$ & 9,8 & $10: 00$ & $11: 00$ & 21,7 & $01 / \mathrm{Jul}$ \\
7 & 18,2 & $-9,6$ & 5,4 & $11: 00$ & $09: 00$ & 21,3 & $03 / \mathrm{Jul}$ \\
\hline & 18,2 & $-8,9$ & 6,2 & $11: 00$ & $10: 00$ & 21,0 & $03 / \mathrm{Jul}$ \\
\hline
\end{tabular}

*Temperaturas medidas antes do batimento. 
Tabela A.2: Tempos de batimento e temperaturas da farinha e da água antes do batimento e da massa no final do batimento (Etapa II, Projeto de misturas com os componentes CSL, PS80 e DATEM).

\begin{tabular}{|c|c|c|c|c|c|c|c|}
\hline Mistura & $\begin{array}{c}\mathbf{T}_{\text {ambiente }} \\
\left({ }^{\circ} \mathrm{C}\right)\end{array}$ & $\begin{array}{c}\mathbf{T}_{\text {farinha }} \\
\left({ }^{\circ} \mathbf{C}\right)^{*}\end{array}$ & $\begin{array}{l}\mathrm{T}_{\text {água }} \\
\left({ }^{\circ} \mathrm{C}\right)^{*}\end{array}$ & $\begin{array}{c}\mathbf{1}^{\mathrm{a}} \text { velocidade } \\
\text { (minutos) }\end{array}$ & $\begin{array}{c}2^{\mathrm{a}} \text { velocidade } \\
\text { (minutos) }\end{array}$ & $\begin{array}{l}\mathrm{T}_{\text {final }} \\
\left({ }^{\circ} \mathrm{C}\right)\end{array}$ & \\
\hline 0 & 21,5 & 14,5 & 5,4 & 6 & 10 & 22,9 & 23/out \\
\hline 1 & 25,0 & 14,4 & 9,1 & 6 & 10 & 23,4 & 21/out \\
\hline 2 & 23,4 & 18,7 & 5,3 & 6 & 10 & 23,5 & 23/out \\
\hline 3 & 24,2 & 19,5 & 6,0 & 6 & 10 & 25,3 & 21/out \\
\hline 4 & 26,7 & 22,1 & 6,3 & 6 & 10 & & 28/out \\
\hline 5 & 23,8 & 16,2 & 5,6 & 6 & 10 & 24,4 & 28/out \\
\hline 6 & 24,9 & 18,1 & 6,2 & 6 & 10 & 24,7 & 23/out \\
\hline $7 \mathrm{a}$ & 23,1 & 22,2 & 6,7 & 6 & 10 & 26,2 & 21/out \\
\hline $7 \mathrm{~b}$ & 23,2 & 9,9 & 5,6 & 6 & 10 & 23,8 & 28/out \\
\hline $7 \mathrm{c}$ & 23,1 & 20,2 & 6,4 & 6 & 10 & 25,3 & 28/out \\
\hline
\end{tabular}

*Temperaturas medidas antes do batimento. 
Tabela A.3: Tempos de batimento e temperaturas da farinha e da água antes do batimento e da massa no final do batimento (Etapa III, com adição de ácido ascórbico em 4 níveis, 0, 100, 200 e 300 ppm).

\begin{tabular}{cccccccc}
\hline $\begin{array}{c}\text { Ácido } \\
\text { ascórbico } \\
(\mathbf{p p m})\end{array}$ & $\begin{array}{c}\mathbf{T}_{\text {ambiente }} \\
\left({ }^{\mathbf{}} \mathbf{C}\right)\end{array}$ & $\begin{array}{c}\mathbf{T}_{\text {farinha }} \\
\left({ }^{\mathbf{o}} \mathbf{C}\right) *\end{array}$ & $\begin{array}{c}\mathbf{T}_{\text {água }} \\
\left({ }^{\mathbf{o}} \mathbf{C}\right) *\end{array}$ & $\begin{array}{c}\mathbf{1}^{\mathbf{a}} \text { velocidade } \\
(\mathbf{m i n u t o s})\end{array}$ & $\mathbf{2}^{\mathbf{a}}$ velocidade & $\mathbf{T}_{\text {final }}$ & \\
$(\mathbf{m i n u t o s})$ & $\left({ }^{\mathbf{}} \mathbf{C}\right)$ & \\
\hline 0 & 23,7 & 22,5 & 8,3 & 6 & 10 & 26,3 & $02 / \mathrm{dez}$ \\
100 & 26,7 & 24,9 & 8,6 & 6 & 10 & 27,1 & $02 / \mathrm{dez}$ \\
200 & 27,1 & 25,8 & 8,5 & 6 & 10 & 27,3 & $02 / \mathrm{dez}$ \\
300 & 26,8 & 26,0 & 8,5 & 6 & 10 & 27,5 & $02 / \mathrm{dez}$ \\
\hline
\end{tabular}

*Temperaturas medidas antes do batimento.

Tabela A.4: Tempos de batimento e temperaturas da farinha e da água antes do batimento e da massa no final do batimento (Etapa IV)

\begin{tabular}{|c|c|c|c|c|c|c|c|}
\hline $\begin{array}{c}\text { Ácido } \\
\text { ascórbico } \\
\text { (ppm) }\end{array}$ & $\begin{array}{c}\mathbf{T}_{\text {ambiente }} \\
\left({ }^{\circ} \mathrm{C}\right)\end{array}$ & $\begin{array}{l}\mathrm{T}_{\text {farinha }} \\
\left({ }^{\circ} \mathrm{C}\right)^{*}\end{array}$ & $\begin{array}{l}\mathrm{T}_{\text {água }} \\
\left({ }^{\circ} \mathrm{C}\right)^{*}\end{array}$ & $\begin{array}{c}\mathbf{1}^{\mathrm{a}} \text { velocidade } \\
\text { (minutos) }\end{array}$ & $\begin{array}{c}2^{\mathrm{a}} \text { velocidade } \\
\text { (minutos) }\end{array}$ & $\begin{array}{r}\mathbf{T}_{\text {final }} \\
\left({ }^{\circ} \mathrm{C}\right)\end{array}$ & \\
\hline 0 & 24,0 & 14,0 & 4,7 & 6 & 10 & 25,0 & 22/jan \\
\hline 200 & 24,8 & 15,7 & 3,4 & 6 & 10 & 24,8 & 22/jan \\
\hline
\end{tabular}

*Temperaturas medidas antes do batimento. 
Curvas de congelamento MO

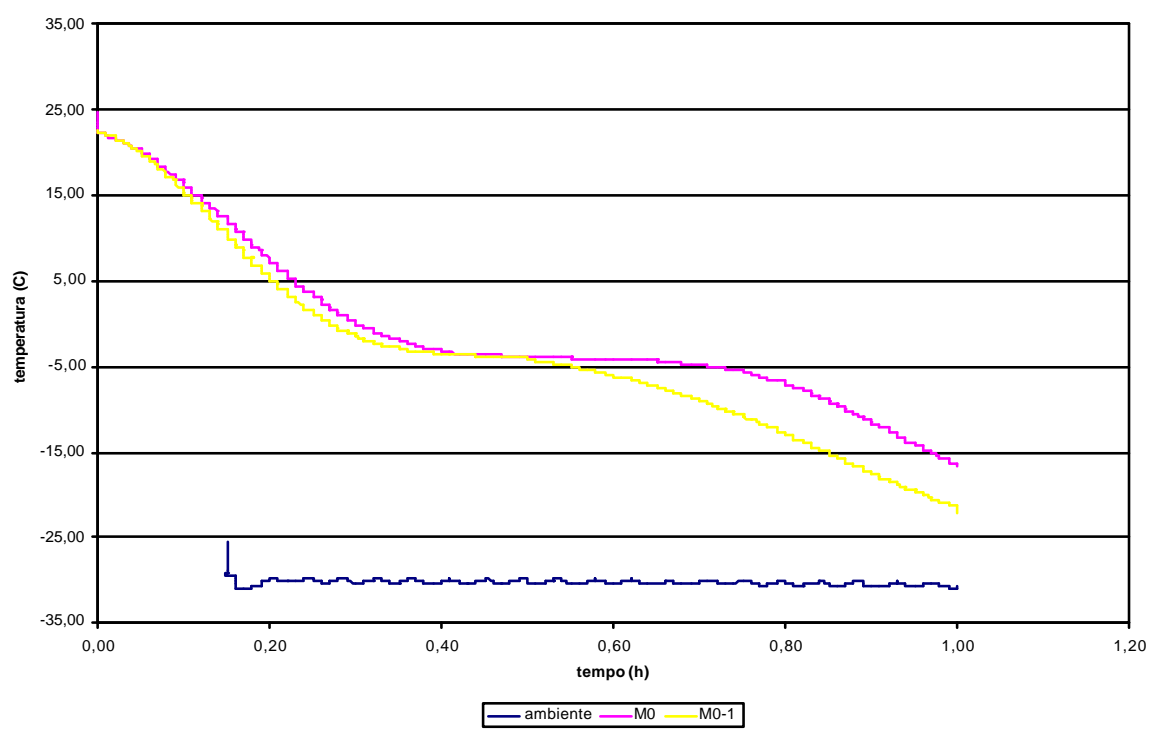

Curvas de congelamento M2

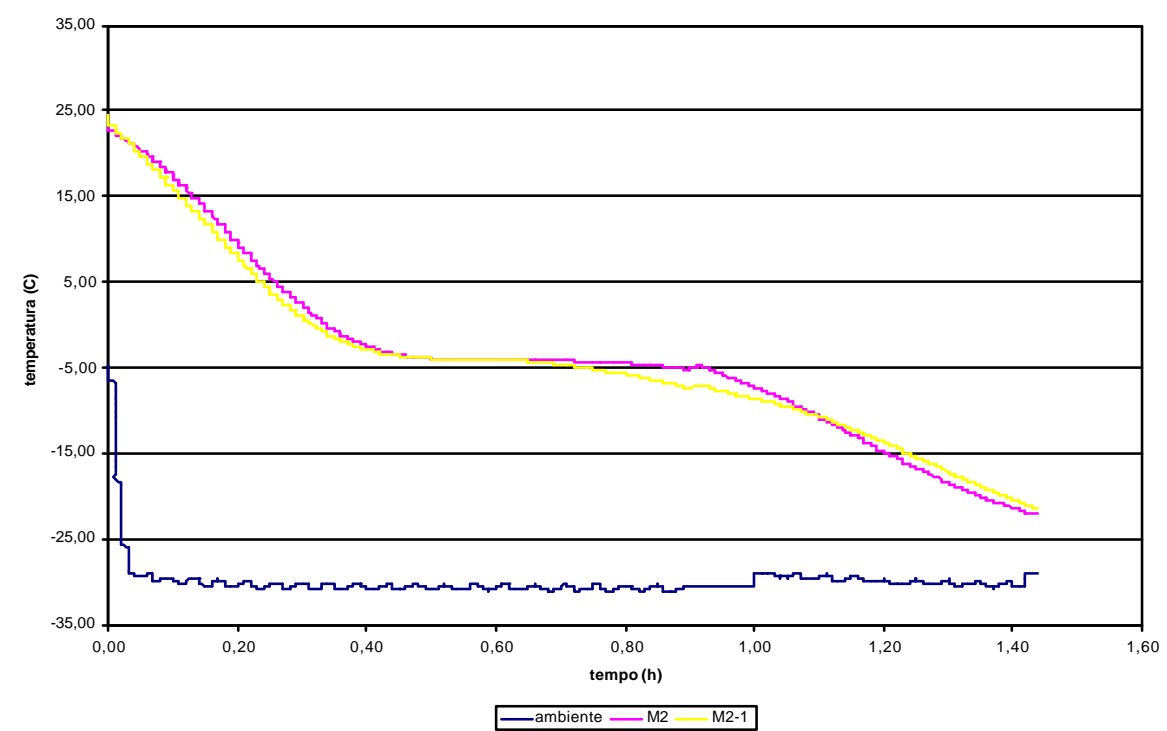

ANEXO B

Curvas de congelamento $\mathrm{M}$

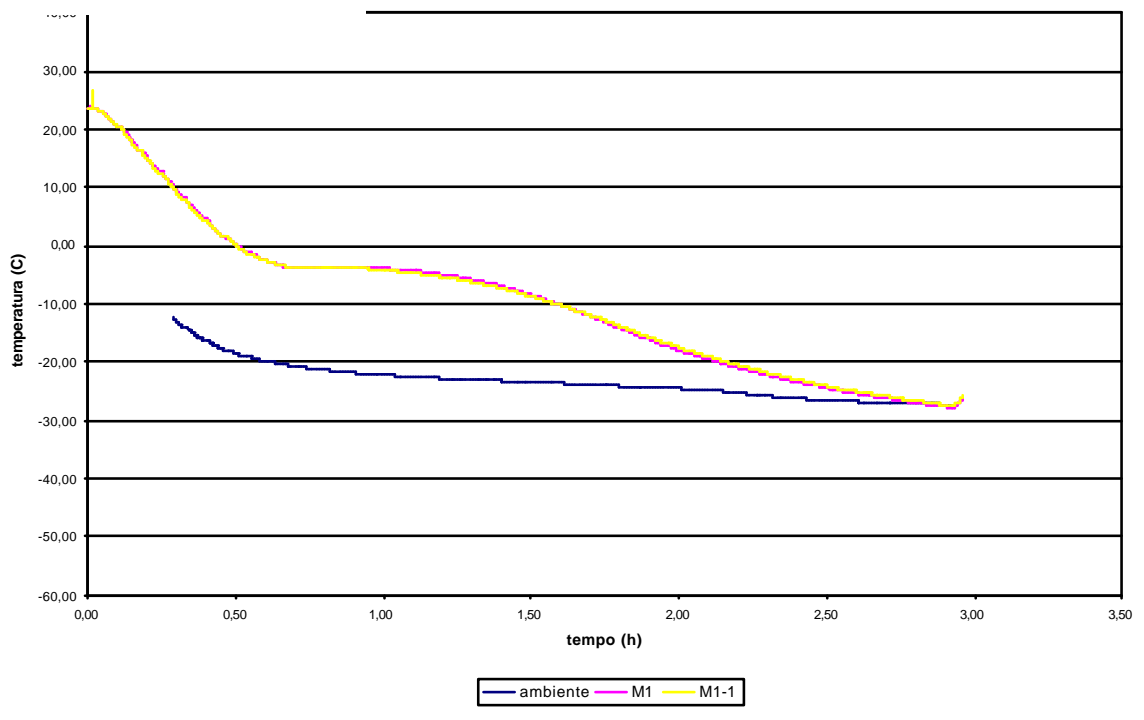

Curvas de congelamento M3

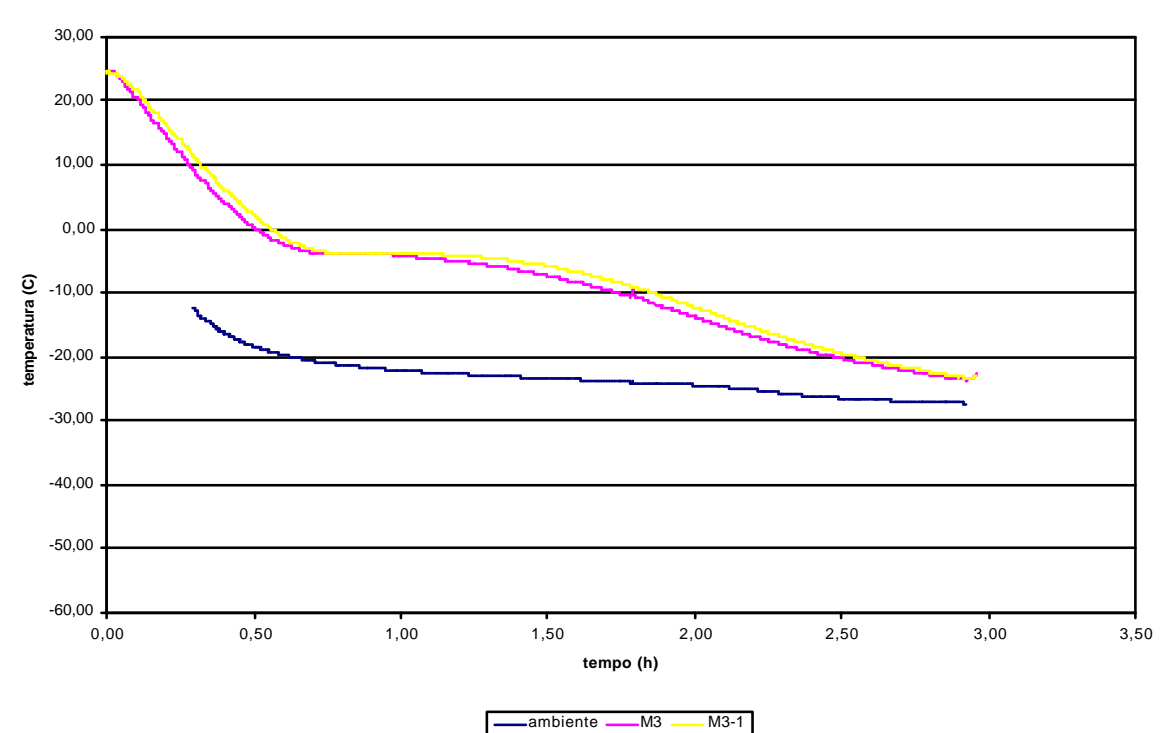

-ambiente $=\mathrm{M3}=\mathrm{M3-1}$

Figura B.1: História de temperatura no centro geométrico da massa, ao longo do tempo de congelamento, referentes às misturas com os componentes CSL, PS80 e DATEM. 
Curvas de congelamento M4

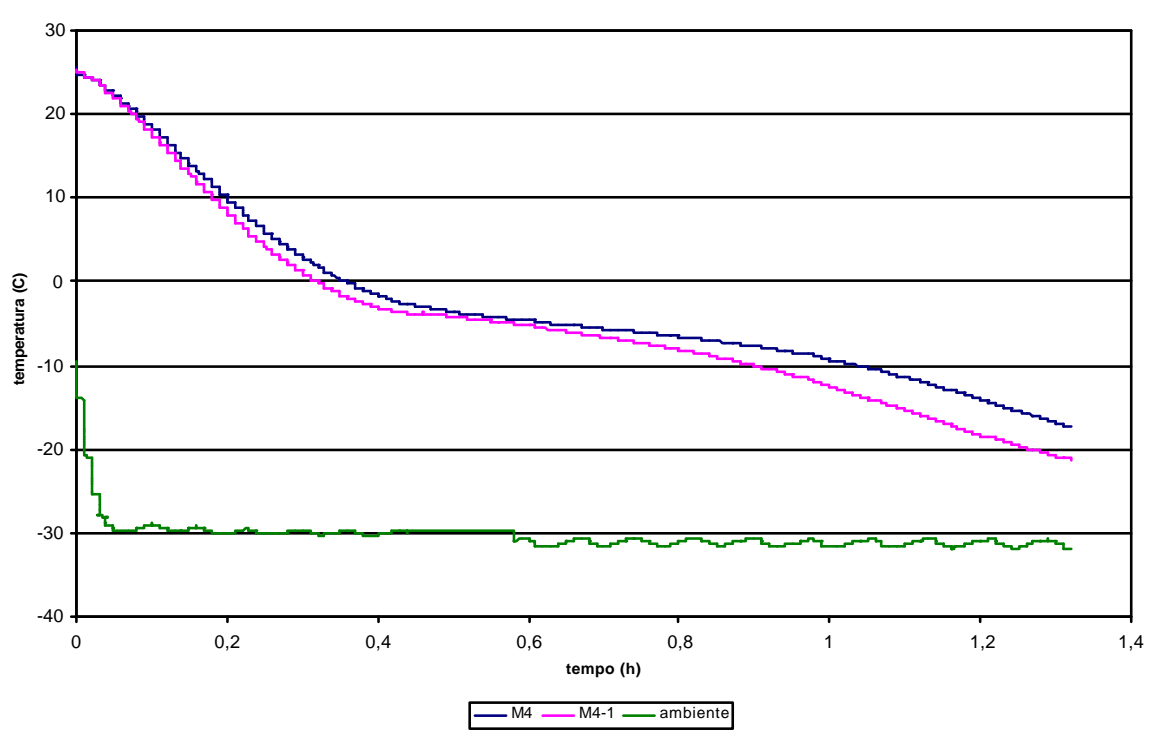

Curvas de congelamento M€

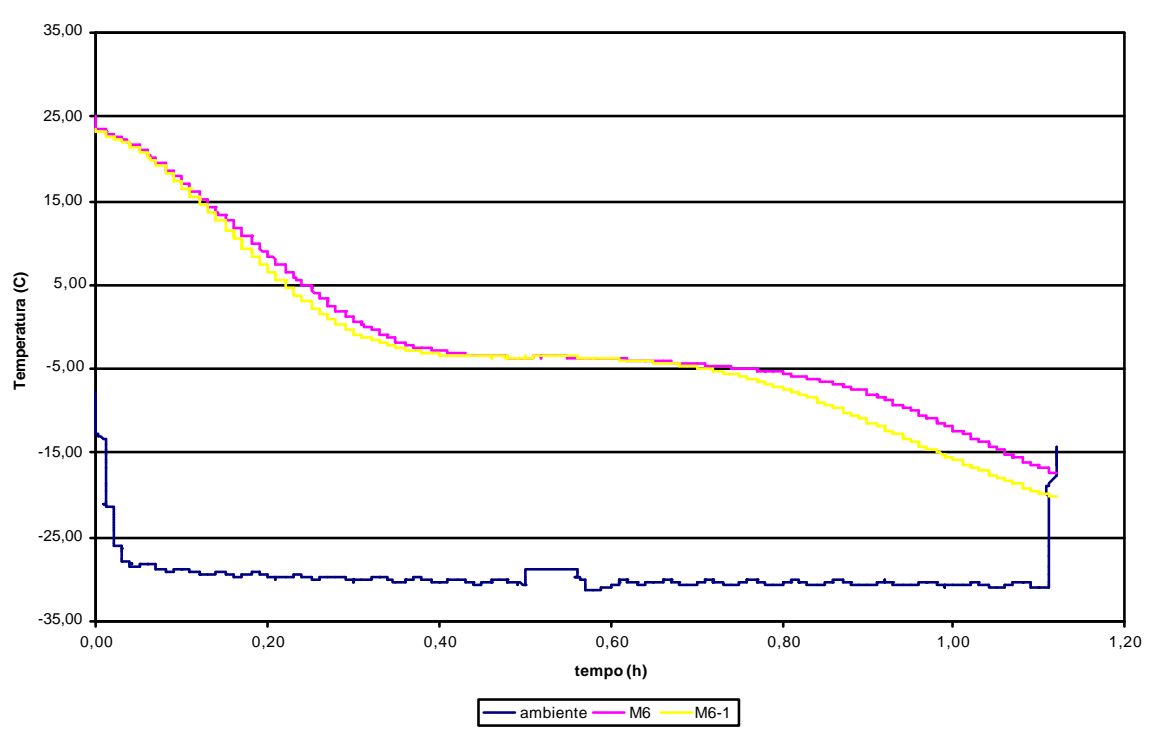

Curvas de congelamento M5

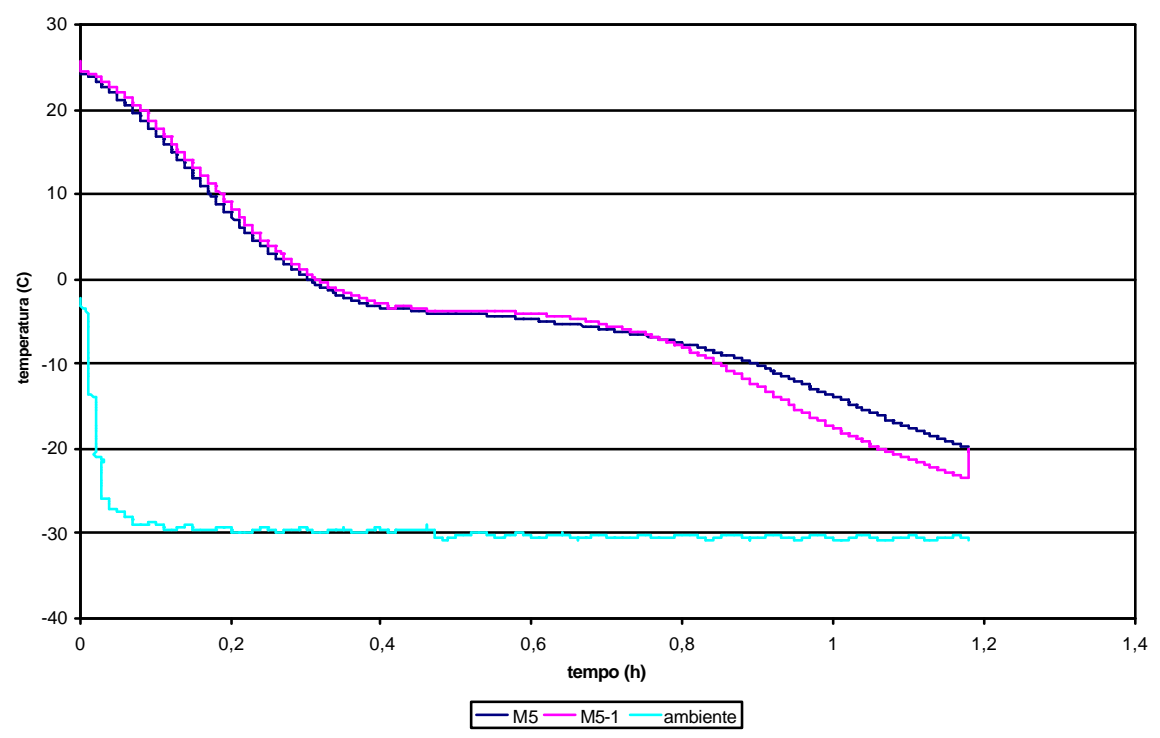

Curvas de congelamento M7a

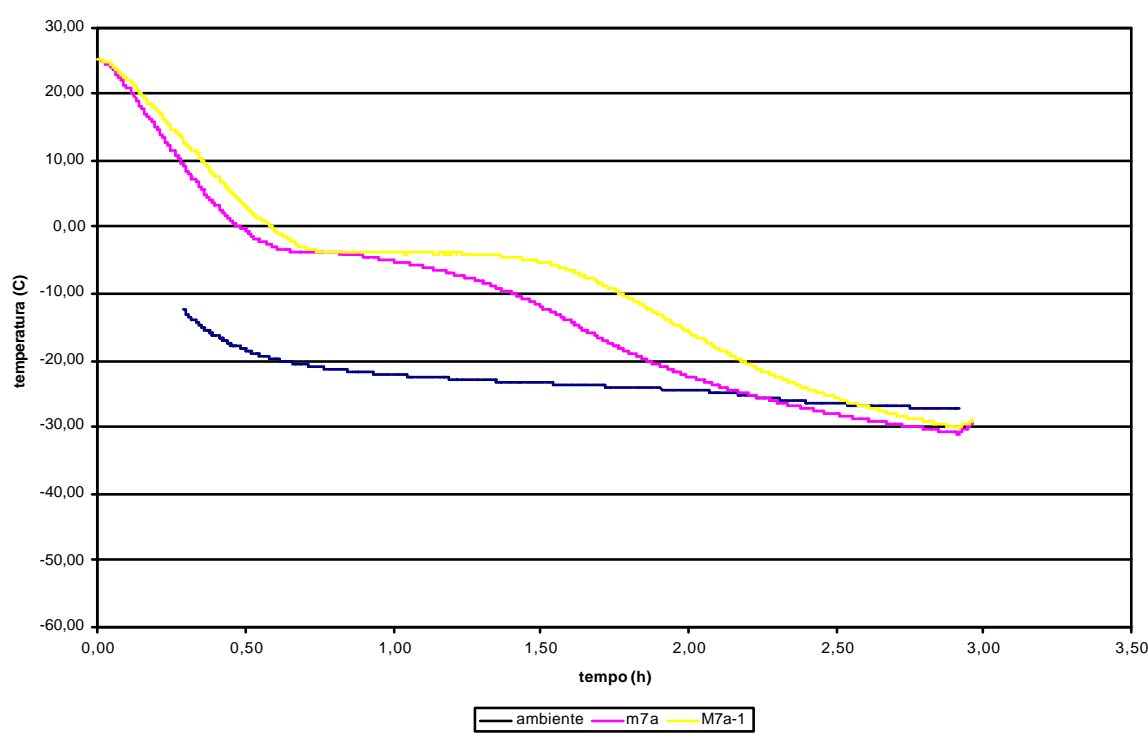

Figura B.1 (continuação): História de temperatura no centro geométrico da massa, ao longo do tempo de congelamento, referentes às misturas com os componentes CSL, PS80 e DATEM. 
Curvas de congelamento M7b

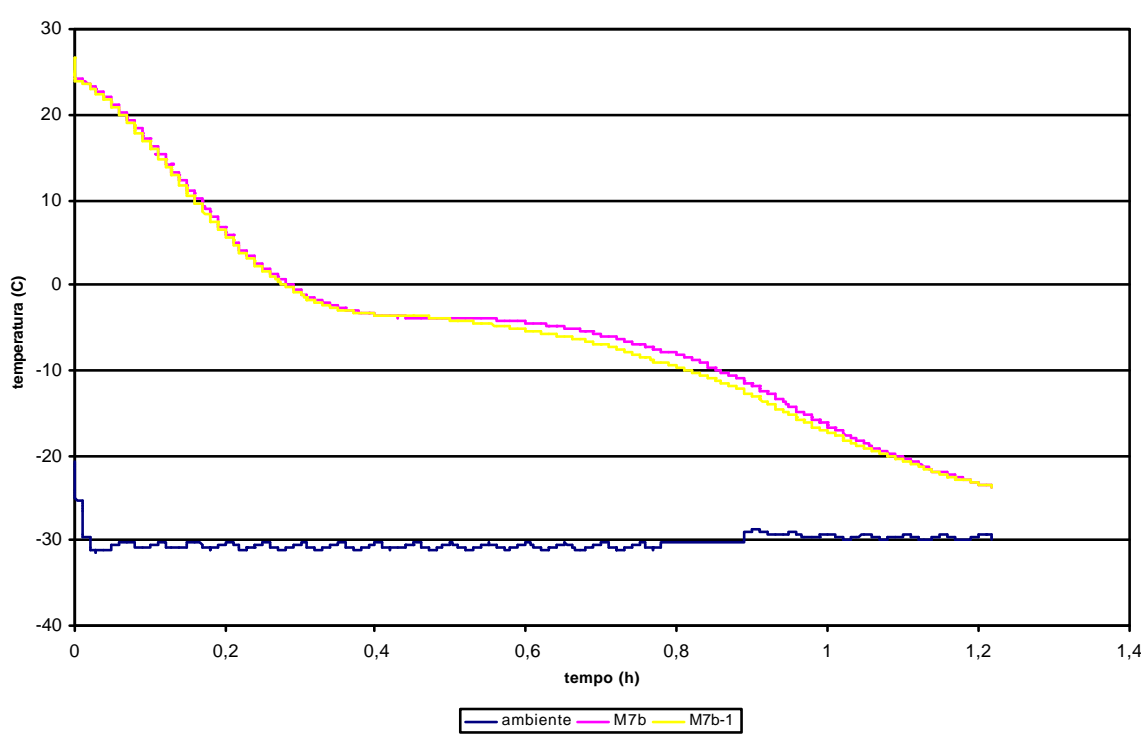

Curvas de congelamento M7C

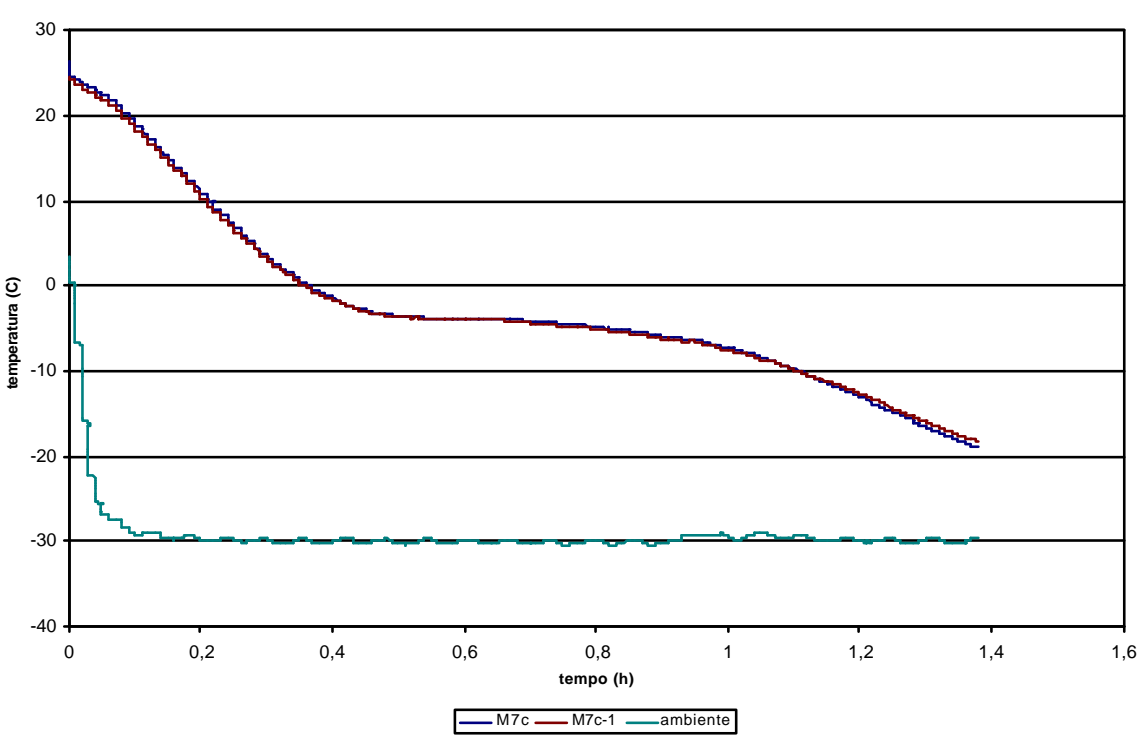

Figura B.1 (continuação): História de temperatura no centro geométrico da massa, ao longo do tempo de congelamento, referentes às misturas com os componentes CSL, PS80 e DATEM 

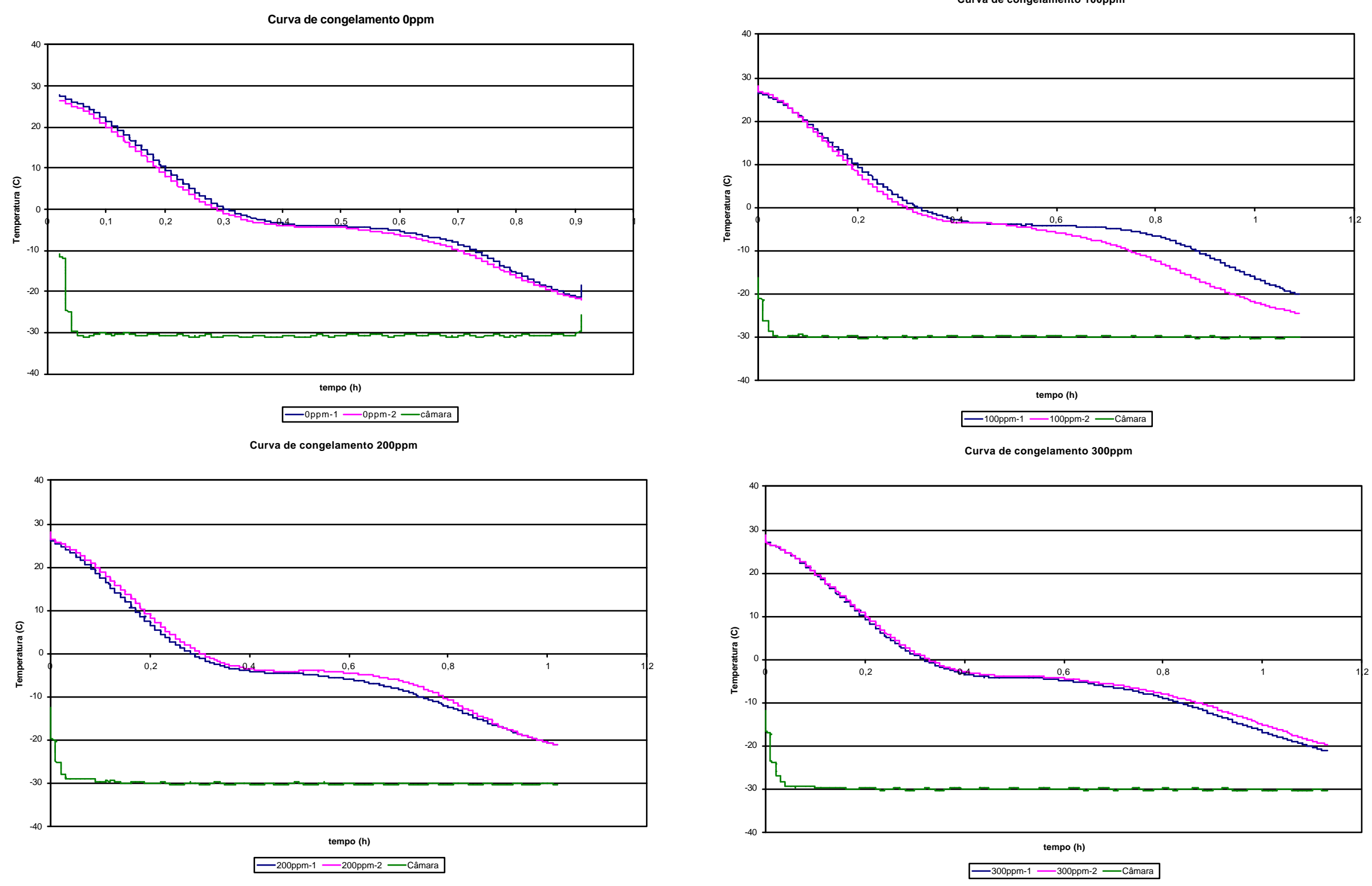

Figura B.2: História de temperatura no centro geométrico da massa, ao longo do tempo de congelamento, referentes à mistura $(0,3 \%$ de PS 80 e $0,2 \%$ de DATEM) com diferentes níveis de ácido ascórbico $(0,100,200$ e 300ppm). 
Curva de congelamento (0ppm)

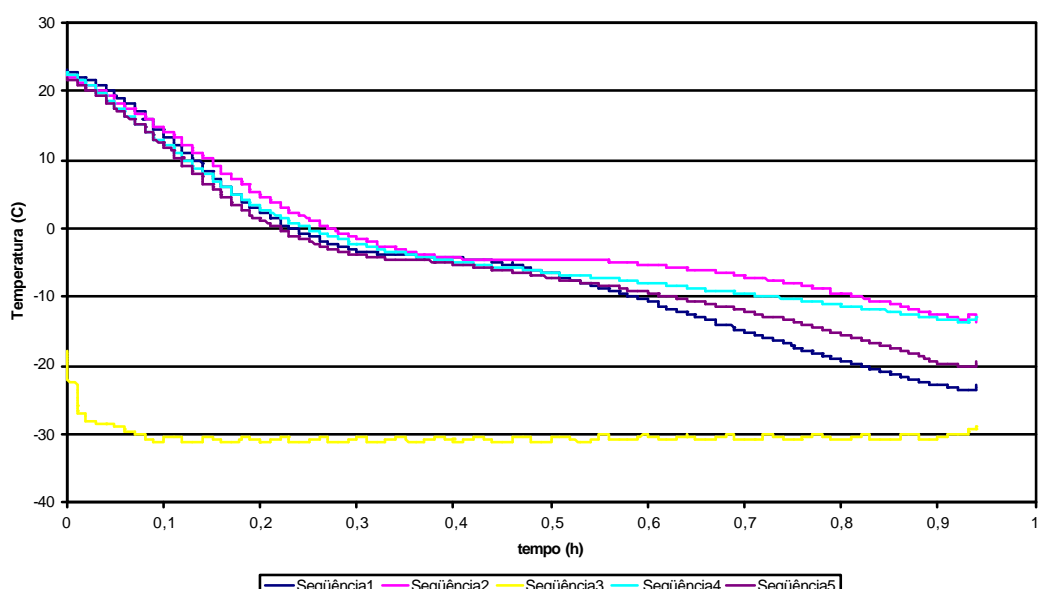

Curva de congelamento (200ppm)

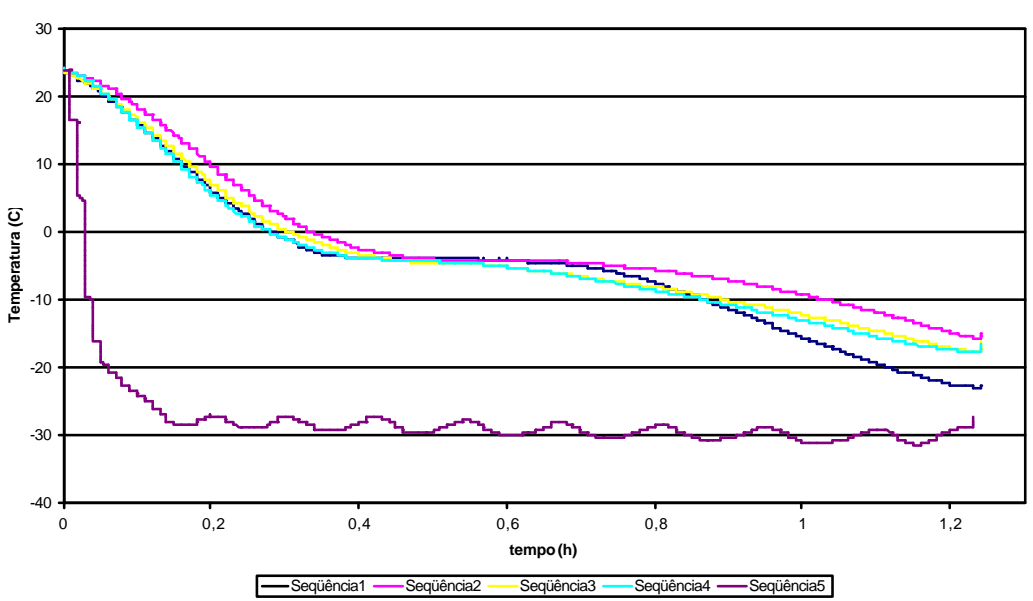

Figura B.3: História de temperatura no centro geométrico da massa, ao longo do tempo de congelamento, referentes a mistura $(0,3 \%$ de PS80 e $0,2 \%$ de DATEM) e adição de 0 e 200 ppm de ácido ascórbico. 
$0 \mathrm{ppm}$

Curvas de desenvolvimento da massa (0 dias)

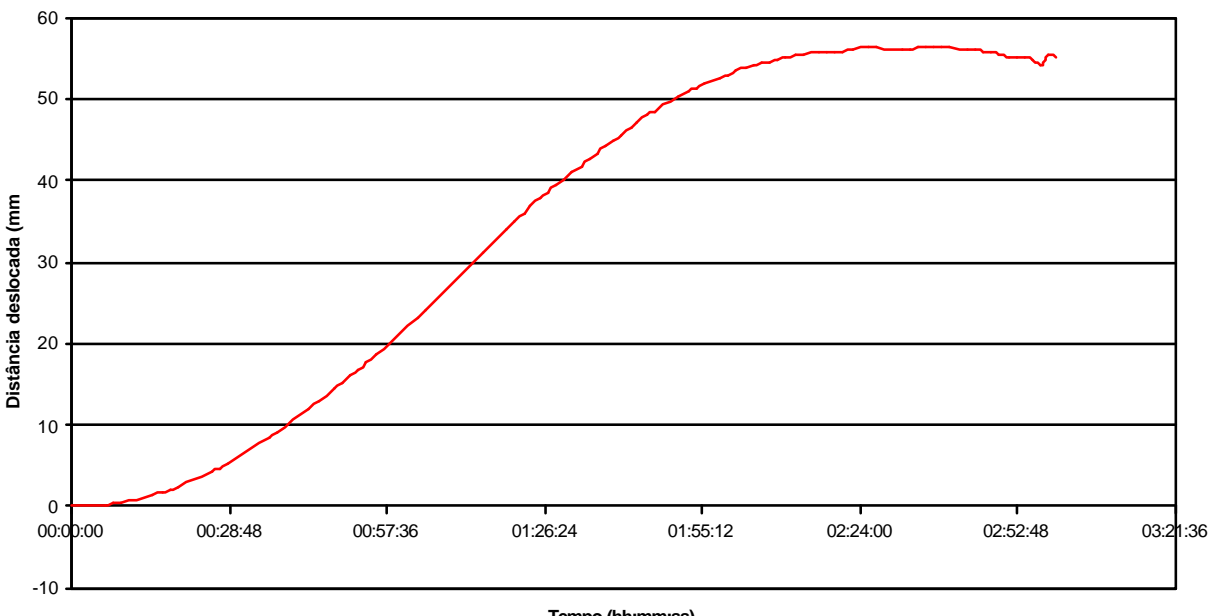

Tempo (hh:mm:ss)

Curvas de desenvolvimento da massa (1 dia)

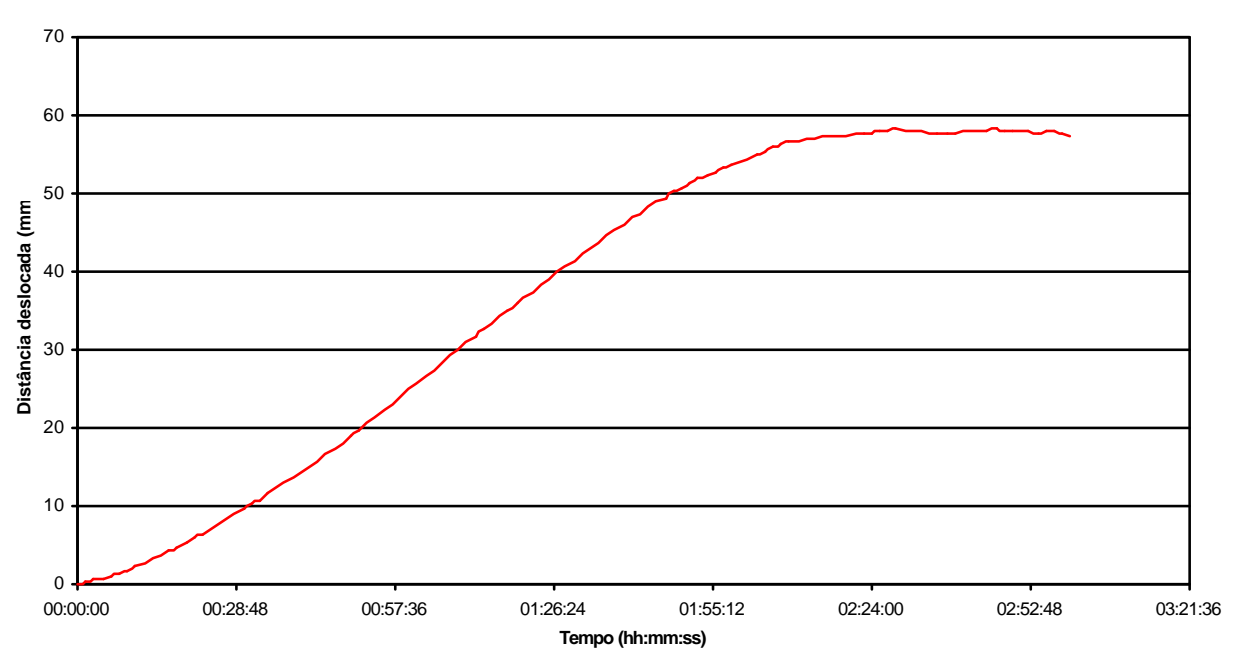

200 ppm

Curvas de desenvolvimento da massa ( 0 dias)

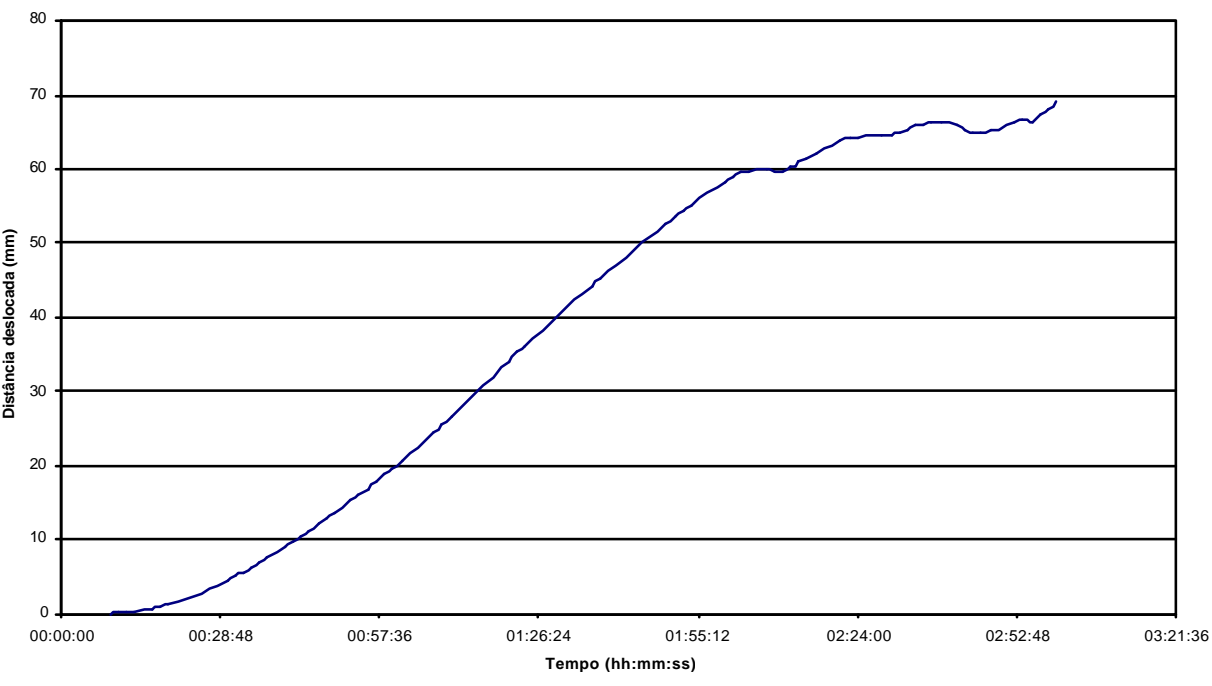

Curvas de desenvolvimento da massa (1 dia)

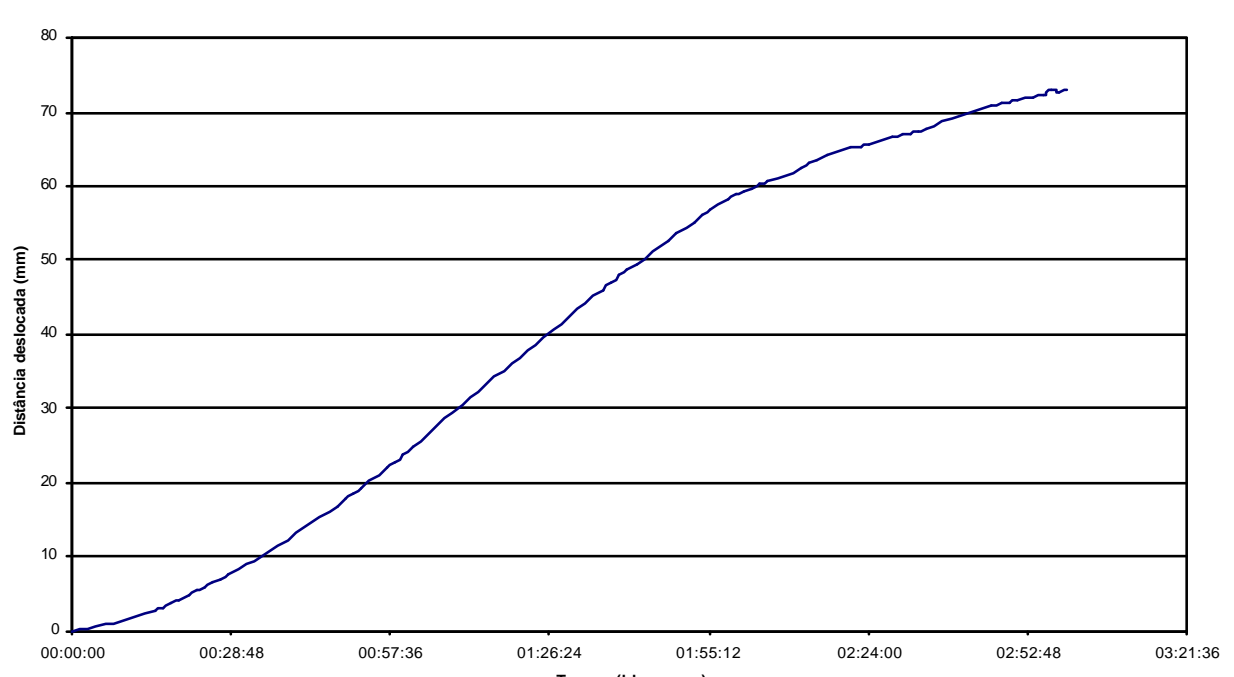

Figura C.1: Curvas de desenvolvimento das massas referentes a mistura ( $0,3 \%$ de PS80 e 0,2 \% de DATEM) e adição de ácido ascórbico (0 e 200 ppm) ao longo do tempo de armazenamento congelado. 
0 ppm

Curvas de desenvolvimento da massa (4 dias)

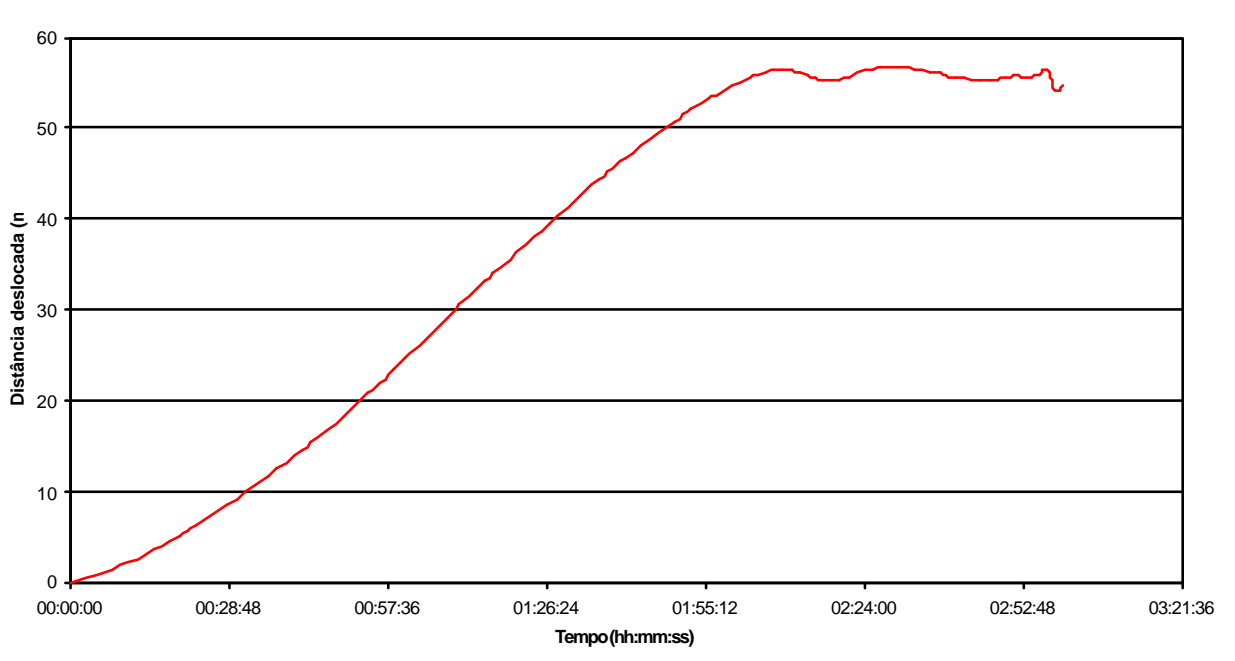

Curvas de desenvolvimento da massa ( 7 dias)

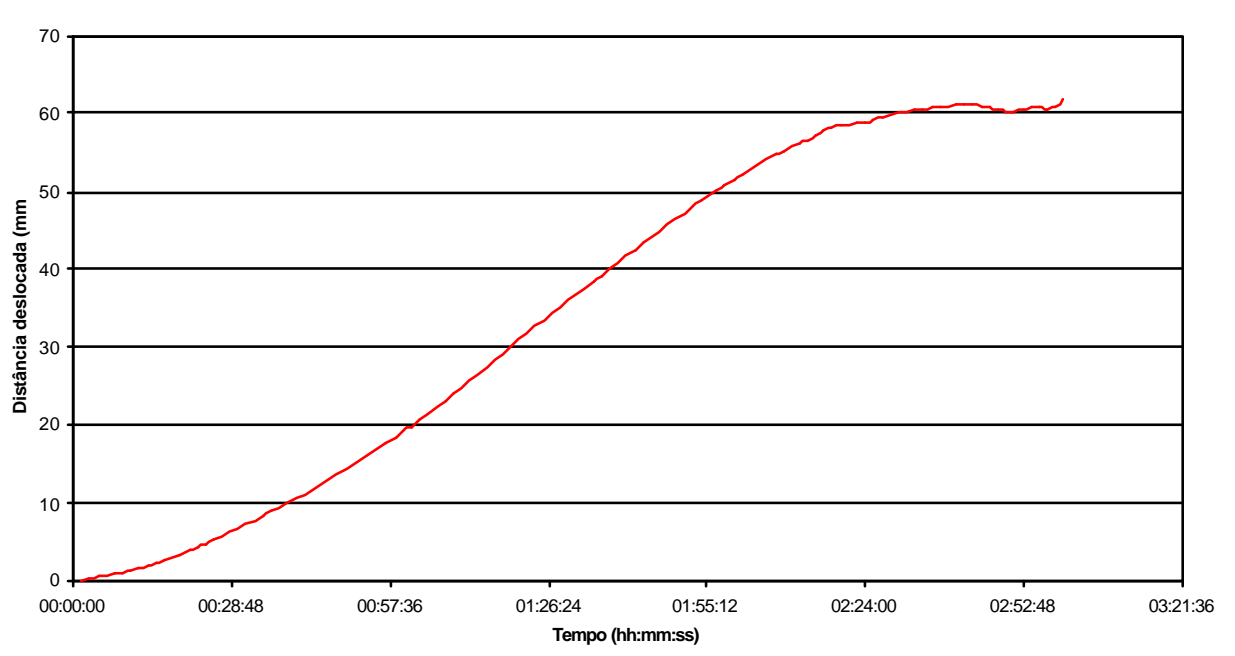

200 ppm

Curvas de desenvolvimento da massa (4 dias)

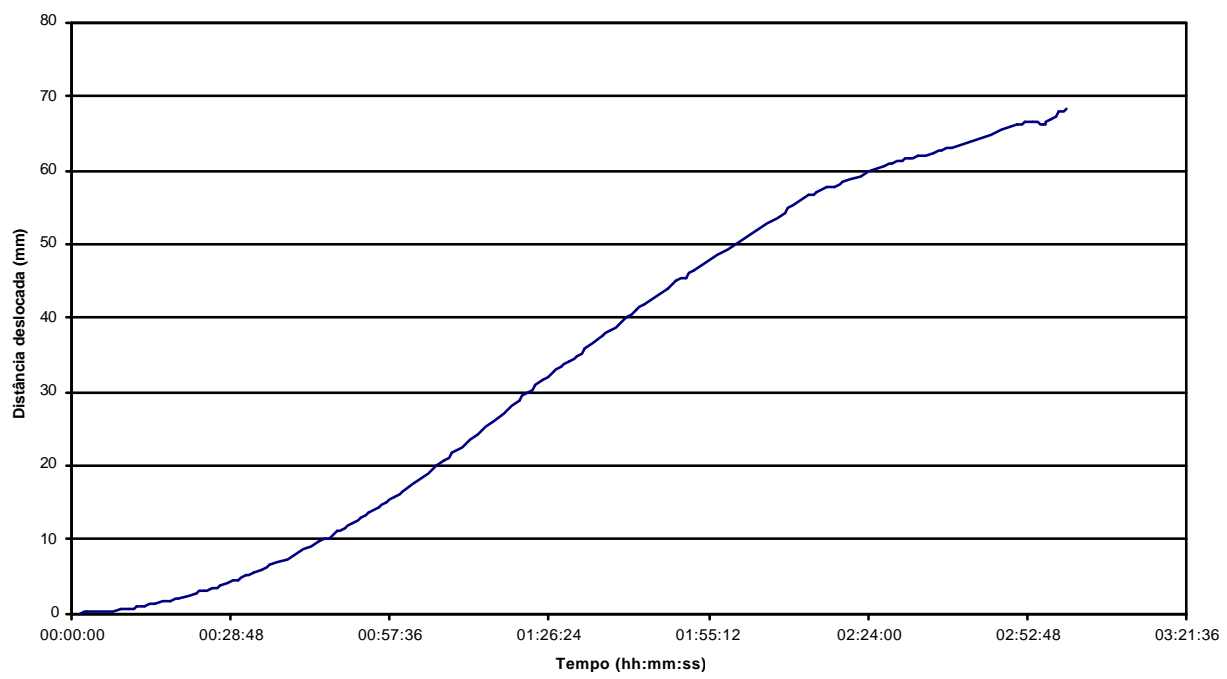

Curvas de desenvolvimento da massa (7 dias)

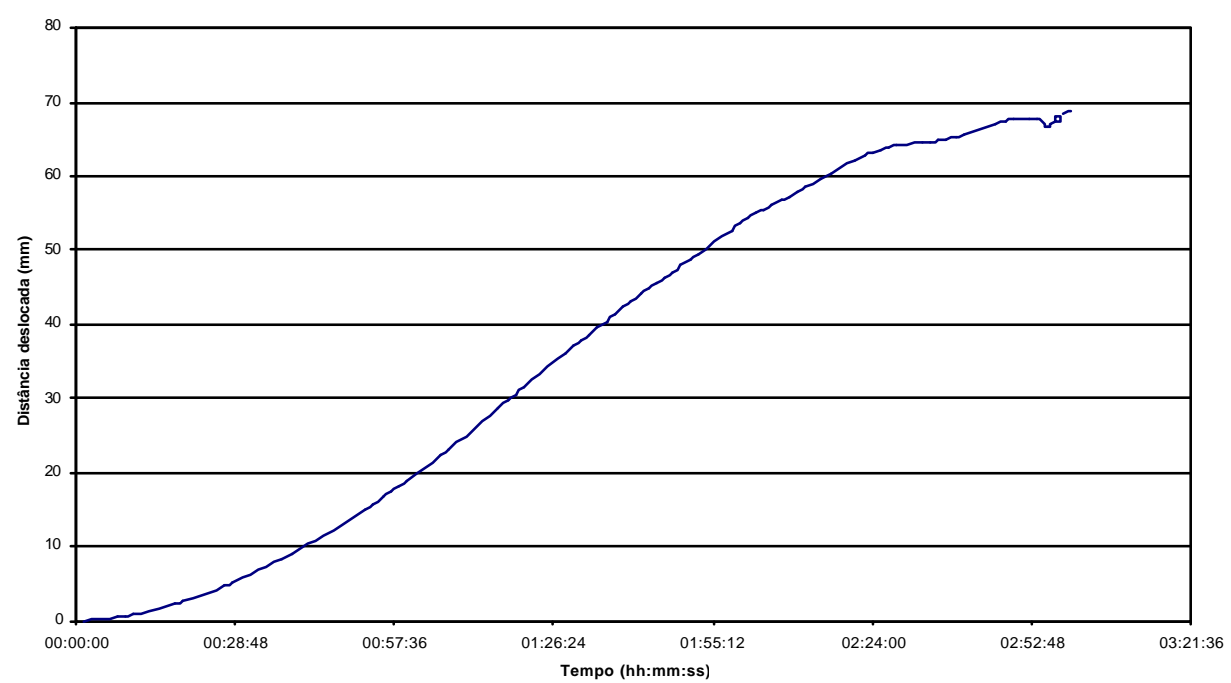

Figura C.1 (continuação): Curvas de desenvolvimento das massas referentes a mistura ( $0,3 \%$ de PS 80 e $0,2 \%$ de DATEM) e adição de ácido ascórbico (0 e 200 ppm) ao longo do tempo de armazenamento congelado. 
$0 \mathrm{ppm}$

Curvas de desenvolvimento da massa (11 dias)

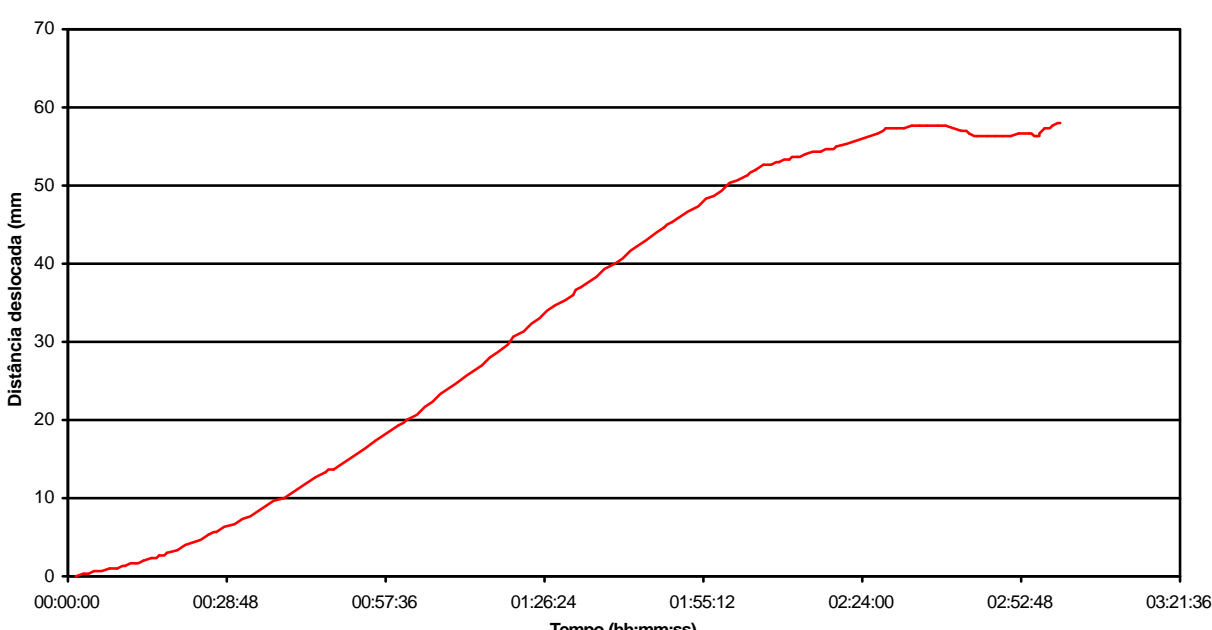

Curvas de desenvolvimento da massa (13 dias)

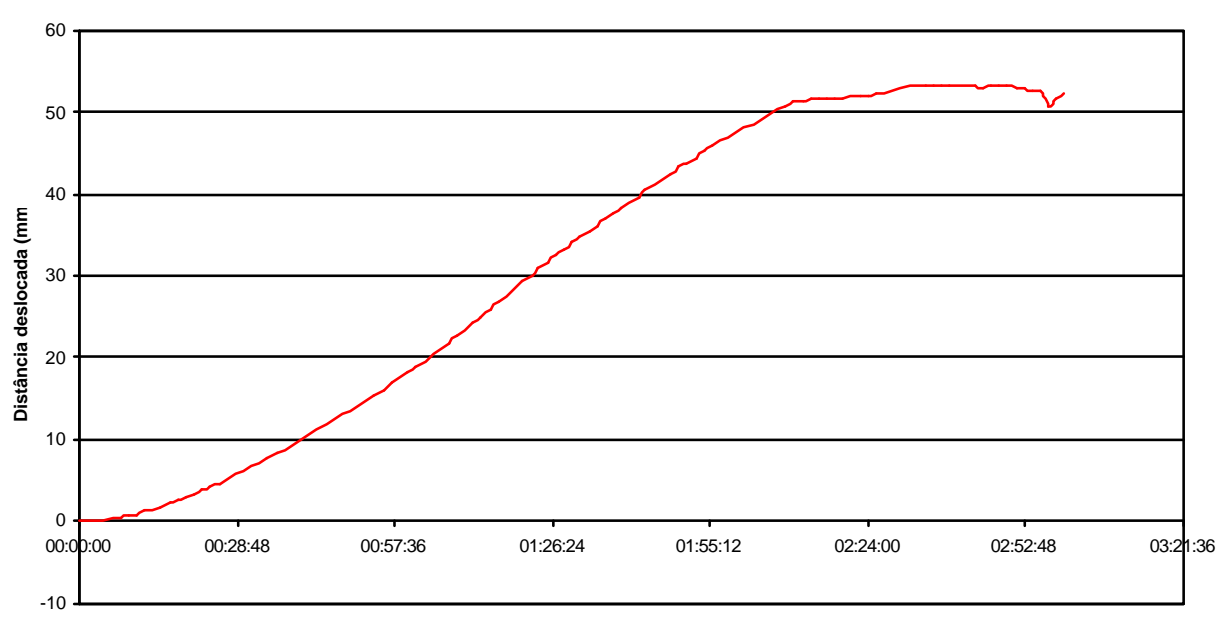

200 ppm

Curvas de desenvolvimento da massa (11 dias)

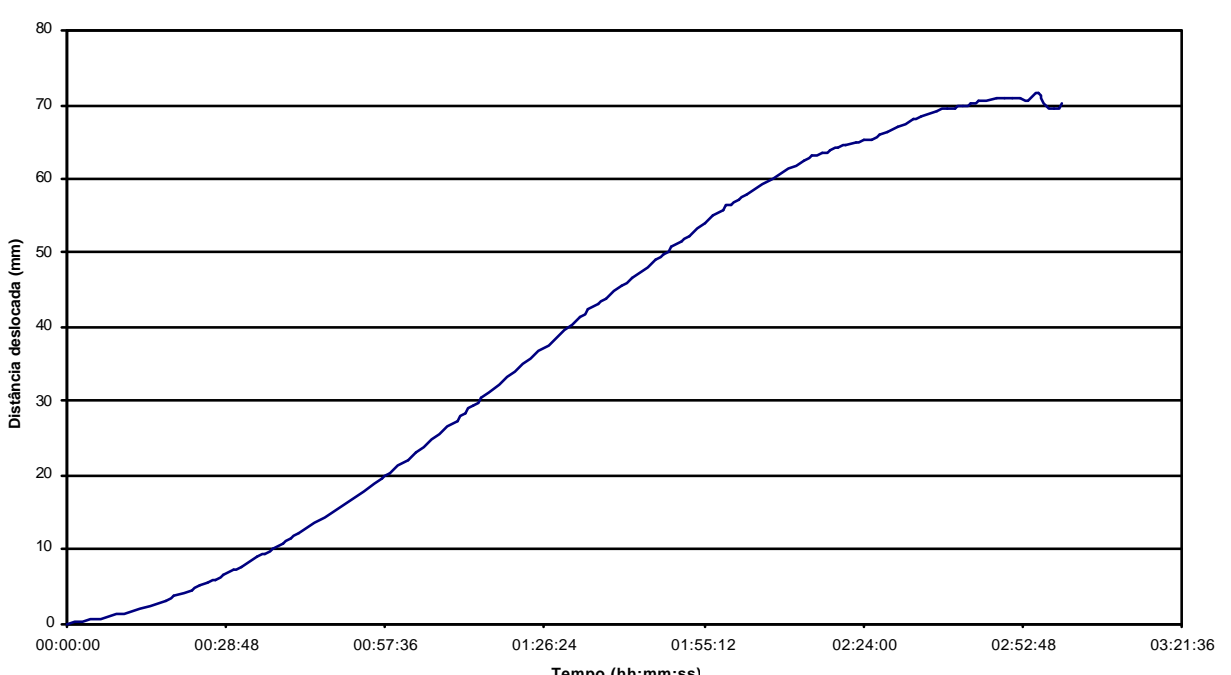

Curvas de desenvolvimento da massa (13 dias)

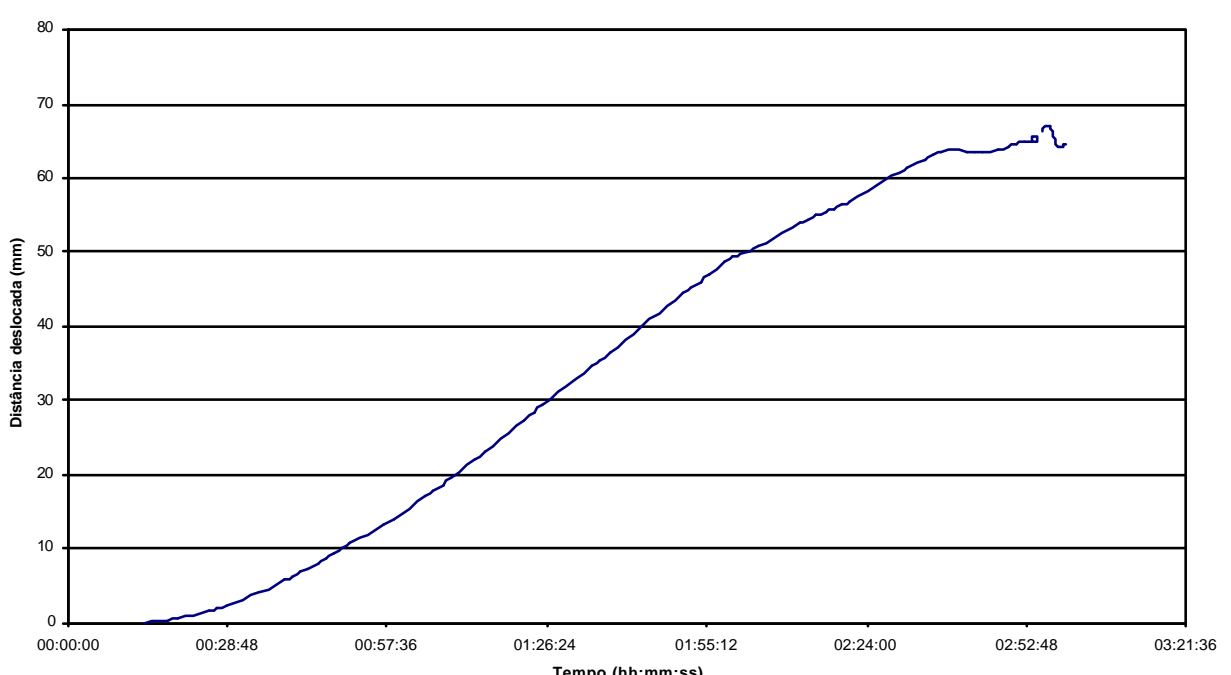

Figura C.1 (continuação): Curvas de desenvolvimento das massas referentes a mistura (0,3 \% de PS80 e 0,2 \% de DATEM) e adição de ácido ascórbico (0 e 200 ppm) ao longo do tempo de armazenamento congelado. 
Geração de CO2 (200ppm - 0 dias)

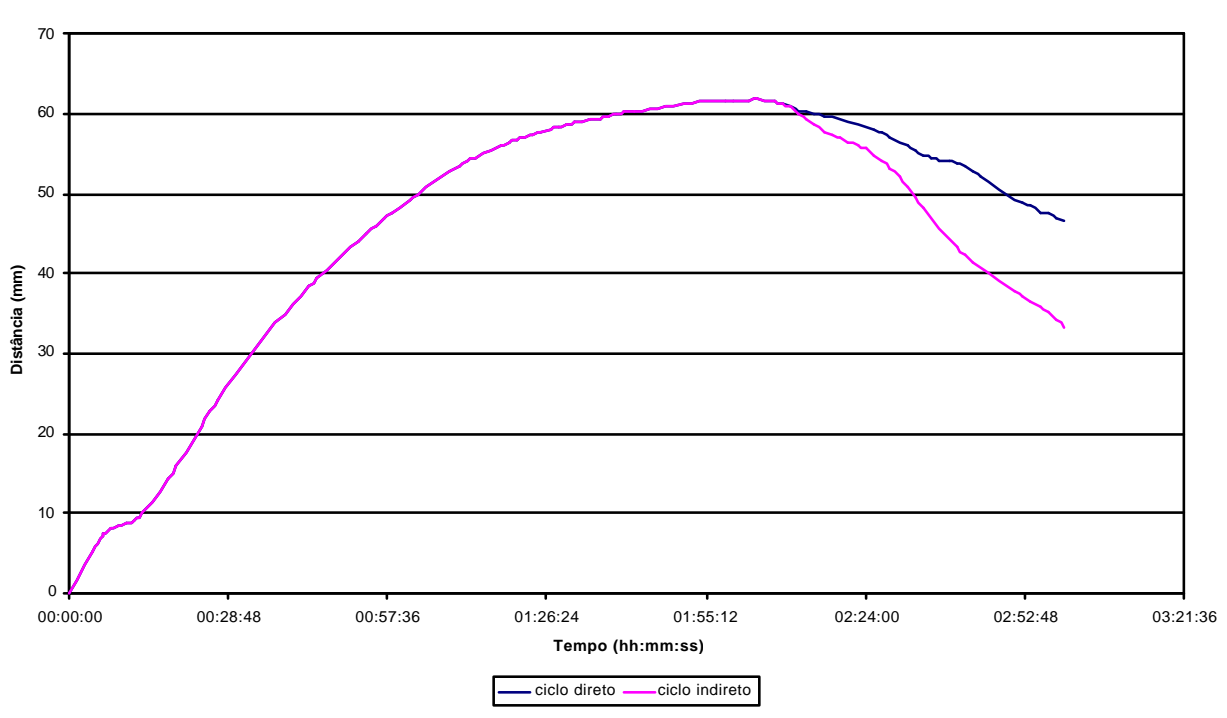

Geração de CO2 (200ppm - 1 dias)

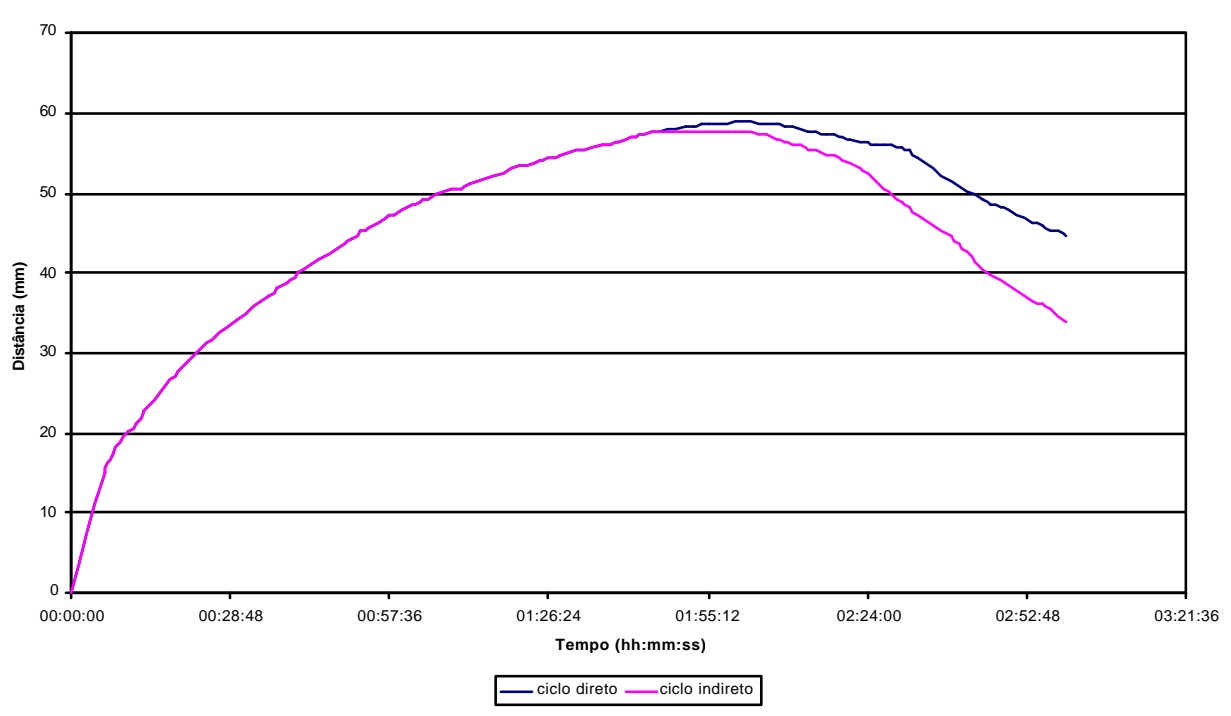

Geração de $\operatorname{CO2}$ (0ppm - 0 dias)

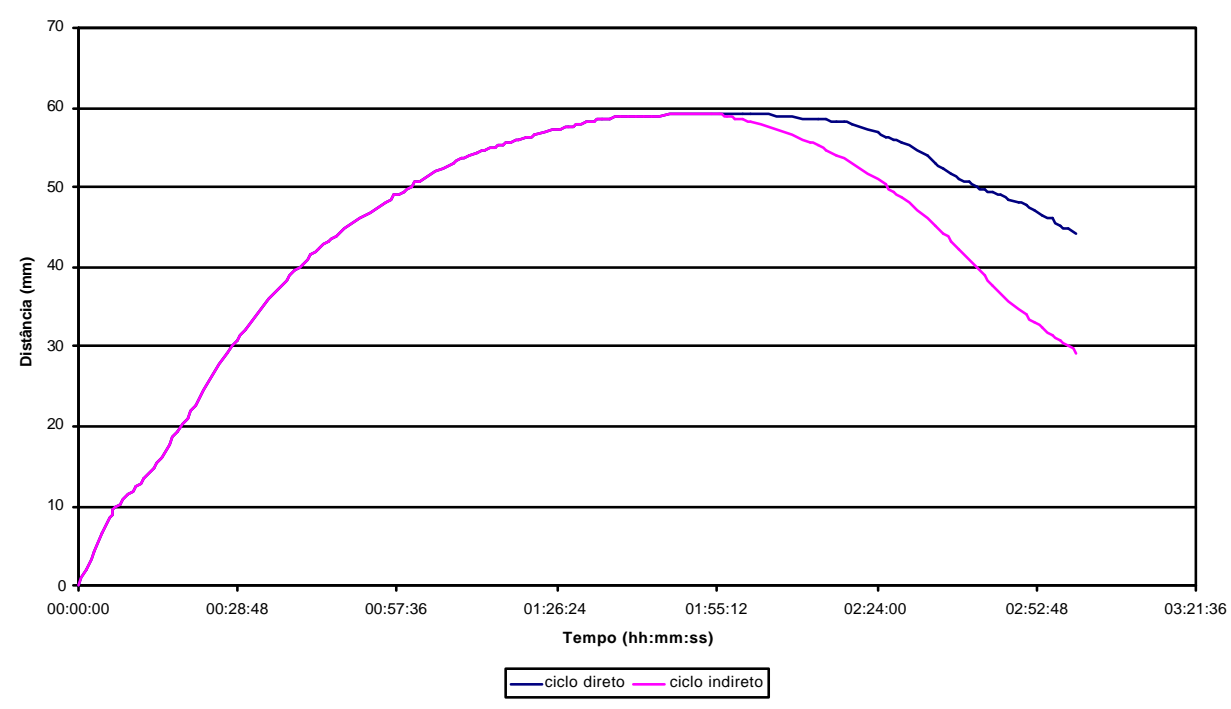

Geração de CO2 (0ppm - 1 dia)

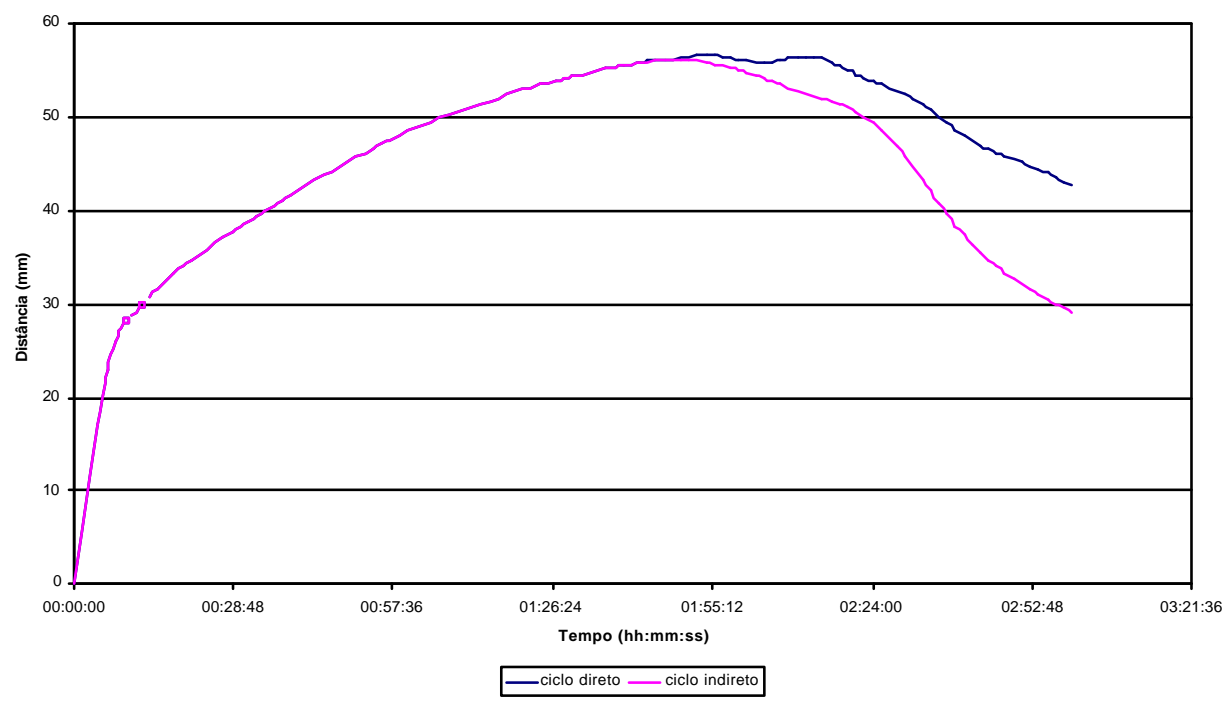

Figura C.2: Curvas de produção de $\mathrm{CO}_{2}$ das massas referentes a mistura (0,3 \% de PS80 e 0,2 \% de DATEM) e adição de ácido ascórbico (0 e 200 ppm) ao longo do tempo de armazenamento congelado. 
Geração de CO2 (200ppm - 4 dias)

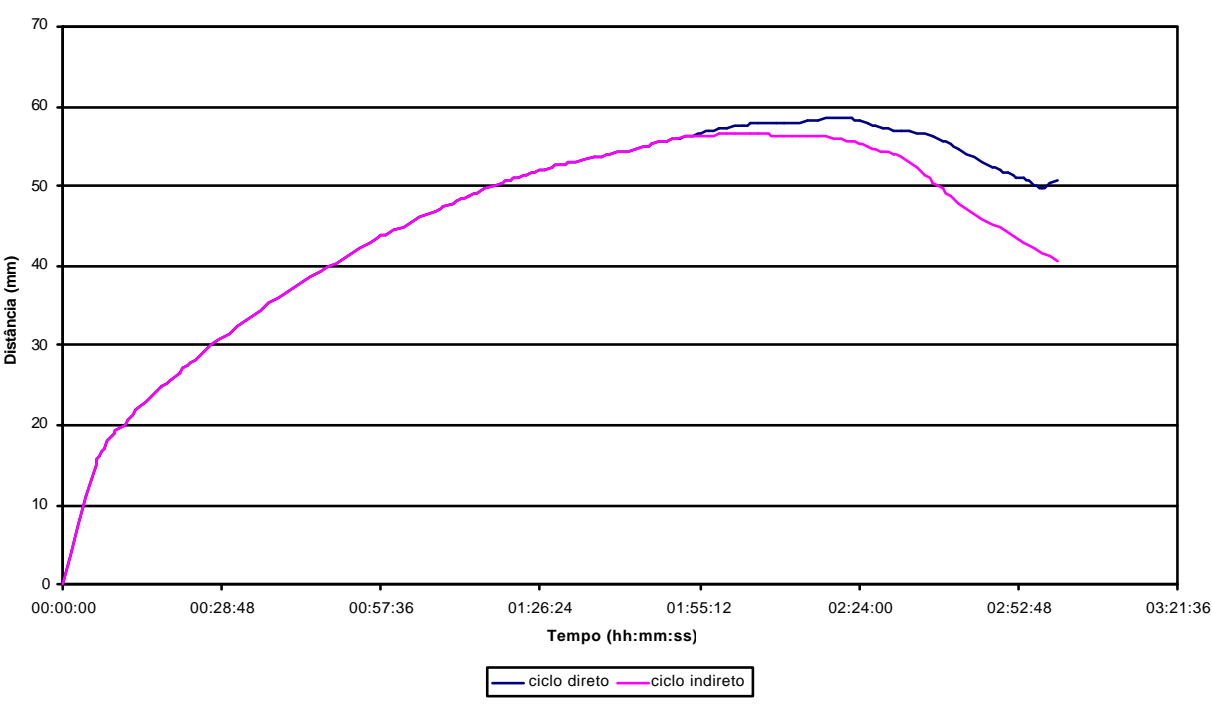

Geração de CO2 (200ppm - 7 dias)

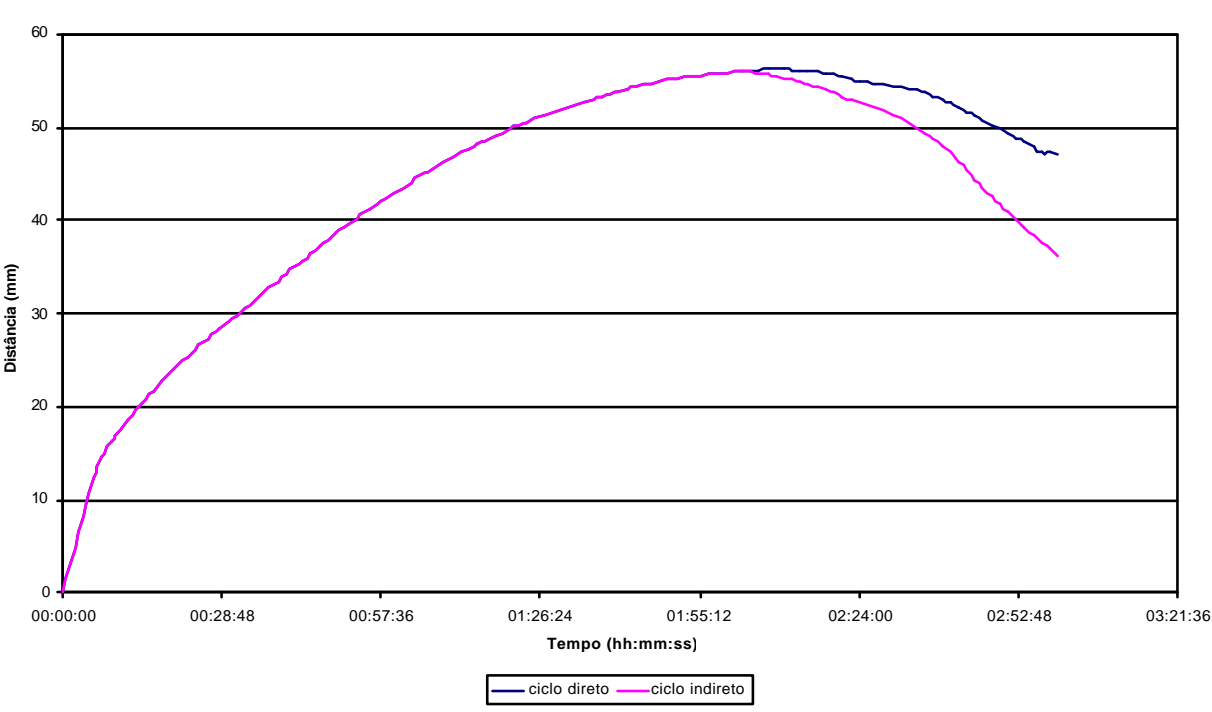

Geração de $\operatorname{CO2}$ (0ppm - 4 dias)

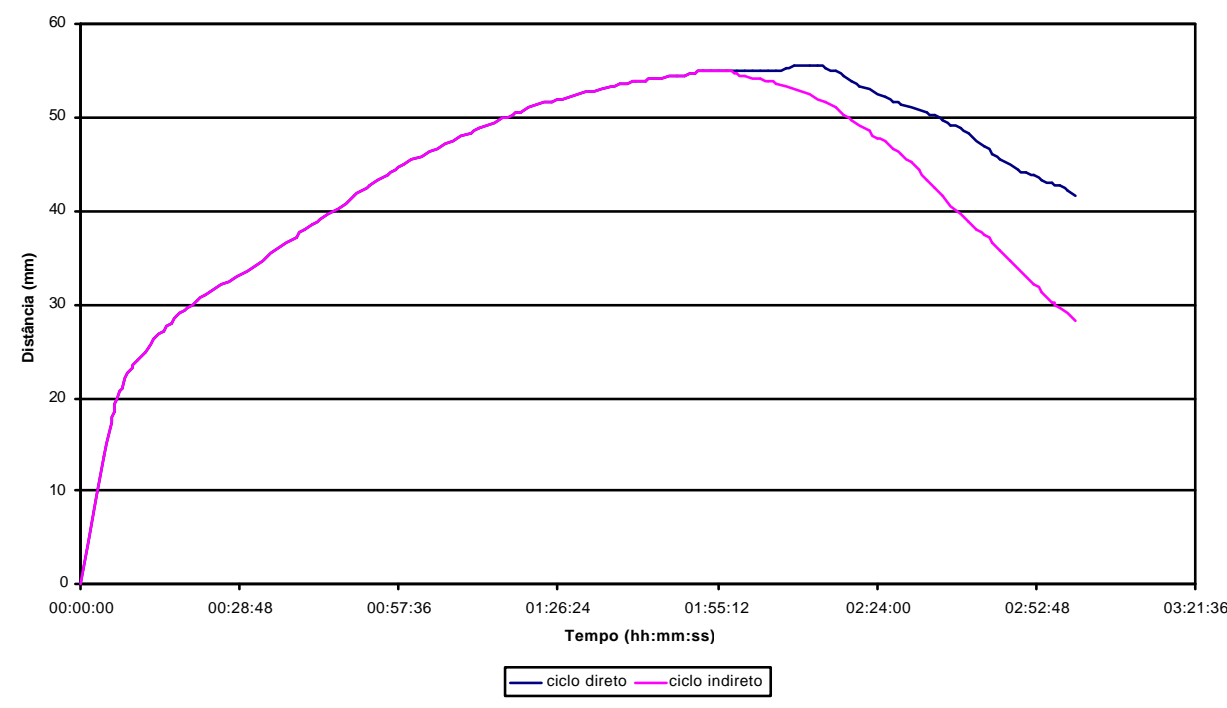

Geração de $\mathrm{CO2}$ (0ppm - 7 dias)

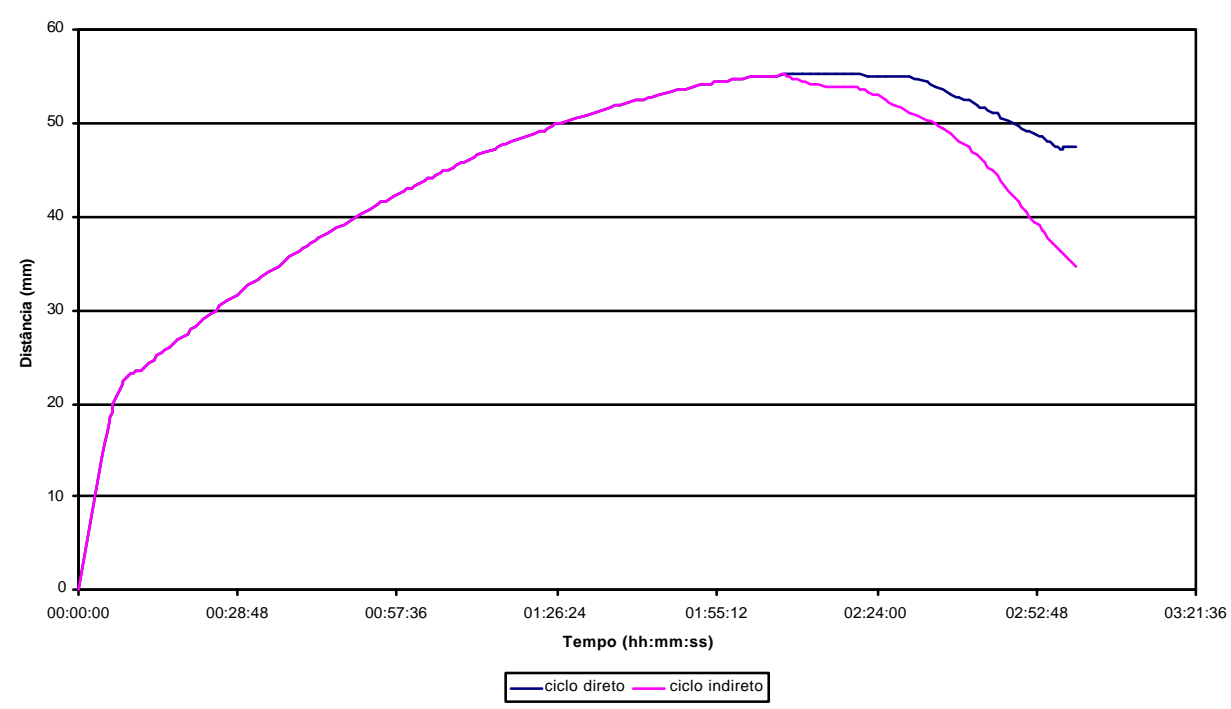

Figura C.2 (continuação): Curvas de produção de $\mathrm{CO}_{2}$ das massas referentes a mistura (0,3 \% de PS80 e 0,2 \% de DATEM) e adição de ácido ascórbico (0 e 200 ppm) ao longo do tempo de armazenamento congelado. 
Geração de CO2 (200ppm - 11 dias)

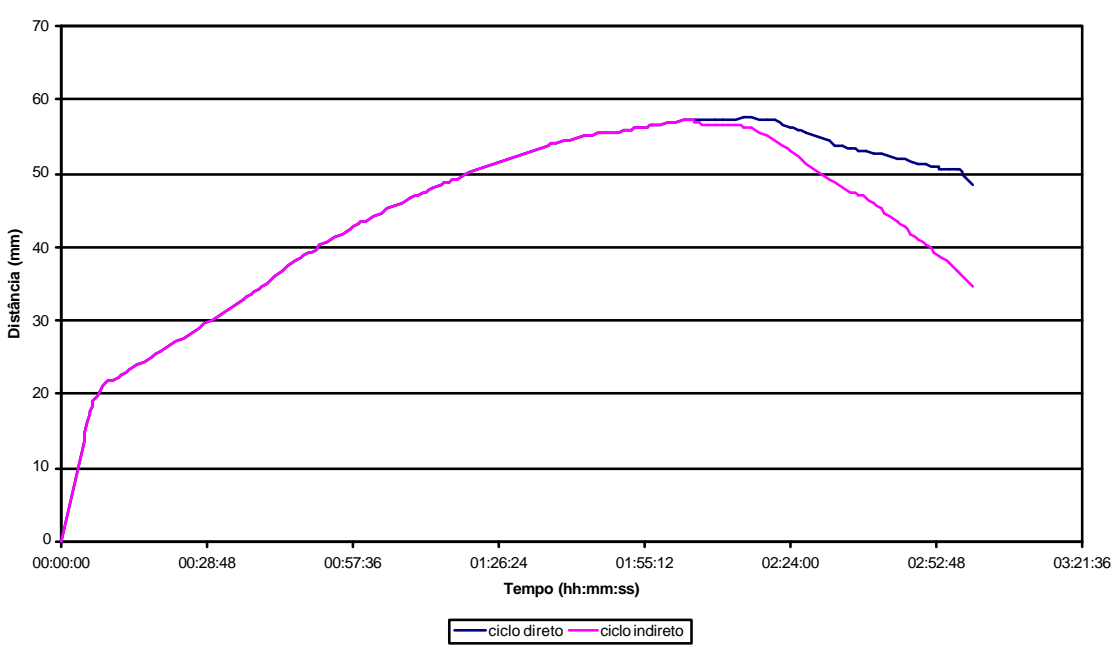

Geração de CO2 (200ppm - 13 dias)

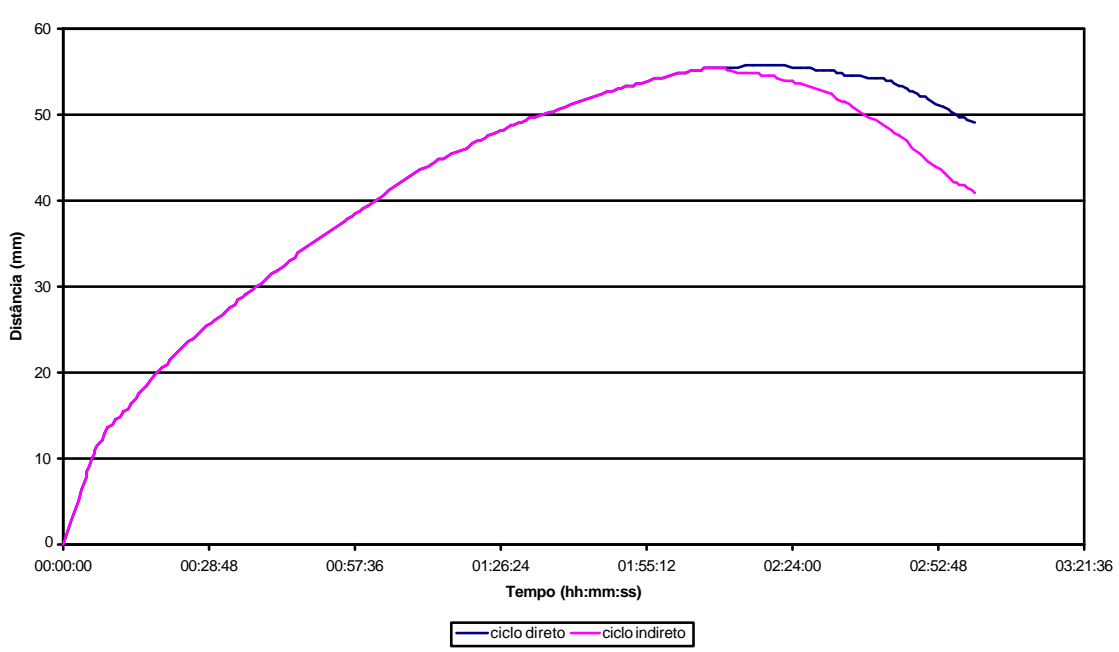

Geração de CO2 (0ppm - 11 dias)

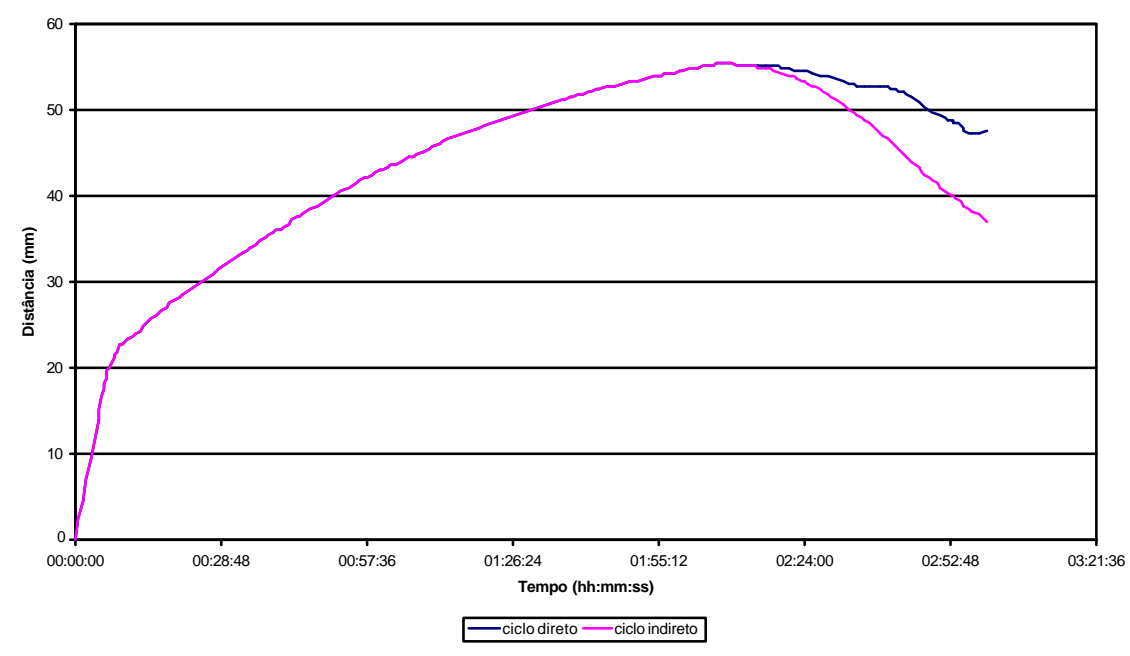

Geração de CO2 (0ppm - 13 dias)

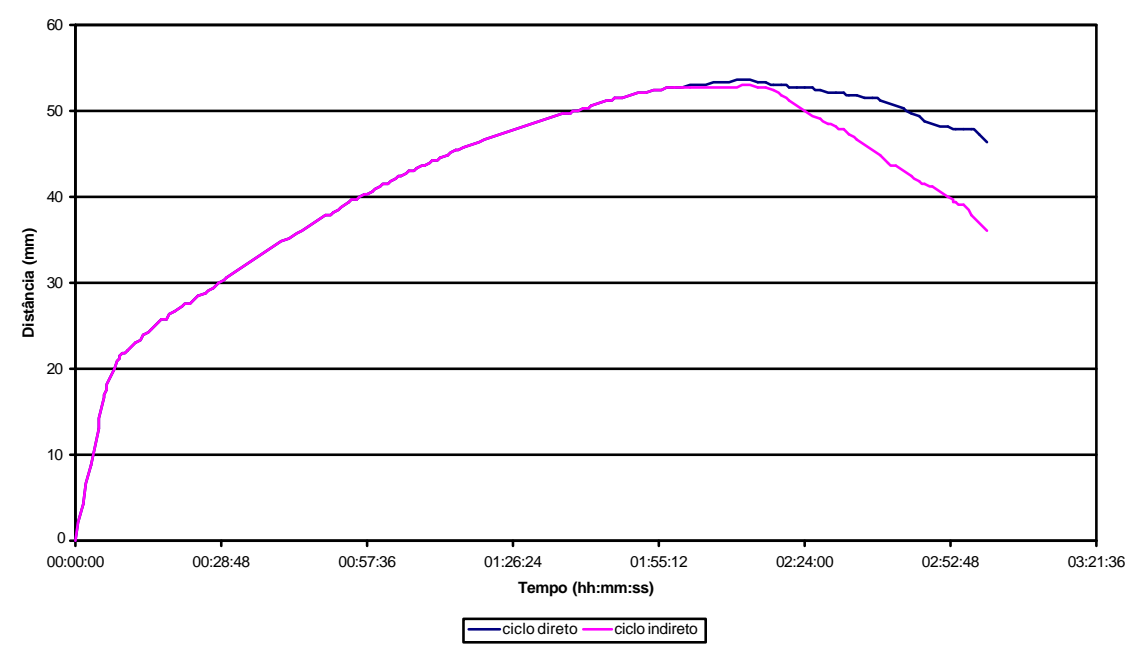

Figura C.2 (continuação): Curvas de produção de $\mathrm{CO}_{2}$ das massas referentes a mistura (0,3\% de PS80 e 0,2\% de DATEM) e adição de ácido ascórbico (0 e 200 ppm) ao longo do tempo de armazenamento congelado 


\section{REFERÊNCIAS BIBLIOGRÁFICAS*}

AACC, APPROVED METHODS OF THE AMERICAN ASSOCIATION OF CEREAL CHEMISTS, $9^{\mathfrak{a}}$ edição. Saint Paul: American Association of Cereal Chemists, 1995.

ABD EL-HADY, E. A.; EL-SAMAHY, S. K.; BRÜMMER, J. -M. Effect of oxidants, sodium-stearoyl-2-lactylate and their mixtures on rheological and baking properties of nonprefermented frozen doughs. Lebensmittel Wissenschaft undTechnologie, v. 32, p. 446-454, 1999.

AEE, L. H.; HIE, K. N.; NISHINARI, K. DSC and rheological studies on the effects of sucrose on the gelatinization and retrogradation of acorn starch. Thermochimica acta, v. 322, n. 1, p.39-46, 1998.

ANVISA, AGÊNCIA NACIONAL DE VIGILÂNCIA SANITÁRIA. Regulamento Técnico para o uso de Aditivos Alimentares para Produtos de Panificação e Biscoitos. Resolução no 383, de 5 de agosto de 1999.

ANVISA, AGÊNCIA NACIONAL DE VIGILÂNCIA SANITÁRIA. Legislação Específica de Alimentos. Regulamentos Técnicos por Assunto. Resolução. Pão RDC $\mathrm{n}^{\circ}$ 90, de 18 de outubro de 2000.

ANVISA, AGÊNCIA NACIONAL DE VIGILÂNCIA SANITÁRIA. Uso do bromato de potássio na farinha e nos produtos de panificação. Lei $n^{\circ} 10.273$, de 5 de setembro de 2001.

ARAÚJO, M. S. O início da panificação - A história do pão In ARAÚJO, M.S. Falando de Panificação n. 2, BT Consultores e Editores Ltda. São Paulo, 1996. $229 \mathrm{p}$.

ASHRAE. Handbook: refrigeration. Atlanta, American Society of Heating, Refrigerating and Air-conditioning Engineers, 1994.

ASSOCIAÇÃO BRASILEIRA DAS INDÚSTRIAS DE PANIFICAÇÃO (ABIP). São Paulo. 2002. Perfil de mercado. Disponível em 〈http://www.abip.org.br〉. Acesso em jan.2003.

AUTIO, K.; SINDA, E. Frozen doughs: rheological changes on yeast viability. Cereal Chemistry, v. 69, n. 4, p. 409-413, 1992.

BAARDSETH, P. et al. The effects of bread making process and wheat quality on French baguettes. Journal of Cereal Science, v. 32, n. 1, p. 73-87, 2000.

* Conforme Diretrizes para Apresentação de Dissertações e Teses elaborada pelo Serviço de Bibliotecas da EPUSP com adaptações da norma ABNT-NBR 6023/2000 
BERGLUND, P. T.; SHELTON, D. R.; FREEMAN, T.P. Frozen bread dough ultrastructure as affected by duration of frozen storage and freeze-thaw cycles. Cereal Chemistry, v. 68, n. 1, p. 105-107, 1991.

BILIADERIS, C. G. Thermal analysis of food carbohydrates. In HARWALKAR, V. R.; MA, C. -Y. Thermal Analysis of Food. London: Elsevier Science, 1990. p.168220.

BHANDARI, B. R.; HOWES, T. Implication of glass transition for the drying and stability of dried foods. Journal of Food Engineering, v. 40, n. 1-2, p. 71-79, 1999. BHATTACHARYA, M.; LANGSTAFF, T. M.; BERZONSKY, W. A. Effect of frozen storage and freeze-thaw cycles on the rheological and baking properties of frozen doughs. Food Research International, v. 36, n. 4, p. 365-372, 2003.

BJERKE, F.; NAS, T.; ELLEKJ/RR, M. R. An aplication of projection design in product development. Chemometrics and Intelligent Laboratory Systems, v. 51, n. 1, p. 23-36, 2000.

BONATTO, A. O pão congelado reduz custo e gera nova opção no varejo: o ponto quente. Food Express, ano 11, n.1, p.10-13, 1999.

BOT, A. Differential Scanning Calorimetric study on the effects of frozen storage on gluten and dough. Cereal Chemistry, v. 80, n. 4, p. 366-370, 2003.

BRACK, G., HANNEFORTH, U. Freezing of confectionery dough units in Germany. In KULP, K.; LORENZ, K.; BRÜMMER, J. Frozen and Refrigerated Doughs and Batters, Minnesota: AACC 1995. p. 177-192.

BRANDT, L. Emulsifiers in Baked Goods - Applications, Fev-1996. Disponível em <http://www.foodproductdesign.com/archive/1996/0296AP.html $>$. Acesso em dez. 2002.

BRENNAN, J. G. Texture perception and measurement. In: PIGGOTT, J. R. Sensory analysis of foods. Massachusetts: Elsevier Science, 1988. p. 69-101.

BRÜMMER, J. -M. Bread and rolls from frozen dough in Europe. In KULP, K.; LORENZ, K.; BRÜMMER, J. Frozen and Refrigerated Doughs and Batters, , Minnesota: AACC, 1995. p. 155-166.

CALVEL, R. O pão francês e os produtos correlatos - Tecnologia e prática da panificação. J. Macêdo S.A, 1987. 287p. 
CASEY, G. P.; FOY,J. J. Yeast performance in frozen doughs and strategies for improvement In KULP,K.; LORENZ, K.; BRÜMMER, J. Frozen and Refrigerated doughs and batters, Minnesota: AACC, 1995. p. 19-52.

CARR, L. G.; TADINI, C. C. Influence of yeast and vegetable shortening on physical and textural parameters of frozen part baked French bread. Lebensmittel Wissenschaft und-Technologie., v. 36, n. 6, p. 609-614, 2003.

CAUVAIN, S. P; YOUNG, L. S. Technology of breadmaking. London: Blackie Academic \& Professional, 1998. 354p.

CHAVALLIER, S. et al. Contribution of major ingredients during baking of biscuit dough systems. Journal of Cereal Science, v. 31, n. 3, p. 241-252, 2000.

CHOPIN. Reofermentômetro F3. In Manual de instruções, s.l: s.n., 2001.

COLLAR, C. et al. Optimization of hydrocolloid addition to improve wheat bread dough functionality: a response surface methodology study. Food Hydrocolloids, v. 13 , n. 6 , p. 467-475, 1999.

CORNELl, J. A. How to Run Mixture Experiments for Product Quality, v. 5. American Society for Quality Control, 1990. 96p.

CZUCHAJOWSKA, Z.; POMERANZ, Y. Differential Scanning Calorimetry, water activity, and moisture contents in crumb center and near-crust zones of bread during storage. Cereal Chemistry, v. 66, n. 4, p. 305-309, 1989.

De STEFANIS, V. A. Functional role of microingredients in frozen doughs In KULP, K.; LORENZ, K.; BRÜMMER, J. Frozen and Refrigerated dough and batters, Minnesota: AACC, 1995. p. 91-118.

DEFLOOR, I.; DELCOUR, J. A. Impact of maltodextrins and antistaling enzymes on the differential scanning calorimetry staling endotherm of baked bread doughs. Journal of Agricultural and Food Chemistry, v. 47, n. 2, p. 737-741, 1999.

DONALD, A. What is starch? Disponível em <http://www.poco.phy.cam.ac.uk/research/starch/whatis.htm > Acesso em mar. 2004. FESSAS, D.; SCHIRALDI, A. Texture and staling of wheat bread crumb: effects of water extractable protein and pentosans'. Thermochimica acta, v. 323, p. 17-26, 1998.

FESSAS, D.; SCHIRALDI, A. Starch gelatinization kinetics in bread dough-DSC investigations on 'simulated' baking process. Journal of Thermal Analysis and Calorimetry, v. 61, n. 2, p. 411-423, 2000. 
FARGESTAD, E. M. et al. Influence of flour quality and baking process on hearth bread characteristics made usind gentle mixing. Journal of Cereal Science, v. 30, n. 1, p. 61-70, 1999.

GIANNOU, V.; KESSOGLOU, V.; TZIA, C. Quality and safety characteristics of bread made from frozen dough. Trends in Food Science and Technology, v. 14, n. 1, p. 99-108, 2003.

GORMAN, J. W.; HINMAN, J. E. Simplex lattice designs for multicomponent systems. Technometrics, v.4, p. 463-487, 1962.

HARWALKAR, V. R.; MA, C. -Y. Thermal Analysis of Food. London: Elsevier, 1990. 362p.

HAVET, M., MANKAI, M., Le BAIL, A. Influence of the freezing condition on the baking performances of French frozen dough. Journal of Food Engineering, v. 45, n. 3, p. 139-145, 2000.

ICC, INTERNATIONAL ASSOCIATION FOR CEREAL SCIENCE AND TECHNOLOGY. Disponível em <http://www.icc.or.at/methods3.php\#ICC114>. Acessado em jul. 2003.

INOU,Y.; BUSHUK, W. Studies on frozen doughs I. Effects of frozen storage and freeze-thaw cycles on baking and rheological properties. Cereal Chemistry, v. 68, n. 6, p. 627-631, 1991.

JACOBS, H.; DELCOUR, J. A. Hydrothermal modifications of granular starch, with retention of the granular structure: A Review. Journal of Agricultural and Food Chemistry, v. 46, n. 8, p. 2895-2905, 1998.

KARIM, A. A.; NORZIAH, M. H.; SEOW, C. C. Methods for the study of starch retrogradation. Food Chemistry, v.71, n. 1, p. 9-36, 2000.

KENNY, S. et al. Correlations between empirical and fundamental rheology measurements and baking performance of frozen bread dough. Cereal Chemistry, v. 76, n. 3, p. 421-425, 1999.

KIEFFER, R. et al. Correlations of the breadmaking performance of wheat flour with rheological measurements on a micro-scale. Journal of Cereal Science, v. 27, n. 1, p. 53-60, 1998. 
KLIMAQUIP. GUIA KLIMAQUIP - Frio profissional. Disponível em < http://www.klimaquip.com.br/guia_klimaquip.htm> Acesso em mar. 2003.

KROG, N. Theoretical aspects of surfactants in relation to their use in breadmaking. Cereal Chemistry, v. 58, n. 3, p. 158-164, 1981.

KOWASLKI, M. B.; CARR, L. G.; TADINI, C. C. Parâmetros físicos e de textura de pão francês produzido na cidade de São Paulo. In Congresso Brasileiro de Ciência e Tecnologia de Alimentos, 18., Porto Alegre, 2002. CBCTA 2002: anais. Porto Alegre: SBCTA, 2002. p. 3133-3136.

KUROTORI, I. S. Experiments with mixtures of components having lower bounds. Industrial Quality Control, v. 22, p. 592-596, 1966.

LAAKSONEN, T. J; ROSS, Y. H. Thermal, dynamic-mechanical, and dielectric analysis of phase and state transitions of frozen wheat doughs. Journal of Cereal Science, v. 32, n. 3, p. 281-292, 2000.

LAAKSONEN, T. J. Effects of ingredients on phase and state transitions of frozen wheat doughs. Academic Dissertation. Helsink, 2001.

Le BAIL, A, HAVET, M., HAYERT, M. Improvement of the baking performance of frozen dough by short freezing method. Application to French baguette. In IIF-IIRCommission C2-BRISTOL-GB-2001.

Le BAIL, P. Structural transitions of starchs and their constituents inducted by hidrotermal treatments. São Paulo, Universidade de São Paulo, 2002. /Palestras proferidas por ocasião do curso Análise Térmica de Processos de Congelamento e Descongelamento de Massa de Pães, São Paulo, 2001.

LEÓN, A. E.; DURÁN, E.; BARBER, C. B. Utilization of enzyme mixtures to retard bread crumb firming. Journal of Agricultural and Food Chemistry, v.50, n. 6, p. 1416-1419, 2002.

LEVINE, H.; SLADE, L., Influences of the glassy and rubbery states on the thermal, mechanical, and structural properties of doughs and baked products In FARIDI, H.; FAUBION, J. M. Dough rheology and baked product texture, New York: avi book, 1990. p. 157-330.

LORENZ, K.; KULP, K. Freezing of dough for the production of breads and rolls in the United States In KULP, K.; LORENZ, K.; BRÜMMER, J. Frozen and Refrigerated Doughs and Batters, Minnesota: AACC, 1995. p. 135-154. 
LU, W.; GRANT, L. A. Effects of prolonged storage at freezing temperatures on starch and baking quality of frozen doughs. Cereal Chemistry., v. 76, n. 5, p. 656662, 1999.

MA, C. - Y. Thermal Analysis of vegetable proteins and vegetable protein-based food products In HARWALKAR, V. R.; MA, C. -Y Thermal Analysis of Food. London: Elsevier, 1990. p. 149-167.

MA, C. -Y.; HARWALKAR, V. R.; MAURICE, T. J. Instrumentation and techniques on thermal analysis in food research In HARWALKAR, V. R.; MA, C. Y Thermal Analysis of Food. London: Elsevier, 1990. p. 1-15.

MARCHISANO, C. et al. Characterizing in situ starch gelatinization - thermal and dynamic mechanical analysis of durum wheat dough. Journal of Thermal Analysis, v. 47, n. 1, p. 181-194, 1996.

MARSH, D. Mixing and dough processing In CAUVAIN, S. P.; YOUNG, L. S. Technology of Breadmaking, London: Blackie Academic \& Professional, 1998. p. 81-119.

NAKAMURA, M.; KURATA, T. Effects of L-ascorbic acid on the rheological properties of wheat flour dough. Cereal Chemistry, v.74, n. 5, p. 647-650, 1997.

NETO, B. B.; SCARMINIO, I. S.; BRUNS, R. E. Como fazer experimentos Pesquisa e desenvolvimento na ciência e na indústria. Segunda edição. Editora Unicamp, 2002. 401p.

NEYRENEUF, O.; DELPUECH, B. Freezing experiments on yeasted dough slabs: effects of cryogenic temperatures on the baking performance. Cereal Chemistry, v. 70, n. 1, p. 109-111, 1993.

NUTRINEWS. Semi assados: a nova era da panificação. Edição 161. São Paulo, 1999. Disponível em <http://www.nutrinews.com.br/edicoes/9905/mat01.html> Acesso em jan. 2002.

NAS, T.; BJERKE, F.; FARGESTAD, E. M. A comparison of design and analysis techniques for mixtures. Food Quality and Preference, v. 10, n. 3, p. 209-217, 1999.

OPTA FOOD INGREDIENTS. Disponível em < food.com/access/amylose.html> Acesso em jun 2003. 
PATERAS, I. M. C. Bread spoilage and staling In CAUVAIN, S. P.; YOUNG, L. S. Technology of Breadmaking, London: Blackie Academic \& Professional, 1998. p. $240-261$.

PENFIELD, M. P.; CAMPBELL, A. M. Experimental Food Science, San Diego: Academic Press, 1990. 541p.

QUEIROZ, G. M. Determinação de propriedades termofísicas do pão tipo francês durante o processo de assamento.2001. 152p. Dissertação (Mestrado) Escola Politécnica, Universidade de São Paulo. São Paulo, 2001.

QUAGLIA, G. Ciencia y tecnología de la panificación. Zaragoza: Acribia, 1991. $485 \mathrm{p}$.

RAHMAN, S. Food Properties Handbook, New York: CRC Press, 1995. 500p.

RIBOTTA, P. D.; LEÓN, A. E.; AÑÓN, M. C. Effect of freezing and frozen storage of doughs on bread quality. Journal of Agricultural and Food Chemistry, v. 49, n. 2, p. 913-918, 2001.

RIBOTTA, P. D.; LEÓN, A. E.; AÑóN, M. C. Effect of freezing and frozen storage on the gelatinization and retrogradation of amylopectin in dough baked in a differential scanning calorimeter. Food Research International, v. 36, n. 4, p. 357 363, 2003.

ROUILLÉ, J.; LE BAIL, A.; COURCOUX, P. Influence of formulation and mixing conditions on breadmaking qualities of French frozen dough. Journal of Food Engineering, v. 43, n. 4, p. 197-203, 2000.

ROMAN-GUTIERREZ, A. D.; GUILBERT, S.; CUQ, B. Frozen and unfrozen water contents of wheat flours and their components. Cereal Chemistry, v. 79, n. 4, p. 471-475, 2002.

SALAS-MELLADO, M. M. Estudo da influência da formulação e das condições operacionais dos tipos de congelamento na qualidade da massa e do pão. 2003. 242p. Tese (Doutorado) - Faculdade de Engenharia de Alimentos, Universidade Estadual de Campinas. Campinas, 2003.

SEETHARAMAN, K. et al. Changes in textural, pasting and thermal properties of wheat buns and tortillas during storage. Journal of Cereal Science, v. 35, n. 2, p. 215-223, 2002.

SMS, STABLE MICRO SYSTEMS. Extensibility of Dough and measure of gluten quality (TA-XT2 application study REF: DOU1/KIE), 1995. 
SMITH, A. C. Starch-Based Foods In ROSENTHAL, A. J. Food Texture Measurement and Perception Gaithersburg: Aspen, 1999. p. 152-184.

STAUFFER, C. E. Principles of Dough formation In CAUVAIN, S. P.; YOUNG, L.S. Technology of Breadmaking, London: Blackie Academic \& Professional, 1998. p. 262-295.

STAUFFER, C. E. Functional Additives for Bakery Foods. New York: AVI Books, 1990. 279p.

STAMPFLI, L.; NERSTEN, B. Emulsifiers in bread making, Review. Food Chemistry, v.52, n. 4, p. 353-360, 1995.

STECCHINI, M. L. et al. Properties of wheat dough at sub-zero temperatures and freeze tolerance of a baker's yeast (Saccharomyces cerevisae) Journal of Food Science, v. 67, n. 6, p. 2196-2201, 2002.

SZCZESNIAK, A. S. Texture is a sensory property. Food Quality and Preference, v. 13, n. 4, p. 215-225, 2002.

TAKAYA, T.; SANO, C.; NISHINARI, K. Thermal studies on the gelatinization and retrogradation of heat-moisture treated starch. Carbohydrate Polymers, v. 41, n. 1, p. 97-100, 2000.

WILLIAMS, T.; PULLEN, G. Functional ingredients In CAUVAIN, S. P.; YOUNG, L. S. Technology of Breadmaking, London: Blackie Academic \& Professional, 1998. p. 45-80.

WHITE, P. J.; ABBAS, I. R.; JOHNSON, L. A. Freeze-thaw stability and refrigerated-storage retrogradation of starches. Starch, v. 41, p. 176-180, 1989.

WOLT, M. J.; d'APPOLONIA, B. L. Factors involved in the stability of frozen dough. II. The effects of yeast type, flour type, and dough additives on frozen-dough stability. Cereal Chemistry, v. 61, n. 3, p. 213-221, 1984.

YU, L.; CHRISTIE, G. Measurement of starch thermal transitions using differential scanning calorimetry. Carbohydrate Polymers, v. 46, n. 2, p. 179-184, 2001.

ZOUNIS, S. et al. Studying frozen dough structure using low-temperature scanning electron microscopy. Journal of Cereal Science, v. 35, n. 2, p. 135-147, 2002. 